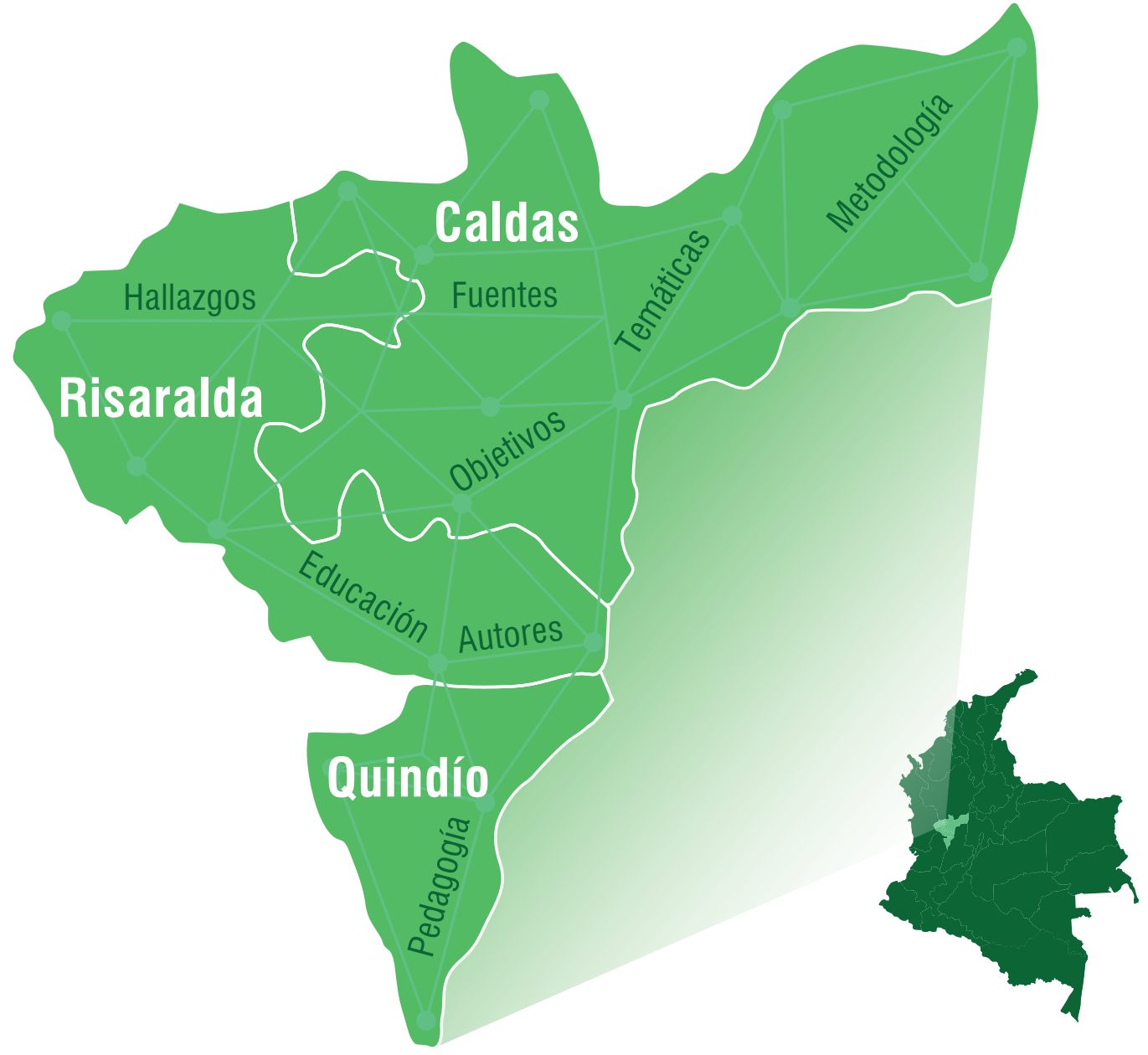

\title{
Relieve investigativo en educación y pedagogía en el Eje Cafetero (2010-2017)
}

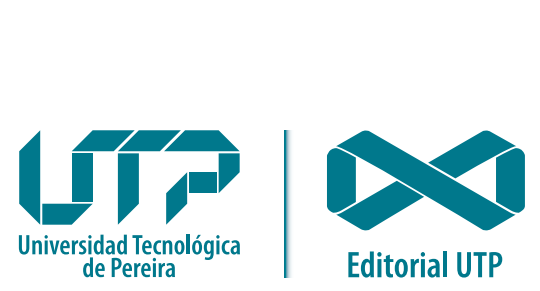

Héctor Fabio Ospina Martha Cecilia Arbeláez

Clara Lucía Lanza

María Camila Ospina-Alvarado

Martha Lucía Garzón

Karen Hasleidy Machado

Sara Victoria Alvarado

Luz Amparo Arroyave

Claudia Patricia Jiménez

Luz Stella Montoya

Elizabeth Gallego

Jhon Wilmar Toro

Jhon Fredy Orrego

María Alejandra Fajardo

Claudia Liliana Sánchez

Juan David Lalinde 



\title{
Relieve investigativo en educación y pedagogía en el Eje Cafetero (2010-2017)
}

\author{
Héctor Fabio Ospina \\ Martha Cecilia Arbeláez \\ Clara Lucía Lanza \\ María Camila Ospina-Alvarado \\ Martha Lucía Garzón \\ Karen Hasleidy Machado \\ Sara Victoria Alvarado \\ Luz Amparo Arroyave \\ Claudia Patricia Jiménez \\ Luz Stella Montoya \\ Elizabeth Gallego \\ Jhon Wilmar Toro \\ Jhon Fredy Orrego \\ María Alejandra Fajardo \\ Claudia Liliana Sánchez \\ Juan David Lalinde
}

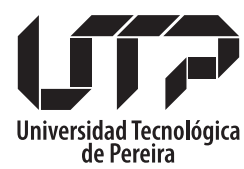

Facultad de Ciencias de la Educación

Colección Trabajos de Investigación

2021 
Relieve investigativo en educación y pedagogía en el Eje Cafetero (2010 - 2017) / Héctor Fabio Ospina y otros.

Pereira : Editorial Universidad Tecnológica de Pereira,

2021.

405 páginas. -- (Colección Trabajos de investigación).

ISBN: 978-958-722-514-3

e-ISBN: 978-958-722-515-0

1. Investigación educativa 2. Educación y pedagogía 3.

Didáctica - Enseñanza 4. Tecnologías de la información y la

comunicación - Educación 5. Educación inclusiva 6.

Educación - Investigación 7. Educación - Investigación -

Metodología

CDD. 370.72

Relieve investigativo en EdUCACión y PEDAgogía EN EL Eje CAFetero (2010-2017)

(C) Héctor Fabio Ospina

(C) Martha Cecilia Arbeláez

(C) Clara Lucía Lanza

(C) María Camila Ospina-Alvarado

(C) Martha Lucía Garzón

(C) Karen Hasleidy Machado

(C) Sara Victoria Alvarado

(C) Luz Amparo Arroyave

(C) Universidad Tecnológica de Pereira
(C) Claudia Patricia Jiménez

(c) Luz Stella Montoya

(C) Elizabeth Gallego

(C) Jhon Wilmar Toro

(C) Jhon Fredy Orrego

(C) María Alejandra Fajardo

(C) Claudia Liliana Sánchez

(C) Juan David Lalinde

ISBN: 978-958-722-514-3

eISBN: 978-958-722-515-0

Imagen de Cubierta: Ilustración, Sofia Aristizabal Lanza.

Trabajo de Investigación: Proyecto regiones investigativas en maestria en educacion que se encuentra registrado en la Vicerrectoria de Investigaciones, Innovacion y Extension de la Universidad, con el codigo Codigo: 4-18-8.

Universidad Tecnológica de Pereira

Vicerrectoría de Investigaciones, Innovación y Extensión

Editorial Universidad Tecnológica de Pereira

Pereira, Colombia

Coordinador editorial:

Luis Miguel Vargas Valencia

luismvargas@utp.edu.co

Teléfono 3137381

Edificio 9, Biblioteca Central "Jorge Roa Martínez"

Cra. 27 No. 10-02 Los Álamos, Pereira, Colombia

www.utp.edu.co

Montaje y producción:

María Alejandra Henao Jiménez

Universidad Tecnológica de Pereira

Pereira

Impresión y acabados

Graficas Olimpica

Pereira

Reservados todos los derechos 


\section{CONTENIDO}

Horizontes y sentidos investigativos

en educación y pedagogía ...........................................................................................

Referencias bibliográficas .....................................................................................16

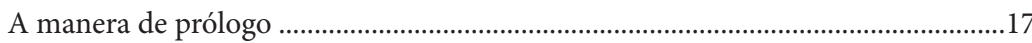

Referencias bibliográficas ...................................................................................2

Introducción. invitación a recorrer las regiones

investigativas en educación y pedagogía del eje cafetero ..............................................25

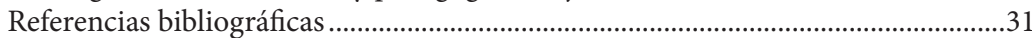

\section{Capítulo uno.}

Metodología de regiones investigativas en educación

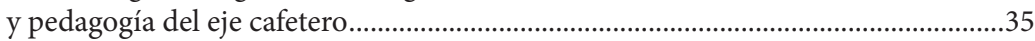

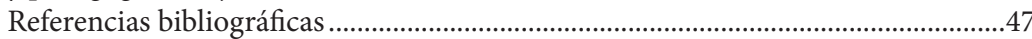

\section{Capítulo dos.}

Corpus documental de educación y pedagogía, zona eje cafetero..............................51

2.1. Caracterización del corpus documental. Universidades y autores..............54

2.2. Las referencias bibliográficas, de la norma y la influencia ............................67

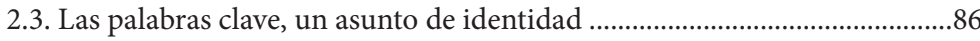

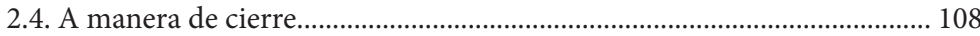

2.5. Referencias bibliográficas....................................................................... 110

\section{Capítulo tres.}

Alcances y metodologías en investigaciones

de educación y pedagogía en la zona del Eje Cafetero (2010-2017)....................... 117

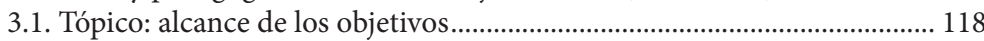

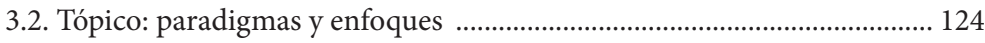

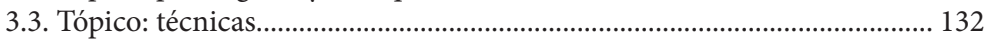

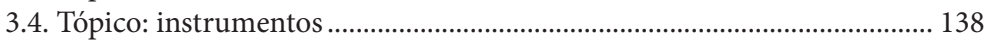

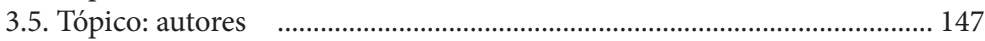

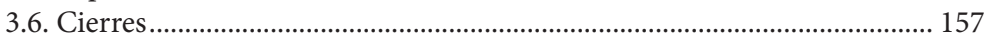

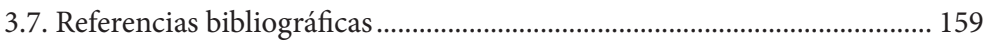

\section{Capítulo cuatro.}

Aproximación conceptual: regiones, educación

y pedagogía en el Eje Cafetero

4.1. Análisis de las regiones, educación y pedagogía

en la zona del Eje Cafetero

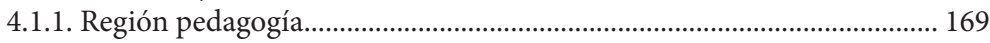

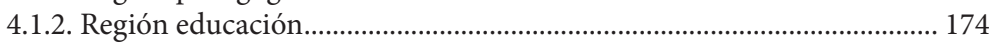

4.2. Análisis. Reporte conceptual por universidades ........................................ 178

4.2.1. Reporte conceptual Universidad Tecnológica de Pereira (UTP)........... 179

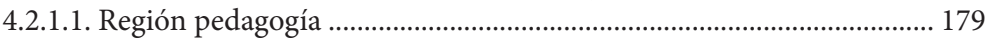

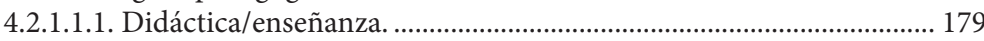




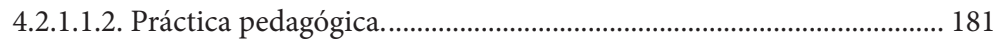

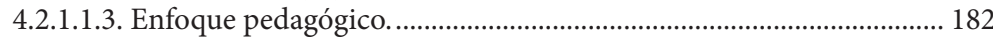

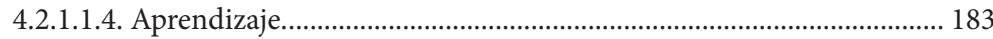

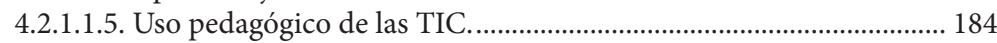

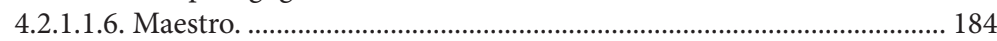

4.2.1.1.7. Concepciones y competencias emocionales. ....................................... 185

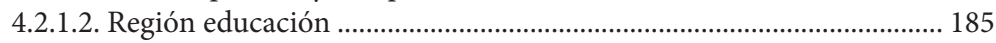

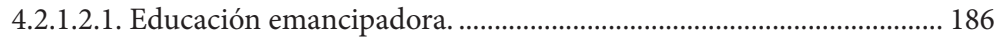

4.2.1.2.2. Educación para la formación de sujetos sociales. ............................... 186

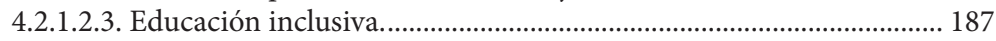

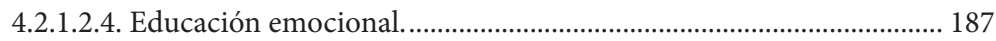

4.2.1.2.5. Educación de adultos. ....................................................................... 188

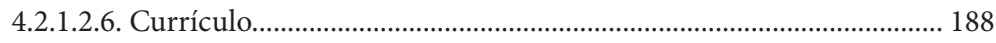

4.2.1.2.7. Evaluación. ...................................................................................... 188

4.2.2. Reporte conceptual Universidad Católica de Pereira (UCP) .................. 189

4.2.2.1. Región pedagogía ..................................................................................... 190

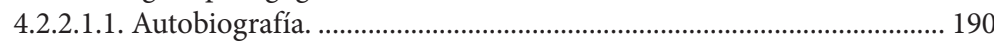

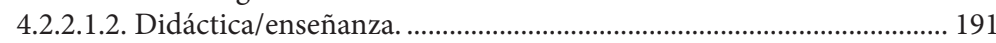

4.2.2.1.3. Práctica pedagógica............................................................................ 191

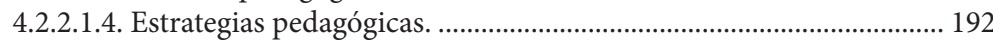

4.2.2.1.5. Uso pedagógico de las TIC.................................................................... 192

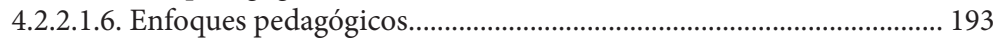

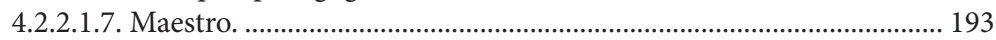

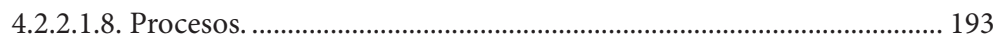

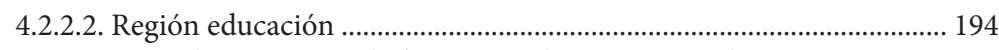

4.2.2.2.1. La educación para la formación de sujetos sociales........................... 194

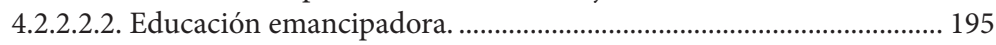

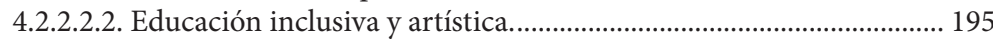

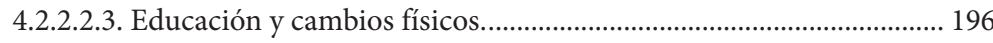

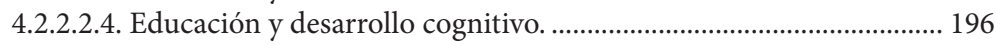

4.2.2.2.5. Educación y factores de riesgo............................................................... 196

4.2.3. Reporte conceptual Universidad de Manizales y Centro de Estudios

Avanzados en Niñez y Juventud (UM-C) .......................................................... 197

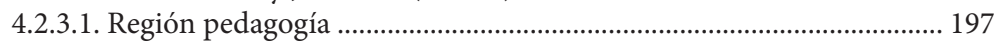

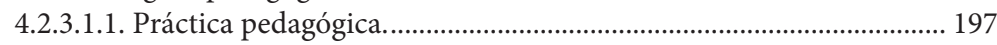

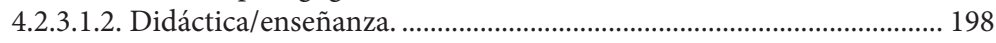

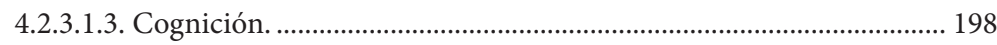

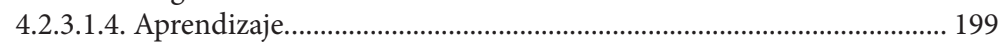

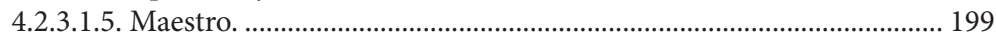

4.2.3.1.6. Enfoque pedagógico......................................................................... 200

4.2.3.1.7. Pedagogía emancipadora......................................................................... 200

4.2.3.1.8. Uso educativo o pedagógico de las TIC............................................... 201

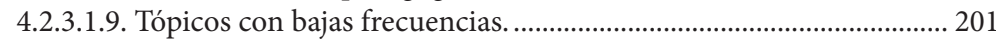

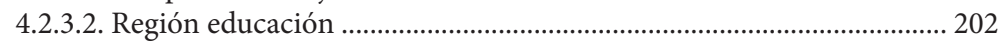

4.2.3.2.1. Educación y formación de sujetos sociales......................................... 202

4.2.3.2.2. Educación y desarrollo humano integral.............................................. 203

4.2.3.2.3. Educación inclusiva-diversidad......................................................... 204

4.2.3.2.4. Formación. ........................................................................................ 204 


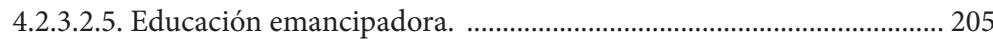

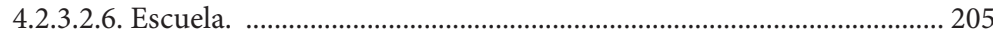

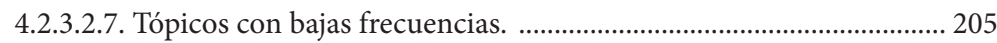

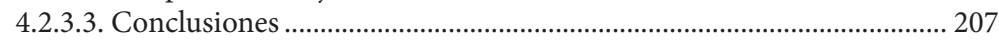

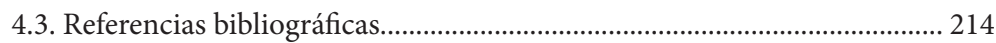

\section{Capítulo cinco.}

Hallazgos en educación, pedagogía y otras regiones

de las tesis y los proyectos de grado del Eje Cafetero (2010-2017) ......................... 245

5.1. Región educación ........................................................................................ 246

5.1.1. Tópico global: educación para la paz y la democracia ............................ 248

5.1.1.1. Participación/participación ciudadana ................................................. 251

5.1.1.2. Convivencia .......................................................................................... 252

5.1.1.3. Ciudadanía/ciudadanía y conciencia crítica.......................................... 255

5.1.1.4. Subjetividad política ........................................................................... 260

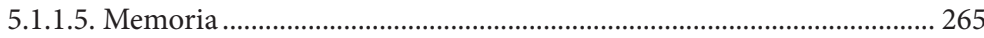

5.1.1.6. Construcción de identidad ................................................................... 265

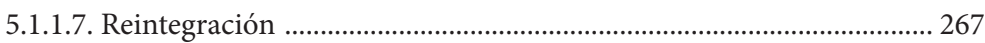

5.1.1.8. Conflicto/resolución de conflictos/pluralidad y conflictos ................ 268

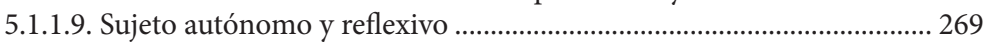

5.1.1.10. Miradas comunes en relación con la educación

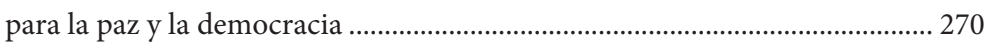

5.1.2. Tópico global: educación inclusiva ........................................................... 275

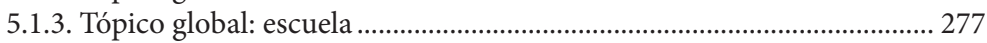

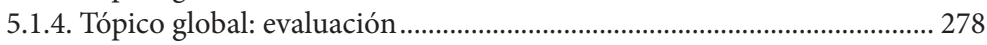

5.1.5. Tópico global: pensamiento crítico ……………………………….......... 279

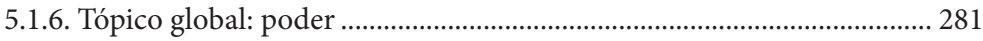

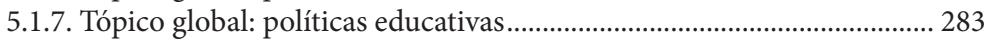

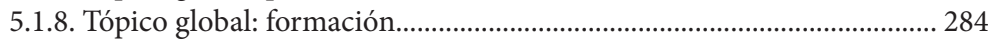

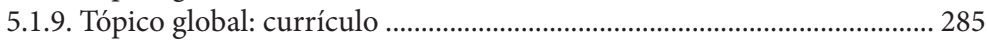

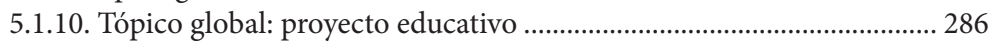

5.1.11. Tópico global: sentido de la educación.................................................... 286

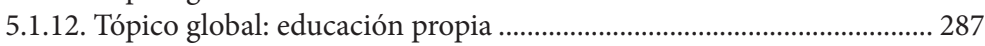

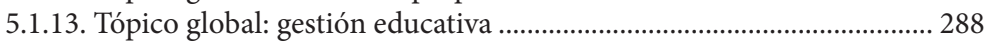

5.1.14. Tópico global: educación ética y moral ................................................ 288

5.1.14.1. Sujeto trascendental kantiano/sujeto emancipado............................ 289

5.1.14.2. Restaurar la confianza .................................................................... 293

5.1.14.3. Miradas comunes en relación con la educación ética y moral ......... 294

5.1.15. Tópico global: cultura juvenil/cultura estudiantil................................. 296

5.1.16. Tópico global: pensamiento social ..................................................... 296

5.1.17. Tópico global: educación para el emprendimiento................................. 297

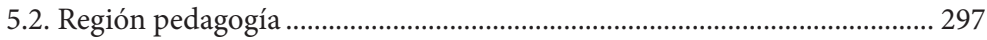

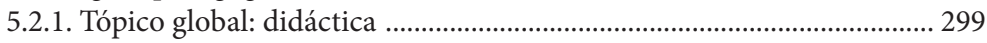

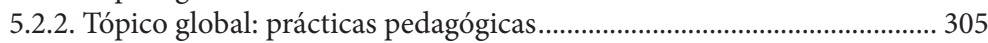

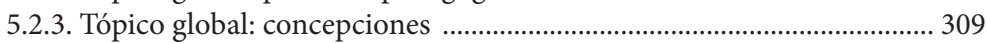

5.2.4. Tópico global: uso educativo y pedagógico de las TIC............................ 312

5.2.5. Tópico global: cognición ....................................................................... 314

5.2.6. Tópico global: aprendizaje ...................................................................... 316 


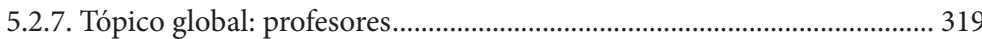

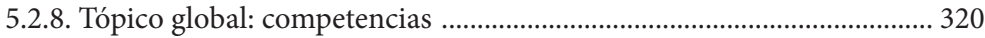

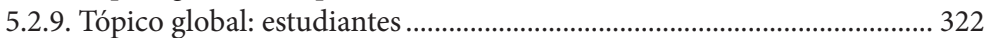

5.2.10. Tópico global: comunicación educativa .............................................. 322

5.3. Territorios recorridos en otras regiones ...................................................... 323

5.3.1. Caminos recorridos en otras regiones que mostraron los hallazgos ... 324

5.3.1.1. Tópico desarrollo humano ................................................................... 324

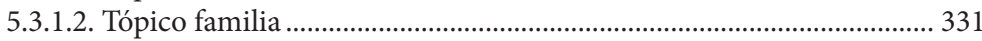

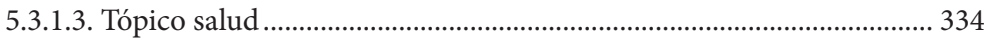

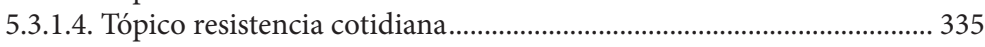

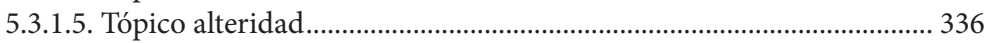

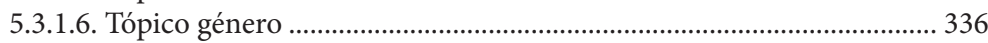

5.4. A manera de discusión e invitación a transitar nuevos territorios ........... 337

Referencias bibliográficas ................................................................................ 349

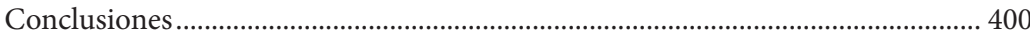

\section{Índice de tablas}

Tabla nro. 1. Número de trabajos de grado y tesis por universidad en la zona del Eje Cafetero.............................................................................................27

Tabla nro. 2. Primer instrumento RIEP. Corpus documental, primera

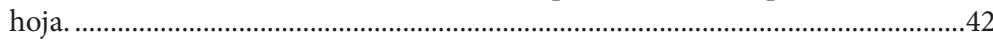

Tabla nro. 3. Segundo instrumento RIEP. Objetivos generales y rutas

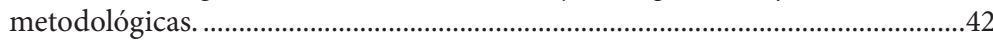

Tabla nro. 4. Tercer instrumento RIEP. Fuentes de la investigación.....................43

Tabla nro. 5. Cuarto instrumento RIEP. Concepto pedagogía y educación........43

Tabla nro. 6. Quinto instrumento RIEP. Hallazgos...............................................4

Tabla nro. 7. Información solicitada en el formato para resúmenes de tesis

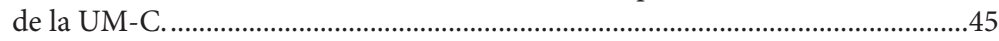

Tabla nro. 8. Caracterización del corpus documental. .........................................55

Tabla nro. 9. Tendencia del género de autores de trabajos de grado y tesis

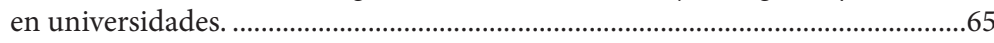

Tabla nro. 10. Nuclearización de las palabras clave por palabra inicial

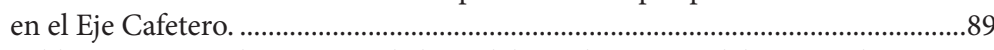

Tabla nro. 11. Nuclearización de las palabras clave por palabra inicial, Maestría en Educación, UTP...............................................................................95

Tabla nro. 12. Nuclearización de las palabras clave por palabra inicial, Maestría en Pedagogía y Desarrollo Humano, UCP. ..............................................99

Tabla nro. 13. Nuclearización de las palabras clave por palabra inicial, Maestría en Educación y Desarrollo Humano, UM-C........................................ 100

Tabla nro. 14. Nuclearización de las palabras clave por palabra inicial, Maestría en Educación desde la Diversidad, UM-C.......................................... 103

Tabla nro. 15. Nuclearización de las palabras clave por palabra inicial, Doctorado en Ciencias Sociales, Niñez y Juventud, UM-C.............................. 106

Tabla nro. 16. Tópico: alcance del objetivo por universidades. ......................... 122

Tabla nro. 17. Paradigmas y enfoques por universidades. ................................ 129

Tabla nro. 18. Técnicas por universidades......................................................... 136 
Tabla nro. 19. Instrumentos por universidad

Tabla nro. 20. Autores por universidades.

Tabla nro. 21. Número y porcentaje de trabajos de grado de maestría y tesis de doctorado por universidad.

Tabla nro. 22. Región pedagogía por tópicos globales en las universidades

del Eje Cafetero.

Tabla nro. 23. Región educación por tópicos globales en las universidades

del Eje Cafetero.

Tabla nro. 24. Tópicos globales de la Región educación de las tesis en las universidades en la zona del Eje Cafetero.

Tabla nro. 25. Tópicos locales para el tópico global de educación para la paz y la democracia.

Tabla nro. 26. Región educación-tópico global de educación ética

y moral

Tabla nro. 27. Tópicos globales de la Región pedagogía de las tesis en las universidades en la zona del Eje Cafetero.

Tabla nro. 28. Frecuencias y porcentajes de la región y otras regiones.

324

\section{Índice de figuras}

Figura nro. 1. Vinculación universidades del eje cafetero en el proyecto de regiones

Figura nro. 2. Representación de las metáforas adaptadas de Michel Serres. ...39

Figura nro. 3. Autores de referencia. Maestría en Educación, UTP.

Figura nro. 4. Autores de referencia. Maestría en Pedagogía y Desarrollo

Humano, UCP.

Figura nro. 5. Autores de referencia. Maestría en Educación y Desarrollo

Humano, UM-C.

Figura nro. 6. Autores de referencia. Maestría en Educación desde la

Diversidad, UM-C

Figura nro. 7. Autores de referencia. Doctorado en Ciencias Sociales, Niñez y Juventud, UM-C.

Figura nro. 8. Palabras clave en el Eje Cafetero. ...................................................87

Figura nro. 9. Palabras clave. Maestría en Educación, UTP..................................94

Figura nro. 10. Palabras clave. Maestría en Pedagogía y Desarrollo Humano,

UCP.

Figura nro. 11. Palabras clave. Maestría en Educación y Desarrollo Humano,

UM-C.

Figura nro. 12. Palabras clave. Maestría en Educación desde la Diversidad,

UM-C.

Figura nro. 13. Palabras clave. Doctorado en Ciencias Sociales, Niñez y

Juventud, UM-C.

Figura nro. 14. Alcance del objetivo, zona Eje Cafetero. .................................... 120

Figura nro. 15. Paradigmas y enfoques, zona Eje Cafetero............................... 128

Figura nro. 16. Técnicas, zona Eje Cafetero. ....................................................... 134

Figura nro. 17. Instrumentos, zona Eje Cafetero................................................ 139

Figura nro. 18. Autores, zona Eje Cafetero...................................................... 149 
Héctor Fabio Ospina, (Filandia, Quindío, Colombia,1952)

Doctor en Educación - (Nova University - CINDE), Filósofo - (Pontificia Universidad Javeriana).

Docente Centro de Estudios Avanzados en Niñez y Juventud del Cinde y la Universidad de Manizales

\section{Publicaciones y premios:}

- Voces infantiles heterogéneas en contextos institucionales cambiantes, (2020).

- Educación y pedagogía. Trayectos recorridos, (2018).

- Voces Insurgentes de la educación popular en Colombia, (2018).

- Pedagogía crítica latinoamericana y género, (2016).

- Regiones Investigativas en Educación y Pedagogía en Colombia, (2012).

Investigador Emérito (IE) con vigencia vitalicia, Minciencias 2018.

Profesor Emérito, Fundación Centro Internacional de Educación y Desarrollo Humano -Cinde, 2010.

Ha publicado artículos en revistas especializadas nacionales.

Pertenece al Grupo de Investigación en "Educación y Pedagogía: Saberes, Imaginarios e Intersubjetividades”.

proyectoumanizales@cinde.org.co

Martha Cecilia Arbeláez Gómez, (Calarcá, Quindío, Colombia,1963).

Doctora en Psicología de la Educación - (Universidad de Barcelona).

Docente titular, Facultad de Ciencias de la Educación (Universidad Tecnológica de Pereira)

\section{Publicaciones:}

- Regiones Investigativas en Educación y Pedagogía en Colombia, (2020).

- Narrar, Exponer y Argumentar (Capitulos de libro), (2018).

- La enseñanza y el aprendizaje de la comprensión lectora y los sistemas geométricos con la mediación de las TIC: MATELETIC, (2016).

Ha publicado artículos en revistas especializadas internacionales .

Líder del Grupo de Investigación en "Educación y Tecnología”

marthace@utp.edu.co 
Clara Lanza, (Bogotá, Cundinamarca, Colombia, 1965).

Magister en Educación - (Universidad de la Sabana), Licenciada en Educación Preescolar - (Universidad Pedagógica Nacional)

Docente asociada, Facultad Ciencias de la Educación (Universidad Tecnológica de Pereira)

\section{Publicaciones:}

- Regiones Investigativas en Educación y Pedagogía en Colombia, (2020).

- La enseñanza y el aprendizaje de la comprensión lectora y los sistemas geométricos con la mediación de las TIC: MATELETIC, (2016).

Miembro del Grupo de investigación en "Educación y Pedagogía”

clalulanz@utp.edu.co

María Camila Ospina Alvarado, (Bogotá, Cundinamrca, Colombia, 1984)

Doctora en Ciencias Sociales, Niñez y Juventud -Summa Cum Laude (Universidad de Manizales-CINDE), Doctora en Estudios de Medios y Comunicación (Universidad Libre de Bruselas-TAOS Institute), Psicóloga -

Summa Cum Laude - (Universidad de los Andes).

Docente investigadora titular, Facultad de Ciencias Sociales y Humanas

(Universidad de Manizales), Campo Nacional Investigación (CINDE).

\section{Publicaciones:}

- Las escuelas como territorios de paz Construcción social del niño y la niña como sujetos políticos en contextos de conflicto armado, (2012).

- Construcción Social de Niñas y Niños en Contextos de Conflicto Armado: Narrativas Generativas para la Construcción de Paz, (2018)

- Construcción Social de Niños y Niñas: Familias, Docentes y Otros Agentes Relacionales, (2018).

- Investigación transformadora sobre paces y memorias con niños, niñas y jóvenes: narrativas generativas, subjetividades políticas y movilización y acción política, (2018).

- Sentidos y Prácticas de Jóvenes Investigadores e Investigadoras: Semillas en Territorios de Paz, (2018).

- Aproximación a un Estado de la Cuestión Sentidos y Prácticas

Políticas de Niños, Niñas y Jóvenes en Territorios marcados por la Violencia:

Paz, Democracia, Reconciliación y Memoria, (2018).

- Nuestra aventura: memorias, logros y aprendizajes, (2018).

- Juventudes e infancias en el escenario latinoamericano y caribeño actual, (2018)

Ha publicado artículos en revistas especializadas nacionales e internacionales . Líder del grupo "Perspectivas Políticas. Éticas y Morales de la Niñez y la Juventud"

$$
\text { mospina@cinde.org.co }
$$


Martha Lucia Garzón Osorio, (Santa Rosa de Cabal, Risaralda, Colombia,1972).

Magister en Educación - (Universidad Tecnológica de Pereira), Fonoaudióloga - (Universidad Católica de Manizales)

Docente asociada, Facultad de Ciencias de la Educación (Universidad Tecnológica de Pereira)

\section{Publicaciones:}

- Regiones Investigativas en Educación y Pedagogía en Colombia, (2020). Narrar, Exponer y Argumentar (Capítulos de libro), (2018).

- Guía para la atención educativa en el aula desde la diversidad (capítulos de libro), (2011).

- $\quad$ Alto Vuelo: Historias de Vida y Experiencias Exitosas de Inclusión Educativa de Población con Necesidades Educativas Especiales. (Capítulos de libro), (2007).

Ha publicado artículos en revistas especializadas internacionales.

Pertenece a los Grupos de investigación Educación y Tecnología y Educación y Desarrollo Humano

malucia@utp.edu.co

Karen Hasleidy Machado Mena, (Bagadó, Chocó, Colombia,1987).

Licenciada en Pedagogía Infantil - (Universidad Tecnológica de Pereira)

Docente auxiliar, Facultad de Bellas Artes y Humanidades (Universidad Tecnológica de Pereira).

Publicaciones:

- Regiones Investigativas en Educación y Pedagogía en Colombia, (2020).

Pertenece a los Grupos de Investigación "Educación y Tecnología" e "Indicios" khmm@utp.edu.co 
Luz Amparo Arroyave Montoya, (Manizales, Caldas, Colombia, 1978).

Magister en Diseño y Creación Interactiva - (Universidad de Caldas)

Candidata a Doctora de las Ciencias Sociales Niñez y Juventud - Universidad de Manizales

\section{Publicaciones:}

- "Regiones investigativas en educación y pedagogía en Colombia: mapa topográfico de la actividad investigativa de tesis de maestrías y doctorados en el periodo 2010-2017", (2020).

Pertenece al Grupo de Investigación "Jóvenes, Culturas y Saberes" larroyavemon@yahoo.com

Luz Stella Montoya, (Cartago, Valle del Cauca,Colombia, 1961).

Magister en Pedagogía y Desarrollo Humano - (Universidad de Manizales CINDE), Psicóloga - (Universidad de Manizales)

Docente asistente, Facultad de Ciencias de la Educación (Universidad Tecnológica de Pereira)

\section{Publicaciones:}

- Regiones investigativas en Educación y Pedagogía en Colombia. Capítulo de libro (2020)

-Las competencias ciudadanas emocionales y la convivencia. Capítulo de libro (2018)

Ha publicado en revistas especializadas nacionales.

Pertenece al Grupo de Investigación "Educación y Desarrollo Humano"

\section{luzes@utp.edu.co}

Elizabeth Gallego, (Manizales, Caldas, Colombia,1964).

Magister en Educación y Desarrollo Humano - (Universidad de Manizales CINDE), Psicóloga - (Universidad de Manizales).

Docente especial, Departamento de Humanidades (Universidad Católica de Pereira)

Ha publicado artículos en revistas especializadas nacionales . Pertenece el grupo de investigación en "Arquitectura y Diseño"

elizabeth.gallego@ucp.edu.co 
Jhon Wilmar Toro Zapata, (Belalcázar, Caldas, Colombia,1978).

Magister en Pedagogía y Desarrollo Humano - (Universidad Católica de Pereira), Licenciado en Educación Religiosa - (Universidad Católica de Pereira)

Docente especial, Facultad de Ciencias Humanas, Sociales y de la Educación (Universidad Católica de Pereira)

\section{Publicaciones:}

- Regiones Investigativas en Educación y Pedagogía en Colombia, (2020).

- Del dicho al hecho: ocupaciones pedagógicas en Clave de desarrollo humano,

(2020).

Ha publicado artículos en revistas especializadas nacionales .

Pertenece el grupo de investigación en "Comunicación, Educación y Cultura

Jhon.toro@ucp.edu.co 


\section{Horizontes y sentidos investigativos en educación y pedagogía}

¿Por qué esta obra debe ser un avance para el campo educativo y la pedagogía? ¿Qué podría aportar este ejercicio de sistematización a la mirada que se tiene de la educación y la pedagogía? Estas son preguntas que emergen al momento de tomar este libro.

Antes de responder dichas preguntas, las cuales se dejarán de invitación a cada lector, se cree importante la referencia a los aspectos metodológicos utilizados para configurar el estudio, ya que entregan mayor valía a la obra, al tener en la base un cuidadoso trabajo de cartografía, el cual ayuda a entender los tópicos principales del escrito. Esto al utilizar categorías rescatadas del 
propio habitar colombiano, y al proponer una metodología para caminar y lograr una ubicación en la intrincada y diversa geografía que son las regiones investigativas de educación y pedagogía.

Rescatando un pensamiento Latinoamericano, Colombia es un «carnaval de fotosíntesis». Por ello, la cartografía posiciona y sorprende en un recorrido que desciende de las nubes, en medio de montañas nevadas y picos que despuntan en el horizonte; nuevos saberes e inquietudes investigativas. En este sentido, el ejercicio cartográfico invita a recorrer en la diversidad de investigaciones en educación y pedagogía, categorías propias de cada región, las cuales entregan una particular visión de lugares tan nuevos como intrincados de comprender, donde a partir de una toponimia categorial de la gente, se ayudaría a cualquier caminante a deslizarse por quebradas culebreras y a maravillarse con hallazgos sobre el habitar de un espacio geográfico en educación y pedagogía el cual anima y deja huella en los recorridos investigativos.

Desde la imponente montaña o desde la llanura, es posible observar relaciones de saberes nuevos e intencionalidades que refrescan el campo de investigación, y de esta forma, invitar a repensar el territorio y su habitar nuevamente, como un lugar que se debe cavilar y sentir desde adentro y desde abajo. Esto desligándose de políticas de investigación marcada por intereses competitivos del capitalismo cognitivo y exógenos al territorio.

La cartografía presentada, invita a explorar, pero también a respetar la propia autonomía. Esto, al indagar bajo otras epistemologías, las cuales hagan sentir comodidad con el conocimiento producido, teniendo en cuenta que caminar siempre es un recorrido y que el trayecto siempre será más importante que su producto. De esta manera, la presente obra invita, no solo a reconocer las regiones de investigación, sino también, a sentir su profundidad, su latir vigoroso el cual empina hacia otros horizontes más humanos y con mayor sentido por lo que se hace; tal como quien, sentado en una vereda cualquiera, reconoce el 
aroma inmarcesible de los cafetales en octubre, a modo de un gesto comprensivo de aquellos hallazgos que emergen en épocas de cosecha.

En este sentido, la metáfora "regiones investigativas» es, en sí misma, un aporte para la comprensión sobre el habitar de los investigadores, los docentes y las personas que toman las de decisiones sobre las políticas públicas; al revelar desde ya, un horizonte donde la pedagogía como región predominante, se instala sobre el sentido que mueve a la investigación en la actualidad. Un mensaje de sentido, es decir, aquel que guía en el camino, pero que, además, llena de sentires propios - más aun cuando sus atributos categoriales se van construyendo desde la evidencia y del propio hacer del aula-, lo que indica que, el hacer investigativo tiene un contexto situado, experiencial y vívido. Todo aquello se convierte en valiosas proposiciones conceptuales para la región de estudio y un mensaje para la política pública, la cual, frecuentemente, construye políticas desde arriba hacia abajo y no con los actores, desde abajo y cuidando criterios de participación deliberativa (Flórez y Olave, 2020).

Sin embargo - y para ser justos -, la región investigativa de educación, también describe orientaciones y nuevos matices, los cuales se articulan con la región pedagógica, destaca, por ejemplo, en las finalidades educativas centradas en la inclusión, el desarrollo humano integral y, como no enunciarlo, una investigación en educación con claros fines en formar ciudadanías para la paz.

Inicialmente, podría afirmarse que esta obra es para aquellos que se inician como caminantes y también para los expertos; sin embrago, es una obra, para quienes gustan de la innovación y la transformación de políticas públicas situadas. Es un gran mensaje para las y los profesores del territorio colombiano, ya que son ellos y su hacer pedagógico, quienes comienzan a tomar mayor relevancia a partir en este escrito. Por lo tanto, este libro, sin pretender serlo, es un reconocimiento a maestras y maestros de esta tierra 
fértil y diversa. Por último y no menos importante, este escrito termina siendo un aporte para quienes creen que la educación y la pedagogía son regiones del saber humano comprometidas con la justicia social y la transformación de Latinoamérica.

Santiago de Chile, Primavera de octubre de 2020. José Miguel Olave Astorga Universidad de Chile.

\section{Referencias bibliográficas}

Flórez, M. T. y Olave. J. M. (2020). Hacia una construcción participativa de la política educacional: La propuesta alternativa del proyecto éxito escolar en Valparaíso. Revista on line de Política e Gestão Educacional, 24(1), 867-890. 


\title{
A manera de prólogo
}

\author{
David Alberto Londoño Vásquez \\ Docente Titular de la Facultad de Ciencias Sociales \\ Institución Universitaria de Envigado
}

La educación se ha convertido en un campo complejo, dinámico y deseable (Bruner, 2015; Durkheim, 2002; Freire, 1996;). Complejo frente a las posibilidades conceptuales desde diversas disciplinas de las Ciencias Sociales y Humanas, donde la Antropología, la Filosofía, la Psicología yla Sociología han realizado aportes teóricos y epistemológicos los cuales enriquecieron las posibilidades metodológicas de conocer, participar e investigar (Shapiro y Stefkovich, 2016). Dinámica porque constantemente están en revisión, reflexión y reconstrucción; lo que significa que la educación es el centro de interés de padres de familia, miembros de la comunidad, expertos educativos, estudiantes y políticos 
(Flórez et al., 2017) donde, cada uno de ellos, revisa cómo se lleva a cabo el proceso educativo de su entorno, al reflexionar respecto a los aspectos positivos y negativos que pueden evidenciar y al participar de la reconstrucción de dicho proceso para el bienestar de su colectividad (Brunner y Ganga, 2016). Deseable dadas las potencialidades que brinda a las comunidades en las cuales prime. No solo desde una mirada formativa y cognitiva, sino constitutiva de subjetividades que permiten alcanzar miradas críticas, participativas y autónomas en relación con aquellos espacios comunitarios (Ramírez et al., 2020).

Por ello, el número de profesionales interesados en afianzar sus prácticas docentes, mejorar las estrategias didácticas, participar de la construcción curricular, develar potencialidades en los proceso formativos, reelaborar proyectos educativos, ahincar esfuerzos en la enseñanza, humanizar el aprendizaje, rescatar las vivencias escolares, reconocer los roles participativos de la escuela y fortalecer el agenciamiento desde la educación; han crecido significativamente en América Latina (Murcia et al., 2012). Esto se ve materializado en los programas de maestría y doctorado que constantemente se abren, los cuales han construido un escenario de alfabetización educativa, donde la investigación permea las propuestas curriculares y demanda una actitud crítica frente a los paradigmas predominantes en la tradición escolar (Ospina et al., 2018).

Así, la apertura al replanteamiento teórico, epistemológico y metodológico frente a la investigación en la educación sugiere condiciones sine qua non como la apuesta por investigaciones contextualizadas, situadas y significativas (Santos, 2019). Contextualizadas, puesto que los procesos educativos no se pueden replicar de una comunidad a otra, sin analizar sus características sociales, culturales y familiares, ni tampoco, de institución a institución, dadas las posibles inequidades en infraestructura, formación docente o número de estudiantes, tan comunes en la mayoría de las regiones de los países latinoamericanos (Dussel, 
2011). Situadas, ya que las soluciones a problemas presentes del proceso de formación son funcionales para un grupo de estudiantes específicos, los cuales interactúan en un curso o un grupo, donde se tejen relaciones sociales y se responde a las realidades presentes y habituales del entorno (Kohan, 2017). Significativas, por el interés constante de los agentes educativos por generar espacios de interés, de aprendizaje y de retroalimentación; los cuales se puedan emplear en los diferentes planes de vida de los participantes; esto de forma inclusiva y equitativa (Abero et al., 2015).

Estas tres condiciones demandan de la investigación en educación un conocimiento tanto de las perspectivas epistemológicas institucionalizadas, como de las opciones teóricas y conceptuales tejidas en la historia de los tópicos allí presentes (Barrios y Herrera, 2016). Es por ello que, las perspectivas empíricoanalíticas de corte positivo, hermenéutico-comprensivas, postestructuralistas y la acción crítico-social siguen siendo las más recurrentes en las opciones propuestas por los programas posgraduales en educación (Londoño et al., 2018). No obstante, cada vez con mayor frecuencia, emergen apuestas desde otras formas de entender y construir las realidades enunciadas en el mundo, algunas de ellas desde el feminismo (Maynard y Purvis, 2013) y la construcción simbólica (Hargreaves, 2017).

Dichas perspectivas epistemológicas, tanto las fortalecidas como las emergentes, han dinamizado la re-semantización de conceptos tradicionalmente trabajados en la educación como son el aprendizaje, la cognición, el currículo, la didáctica o la pedagogía (Villanueva y López, 2019). Ello ha permitido la génesis de otras nociones tales como alteridad, el alcance de los logros, la construcción de habilidades, el desarrollo de competencias, las mediaciones pedagógicas, las Tecnologías de la Información y Comunicación (TIC) y los procesos educativos mediados por la virtualidad, la resiliencia, entre otros (Martínez, 2017). En otras palabras, la educación como campo del conocimiento resalta por sus posibilidades conceptuales y teóricas, imbricadas en las 
perspectivas anteriormente mencionadas (Londoño y Ospina, 2016).

Deallíque sea ampliamente deseable, tanto para investigadores no reconocidos como reconocidos, las investigaciones que se centren en identificar y caracterizar tendencias, enfoques, intereses y vocaciones en la exploración en educación y pedagogía en Colombia; llevando a configurar las regiones investigativas, a partir de la investigación adelantada en el marco de los trabajos de grado o tesis finalizadas de maestrías y doctorados. Puesto que, tener al alcance un texto que consolide esta información de forma clara, confiable y coherente, facilita el acceso al panorama de las tendencias investigativas de la educación y la pedagogía, y a la toma de decisión frente a los intereses presentes en las líneas de investigación de los programas posgraduales, de los docentes que conforman el equipo de tutores y de los participantes en formación investigativa.

Es por ello que se invita a los interesados en la educación, especialmente aquellos que sienten pasión por la investigación, a revisar con asiduidad, aprensión, criticidad y parsimonia los resultados obtenidos en el proyecto de investigación regiones investigativas en Educación, desarrollada entre 2010 y 2017 en la Zona Eje Cafetero, lugar en el que participaron la Universidad de Manizales en su alianza con la Fundación Centro Internacional y Desarrollo Humano (CINDE), la Universidad Tecnológica de Pereira y la Universidad Católica de Pereira.

\section{Referencias bibliográficas}

Abero, L.; Berardi, L.; Capocasale, A.; García Montejo, S. y RoJAs Soriano, R. (2015). Investigación Educativa: Abriendo puertas al conocimiento. CLACSO. 
Barrios, D. M. y Herrera, J. D. (2016). Formación posgradual en investigación y profesión docente. Voces y silencios. Revista Latinoamericana de Educación, 7(1), 32-64. https://revistas. uniandes.edu.co/doi/full/10.18175/vys 7.1.2016.03.

Bruner, J. (2015). La educación, puerta de la cultura. Antonio Machado Libros.

Brunner, J. J. y Contreras, F. G. (2016). Dinámicas de transformación en la educación superior latinoamericana: Desafíos para la gobernanza. Opción: Revista de Ciencias Humanas y Sociales, (80), 12-35.

DurKheIM, É. (2002). La educación moral. Ediciones Morata.

Dussel, E. (2011). Filosofía de la liberación. México: Fondo de cultura económica.

FlóRez, G. A.; Villalobos, J. L. y Londoño, D. A. (2017). El acompañamiento familiar en el proceso de formación escolar para la realidad colombiana: de la responsabilidad a la necesidad. Psicoespacios: Revista virtual de la Institución Universitaria de Envigado, 11(18), 94-119. https://dialnet. unirioja.es/servlet/articulo?codigo $=5893097$

Freire, P. (1996). Política y educación. Siglo XXI.

HARgREAVES, D. H. (2017). Interpersonal relations and education. Routledge.

KoHAn, W. (2017). O mestre inventor-relatos de um viajante educador. Autêntica. 
Londoño, D. y Ospina, H. F. (2016). Alfabetización crítica: Requerimiento social. En H. F. Ospina, C. A. y Ramírez. Pedagogía crítica latinoamericana y género. Siglo del Hombre Editores.

Londoño, D.; Olave, J.; Jaime, J. y Losada, N. (2018). Lógicas, enfoques y epistemologías sobre educación y pedagogía. En H. F. Ospina, A. K. Runge-Peña, M. P. Marín Gutiérrez, C. Vélez De la Calle, B. Ramírez Aristizábal, B. Gallardo Cerón,... Y G. M. Ordóñez Andrade. Educación y Pedagogía. Trayectos recorridos (pp. 96-155). Universidad de Manizales.

Martínez Boom, A. (2017). Teoría pedagógica. Una mirada arqueológica a la pedagogía. Universidad Pedagógica Nacional.

Maynard, M. y Purvis, J. (Eds.). (2013). Researching women's lives from a feminist perspective. Routledge.

Murcia, N.; Ramírez, C.A. y Ospina, H. F. (2012). La investigación en educación y pedagogía en el eje cafetero. Revista Latinoamericana de Estudios Educativos (Colombia), 8(1), 11-38. https://www.redalyc.org/pdf/1341/134129256002. pdf.

Ospina, H. F., Runge-Peña, A. K., Marín Gutiérrez, M. P., Vélez De la Calle, C., Ramírez Aristizábal, B., Gallardo CERÓn, B.,... Y Ordóñez Andrade, G. M. (2018). Educación y Pedagogía. Trayectos recorridos. Universidad de Manizales.

Ramírez, A., Londoño, D., Uribe, M., Párraga, H., Klimenko, O., TAMAYO D y CórdobA, V. (2020). Tendencias investigativas y referentes en los campos de saber: el caso de las líneas de investigación del grupo PAYS. Editorial IUE. 
Ruiz, A., Prada, M., Quintero, M., Gómez, J. H., Yáñez, J., Kriger, M.,... Y Torres, A. (2017). Educación, política y subjetividad. Bogotá: Universidad Pedagógica Nacional.

SAnTos, B. (2019). Educación para otro mundo posible. CLACSO.

Shapiro, J. P. \& Stefkovich, J. A. (2016). Ethical leadership and decision making in education: Applying theoretical perspectives to complex dilemmas. Routledge.

Villanueva, Ó. E. y LóPEZ, L. I. (2019). La atención selectiva del docente en los procesos de planeación curricular, aprendizaje y evaluación. Diálogos sobre educación. Temas actuales en investigación educativa, 10(19). http://www.scielo.org.mx/ scielo.php?pid=S2007-21712019000200010\&script $=$ sci arttext 



\section{Introducción: invitación a recorrer las regiones investigativas en educación y pedagogía del Eje Cafetero}

El presente libro recoge los resultados parciales de la investigación nacional «Regiones Investigativas en Educación», desarrollada entre 2010 y 2017, y da continuidad a la investigación en este campo en el período del 2000 al 2010. El estudio contó con la participación de diecinueve instituciones (Universidad Cooperativa de Colombia -Córdoba-, Universidad Francisco de Paula Santander —Cúcuta—, Universidad de la Salle, Universidad San Buenaventura -Bogotá-, Universidad Externado de Colombia, Fundación Centro Internacional de Educación y Desarrollo Humano CINDE, Universidad Pedagógica Nacional, Institución Universitaria Tecnológico de Antioquia, Universidad Católica de Oriente, Universidad de Antioquia, Universidad Pontificia Bolivariana, Universidad Mariana de Pasto, Universidad de Nariño, Universidad Cesmag de Pasto, Universidad del Tolima, Universidad Católica de Pereira, Universidad de Manizales, Universidad Tecnológica de Pereira y Centro de Estudios Avanzados en Niñez y Juventud de la Universidad de Manizales 
y la Fundación Centro Internacional de Educación y Desarrollo Humano CINDE), agrupadas en siete zonas: zona Centro, zona Sur, zona Eje Cafetero, zona Caribe, zona Norte, zona Antioquia y zona Tolima.

Dicho estudio se orientó a analizar los trabajos de grado de las maestrías y tesis de doctorados con énfasis en educación y pedagogía en el país, para así, comprender las regiones y las tendencias investigativas en educación y en pedagogía entre el 2010 y el 2017 en el país, a través de la revisión y análisis de mil novecientos ochenta y seis trabajos de grado de maestría y tesis doctorales. Como se indica en el documento técnico del proyecto, los objetivos específicos se encaminaron a:

Identificar y caracterizar tendencias, enfoques, intereses y vocaciones en la investigación en educación y pedagogía, en las siguientes zonas: zona Norte (Cúcuta), zona Antioquia, zona Centro (Bogotá), zona Sur (Pasto), zona Eje Cafetero.

Configurar las regiones investigativas en educación y pedagogía en Colombia, a partir de la investigación adelantada en el marco de los trabajos de grado de maestría y doctorado finalizadas (Ospina-Serna y Gallardo-Cerón, 2017, p. 11).

El análisis se dio a través de la revisión del corpus documental, las fuentes citadas en las tesis, las palabras clave y su recurrencia, la aproximación conceptual respecto a la educación y la pedagogía, la orientación metodológica con el alcance, las técnicas y los instrumentos empleados, y los hallazgos de las investigaciones.

En particular, este libro se centra en los resultados de la investigación obtenidos en la Zona Eje Cafetero, territorio en el que participaron la Universidad de Manizales en su alianza con la Fundación Centro Internacional y Desarrollo Humano (CINDE), la Universidad Tecnológica de Pereira y la Universidad Católica de Pereira. En esta zona se analizaron trecientos quince trabajos 
de grado y tesis, ciento ochenta y cuatro de la Universidad de Manizales y el CINDE (58.4\%), cien trabajos de grado de la Universidad Tecnológica de Pereira $(31.7 \%$ ) y treinta y un trabajos de grado de la Universidad Católica de Pereira (9.8 \%) —-debido a su reciente constitución en el campo posgradual en educación-. A continuación, se presenta el total de trabajos de grado y tesis por institución abordados en la zona del Eje Cafetero:

TABLA NRO. 1. Número de trabajos de grado y tesis por universidad en la zona del Eje Cafetero.

\begin{tabular}{lllll}
\hline Datos & $\begin{array}{l}\text { Universidad de } \\
\text { Manizales y } \\
\text { CINDE }\end{array}$ & $\begin{array}{l}\text { Universidad } \\
\text { Católica de Pereira }\end{array}$ & $\begin{array}{l}\text { Universidad } \\
\text { Tecnológica de Pereira }\end{array}$ & $\begin{array}{l}\text { Total Eje } \\
\text { Cafetero }\end{array}$ \\
\hline $\begin{array}{l}\text { Nro. de } \\
\text { trabajos de } \\
\text { grado y } \\
\text { tesis }\end{array}$ & $\begin{array}{l}184 \\
\text { (Dos maestrías y } \\
\text { un doctorado) }\end{array}$ & $\begin{array}{l}31 \\
\text { (Una maestría) }\end{array}$ & $\begin{array}{l}100 \\
\text { (Una maestría) }\end{array}$ & $\begin{array}{l}315 \\
\text { (Cinco } \\
\text { postgrados) }\end{array}$ \\
\hline $\begin{array}{l}\text { Porcentaje } \\
\text { de trabajos } \\
\text { de grado y } \\
\text { tesis }\end{array}$ & 58.4 & 9.8 & 31.7 & 100.0 \\
\hline
\end{tabular}

Elaboración propia.

Los postgrados incluidos en el estudio de la Universidad de Manizales y la Fundación Centro Internacional de Educación y Desarrollo Humano (CINDE) son el Doctorado en Ciencias Sociales, Niñez y Juventud -con una línea investigativa en educación y pedagogía-, y la Maestría en Educación y Desarrollo Humano. Así mismo, se incluye la Maestría en Educación desde la Diversidad, desarrollada por la Universidad de Manizales. Para el caso de la Universidad Tecnológica de Pereira, se encuentra que tiene cinco maestrías y dos doctorados en áreas afines a la educación y la pedagogía; no obstante, de estos solo se tomó la Maestría en Educación. Por su parte, la Universidad Católica de Pereira, con tradición más reciente en los postgrados en educación, presenta la Maestría en Pedagogía y Desarrollo Humano. 
Es necesario aclarar que, en el Eje Cafetero, se encuentran otras instituciones de educación superior que no hicieron parte del estudio, pero que poseen postgrados en educación. Entre ellas se hallan la Universidad de Caldas, la Universidad Católica de Manizales, la Universidad del Quindío, entre otras.

La obra integra seis capítulos. En el primero, «Metodología de regiones investigativas en educación y pedagogía del Eje Cafetero», escrito por Luz Amparo Arroyave, se describe la metodología del estudio, se presenta de dónde emerge la presente investigación al tomar como referencia la primera versión del proyecto de regiones, se describen las instituciones participantes al especificar los programas de posgrado tanto de maestría como de doctorado que fueron incluidos. Además, se muestran las metáforas empleadas en el estudio con inspiración en los planteamientos de Michel Serres (1995). Así mismo, se presentan los instrumentos diseñados para la recopilación de la información y se describe el tipo de información que se analiza, con su discriminación, análisis y tratamiento.

El segundo capítulo, «Corpus documental de educación y pedagogía, zona Eje Cafetero», escrito por Karen Hasleidy Machado Mena, Martha Cecilia Arbeláez Gómez y Martha Lucía Garzón Osorio, recoge el corpus documental en el cual se analizan las diferentes tendencias identificadas en los trabajos de grado de maestría y las tesis doctorales participantes en el proceso investigativo. Se desarrollan tres ejes: el primero hace referencia a las diferentes líneas de investigación en las cuales están vinculados los proyectos, el género y las fuentes de información; el segundo se centra en el análisis de las referencias bibliográficas y el último tiene que ver con las palabras claves usadas por los estudiantesinvestigadores.

A partir de la identificación y el análisis de las temáticas y los autores referenciados en los trabajos de grado de maestría y las tesis de doctorado, de los programas identificados como el 
objeto de estudio en este escrito, se concluye que, con relación a las referencias es necesario realizar lecturas más polifónicas y contextuales de las problemáticas relacionadas con la educación y la pedagogía, y fortalecer la capacidad investigativa y difusora de los programas y los investigadores. De igual manera, las temáticas de los proyectos y de los autores referidos, advierten sobre la emergencia de otras formas de entender la educación y la pedagogía, y sobre las apuestas en relación con la práctica, las cuales parecen estar ligadas al pensamiento crítico de las pedagogías latinoamericanas.

El tercer capítulo, «Alcances y metodologías en investigaciones en educación y pedagogía 2010-2017, zona Eje Cafetero», escrito por Luz Stella Montoya-Alzate, Elizabeth Gallego-Correa y Jhon Wilmar Toro, se centra en los alcances y las metodologías que buscan conocer las tendencias de las investigaciones desde los objetivos planteados, el paradigma investigativo, el enfoque o perspectiva y sus diseños, las técnicas e instrumentos utilizados para recolectar la información y los escritores sobre los cuales se sustenta la metodología aplicada.

Así, la diversidad planteada en dichas apuestas investigativas desde los objetivos, las metodologías, los paradigmas y enfoques, los instrumentos y autores denotan el espíritu de libertad que acompaña los procesos. De esta manera, se observa una coherencia y coincidencia investigativa en las tres universidades, sobre todo, en el alcance que tienen los objetivos y los investigadores al dejar claro que en la zona del Eje Cafetero; aunque son universidades distintas, hay unión en lo investigativo a través de los intereses, por lo que se deja la consigna de que lo importante es la lectura de lo educacional para la comprensión de lo humano.

El cuarto capítulo, «Aproximación conceptual: regiones, educación y pedagogía en el Eje Cafetero», escrito por Martha Lucía Garzón, Claudia Liliana Sánchez-Sánchez y Juan David LalindeSánchez, pone en evidencia que la construcción teórica que se 
viene edificando, privilegia la región pedagogía sobre la región educación. Pero esta última establece una estrecha interacción con asuntos inherentes al contexto escolar; diálogo que converge con las temáticas relacionadas con la formación de sujetos sociales en los espacios áulicos de las instituciones educativas formales. Es decir que ambas regiones se orientan a comprender teóricamente la complejidad de los procesos de enseñanza y de aprendizaje.

El quinto capítulo, «Hallazgos en educación, pedagogía y otras regiones de las tesis y los proyectos de grado del Eje Cafetero (2010-2017)», escrito por Héctor Fabio Ospina, Martha Cecilia Arbeláez, Clara Lucía Lanza, María Camila Ospina-Alvarado, Sara Victoria Alvarado, Claudia Patricia Jiménez-Guzmán, Jhon Fredy Orrego y María Alejandra Fajardo, se enmarca en los resultados de investigación en educación, pedagogía y otras regiones de las tesis analizadas. El capítulo describe y analiza los distintos tópicos alrededor de la educación, la pedagogía y de otras regiones, así como sus subtópicos. Este muestra cómo los resultados se concentran principalmente en la región pedagogía con un $56 \%$, seguidos de la región educación con el $38.5 \%$ y de otras regiones con el $5.5 \%$; y presenta algunas interpretaciones, conclusiones y posibilidades futuras para la investigación en educación y pedagogía en la zona del Eje Cafetero.

Las «Conclusiones» recogen y articulan los principales resultados emergentes de los distintos capítulos. Se concluye que la producción y la asesoría de trabajos de grado y tesis es prioritariamente de mujeres. Respecto a las referencias bibliográficas, se destaca que el referente más citado es el Ministerio de Educación Nacional de Colombia (MEN), lo que puede ser explicado en términos de los intereses de los maestrantes y doctorandos, así como de los programas de becas que han insistido en la intervención en el aula, por lo cual el MEN se ha empleado para citar lineamientos y estándares. Así mismo, se identifica que los autores más citados provienen del contexto español, seguidos por escritores como Freire y Vygotsky; y en el caso del doctorado 
analizado, el autor más citado corresponde a Foucault, situación que evidencia una perspectiva crítica. La identidad de los trabajos de grado y las tesis es un asunto que no parece tener tanta relevancia en la revisión; sin embargo, el equipo de investigación reconoce su pertinencia. Frente al alcance de los objetivos y el uso de las metodologías, priman los elementos comprensivos o interpretativos, las metodologías cualitativas, pero no con mucha distancia de las empírico-analíticas. En relación con los hallazgos en pedagogía, se evidencia la prevalencia de una visión procedimental centrada en las didácticas; frente a los resultados en educación, el foco principal se encuentra en la formación para la paz, seguida de la enseñanza inclusiva, sobre la escuela y la evaluación; $y$, con respecto a otras regiones, los descubrimientos se concentran en el desarrollo humano, y en lo tenido en cuenta, por algunas de las tesis, sobre la familia.

Se invita a los lectores y las lectoras a recorrer esta obra.

\section{Referencias Bibliográficas}

Ospina-Serna, H. F. y Gallardo-Cerón, B. N. (2017). Proyecto regiones investigativas en maestrías y doctorados en educación y pedagogía 2010-2017. Centro de Estudios Avanzados en Niñez y Juventud Universidad de Manizales-Cinde, Universidad Católica de Oriente.

Serres, M. (1995). Atlas. Éditions Julliard. 



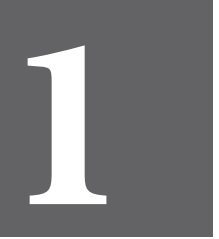

CAPÍTULO

UNO 



\title{
Metodología de regiones investigativas en educación y pedagogía del Eje Cafetero
}

\author{
Luz Amparo Arroyave Montoyal
}

\begin{abstract}
«Hay sitios que no se encuentran en la llanura; se hace necesario buscarlos en la colina, en los pliegues» (Bernstein y Frémont, 2008, s. p.).
\end{abstract}

No hay camino o proyección definida de cómo será el futuro ni tampoco existen pociones mágicas que favorezcan, o agobien los procesos educativos y pedagógicos. Las exploraciones varían de acuerdo al contexto, la época, los individuos y las metodologías. Por lo anterior, antes de empezar este recorrido fue necesario recargar el equipaje para poder hacerlo con mirada inquieta y crítica, y con el interés de construir de manera colectiva, dado que estos procesos dependen totalmente de construir con el otro. Las alforjas llenas de preguntas, con disposición a la escucha, con la

1 Candidata a doctora en Ciencias Sociales, Niñez y Juventud. Universidad de Manizales-Cinde 
intención de construir un espacio donde el acto reflexivo invite a los individuos a pensarse como instrumento y fin de la educación y la pedagogía.

Regiones investigativas en educación y pedagogía en Colombia: mapa topográfico de la actividad investigativa de tesis de maestría $y$ doctorados en el período 2010-2017, invita a recorrer el territorio de los programas de posgrado, los cuales permiten conocer la geografía al explorar e identificar picos, montañas y llanuras presentes en las investigaciones realizadas en el Eje Cafetero; y de esta manera, "comprender regiones y tendencias investigativas en educación y pedagogía entre los años 2010 y 2017» (Ospina et al., 2020, p. 6).

El abordaje de los procesos de educación posgradual —en la primera versión de regiones investigativas-, tomó como referentes trabajos de grado de maestría y tesis de doctorado concluidas entre el 2000 y 2010. Dado el impacto y el interés de la ruta metodológica se plantea una segunda fase iniciada en el 2016, la cual ha llegado a su final en el 2020. Esta propuesta surge desde el grupo de investigación de Educación y Pedagogía del Centro de Estudios Avanzados en Niñez y Juventud de la Universidad de Manizales y el CINDE, proyectándose a nivel nacional, a través de la articulación de cinco regiones: Centro (Bogotá), Eje Cafetero (Caldas, Risaralda), Norte (Norte de Santander), Antioquía (Antioquia) y Sur (Nariño).

La zona Eje Cafetero se encuentra ubicada en el centro de Colombia, conformada por los departamentos de Caldas, Risaralda y Quindío. En primera instancia, fueron convocadas las universidades del sector para que se vincularan al proyecto $y$, de esta manera, poder contar con una región más extensa la cual diera cuenta de la geografía en el terreno de la educación y la pedagogía. De los tres departamentos, se asociaron Risaralda y Caldas con tres universidades y un centro de estudios avanzados (ver FIGURA 
NRO. 1). Lugares donde se desarrollan algunos programas de posgrado, los cuales cuentan con planes relacionados con la temática del proyecto regiones investigativas:

- La Universidad de Manizales y el Centro de Estudios Avanzados en Niñez y Juventud se vincularon con información de ciento quince trabajos de grado de maestría correspondientes a la Maestría en Educación desde la Diversidad, y a la Maestría en Educación y Desarrollo Humano; también con veintinueve tesis del Doctorado en Ciencias Sociales, Niñez y Juventud. Todo esto para completar un total de ciento ochenta y cuatro documentos.

- La Universidad Tecnológica de Pereira, por su parte se asoció con cien trabajos de grado de la Maestría en Educación.

- Y la Universidad Católica de Pereira, con treinta y un trabajos de grado de la Maestría en Pedagogía y Desarrollo Humano.

FIGURA NRO. 1. Vinculación universidades del eje cafetero en el proyecto de regiones.

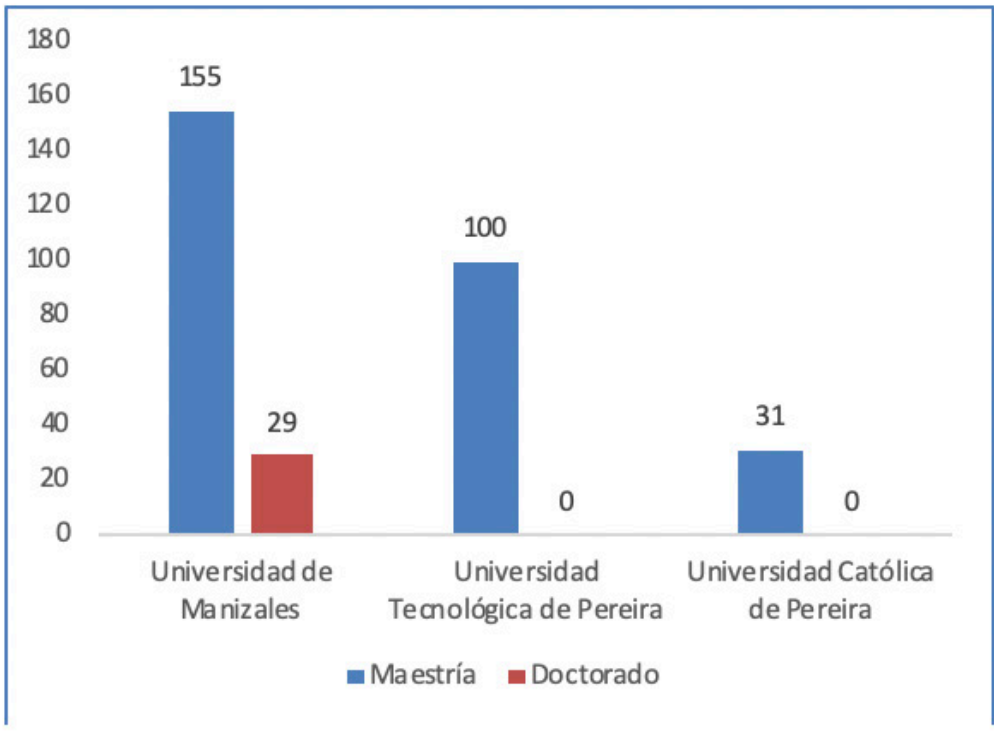

Elaboración propia. 
Para contar con los trecientos quince documentos, fue necesario indagar en los proyectos de investigación culminados en el período de 2010-2017 y analizar cuáles cumplían con el objetivo de regiones. Para hacer la selección se tuvo en cuenta el objeto, la metodología y las fuentes presentadas en los documentos revisados. De igual manera, se hizo ineludible depurar aquellos escritos que, a pesar de hacer parte de líneas de investigación, orientadas a la educación y la pedagogía, no respondían a los intereses. Se hizo un llamado a la participación de todas las instituciones del Eje Cafetero, no obstante, solo se consolidó la vinculación de las antes mencionadas.

Con el propósito de unificar criterios en el abordaje de la educación, la pedagogía y la didáctica, el grupo de investigación participó en seminarios nacionales y locales en los cuales se presentaban diferentes posturas teóricas al respecto, las cuales permitieran centrar las ideas y ampliar el tema orientado al objetivo de la investigación, y así adquirir herramientas conceptuales y metodológicas para la comprensión de estos tópicos. Se contó también con asesoría de expertos en Michel Serres para clarificar las posturas del autor, el cual fue tomado como referencia para el análisis y comprensión del trabajo de regiones investigativas.

La topografía esbozada en estas líneas está basada en metáforas adaptadas de las palabras de Serres, en su libro Atlas (1995), las cuales permiten ver el terreno investigativo desde la óptica de un cartógrafo, el cual recorre territorios para descubrir sus pliegues. Así, en la recolección de datos útiles, se puede encontrar al individuo, y con él, el saber cómo hacer los recorridos, saber dónde se está y hacia dónde ir. En este sentido, el grupo de investigadores consideró algunas metáforas las cuales aplican a las derivas investigativas evidenciadas en este proyecto y se acogió a ellas para el análisis de la información recabada en el proceso.

A continuación, se encuentran las representaciones presentes en el ejercicio de escritura, y se parte desde la región (área 
general del paisaje), en la cual se evidencian los pliegues como deformaciones de la geografía (picos, montañas, llanuras) -ver Figura NRO. 2-.

FIGURA NRO. 2. Representación de las metáforas adaptadas de Michel Serres.

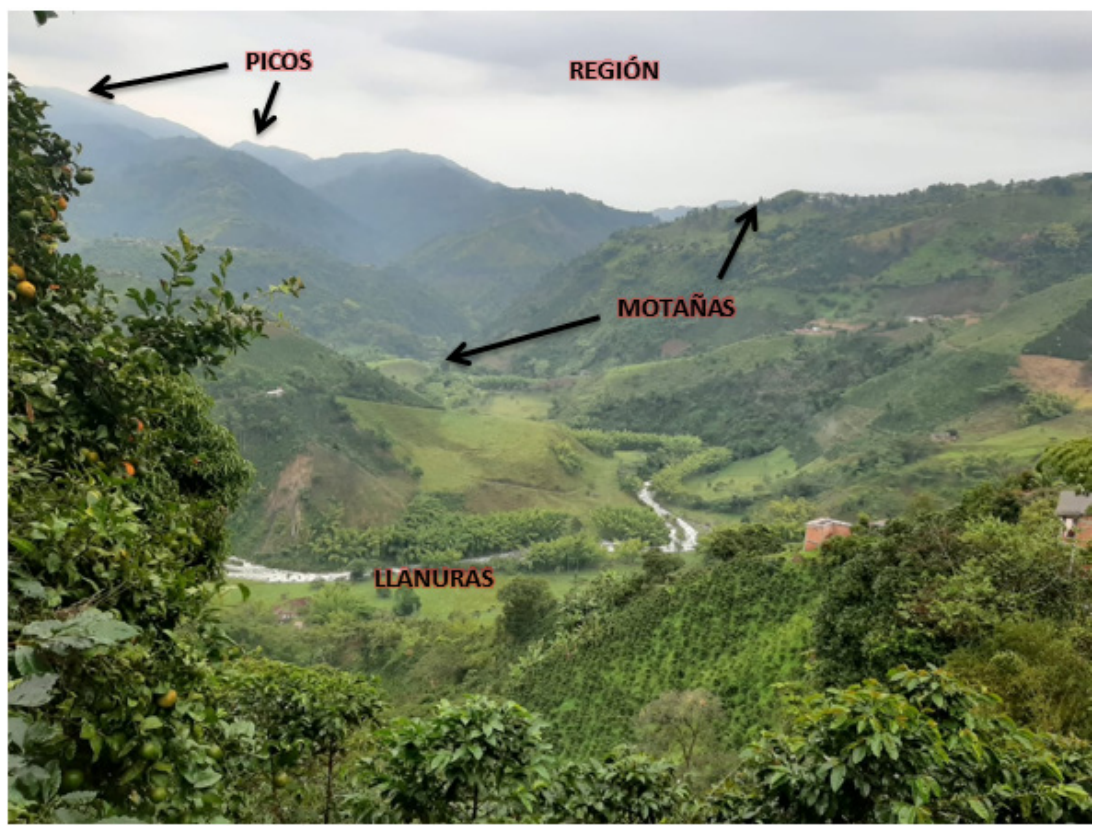

Elaboración propia.

- Región: porción de territorio, de espacio delimitado. En ella se presentan los pliegues, las relevancias y opacidades. En este caso, la región estará constituida por los trecientos quince documentos procesados para la investigación.

- Topografía: técnica de describir las particularidades las cuales presenta un terreno. En este sentido, el proyecto de regiones representa y describe dicha tarea sobre un espacio en específico, es decir, sobre la educación y la pedagogía en la zona del Eje Cafetero. 
- Cartografía: encargada de reunir y analizar datos sobre regiones geográficas para representarlos de manera gráfica. Así las cosas, la metáfora cartografía emerge como posibilidad de agrupar los resultados de los proyectos de investigación y tesis que indagan en educación y pedagogía, para poder analizar y presentar el panorama en contextos actuales y vigentes, y con proyección a futuros escenarios de investigación.

- Cartógrafo: persona que se dedica a la cartografía. En el presente caso, son los investigadores vinculados al proyecto, quienes nutrieron con sus aportes esta investigación.

- Tópicos: manifestaciones que dan cuenta de la topografía del lugar, una manera de organizar y entretejer la información.

- Subtópicos: dan cuenta de los tópicos para describirlos.

- Pliegues: son aquellas deformaciones las cuales se presentan en el terreno, pueden ser marcadas o acentuadas. Los pliegues permiten evidenciar las relevancias desde los picos y/o montañas y las opacidades desde las llanuras.

- Relevancias: pliegues marcados por su gran altura, es decir, resaltan ante los demás. Entre ellos están los picos y las montañas -las maneras de enunciar dependen de la cantidad de datos-.

- Opacidades: pliegues no pronunciados o de escaso pronunciamiento en la geografía. A saber, emergen como llanuras.

- Pico: pliegue de mayor relieve que la montaña. Es usado cuando la marca de un dato resalta sustancialmente ante los demás.

- Montaña: pliegue de gran relieve - relevancia-, el cual presenta una tendencia o una concentración amplia. Dato visible en los instrumentos de Regiones Investigativas en Educación y Pedagogía (RIEP).

- Llanura: pliegue pobremente marcado. 
En el Eje Cafetero se vincularon investigadores, los cuales hacen parte de las universidades integradas al proyecto, ya sea como docentes, investigadores o estudiantes de posgrado. Ellos asumieron el papel de cartógrafos inquietos por explorar la topografía. Con este grupo de trabajo fue posible explorar aspectos como el corpus documental, la metodología, las fuentes, los conceptos y los hallazgos, con la información de los proyectos de investigación y tesis. Esto, al entretejer y dar cuenta del panorama al que se integran estudiantes de maestría y doctorado de la región para explorar, dinamizar o profundizar aspectos en educación y pedagogía. Un buen topógrafo es aquel que, de manera inquieta y crítica, indaga las regiones, las recorre, las analiza e interpreta, para presentar un testimonio desde su lugar de enunciación - en este caso, investigadores vinculados a programas y/o establecimientos adscritos al Ministerio de Educación Nacional-, apoyados por los tópicos y subtópicos emergidos en el proceso.

La visión diversa de los cartógrafos ha permitido hacer una lectura amplia de los trecientos quince documentos de investigación integrados al proyecto para así aclarar el horizonte; pues al hablar desde diferentes disciplinas se enriquece el discurso, más aun, cuando se tiene en cuenta la diversidad profesional de los investigadores vinculados. El estudio «Regiones investigativas en educación y pedagogía» propició un espacio académico de reflexión, en el cual el trabajo colaborativo fue protagonista, y de igual manera, el hacer parte de distintas universidades y ciudades enriqueció el proceso de lectura y escritura.

Para iniciar el proceso de investigación en regiones, los cartógrafos adheridos al programa conformaron grupos de trabajo; aquellos facilitaron el procesamiento y análisis de la información. En cinco mesas de trabajo se distribuyeron los instrumentos de investigación $\mathrm{y}$, en ellos, los datos arrojados por los trabajos de grado de maestría y tesis de doctorado, para así, procurar realizar una cartografía lo más real posible sobre la situación de los programas de posgrado vinculados. 
Los documentos fueron procesados por medio de instrumentos elaborados en Excel. En ellos se consignaban aspectos específicos los cuales dieran cuenta de la intención, la metodología, las fuentes, los conceptos y los hallazgos de los autores. Estos instrumentos fueron denominados RIEP por las iniciales del proyecto en regiones investigativas en educación y pedagogía y discriminaron la información de la siguiente manera:

- RIEP número uno. Corpus documental, temáticas y referencias: en este documento se presenta la información general y lo que permite, a los autores de los documentos procesados, ubicar en un contexto. Este cuenta con cuatro hojas en el documento de Excel donde se presentan los autores de los trabajos de grado de maestría y tesis de doctorado, los programas académicos, los grupos y líneas de investigación, además de las referencias bibliográficas empleadas y las palabras clave (ver TABLA NRO. 2).

TABLA NRO. 2. Primer instrumento RIEP. Corpus documental, primera hoja.

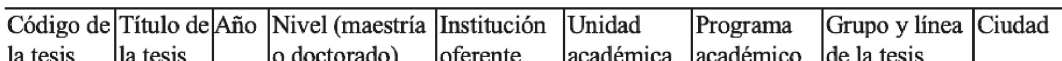

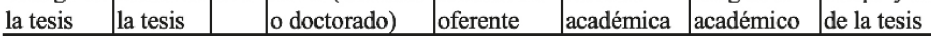
Elaboración propia.

- RIEP número dos. Objetivos generales y rutas metodológicas: en este documento se recogen y analizan los objetivos generales, los alcances, la metodología, el paradigma, el enfoque, los instrumentos y las técnicas presentadas en los trabajos de grado de maestría y tesis de doctorado. Este RIEP se completa con el anterior, ya que presenta información general de los documentos procesados, y permite identificar el qué y el cómo se realizan los procesos de investigación en educación y pedagogía en el Eje Cafetero (ver TABla NRO. 3).

TABLA NRo. 3. Segundo instrumento RIEP.

Objetivos generales y rutas metodológicas.

\begin{tabular}{l|l|l|l|l|l|l|l}
\hline $\begin{array}{l}\text { Código de } \\
\text { la tesis }\end{array}$ & $\begin{array}{l}\text { Objetivo } \\
\text { general }\end{array}$ & $\begin{array}{l}\text { Alcance del } \\
\text { objetivo }\end{array}$ & $\begin{array}{l}\text { Reporte } \\
\text { metodológico }\end{array}$ & $\begin{array}{l}\text { Paradigma, enfoque } \\
\text { o perspectiva }\end{array}$ & Instrumentos & Técnicas & Autores \\
\hline
\end{tabular}

Elaboración propia. 
- RIEP número tres. Fuentes de la investigación: en este documento se analiza la pregunta ¿De quién se habla en educación y pedagogía? Este RIEP da cuenta de las variadas y amplias fuentes las cuales se tienen en cuenta en las investigaciones orientadas hacia el tema, en él se especifica hacia donde se dirige la mirada para las indagaciones, es decir, tipo de fuente (persona, documento, institución, mixto), papel de la fuente, sector, tipo de zona, nivel socioeconómico y niveles de formación. Es necesario aclarar que este RIEP, no fue analizado de manera aislada para la zona del Eje Cafetero, sino que se tomaron algunos elementos, los cuales fueron incorporados al RIEP número uno (ver TABLA NRO. 4).

TABLA NRO. 4. Tercer instrumento RIEP. Fuentes de la investigación.

\begin{tabular}{l|l|l|l|l|l|l|l|l|l|l}
\hline $\begin{array}{l}\text { Código } \\
\text { de la } \\
\text { tesis }\end{array}$ & $\begin{array}{l}\text { Fuente de la } \\
\text { investigación }\end{array}$ & $\begin{array}{l}\text { Tipo } \\
\text { de } \\
\text { fuente }\end{array}$ & $\begin{array}{l}\text { Rol de la } \\
\text { fuente }\end{array}$ & Población & $\begin{array}{l}\text { Número } \\
\text { de casos }\end{array}$ & $\begin{array}{l}\text { Sector Tipo de } \\
\text { zona }\end{array}$ & $\begin{array}{l}\text { Nivel } \\
\text { socioeconómico }\end{array}$ & Lugar Nivel \\
\hline
\end{tabular}

Elaboración propia.

- RIEP número cuatro. Conceptos de pedagogía y educación: en este documento se consignan aquellos elementos que surgen de los procesos de investigación, es decir, los referentes teóricos y conceptuales de la educación y la pedagogía (ver TABLA NRO. 5).

TABLA NRO. 5. Cuarto instrumento RIEP. Conceptos de pedagogía y educación.

\begin{tabular}{c|c|c|c}
\hline $\begin{array}{c}\text { Código de la } \\
\text { tesis }\end{array}$ & Reporte conceptual & $\begin{array}{c}\text { Aproximación conceptual a la pedagogía y/o la } \\
\text { educación }\end{array}$ & Observaciones \\
\hline
\end{tabular}

Elaboración propia.

- RIEP número cinco. Hallazgos: en este documento se presentan resultados destacados y categorías emergentes; con ello se presentan las relevancias y opacidades entre los tópicos abordados. A partir de la información recopilada se debía consolidar los tópicos globales y locales por regiones (ver TABLA NRO. 6). 
Tabla NRO. 6. Quinto instrumento RIEP. Hallazgos.

\begin{tabular}{c|c|c|c}
\hline $\begin{array}{c}\text { Código de la } \\
\text { tesis }\end{array}$ & Reporte hallazgos & $\begin{array}{c}\text { Aproximación conceptual a la pedagogía y/o la } \\
\text { educación }\end{array}$ & Observaciones \\
\hline
\end{tabular}

Elaboración propia.

Para el diligenciamiento de estos documentos, los cartógrafos se dirigieron a un terreno fértil, dado que, con los datos recabados e incluso los que no se presentan en los RIEP, se pudo realizar lecturas, interpretaciones y análisis respecto a las relevancias (sea en picos o montañas) y opacidades (llanuras). Las diversas miradas permitieron descomponer la realidad para interpretar cómo están los procesos de investigación en programas de posgrado en el campo de la educación y la pedagogía. Los resultados de ello serán presentados en los capítulos siguientes.

Para ingresar los datos a los instrumentos RIEP, los investigadores buscaban la información en los trabajos de grado de maestría y tesis de doctorado. Para el caso de Manizales se usó un formato de resúmenes de tesis (TABLA NRO. 7), el cual usan la Universidad de Manizales y el Centro de Estudios Avanzados en Niñez y Juventud (UM-C). Este se tomó como insumo y referencia dado que la gran mayoría de proyectos de investigación contaban con dicho documento diligenciado. En este los autores hacen una síntesis de su trabajo, elemento que facilitaba el diligenciamiento de los instrumentos. 


\section{TABLA NRO. 7. Información solicitada en el formato para resúmenes de tesis de la UM-C.}

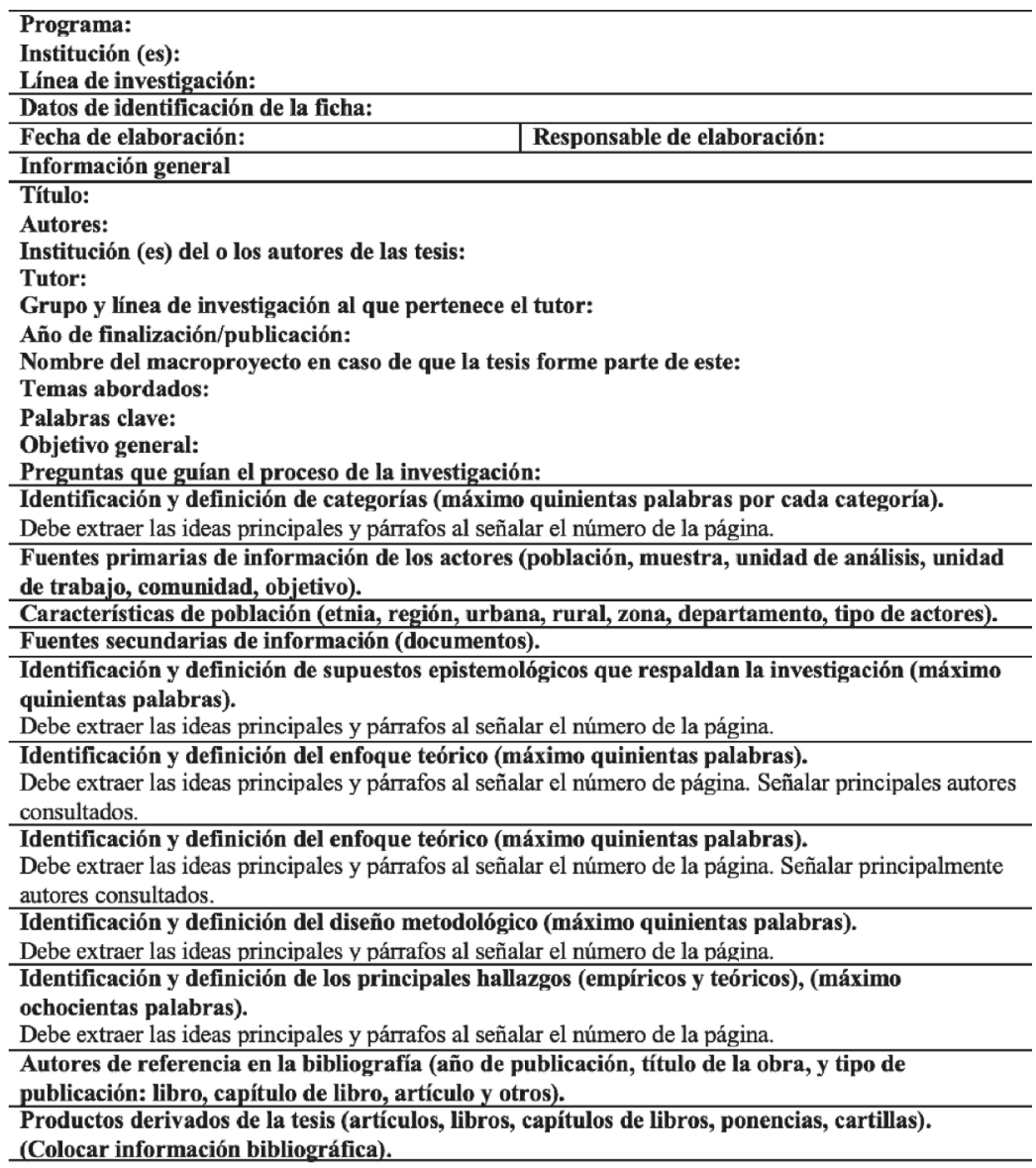

Elaboración propia.

En la etapa de preparación y procesamiento de la información hubo diferentes momentos los cuales permitieron favorecer el diseño de los instrumentos. Al hacer las revisiones y al tomar como referencia la primera versión del proyecto, fue posible gestionar la información de manera más efectiva, y los formatos presentados en un inicio empezaron a sufrir trasformaciones para acotar y garantizar una mejor recolección de la misma. Fue así como desaparecieron algunos aspectos y emergieron otros - los 
cuales serán presentados en los capítulos siguientes-. Dichos ajustes, al igual que todos los procesos, fueron definidos por el grupo investigador, esto con el fin de describir la región de manera más clara y completa. Para ello se contó con varios encuentros en los cuales se justificaba y validaba la modificación de los mismos.

Las lecturas de los cartógrafos en su proceso de investigación, y con la objetividad que los caracteriza, permitió, que aún en la marcha, se hicieran ajustes necesarios a los instrumentos sin afectar la veracidad de la información.

Es de anotar que, al igual que se presentaron aciertos, se evidenciaron algunas inconsistencias las cuales deben ser tenidas en cuenta para futuras versiones del proyecto de regiones. Entre ellas se tienen:

- No contar con todos los formatos de resumen de tesis hizo dispendioso el diligenciamiento de los instrumentos.

- Algunos resúmenes de tesis contaban con información incipiente o no correspondiente a lo solicitado, esto implicaba volver sobre el documento original.

- Información insuficiente o ambigua generaba categorías difíciles de interpretar.

- Inconsistencias en el diligenciamiento de los instrumentos, encontrándose palabras o conceptos los cuales no aplicaban.

A pesar de las dificultades presentadas, se culminó el proceso de regiones investigativas con éxito. Es importante tener en cuenta que, el factor humano, favorece el proceso de investigación dada la multiplicidad de disciplinas de los investigadores. Esto al permitir una lectura crítica de los datos, aspecto el cual debe fortalecerse para permitir diálogos que enriquezcan el panorama de regiones. Posterior a la recopilación de los datos a través de los formatos, se gestionó la información y se hizo lectura «objetiva» de la misma, 
para hacer los análisis respectivos y transitar desde lo cuantitativo hacia lo cualitativo.

Al finalizar el procesamiento de la información se generaron reflexiones y conclusiones las cuales permitieron dar cuenta de la geografía en educación y pedagogía. Para ello se hizo uso de las ventajas del instrumento en Excel, el cual permite hacer análisis estadístico a través de tablas dinámicas, de gráficos, entre otros elementos. El entrecruzamiento del dato con la reflexión permitió presentar relaciones discursivas las cuales dan cuenta de la situación de la zona del Eje Cafetero.

Las representaciones que se hicieron en el recorrido por Regiones Investigativas en Educación y Pedagogía son un atlas que advierte de la topografía en la zona ya mencionada. Este será presentado en los siguientes capítulos.

\section{Referencias Bibliográficas}

Bernstein, C. y Frémont, C. (2008, 18 de enero). El viaje enciclopédico de Michel Serres [Vídeo]. YouTube. https:// www.youtube.com/watch? $\mathrm{v}=\mathrm{dfzAEmksbRo.}$

Ospina, H. F. Gallardo-Cerón, B. N. Montoya-Rodas S. y Arroyave-Montoya, L. A. (coords.) (2020). Regiones investigativas en educación y pedagogía en Colombia: mapa topográfico de la actividad investigativa de tesis de maestrías y doctorados en el periodo 2010-2017. Centro Editorial Cinde. 



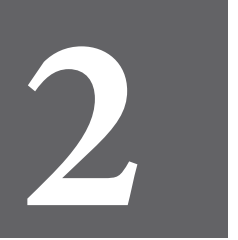

CAPÍTULO DOS 



\title{
Corpus documental de educación y pedagogía, zona Eje Cafetero
}

\author{
Karen Hasleidy Machado Mena ${ }^{2}$ \\ Martha Cecilia Arbeláez Gómez ${ }^{3}$ \\ Martha Lucía Garzón Osorio ${ }^{4}$
}

Las tesis y trabajos de grado, como objeto de investigación, son un interés reciente de los teóricos e investigadores en Latinoamérica y otros continentes. Cada vez son más los estudios y publicaciones al respecto los cuales, según la clasificación de Sime Poma y Revilla Figueroa (2014), se realizan desde cuatro perspectivas: la primera pone el acento en las tendencias temáticas, metodológicas y bibliográficas de las tesis; la segunda indaga acerca de los problemas de los estudiantes en el desarrollo y culminación de las tesis; la tercera se aproxima a estudiar y proponer instrumentos de evaluación; y finalmente, una cuarta centra su mirada en aspectos sobre el asesoramiento de las mismas.

2 Universidad Tecnológica de Pereira - Licenciatura en Artes Visuales

3 Universidad Tecnológica de Pereira

4 Universidad Tecnológica de Pereira 
En el contexto colombiano, las tesis y trabajos de grado como objetos de estudio también han venido tomado fuerza en las investigaciones, las cuales se han focalizado en la identificación, la categorización y comprensión de los objetivos; en las opciones metodológicas; en las temáticas; las tendencias bibliográficas; los intereses y campos de estudio; en el asesoramiento y las dificultades en su elaboración (Bonilla Murcia y Rocero Pardo, 2011; García Pérez y García Aretio, 2014; Murcia-Peña et al., 2011; Murcia-Peña et al., 2012).

En esta línea y como interés de estudio, el presente capítulo tiene por objetivo analizar las tendencias temáticas y referenciales de los trabajos de grado de maestrías y las tesis doctorales. Para ello, este se desarrolla desde tres ejes: en el primero se caracterizan los trabajos de grado y las tesis desde su vinculación a líneas de investigación, el género de los autores y asesores, y las fuentes de información a las cuales recurrieron; el segundo se desarrolla en torno al análisis de las referencias bibliográficas de los trabajos y las tesis; y finalmente, el último eje presenta el análisis de las palabras clave usadas por los estudiantes-investigadores.

Respecto al primer eje, el análisis de 317 documentos tesis y trabajos de grado-, devela que 205 (65\%) se encuentran vinculados a una línea de investigación, y que pocas de ellas se mantuvieron constantes en la producción académica; en un proceso que puede llamarse de auge y de declive, donde incluso alguna aparece una sola vez. El análisis también indica que entre los 601 profesionales que acuden a los posgrados, 433 (72 \%) son mujeres, en las tres universidades, programas y periodos de estudio; de igual manera, muestra que si bien son ellas quienes han tenido mayor cantidad de dirección de las tesis (167) no están muy distante de lo que sucede con los hombres (154). Esto teniendo en cuenta las diferencias en cada uno de los programas. En este sentido, la producción académica de las maestrías y doctorados en el Eje Cafetero está principalmente direccionada y realizada por mujeres profesionales en el campo de la educación, que acuden 
especialmente a las líneas de investigación de esos programas para estudiar las realidades de sus contextos educativos, y usar como fuentes las personas, en sus papeles institucionales de estudiantes y docentes.

En el segundo eje, el análisis de 18025 referencias devela que en la cumbre de la montaña se ubica al Ministerio de Educación Nacional Colombiano (MEN), como la mayor fuente en los trabajos de grado de maestría y tesis de doctorado del Eje Cafetero. También muestra que al MEN le siguen autores como César Coll y Paulo Freire; asunto que puede indicar una posible tensión entre los aportes ministeriales, que regulan y enmarcan la educación colombiana, y vertientes más orientadas hacia las perspectivas constructivistas, especialmente las de orientación social y crítica.

El análisis muestra que la mayoría de las referencias son documentos publicados en la primera década del siglo XXI, asunto que puede estar ligado al aumento de los recursos electrónicos a través del internet $\mathrm{y}$ al acceso rápido que puede tener un investigador a este tipo de escritos (García Pérez y García Aretio, 2014). Esta podría ser una explicación de la extensa llanura que componen las referencias mencionadas una única vez, las cuales posiblemente, se remiten a otras tesis e investigaciones, que hacen parte de las propias búsquedas realizadas por los autores de los trabajos de grado y las tesis.

Finalmente, en el tercer eje se describen y clasifican las temáticas de las palabras clave expresas en los trecientos diecisiete documentos, para un total de 1672 palabras. Algunos hallazgos evidencian que las temáticas de mayor relevancia son prácticas pedagógicas, diversidad, educación, secuencia didáctica y aprendizaje; mientras que las opacidades residen en aquellas a las que se alude una única vez, esto es, más de 500 términos clave; situación que podría estar relacionada con la necesidad de asignar palabras clave significativas que representen el contenido particular de cada uno de los trabajos realizados por los tesistas, de 
manera que el trabajo pueda destacarse dentro de otros parecidos y facilite su búsqueda con los tesauros especializados.

A continuación, se presenta el análisis de cada uno de los ejes expuestos en el orden en que fueron mencionados.

\subsection{Caracterización del corpus documental. Universidades y autores}

El capítulo pretende identificar, clasificar y analizar los trabajos de grado de maestrías y tesis de doctorados en cuanto a la cantidad, la procedencia (líneas de investigación), las fuentes usadas para la recolección de la información y el género de autores y asesores. En atención a ese objetivo, se presenta a continuación los reportes descriptivos, que dan inicio al croquis para delinear las tendencias de los programas de posgrados y constituyen la presente zona. Estos son:

- Universidad Católica de Pereira: Maestría en Pedagogía y Desarrollo Humano.

- Universidad Tecnológica de Pereira: Maestría en Educación.

- Universidad de Manizales, en alianza con la Fundación Centro Internacional de Educación y Desarrollo Humano (CINDE): Maestría en Educación y Desarrollo Humano, Maestría en Educación desde la Diversidad y Doctorado en Ciencias Sociales, Niñez y Juventud.

El análisis general de los cinco programas permite caracterizar en la TABLA NRO. 8 los datos aportados por cada uno de ellos, en cuanto a cantidad de trabajos de grado y tesis, líneas de investigación, autores, asesores, autores de referencia y palabras clave. 
TABLA NRO. 8. Caracterización del corpus documental.

\begin{tabular}{lllllll}
\hline Universidades & $\begin{array}{l}\text { Universidad } \\
\text { Tecnológica } \\
\text { de Pereira } \\
\text { (UTP) }\end{array}$ & $\begin{array}{l}\text { Universidad } \\
\text { Católica de } \\
\text { Pereira } \\
\text { (UCP) }\end{array}$ & Universidad de Manizales y el CINDE & \\
\hline $\begin{array}{l}\text { Programas } \\
\text { académicos }\end{array}$ & $\begin{array}{l}\text { Maestría en } \\
\text { Educación }\end{array}$ & $\begin{array}{l}\text { Maestría en } \\
\text { Pedagogía y } \\
\text { Desarrollo } \\
\text { Humano }\end{array}$ & $\begin{array}{l}\text { Maestría en } \\
\text { Educación y } \\
\text { Desarrollo } \\
\text { Humano }\end{array}$ & $\begin{array}{l}\text { Maestría en } \\
\text { Educación } \\
\text { desde la } \\
\text { Diversidad }\end{array}$ & $\begin{array}{l}\text { Doctorado } \\
\text { en Ciencias } \\
\text { Sociales, } \\
\text { Niñez y } \\
\text { Juventud }\end{array}$ & Total \\
\hline $\begin{array}{l}\text { Trabajos de } \\
\text { grado de } \\
\text { maestría y tesis } \\
\text { de doctorado }\end{array}$ & 100 & 31 & 76 & 80 & 30 & $\mathbf{3 1 7}$ \\
\hline $\begin{array}{l}\text { Líneas de } \\
\text { investigación }\end{array}$ & 9 & 1 & 6 & 1 & 7 & $\mathbf{2 0}$ \\
\hline Autores & 46 & 21 & 31 & 60 & 10 & $\mathbf{1 6 8}$ \\
\hline Autoras & 105 & 43 & 94 & 171 & 20 & $\mathbf{4 3 3}$ \\
\hline Asesoras & 61 & 13 & 24 & 56 & 13 & $\mathbf{1 6 7}$ \\
\hline Asesores & 45 & 19 & 50 & 21 & 19 & $\mathbf{1 5 4}$ \\
\hline $\begin{array}{l}\text { Autores de } \\
\text { referencia }\end{array}$ & 6196 & 878 & 3509 & 3000 & 4442 & $\mathbf{1 8 2 5}$ \\
\hline Palabras clave & 449 & 173 & 488 & 411 & 151 & $\mathbf{1 6 7 2}$ \\
\hline
\end{tabular}

Elaboración propia.

Los datos de la tabla anterior relacionan las tres universidades y los cinco programas académicos que forman parte de la investigación. Entre ellos se recopilan trecientos diecisiete trabajos de grado y tesis, adscritas a veinte líneas de investigación realizadas por 601 autores, dirigidos por 321 asesores. Los documentos incluyen un total de 18025 referencias y 1672 palabras clave.

Una comparación entre estos datos y los reportados en el estudio anterior, realizado por Sánchez Amaya y Arias Murillo (2012), indica un aumento considerable de la actividad investigativa en los programas de maestría y doctorado del Eje Cafetero. Se pasa de un promedio aproximado de 28 tesis por año, en el período del 2000 al 2010, a 39 tesis por año en el período del 2010 al 2017. La progresión en la producción académica puede rastrearse comparativamente, pues en el primer proyecto de «regiones investigativas» se incluían los trabajos de grado de siete programas académicos en once años, mientras que el presente estudio, como muestra la tabla anterior, se recopila la producción 
de cinco programas académicos en ocho años. Es decir, menos programas, un período de tiempo menor, y mayor producción de obras o escritos de grado.

Esta situación puede explicarse en el aumento de la demanda de los programas de maestría y doctorado en la región y en el país, por dos asuntos: primero, las exigencias de formación y actualización continuada para la producción y el uso de nuevos conocimientos en materia educativa que el gobierno, diferentes organismos trasnacionales que ejercen influencia en las políticas educativas del país - la Organización de las Naciones Unidas para la Educación, la Ciencia y la Cultura (UNESCO), la Organización para la Cooperación y el Desarrollo Económicos (OCDE), el Banco Mundial (BM) y el Banco Interamericano de Desarrollo (BID) - , instituciones educativas y la misma práctica, le hacen a los maestros y demás agentes educativos, con miras a mejorar la calidad de la educación en el país; y segundo, debido a las aspiraciones que tienen los mismos educadores por mejorar sus condiciones salariales y laborales, pues a medida que se avanza en la formación profesional, se incrementan los salarios y las tasas de vinculación, es decir, que «estudiar si paga» (MEN, 2015, p. 2).

Con estas y otras posibles pretensiones, 601 autores han investigado sobre temáticas relacionadas con la educación y la pedagogía en el marco de los grupos y líneas de investigación adscritas a los programas académicos aludidos. En el caso de la Universidad Tecnológica de Pereira, han sido nueve las líneas que enfocaron la producción académica de las cien tesis reportadas en la Maestría en Educación, a saber:

A) Concepciones de práctica pedagógica. A la línea se vinculan cuatro trabajos de grado. Todos ellos realizados con fuentes de tipo persona (tres trabajos de grado con docente y una con estudiantes y docente). 
B) Didáctica de las artes. A esta línea se vincula un trabajo de grado, este realizado en el año 2010 con fuentes de tipo persona en su papel institucional de docentes.

C) Didáctica de las ciencias naturales. A la línea se adscriben diez trabajos de grado realizados con tres tipos de fuentes: dos con documentos (texto escolar de ciencias naturales), uno con fuente de tipo mixta (expertos, estudiantes, madres de familia, programas curriculares, investigaciones en educación artística, experiencias significativas mundiales) y siete con fuentes de tipo persona (todas con estudiantes).

D) Didáctica de las ciencias sociales. A la línea se vinculan treinta y dos trabajos de grado realizados con fuente de tres tipos: treinta con personas (veinte de estudiantes, seis de docentes, dos de estudiante y docente, uno con más de un actor -actores educativos de los estamentos de docente, estudiante-tutor y administrativo-, y uno con otro - teorías implícitas de dos grupos, uno de instructores y otro de docentes, ambos grupos de instituciones diferentes-), uno con documentos (texto escolar: libros de texto escolar de ciencias sociales, de los grados tercero a quinto de básica primaria, de seis editoriales y con temáticas relacionadas con el conflicto colombiano desde mitad del siglo $\mathrm{xx}$ hasta la actualidad) y uno con fuente de tipo institución (docentes y directivos de básica primaria).

E) Didáctica de las matemáticas. A la línea se encuentran vinculados seis trabajos de grado realizados con fuentes de tipo persona (tres docentes y tres estudiantes).

F) Didáctica del lenguaje. A esta línea se adscriben veintisiete trabajos de grado realizados con fuentes de tipo personas (veinticuatro de estudiantes, dos de docente, y con un estudiantes y docente). 
G) Educación inclusiva. A la línea se encuentran asociados seis trabajos de grado realizados con fuentes de tipo persona (tres de estudiantes y docente, dos de estudiante, y uno de docente).

H) Didáctica de la Salud. A la línea solo pertenece un trabajo de grado, realizado en el año 2010 con personas en sus roles institucionales: estudiante y docente (profesora de Informática Educativa II y un grupo de estudiantes de la Licenciatura en Pedagogía Infantil, del Programa CERES).

I) TIC-Tecnologías de la Información y la Comunicación. En la línea hay trece trabajos de grado realizados con fuentes de tipo persona: siete de estudiante, tres de estudiante y docente, dos de docente, y uno con más de un actor (curadores de contenido educativo: docentes, directivos, investigadores, desarrolladores, entre otros).

Cabe mencionar que las únicas dos líneas que han permanecido durante todo el período de estudio, han sido Didáctica de las Ciencias Sociales y Didáctica del Lenguaje.

En la Universidad Católica de Pereira, de los treinta y un trabajos de grado reportados por la Maestría en Pedagogía y Desarrollo Humano, ocho se vinculan a la línea de educación, comunicación y cultura; particularmente a los proyectos «Narrativas pedagógicas en contextos» (con un trabajo de grado), «Narrativas pedagógicas inclusivas en contextos educativos vulnerables» (con tres trabajos de grado); y, a los macroproyectos «Lenguajes de los poderes. Las homogeneizaciones/diversidades y las exclusiones/inclusiones en los sistemas educativos superiores en Argentina, España, México, Chile y Colombia. Diálogos de saberes (2014-2019)» (con dos trabajos de grado) y «Lenguajes del poder». "Las homogeneizaciones/diversidades y las exclusiones/ inclusiones en los sistemas Educativos Superior en Argentina, España, México, Chile y Colombia. Diálogos de saberes (2014- 
2017)»(dos trabajos de grado). El resto de trabajos de grado (veintitrés) no reporta un grupo o línea de investigación, así como tampoco un proyecto que caracterice el eje temático de las mismas.

Un panorama parecido se dilucida en la Maestría en Educación desde la Diversidad de la Universidad de Manizales y el CINDE, pues de los ochenta trabajos de grado incluidos en el estudio, solo uno reporta estar vinculado a la línea de desarrollo humano (realizado con fuentes de tipo persona, en su rol institucional de docentes), y treinta y dos de ellos están articuladas a diez proyectos, como son: «Prácticas pedagógicas y huellas vitales» (siete trabajos de grado), «Concepciones, creencias y prácticas de la gestión escolar» (dos resultados), «Concepciones y prácticas pedagógicas de los maestros de jóvenes en situación de vulnerabilidad institucional, cultural, ambiental y/o de entorno de las instituciones educativas de Nariño y Cauca» (once trabajos de grado), «El desempeño académico: una opción para la cualificación de las instituciones educativas» (un trabajo), «Sujetos y diversidad: una mirada desde el desarrollo humano» (un trabajo de grado), «Práctica pedagógica transformadora: hacia una construcción del pensamiento crítico en la escuela caucana» (tres trabajos de grado), «Maestros e intelectuales en la educación colombiana» (un trabajo de grado), «Sentidos y significados de la diversidad: perspectivas para una educación incluyente en jóvenes en la región andina, amazónica y pacífica de Colombia, desde las voces de los niños, niñas y jóvenes» (un trabajo de grado), «Didácticas alternativas: una posibilidad a la diversidad en el aula» (cuatro trabajos de grado) y «Saberes imaginarios e intersubjetividades» (un trabajo de grado).

Para el caso de los dos programas restantes de la Universidad de Manizales y el CINDE, la Maestría en Educación y Desarrollo Humano aporta setenta y seis trabajos de grado vinculados en cuatro grupos de investigación y seis líneas. Esto de la siguiente manera: 
A). Grupo educación y pedagogía: saberes, imaginarios e intersubjetividades, con dos líneas:

- Cognición, emoción y praxis humana. A la línea se inscriben veintiséis trabajos de grado, todos ellos realizados con fuentes de tipo persona; esto, de la siguiente manera: quince de estudiante, dos de docente, dos de egresados, dos de estudiante y docente, cuatro con más de un actor - jóvenes; funcionarios de las instituciones de educación superior; estudiantes, docentes de educación física, directivos de instituciones públicas; estudiantes, docentes y padres de familia; actores que han participado activamente de los procesos de la Red Hidroclimatológica de Risaralda (REDH)-, y un otro - participantes de las cuatro etapas de reintegración-.

- Educación y pedagogía. A la línea se asocian veinticinco trabajos de grado, los cuales emplean fuentes de la siguiente manera: de tipo documento con un trabajo de grado (con texto escolar-libros de texto de ciencias naturales); de tipo personas con veintitrés trabajos de grado - cuatro de docente, diez de estudiante, cinco de estudiante y docente, dos con más de un actor (adultos, niños y niñas, agentes educativos; docentes, estudiantes y padres de familia), dos con otro (agentes educativos, niños y niñas en primera infancia, familias; y jóvenes hijos de asociados a un fondo de empleados) —; y, de tipo institución con un trabajo de grado centro de atención infantil del Instituto Colombiano de Bienestar Familiar (ICBF)-.

Esta línea es la única que se mantuvo constante en todo el período objeto de análisis, es decir, aportó trabajos de grado en todos los años estudiados.

B) Grupo perspectivas políticas, éticas y morales de la niñez y la juventud, con tres líneas:

- Construcción de las paces. A la línea se inscriben seis trabajos de grado, todos ellos realizados con fuentes de tipo persona: cinco con estudiantes, y uno con otro (jóvenes del colectivo de educación popular «Huellas de Vida»). 
- Socialización política y construcción de subjetividades. A esta línea se vinculan tres trabajos de grado desarrollados con fuentes de tipo persona: dos estudiantes y un docente.

Políticas públicas y programas en niñez y juventud. A la línea se asocian diez trabajos de grado realizados con fuentes de tipo diferente: mixto con un trabajo de grado - este con más de un actor (jóvenes y documentos)—; de tipo persona, con nueve trabajos de grado (dos de docente, dos de estudiante, uno de jóvenes, y cuatro con más de un actor - jóvenes, niños e institución de protección; niños, niñas y adolescentes; directivos, administrativos y docentes; estudiantes resguardados, padres de familia o acudiente resguardados y docentes etnoeducadores; $y$, mediadoras del proceso, madres comunitarias, actores institucionales, instructoras del Servicio Nacional de Aprendizaje (SENA), asesores del ICBF-.

C) Grupo jóvenes, culturas y poderes, con una línea:

- Jóvenes, culturas y poderes. A la línea se inscribe un trabajo de grado realizado en el 2015. Este no especifica el tipo de fuente empleada.

D) Grupo socialización política y construcción de subjetividades. Al grupo se adhieren tres trabajos de grado los cuales utilizan fuentes de tipo personas: un estudiante, un docente y uno sin especificar.

Este programa solo tiene un trabajo de grado vinculado al proyecto «Sentidos y prácticas políticas de niños, niñas y jóvenes en contextos de vulnerabilidad en el Eje Cafetero, Antioquia y Bogotá: un camino posible a la consolidación de la democracia, la paz y la reconciliación mediante procesos de formación ciudadana». 
Por último, el Doctorado en Ciencias Sociales, Niñez y Juventud aporta treinta tesis para el estudio, veintiuna de ellas vinculadas a cinco grupos de investigación y siete líneas:

A) Grupo didáctica del lenguaje inicial, desarrollo de la literacidad en la primera infancia, alfabetización inicial, procesos de argumentación infantil, didáctica del lenguaje en la formación docente, con una línea:

- Educación y pedagogía: en esta se inscribe una tesis realiza en el 2016 con fuentes de tipo persona en su papel docente.

B). Grupo educación y pedagogía: saberes, imaginarios e intersubjetividades. Esta contiene tres líneas:

- Desarrollo cognitivo-emotivo en niños, niñas y jóvenes en escenarios sociales. A la línea se inscribe una tesis realizada en el 2010 con fuentes de tipo persona, concretamente niños y jóvenes estudiantes.

- Educación y pedagogía. En esta se vinculan diez tesis realizadas con tres tipos de fuentes: nueve tesis con personas (cuatro estudiantes, dos estudiantes y docentes, un docente, una con más de un actor - estudiantes, profesores, egresados y otros actores-); una tesis con instituciones (instituciones educativas); y mixto (una tesis con más de un actor: niñas, niños, maestra y documentos).

- Crianza, familia y desarrollo. A la línea se adscriben dos tesis realizadas con dos tipos de fuente: persona (estudiante y familia) y mixta (con más de un actor: padres, estudiantes e instituciones).

C) Grupo jóvenes, culturas y poderes. Este, con la línea «óvenes, culturas y poderes», a la cual se inscribe una tesis realiza en el 2011 con fuente de tipo persona, particularmente docente.

D). Grupo perspectivas políticas, éticas y morales de la niñez y la juventud, el cual cuenta con dos líneas: 
- Socialización política y construcción de subjetividades. Línea en la cual se inscriben tres tesis realizadas con tres tipos de fuente: persona (más de un actor: rector, integrantes del equipo de apoyo, padres de familia, coordinadores, profesores y estudiantes), institución (colegio) y mixta (más de un actor: estudiantes, directivos, orientadores, equipo de apoyo, profesores y documentos).

- Políticas públicas y programas en niñez y juventud. En esta línea se vincula una tesis realizada en el 2016, con fuente de tipo persona (una tesis con estudiante y docente, y otra con más de un actor estudiantes, docente y directivo de la institución-).

E) Grupo socialización política y construcción de subjetividades, con dos líneas:

- Infancias, juventudes y ejercicio de la ciudadanía. Línea a la cual se vincula una tesis realizada en el 2014 con fuentes de tipo persona, particularmente estudiantes.

- Socialización política y construcción de subjetividades. A la línea se asocia una tesis realizada en el 2016 con fuentes de tipo institución, especialmente, universidad.

Este programa, es decir, el Doctorado en Ciencias Sociales, Niñez y Juventud solo cuenta con una tesis vinculada al proyecto titulado «Una metodología alternativa para la enseñanza y el aprendizaje del concepto de límite».

Como puede evidenciarse, los programas de la Universidad de Manizales; concretamente la Maestría en Educación y Desarrollo Humano $^{5}$ y el Doctorado en Ciencias Sociales, Niñez y Juventud ${ }^{6}$

5 Entre las seis líneas de investigación mencionadas, son exclusivas de este programa: línea «Cognición, emoción y praxis humana», con veintiséis trabajos de grado; y, la línea «Construcción de las paces», con seis trabajos de grado.

6 De las siete líneas mencionadas, son exclusivas del este programa: línea de investigación «Desarrollo cognitivo-emotivo en niños, niñas y jóvenes en escenarios sociales», con una tesis del 2010; línea "Crianza, familia y desarrollo», con dos tesis; y, línea «Infancias, juventudes y ejercicio de la ciudadanía», con una tesis en el año 2014. 
comparten los grupos y líneas de investigación, las cuales enfocan y tematizan la producción académica en educación y pedagogía.

En cuanto a los autores de los trabajos de grado de maestría y las tesis de doctorado en el Eje Cafetero, los datos de la tabla antes presentada muestran una clara predominancia del género femenino, pues de los 601 trabajos de grado y tesis, 433 son realizados por mujeres (72\%) y 168 por hombres ( $28 \%)$. Estos datos concuerdan con la tendencia reportada por el Observatorio Laboral para la Educación (OLE), puesto que el porcentaje de mujeres graduadas de posgrado - maestrías y doctorado-, ha ido creciendo sistemáticamente durante los últimos diez años. En particular, se destaca que el número de ellas ha superado al de los hombres en el nivel de maestría, pasando del $44 \%$ en 2008, al $53 \%$ en el 2016. Por su parte, en el nivel de doctorado, las titulaciones obtenidas por mujeres han aumentado su proporción en un $27 \%$; pasando de un $28 \%$ en 2008 a un $41 \%$ en 2016 . Un máximo histórico que demuestra que la equidad en el acceso y formación en educación superior en Colombia ha avanzado de manera positiva en el nivel de posgrados (MEN, 2017).

Una mirada más detallada de esta propensión en cada uno de los programas da cuenta del predominio que tiene el género femenino en los avances investigativos de educación y pedagogía en las tres universidades y los cinco programas. La TABLA NRO. 9 así lo evidencia: 
TABLA NRO. 9. Tendencia del género de autores de trabajos de grado y tesis en universidades.

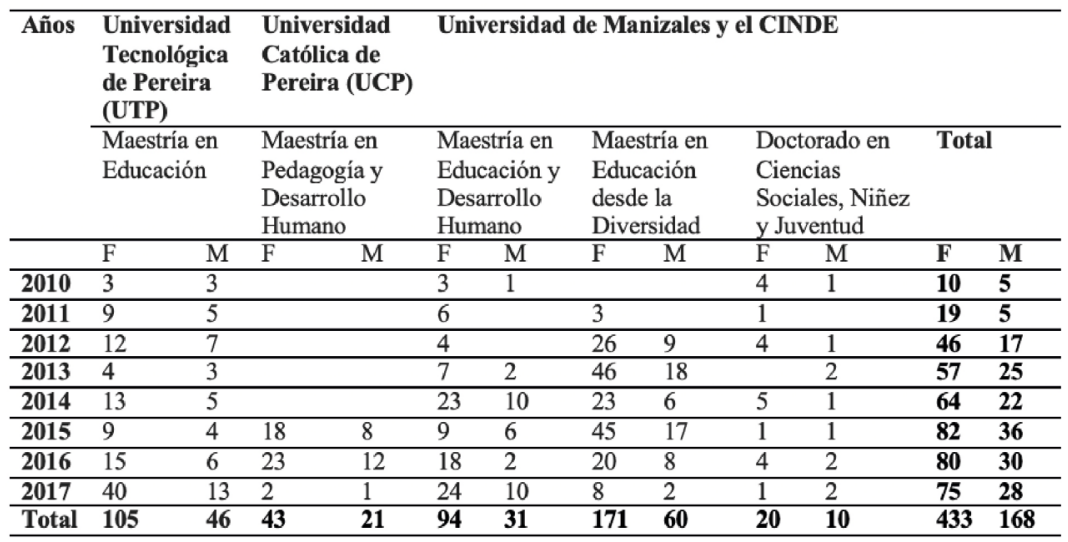

Elaboración propia.

Los datos de dicha tabla permiten algunas interpretaciones, entre ellas, que el mayor aumento en la titulación de las mujeres se evidencia en el 2012. Entre el 2016 y el 2017 disminuyó la cifra de producción de tesis y trabajos de grado tanto para mujeres como para hombres. De igual forma, en la suma de todos los años, se observan las mayores diferencias en la cifra de autoras respecto a los autores en la Maestría en Educación y Desarrollo Humano (sesenta y tres mujeres más que hombres) y en la Maestría en Educación desde la Diversidad (ciento once más que hombres); mientras que las menores divergencias se ubican en el Doctorado en Ciencias Sociales, Niñez y Juventud (diez mujeres más que hombres) y en la Maestría en Pedagogía y Desarrollo Humano de la UCP (veintidós mujeres más que hombres).

El aumento de la producción por parte de las mujeres en los niveles de maestría y doctorado de los programas estudiados podría estar dando cuenta de un mayor interés de las profesionales en desarrollar avances teóricos, prácticos y metodológicos en materia educativa, los cuales permitan atender los desafíos que enfrenta la educación en el momento histórico actual, así 
como contar con mayores cualificaciones para ocupar mejores posiciones en instituciones públicas y privadas relacionadas con lo educativo.

Las autoras y autores de los trabajos de grado de maestría $\mathrm{y}$ las tesis de doctorado han sido acompañados, dirigidos y/o tutorados por 321 asesoras y asesores profesionales de las líneas y temáticas investigadas. En este aspecto, los valores generales son tan cercanos que no permiten establecer una tendencia, como en el análisis de los autores, pues del total de asesores 167 son mujeres y 154 son hombres. No obstante, el registro de la asesoría por programa sí posibilita establecer la propensión que, en el caso de las asesoras, se encuentra en la Maestría en Educación de la Universidad Tecnológica de Pereira (61 mujeres y 45 hombres) y la Maestría en Educación desde la Diversidad de la Universidad de Manizales (56 mujeres y 21 hombres). El caso de los asesores, se ubica en el Doctorado en Ciencias Sociales, Niñez y Juventud de la Universidad de Manizales y el CINDE (13 mujeres y 19 hombres), en la Maestría en Pedagogía y Desarrollo Humano de la Universidad Católica de Pereira (13 mujeres y 19 hombres), y en la Maestría en Educación y Desarrollo Humano de la Universidad de Manizales y el CINDE (24 mujeres y 50 hombres).

Es conveniente resaltar que las asesorías de estos tipos de trabajos como objeto de investigación son una preocupación de diversos teóricos e investigadores en Latinoamérica y el mundo, debido a su papel fundamental como actividad dedicada al acompañamiento y la orientación de la producción académica. De hecho, la asesoría de tesis y trabajos de grado es considerada como un proceso formativo que, en sí mismo, constituye un recurso valioso si se reconoce el papel protagonista, del asesor y del asesorado (De Del Castillo, 2007).

Al respecto, algunas investigaciones han destacado la influencia de la calidad de las relaciones interpersonales entre estudiante-tutor en la graduación, en la autonomía intelectual y en 
la vida del investigador independiente (De La Cruz Torres, 2013; Fresán, 2002). No obstante, también advierten que la sola existencia de una relación idónea en un programa de maestría o doctorado entre profesor-alumno no garantiza una atención adecuada de los aspirantes durante la realización de los trabajos de grado y las tesis (Fresán, 2001; Fresán, 2002; Johnson et al., 2010; Revilla Figueroa, 2017; Valarino et al., 1996). En este sentido, Fresán (2002) afirma que, a diferencia de las ciencias experimentales, en las ciencias sociales y humanidades «el estudiante realiza su tesis en forma individual, con insuficientes encuentros con su asesor $y$, en pocos casos, con espacios de discusión académica donde pueda debatir sus propuestas y avances con sus compañeros o profesores» ( $\mathrm{p}$. 107).

En esta línea de discusión, los datos arrojados podrían servir de insumo para estudiar la confluencia de tres actores claves en la asesoría de trabajos de grado y tesis: el tesista, el asesor y el programa; los cuales requieren trabajar en forma conjunta para lograr el resultado esperado, es decir, el informe de investigación o tesis para fines de la titulación (Revilla Figueroa, 2017).

\subsection{Las referencias bibliográficas, de la norma y la influencia}

Las citas y referencias bibliográficas son fundamentales en la producción académica; pues constituyen el soporte teórico que fundamenta los trabajos de grado y las tesis. Estas enmarcan una línea de investigación y, a la vez, son el hilo para otros investigadores que desean rastrear fuentes de interés en algún campo del conocimiento. Como lo precisa Smith (1981) «una referencia es el reconocimiento que un documento le da a otro y una cita es el reconocimiento que un documento recibe desde otro» [la traducción es propia] (p. 83). Dada su importancia en el proceso de caracterización de la producción de la zona, este apartado se ocupará de las tendencias que se evidencian en las referencias bibliográficas de los trabajos de grado y las tesis (libros, artículos, otras tesis, memorias de congresos, ponencias, 
documentos de trabajo, documentos oficiales, los mismos informantes, páginas web, entre otros) que posiblemente son empleados para fundamentar y construir las posiciones sobre educación y pedagogía, y sus tópicos constituyentes.

En las trecientas diecisiete tesis y trabajos de grado, se reportan dieciocho mil veinticinco referencias $(\mathrm{R})$ de la siguiente manera:

- Maestría en Educación -UTP—, 6196 R en 100 trabajos de grado.

- Maestría en Pedagogía y Desarrollo Humano -UCP—, 878 R en 31 trabajos de grado.

- Maestría en Educación y Desarrollo Humano -UM-C-, 3509 $\mathrm{R}$ en 76 trabajos de grado.

- Maestría en Educación desde la Diversidad -UM-C-, 3000 R en 80 trabajos de grado.

- Doctorado en Ciencias Sociales, Niñez y Juventud -UM-C-, 4 $442 \mathrm{R}$ en 30 trabajos de grado.

Un análisis general de las 18025 referencias destaca la prevalencia del Ministerio de Educación Nacional - MEN- y diversos documentos de Coll, Freire, UNESCO, Pozo, Vygotsky, Cassany y Morín. Se resalta que la predominancia de referencias del MEN es un asunto relacionado con la profesión, la ocupación de base o el interés en el campo educativo. Por tanto, el punto de partida y llegada son las políticas y lineamientos del Ministerio las cuales marcan el deber ser de la educación y de los maestros. No obstante, esta situación alerta sobre la necesidad de realizar lecturas más amplias, que permitan asumir una postura crítica y propositiva, propia de los posgrados, ya que son estos los llamados a generar conocimiento y nuevas propuestas a la sociedad en el campo de la educación. 
Ahora bien, un análisis focalizado de las referencias en cada uno de los programas, permite particularizar las tradiciones teóricas y metodológicas que han sustentado la producción académica. De manera particular, en la Universidad Tecnológica de Pereira, el programa Maestría en Educación evidencia la FIGURA NRO. 3 sobre los de autores de referencia.

Figura nRo. 3. Autores de referencia.

Maestría en Educación, UTP.

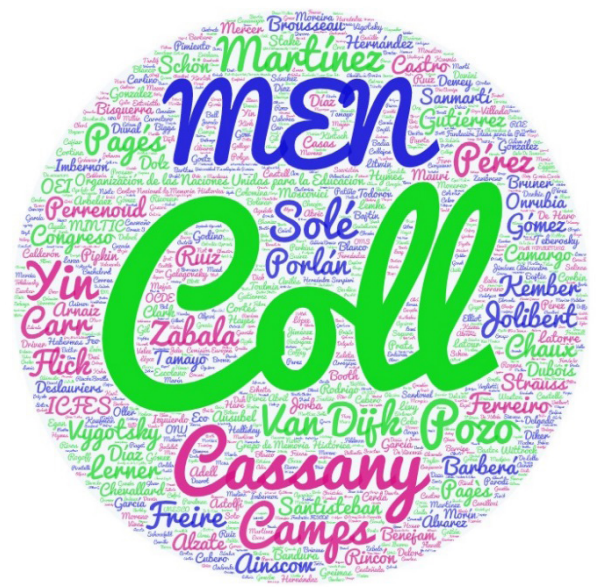

Elaboración propia.

En la Maestría en Educación, con 6196 referencias en 100 trabajos de grado, es decir, con un promedio de 61 referencias por trabajo, se encuentra que los autores más aludidos y que se constituyen en la montaña del paisaje son Coll y el MEN. En tanto en el panorama también sobresalen, con menor nivel de prevalencia, autores de universidades españolas tales como Cassany, Camps, Pozo, Pagés, Solé y Zabala; con menor nivel de predominio, están autores del contexto nacional como es el caso de Martínez, Díaz, Pérez, Gutiérrez, Ruíz, Tamayo, entre otros, quienes han realizado importantes contribuciones a la problematización y conceptualización del fenómeno educativo y 
pedagógico, y parecen estar ganando terreno como fuentes para el análisis y proposición de alternativas de cambio educativo en el país.

Este panorama refleja dos tipos de influencias en la producción nacional. Por un lado, una endógena con el MEN, la cual, como se mencionó antes, puede deberse a la necesidad de enmarcar los trabajos de grado en los lineamientos nacionales, dado que los autores son prioritariamente maestros quienes necesitan partir $o$ enmarcar lo que producen en el contexto local y nacional. Por otro lado, una exógena de origen español que devela, por los autores citados, posiciones constructivistas de orientación social de la enseñanza y el aprendizaje. Esta situación puede estar relacionada con dos asuntos: primero, el idioma lo que hace más fácil el acceso y comprensión de las fuentes citadas; y segundo, la formación de directores de líneas y trabajos de grado, quienes en su mayoría se doctoraron en Europa, especialmente en España, y cuyos profesores son los citados por los estudiantes de los posgrados. Estas referencias van marcando una línea de pensamiento en cuanto a la enseñanza y el aprendizaje en general, pero también, en cuanto a las didácticas específicas, pues varias de las obras citadas, nacionales e internacionales, producen conocimiento sobre la enseñanza del lenguaje, las ciencias naturales y las ciencias sociales.

De otra parte, entre las referencias del programa se pudo evidenciar más de dos mil autores solo referenciados una vez; asunto que hace de la identificación de los menos aludidos una tarea compleja. De igual forma, aparecen más de trecientos autores referenciados dos veces, más de ciento cincuenta autores referidos tres veces y más de sesenta aparecen cuatro veces. No obstante, la clasificación de aquellos que tienen cinco referencias permite apreciar las emergencias de la zona. Estos son: Bolívar, Cabero, Camillioni, Candela, Carretero, Casamayor, Castañeda, Chacón, Chamizo, Cortina, Davini, De Vicenzi, De Zubiria, Delors, Driver, Entwistle, Fernández, Jiménez, Lévy, Martínez, Mejía, Merino, 
Moreno, Mosston, Oller, Osborne, Osborne, Perkins, Rogers, Rogoff, Ruíz, Salinas, Schoenfeld, Segura, Serrano, Tolchinsky, Vogliotti, y Weston.

Para acotar aún más esta caracterización, resulta pertinente la identificación de los años de publicación de las referencias. Al respecto, se encuentra que 141 referencias no especifican la fecha de publicación («s.f.»). Por otra parte, se pueden ubicar tres referencias anteriores al siglo xx: una del año 1548 de Bruno, una del año 1571 de Kepler, y, una de 1893 de Husserl. Entre los años 1910 y 1950 se encuentran veintidós referencias de los siguientes autores: Dewey (1910), Taylor (1911), Vaerting (1923), Lindeman (1926) Lotka (1926), Heidegger (1927), Propp (1928), Vygotsky (1932), Dewey (1933), Vygotsky (1934), Schumpeter (1934), Sigerist (1941), Polya (1945), Klein (1946), Yurchenco (1946), Reichel (1946), ONU (1948), Bourbaki (1948), UNESCO (1949), Bühler (1950) y Dewey (1950).

De 1951 a 1960 se encuentran trece referencias, así: Kluckhohn (1951), Kant (1952), Leavell y Clark (1953), Wittgenstein (1953), Barnes (1954), Greimas (1954), Freinet (1956), Toulmin (1958), Perelman (1958), ONU (1959), Bruner (1959), UNESCO (1960).

De manera más general, se incluyen 42 referencias de 1961 a 1970, entre las cuales se destacan autores como: Freire, Greimas, Hymes, Polya, Guzmán, entre otros. En el periodo siguiente, es decir de 1971 a 1980, se encuentran 189 referencias, entre las que se repiten autores como: Van Dijk, Vigotsky, Hayes, Hymes, Kinstch, Todorov, Ausubel, Flavell, Freire, Lowenfeld, Moscovici, Asimov, Bajtin, Downie, Halliday, Horkheimer, Klinberg, Lalonde, Rumelhart, Saussure, Tyler, Viennot, entre otros más.

De 1981 a 1990 aparecen 400 referencias, las cuales aluden principalmente a autores como: Vygotsky, Brosseau, Carr, Dubois, Ausubel, Coll, Dewey, Cassany, Clark, UNESCO, entre muchos otros. Entre 1991 y 2000 se ubican 1401 referencias con menciones 
destacadas a: el MEN, Coll, Cassany, Camps, Pozo, Vygotsky, el Congreso de la República, Solé, Van Dijk, Zabala, entre otros. Desde el 2001 al 2010 hay 2999 referencias, en las que se destacan autores como: Coll, MEN, Camps, Martínez, UNESCO, Pozo, Pérez Abril, Perrenoud, Jolibert, Pagès, entre muchos otros. Por último, desde el 2011 al 2017 se muestran 986 registros, entre los que sobresalen referencias al MEN, Gutiérrez, Ruiz, Camargo, Uribe y Caro, Centro Nacional de Memoria Histórica (CNMH), Instituto Colombiano para la Evaluación de la Educación (ICFES), Pagés, Pimiento, entre otros.

El panorama expuesto, en términos de los autores de referencia en los períodos establecidos, ratifica que, si bien hay una fuerte presencia del MEN y de autores internacionales, también se destaca una mirada puesta en las contribuciones de los investigadores locales, regionales y nacionales como insumos para los trabajos de grado en la educación y la pedagogía. También se hace notorio que los investigadores están retomando principalmente los aportes que hicieron los autores en la última década del siglo pasado (1991 al 2000) y la primera década del siglo XXI (2001 al 2010). Esta situación devela la distancia temporal entre referencias, la cual va entre diez a veinte años. Precisamente, este alejamiento da un indicio sobre la construcción del estado de arte, donde se espera, sea aproximadamente de cinco años antes de la producción y se constituya mayoritariamente de artículos de investigación; lo que permite dar cuenta hacia dónde va un campo del saber. No obstante, es necesario matizar los datos, porque se toman autores y fuentes como globalidad para el período. Por ello, en un futuro estudio se deberían contrastar en cada uno de los trabajos de grado dichas distancias, y precisar el tipo de fuente (libro, artículo, ponencia, entre otros) para reducir, como lo plantea Arbeláez Gómez (2014), qué tanto se inserta el autor en sus comunidades académicas y qué tan actualizado o no está frente a su campo de investigación. 
En la Universidad Católica de Pereira, particularmente en el programa Maestría en Pedagogía y Desarrollo Humano, emerge la FiguRA NRO. 4 sobre los autores de referencia.

Figura NRo. 4. Autores de referencia. Maestría en Pedagogía y Desarrollo Humano, UCP.

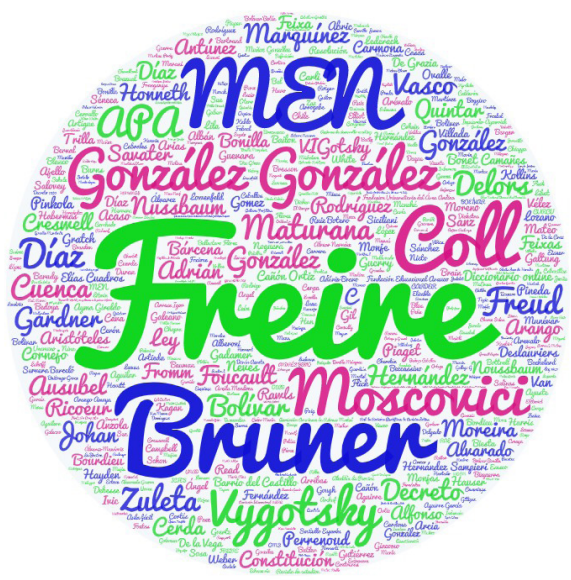

Elaboración propia.

En la Maestría en Pedagogía y Desarrollo Humano, con 878 autores de referencia en 31 trabajos de grado, es decir, con el promedio de 28 referencias por trabajo, se encuentra que los autores más referenciados, los cuales se constituyen en una gran montaña en el paisaje del programa, son Freire y González; un panorama diferente al evidenciado en el programa anterior - Maestría en Educación (UTP) - . Le siguen, en orden de frecuencia, Vygotsky, Bruner y el MEN. Con menor prevalencia aparecen autores de referencia como Bolívar, Hernández, Coll, Moscovici, y Nussbaum. Estos referentes también evidencian una impronta del programa, más orientada a las pedagogías críticas y el desarrollo humano; además, de un énfasis en la psicología y posiblemente en el aprendizaje de orientación socio-cultural. 
De otra parte, el dato de los autores que menos se referencian, es decir, aquellos que se mencionan una única vez, ascienden a más de quinientas referencias. Esta situación puede tener dos explicaciones: la primera, que efectivamente solo se citen una sola vez deja en evidencia que aún no se ha construido una línea de pensamiento con autores fuente específicos; y, la segunda, que existe una laxitud aparente de los autores y programas frente al seguimiento de la norma, pues la sistematización de las referencias bibliográficas en los trabajos de grado no sigue un canon único y estandarizado de inclusión, de manera que no hay un estilo claramente establecido.

Así las cosas, puede encontrarse autores con un solo apellido y una sola inicial del nombre, dos apellidos y una única inicial del nombre, dos apellidos y las dos iniciales del nombre, los apellidos y nombres completos, solo los apellidos, un único apellido, entre otras formas menos comunes. En el caso de las organizaciones e instituciones gubernamentales y no gubernamentales, puede encontrarse: la sigla de la organización, el nombre completo de la organización, el país de origen de la organización, el nombre del autor leído en esa organización, el nombre del documento de esa organización, entre otras formas menos habituales.

Estos resultados indican la necesidad de revisar las formas de referenciación en los programas, máxime cuando estas referencias son una prueba fehaciente de que el autor del trabajo de grado ha hecho un rastreo de los escritos previamente publicados, $y$ ha permitido al lector verificar el origen de las afirmaciones y contenidos propuestos, e identificar los documentos que traten sobre el tema que desea profundizar (Urbano Salido, 2000); asuntos que otorgan mayor nivel de fiabilidad e impacto a la producción académica.

Ahora bien, con el ánimo de identificar aquellos autores de referencia que constituyen las opacidades, es decir, aquellos que son menos aludidos, se diferencia por cantidad de menciones como sigue: 68 autores se referencian dos veces, entre ellos están 
Adrián, Bourdieu, Carmona, De Grazia, Feixas, Galtung, Hayden, Izquierdo-Aymerich, Kollins, Lowenfeld, Monje, Noguera, Ovalle, Piaget, Rawls, Savater, Trilla, Villada, Weber, entre otros.

Respecto a los años de las publicaciones referenciadas, se encuentra lo siguiente: cuatro referencias del siglo XIX —Fröebel (1826), Decreto Nro. 1860 (1860), Platón (1871) y Lafargue (1880)—. En la primera mitad del siglo xx — de 1905 a 1950-, se encuentran también cuatro referencias: Freud (1905), Tagore (1916), Gilligan (1936) y la Ley General de Educación (1948). Luego, de 1950 a 1980 hay 44 referencias entre las cuales destacan: Vygotsky, Moscovici, Lowenfeld, Freire, Hauser, entre otros. De 1981 a 1990, se encuentran 676 referencias, entre ellas predominan autores como Ausubel, Coll, Díaz, Freire, Johan Moscovici, Salovey, entre algunos otros.

Entre 1991 y el 2000 se registran 163 autores, siendo 1994 el año con más referencias, en este periodo se destacan: Bruner, Freire, Rodríguez, Vygotsky, Delors, Gardner, Vasco, American Psychiatric Association, Antúnez, Ayma, entre otros. De 2001 a 2010, emergen 327 referencias de autores recurrentes como Freire, Hernández, Bolívar, González, Bruner, el MEN, Vygotsky, Cañón, Maturana, Ricoeur, entre algunos otros. En la segunda década del siglo XXI (2011-2017) se registran 220 referencias, en ellas se reiteran autores como González, Marquínez, el MEN, Bonilla, Nussbaum, Quintar, Adrián, American Psychiatric Association, Arango, Carmona, entre otros.

Finalmente, se destaca el número de referencias que aparecen sin fecha (50), una práctica que también se evidenció en el programa anterior (141 en los trabajos de grado de la Maestría en Educación de la UTP). Esta práctica, si bien es de uso frecuente en la referenciación de los documentos procedentes de internet, su aplicación en los programas de maestría y doctorado - destinados a la construcción y reconstrucción del conocimiento-, es problemática, pues no permite reconocer la calidad, actualidad 
y pertinencia de las fuentes de información. Esto obstaculiza la valoración de la vigencia de los conceptos y las afirmaciones que de ellas proceden.

En el caso de la Maestría en Educación y Desarrollo Humano de la Universidad de Manizales y el CINDE, en el paisaje de los autores referenciados se vuelve a destacar al Ministerio de Educación Nacional, tal como lo señala la FigURA NRO. 5.

Figura NRO. 5. Autores de referencia. Maestría en Educación y Desarrollo Humano, UM-C.

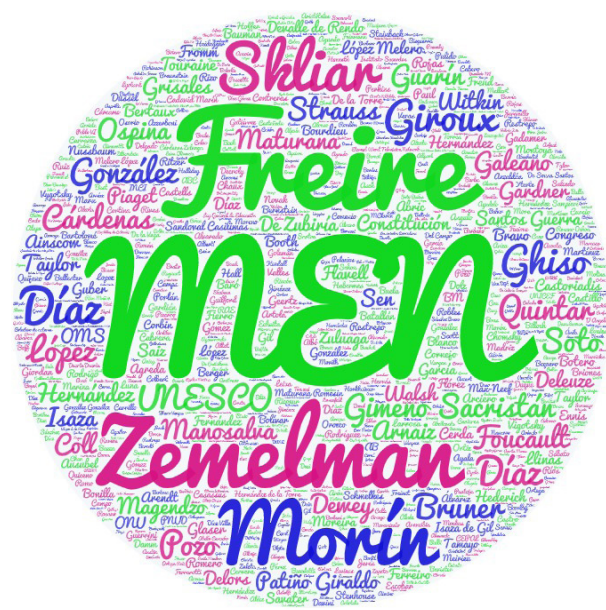

Elaboración propia.

Tal como muestra la figura, el paisaje de los autores de referencia constata una cadena montañosa precedida por el MEN, como la cumbre a la que se unen otras montañas tales como Freire, Zemelman, Morín y Skliar. Así entonces, tal como se evidenció en la Maestría en Educación de la UTP, la referencia de mayor recurrencia sigue siendo el MEN, a la cual —en ese caso-, le sigue Freire. La cuestión será considerar las distancias, las cercanías y las pugnas entre las maneras de entender la educación y la función 
que cada una de estas referencias plantea. De otra parte, podría considerarse que la segunda fuente de prevalencia, es decir Freire, denota una visión de pedagogías críticas.

En cuanto a los autores que poco se mencionan, vuelve a emerger la dificultad experimentada en los programas anteriores, con la salvedad de que esta vez son 1409 referencias, de las 3 509 reportadas entre los 66 trabajos de grado (46 referencias por escrito), las cuales aluden a autores nombrados una sola vez. Ahondar en la cuestión pondría de manifiesto otra posible explicación al hecho: efectivamente, los autores no solo acuden a los autores de «cabecera» de los programas y cada una de sus líneas de investigación, que son «entregados» en los seminarios y asesorías, sino que también realizan sus propias indagaciones sobre el estado de la cuestión. Ellos van construyendo su propia comunidad de autores, de manera que, aunque los trabajos de grado se vinculen a líneas y macroproyectos de investigación, todos ellos aportarán la impronta personal de los autores, producto de su devenir en la comunidad académica y discursiva en la cual van insertándose.

En este sentido, pueden encontrarse como opacidades, producto de esos caminos particulares, los siguientes autores referenciados: Aguado, Araque, Barbosa, Chiner, Cornú, Delgado, Felici, Gautier, Herrera, Jahuira, Larrauri, Lozano, Mazarella, Molano, Ojeda, Rivas, Sarabia, Toro, Vivas, entre muchos otros.

Una mirada a la periodicidad de los autores de referencia da cuenta de una referencia del siglo xvinI a Leibniz (1710), tres del siglo XIX correspondientes a una de la Constitución Política de Colombia (1886) y dos a Dewey (1896). Entre 1910 y 1930, cuatro referencias, Dewey (1913), Pombo (1916), Kilpatrick (1918), y Freud (1930). De 1931 a 1950 se registran quince referencias: De Paris (1932), Piaget (1932), Machado (1933), Vigotsky (1934), Lewin (1935), Allport (1937), Juarroz y Ortega (1939), Fromm (1941), Orwell (1945), Asch y Witkin (1948), Lacan (1948), ONU 
(1948), Dilthey (1949), Guilford (1950), y Tyler (1950). En la década siguiente, es decir, de 1951 a 1960, solo se incluyen siete referencias, a saber: Comenio (1952), Heidegger (1953), Hovland (1953), Marcuse (1954), Marx (1956) y Smirnov (1960).

De manera más general, entre 1961 y 1970, se encuentran cuarenta y dos referencias de autores como Adorno y Horkheimer, Berger y Luckmann, Chomsky, Decroly y Boon, Dewey, Freire, Giroux, Glaser y Strauss, Kuhn, Piaget, Witkin, entre otros pocos. En la década que sigue, de 1971 a 1980, se presentan 62 referencias, entre las que figuran autores como Bowlby, Chomsky, Deleuze, Flavell, Freire, Lowenfeld y Lambert, Morín, Vigotsky, Witkin, entre otros. En el periodo próximo, de 1981 a 1990, se incluyen 164 registros: Giroux, Taylor y Bogdan, Freire, Deleuze, Bruner, Foucault, Braunstein, Witkin, Vygotsky, Castoriadis, entre otros.

En la última década del siglo xx, esto es de 1991 al 2000, se ubican 636 referencias, entre ellas destacan las de Morín, Gimeno, Freire, el MEN, Ghiso, Maturana, UNESCO, Vigotsky y Foucault, Gardner. Entre el 2001 y el 2010 se registran 1367 referencias. En ellas predominan autores como el MEN, Freire, Skliar, UNESCO, Santos, Zemelman, Morín, Magendzo, Hernández, Fernández y Baptista, López, entre muchos otros. Finalmente, entre 2011 y 2017 se encuentran 587 referencias, y sobresalen el MEN, Zemelman, Patiño, González, Cárdenas, Manosalva, Guarín, Hernández, Ospina, Grisales, entre otros. Finalmente, aparecen 112 referencias de autores sin fecha («s.f.»).

Si bien el panorama expuesto reafirma la predominancia de fuentes como el MEN, Freire, Zemelman, Morín, y Skliar, en las alusiones de escritores de los trabajos de grado del programa, también se evidencia la presencia persistente de autores latinoamericanos, nacionales y regionales, considerados como expertos y fuentes teóricas e investigativas; las cuales han trasegado y hecho planteamientos más cercanos a las problemáticas nacionales y latinoamericanas, en el campo de la educación y la pedagogía. 
En el caso de la Maestría en Educación desde la Diversidad, la cual aportó 3000 autores de referencia en 80 trabajos de grado, lo que hace un promedio de 37 textos por tesis, el pico montañoso se localiza en el MEN (tal como sucedió en la Maestría en Educación y Desarrollo Humano de la Universidad de Manizales y el CINDE). La Figura NRo. 6 muestra el paisaje del programa en términos de los autores predominantes en las referencias, así como aquellos que quedan en la periferia.

Figura NRO. 6. Autores de referencia. Maestría en Educación desde la Diversidad, UM-C.

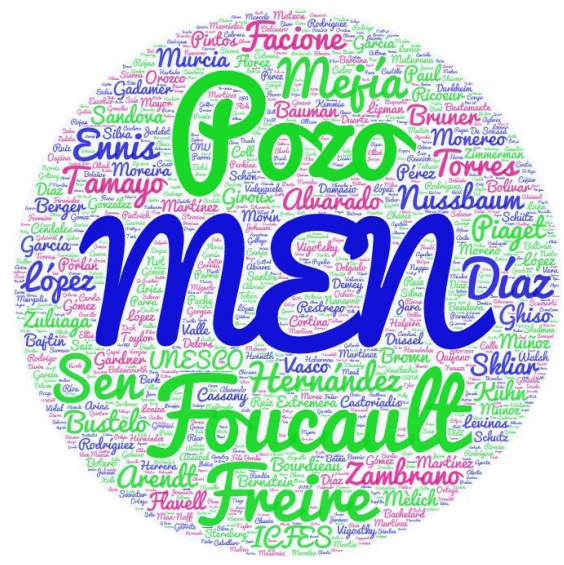

Elaboración propia.

Al MEN, ubicado en el pico de la montaña, le sigue una cordillera compuesta por autores como Pozo, Foucault, Freire, Hernández, Fernández y Baptista, Mejía, Nussbaum y Pintos. Desde estos se sustentan teórica y metodológicamente los trabajos de grado sobre la educación desde la diversidad. En el paisaje también se pueden vislumbrar algunas colinas representadas por Zambrano, Facione, Sen, Tamayo, Díaz, Ennis, Vygotsky y el ICFES, las cuales amplían la comprensión, la interpretación y la transformación de la educación desde la inclusión y la interculturalidad para fortalecer el desarrollo humano. 
De manera inversa, los autores que componen la extensa llanura del paisaje son aquellos que poco se mencionan en las tesis, en este caso se encuentran alrededor de 1500 autores referenciados una vez. (Sobre esto habrá que considerar la posibilidad de las explicaciones dadas en los apartados de los programas anteriores).

Una mirada más cercana al paisaje y la periodicidad de los autores permite identificar dos referencias del siglo XVII Descartes (1637) y Hobbes (1651) - , y cuatro del siglo XIX Pestalozzi (1889), Bransford y Stein (1891), Frege (1982) y Pearson (1892)—. De 1904 a 1930 aparecen nueve referencias: Spearman (1904), Binet y Simon (1905), Terman (1915), Binet (1916), Herbart (1924), Terman (1925), Piaget (1926), Spearman (1927) y Mead (1930). Entre 1932 y 1960 emergen 24 referencias así: Schütz (1932), Benedict (1934), Mead (1934), Thurstone (1938), Skinner (1938), Glaser (1941), Merton y Kendall (1946), Blumer (1946), Watson (1947), Piaget (1948), Garzo (1948), Piaget (1950), Tyler (1950), Piaget (1952), Aristóteles (1954), Buber (1956), Toulmin (1958), Arendt (1958), Tolstoi (1959), Carpenter y Mcluhan (1960).

De manera más general, de 1962 a 1980, se registran 98 autores, entre los cuales destacan Foucault, Freire, Flavell, Piaget, Arendt, Schütz, Vigostky, Resnick, Jensen, Gagné, entre otros. Entre 1981 y 1990, se muestran 260 escritores de referencia: Ennis, Vigostky, Facione, Pozo, Díaz, Bruner, Brown, Sternberg, Berger y Luckmann, entre algunos otros. En el periodo de 1991 al 2000 se encuentran 822 autores donde sobresalen el MEN, Freire, Pozo, Nussbaum, Sen, Zambrano, Facione, Bustelo, UNESCO, Bruner, entre otros.

En el periodo siguiente, es decir, del 2001 al 2010, hay 1567 autores de referencia, entre los cuales son recurrentes el MEN, Hernández, Fernández y Baptista, Pozo, Foucault, Freire, Mejía, Nussbaum, Zambrano, Bauman, Tamayo, entre muchos otros. Finalmente, entre los años 2011 y 2017 aparecen 678 autores de 
referencia, en los cuales figuran el MEN, Alvarado, el ICFES, Mejía, Nussbaum, Tamayo, López, García, García, Martínez, entre otros. Así mismo, se exhiben cuarenta y cinco autores de referencia sin fecha («s.f.»).

En cuanto al programa faltante, a saber, el Doctorado de en Ciencias Sociales, Niñez y Juventud la Figura Nro. 7 evidencia que, en las 4442 referencias, aportadas por las 30 tesis (un promedio de 148 referencias por tesis), los autores con mayor mención son Foucault y el MEN.

Figura nRo. 7. Autores de referencia. Doctorado en Ciencias Sociales, Niñez y Juventud, UM-C.

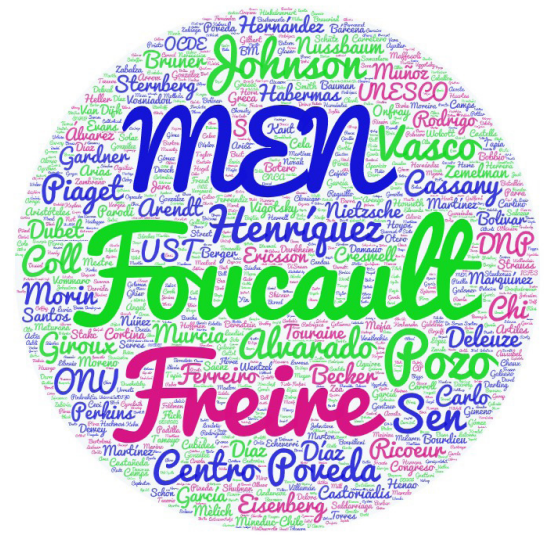

Elaboración propia.

Dicha figura muestra a Foucault como la fuente predominante en el pasaje de los autores de referencia del programa, seguido por el MEN y Freire. Destacan también, con menor relevancia en los datos, autorías como las de Johnson, Centro, Pozo, Henríquez, Vasco, Alvarado, Cassany, Eisenberg, Piaget, y Sen, En esta línea, los autores de referencia encontrados en la periferia se convierten en los de menor inclusión en el paisaje del programa, en tanto se mencionan una sola vez. Estos son cerca de dos mil autores. 
En tal sentido, la diversidad de autores, además de ser una tendencia diferenciada de los más referenciados, puede deberse a la exhaustiva revisión bibliográfica que suele acompañar la realización de una tesis doctoral, ello como situación necesaria para lograr tal nivel de originalidad y aportar al conocimiento científico. También puede deberse a que, como afirman Repiso et al. (2013), las tesis doctorales, desde la perspectiva de la investigación, se caracterizan por ser una investigación original en un campo determinado.

En este sentido, los doctorandos deben ser capaces de demostrar su conocimiento del tema elegido, lo cual está ligado a la disponibilidad de fuentes y referencias bibliográficas de amplio reconocimiento en la temática de investigación, para que, no solo apoyen la fundamentación, sino que también demuestren la fortaleza teórica esperada en este nivel académico; de ahí que proliferen las referencias y predominen fuentes más teóricas, epistemológicas y conceptuales en general.

Ahora, en términos del tiempo de publicación de los autores de referencia, se encuentra una publicación del siglo XIII Aristóteles (1252)—, otra del siglo XVIII —Smith (1776) —, y dieciséis del siglo XIX —Fernández (1815), Bolívar (1815), Alberdi (1842), Alberdi (1845), Mill (1848), Samper (1861), Mill (1863), Bilbao (1865), Freire (1873), Nietzsche (1878), Galton (1883), CP (1886), Cattel (1890), Fodor (1890), Cattel y Farrand (1896) y Dewey (1897)-.

Entre 1901 y 1920 aparecen 27 autores de referencia: Thorndike y Woodworth (1901), Wissler, (1901), Vicepresidencia de la República (1904), Binet y Simon (1905), Decroly (1907), Thorndike (1910), Poveda (1911), Poveda (1912), Mitchell (1912), Godard (1912), Stern (1912), Poveda (1915), Terman (1916), Poveda (1918), y Freud (1920). En el periodo siguiente, de 1921 a 1940, se registran doce escritores referenciados: Dewey (1922), Durkheim (1924), Marshall (1925), Segovia (1926), el Congreso 
de la República (1927), Decroly (1927), Pávlov (1927), Spearman (1927), Vasconcelos (1927), Freud y Einstein (1933), Korn (1940) y Ortiz (1940).

Más adelante, de 1941 a 1960 se encuentran 36 autores de referencia, entre ellos: Samuelson, Arrow, Bachelard, Bloom, Da Vinci, Dewey, Heidegger, Husserl, Inhelder y Piaget, Leontieff, entre algunos otros. De 1961 a 1980, aparecen 236 registros de autores, entre los cuales se hace alusión a: Piaget, Becker, Foucault, Freire, la ONU, Deleuze, Ausubel, Berger y Luckmann, Glaser y Strauss, Marton, entre otros. En la década siguiente, de 1981 a 1990, se registran 438 referencias, entre ellas se destacan autores como Centro, Foucault, Sternberg, Marquínez, Johnson, la Universidad Santo Tomás, Habermas, Artiles, Freire, el MEN, entre otros.

Luego, entre 1991 y el 2000 se muestran 1126 escritores de referencia donde sobresalen Foucault, Pozo, Sen, Rodrigo, el MEN, Freire, Arendt, Giroux, Gardner, Johnson, entre otros. Entre los años 2001 y 2010 se presentan 2024 autores de referencia, siendo los siguientes quienes más se repiten: el MEN, Foucault, Johnson, Ricoeur, Alvarado, Cassany, Freire, Pozo, Eisenberg, Murcia, entre muchos otros. Por último, entre el 2011 y el 2017 aparecen 448 referencias, entre las cuales acentúan autores como Henríquez, el MEN, Alvarado, González, Arias, Sánchez, Vasco, el Ministerio de Educación de Chile, Ángel, Vommaro, entre otros. Por otra parte, son 87 autores de referencia las que aparecen sin fecha («s.f.»).

En suma, en el doctorado se incluyen referencias desde el siglo XIII — Aristóteles (1252) —, siendo la más antigua del Eje Cafetero. El mayor número de estas se ubica en la primera década del siglo xxi con 2024 autores de referencia, lo que quiere decir, junto con el número de la segunda década (448), que la mitad de todas las referencias del programa son de dicho siglo. 
Ahora bien, es necesario precisar que la diversidad de estilos de referencia utilizadas complejizó el análisis de los autores fuente. En este asunto, ligado a las estéticas y cánones de presentación de las referencias bibliográficas en los trabajos de grado de maestría y las tesis de doctorado, llama la atención la inconsistencia en el nivel de rigurosidad, requerido en los posgrados frente a las normas de citación, lo que posteriormente dificultará el rastreo a otros investigadores y, en los estándares del ámbito internacional, generaría «sospechas» frente el ejercicio riguroso de la investigación.

Lo anterior es una alerta frente al estilo, pues parece que, a pesar de estar en los niveles de maestría y doctorado, en las dinámicas de generar investigaciones y conocimiento, persiste el problema de la escritura académica, lo cual se devela en la construcción de las bibliografías. Existen numerosos errores en las maneras de referenciar, por ejemplo, las formas de escribir los nombres de los autores, las fechas y los títulos, asunto que puede generar una actitud de sospecha y poca credibilidad cuando el lector advierte que lo dicho no está sólidamente citado y/o se hace de forma incorrecta.

La situación está desvirtuando la importancia que tienen las referencias, pues estas, en sí mismas, se convierten en fuentes que generaran tradición para la consulta de otros autores y, además, otorgan a cualquier escrito rigor científico y solidez intelectual. Cuando estas referencias se incluyen de forma inadecuada o, peor aún, no se incluyen, se estaría apropiando de forma deshonesta de las ideas, pensamientos o conceptos ajenos; de ahí que referenciar de modo adecuado sea un acto de honestidad, de ética y de valía profesional (López Gil, 2017).

Aún con este panorama, el MEN colombiano es el referente que marca las cumbres en las referencias bibliográficas del Eje Cafetero. Esta tendencia puede considerarse desde el análisis de quiénes son los tesistas, pues como ya se reportó anteriormente, 
hay una fuerte propensión en todos los programas a que las mujeres sean las que mayoritariamente acudan a formarse en los posgrados estudiados, es decir, profesionales ligadas a la educación, maestras de básica, media y universidad, las cuales usan, como una de sus fuentes, el marco normativo general en el que se mueve la educación colombiana: el Ministerio de Educación Nacional. No obstante, queda abierta la discusión frente al papel de una referencia que no solo enmarca y direcciona la educación en el país, sino que también restringe y puede limitar las aperturas y asunción de otras posturas críticas frente al mismo ministerio y la formación colombiana.

Al ministerio les siguen dos fuentes prevalentes: la de César Coll y la de Paulo Freire. Estas evidencian una influencia teórica de posiciones constructivistas, socioconstructivistas y críticas, las cuales dan cuenta de otras vertientes de consumo de información de los autores de los trabajos de grado en las maestrías y las tesis de doctorados. Referenciar a estos autores de manera sistemática no es gratuito. Seguramente, las contribuciones de los asesores - que hacen parte de las líneas y macroproyectos de los programas-, generan unas maneras de entender la educación, la pedagogía, el desarrollo humano, la didáctica, la inclusión, entre otras; y extienden la invitación a los tesistas a beber de esta fuentes, posiblemente recomendadas y entregadas por los asesores, por las líneas y por los seminarios.

Estos referentes se convierten en las fuentes primarias de las líneas a las cuales los autores tesistas se van adhiriendo, asunto que evidencia su inserción en una comunidad académica. Dicho esto, puede afirmarse que las tendencias en las referencias son marcadas por las líneas de investigación de los programas y las opacidades que en ellas se encuentran. Las referencias que poco aparecen pueden dar cuenta de búsquedas autónomas de los autores de las tesis. 
Finalmente, la mayor cantidad de referencias -como pudo evidenciarse-, se ubican en la primera década del siglo XxI. Este hecho puede estar en relación con el aumento de los recursos electrónicos a través del internet y el acceso rápido del investigador a este tipo de documentos (García y García, 2014), así como también, a la extensa llanura compuesta por las referencias mencionadas una única vez. Seguramente, estas provienen de otras tesis e investigaciones, las cuales hacen parte de las propias búsquedas realizadas por los autores cuando delimitan en otros capítulos la problemática de investigación.

\subsection{Las palabras clave, un asunto de identidad}

En el contexto de las publicaciones en internet, las palabras clave (PC) incrementan ostensiblemente las posibilidades de profundización y búsqueda de la información de un área temática, lo que no es posible solo a través del examen del título del trabajo (Granda-Orive et al., 2003). En consideración con lo anterior, los autores sugieren analizar exhaustivamente qué palabras clave registrar, y procurar utilizar aquellas que no estén incluidas en el título del documento, pues de ello dependerá la difusión y recuperación del propio documento. «En este sentido, las palabras clave no solo son útiles para realizar una búsqueda, sino que además sirven para analizar los trabajos por la materia estudiada, permitiendo así descubrir la evolución de las corrientes investigadoras y los aspectos que más o menos interesan a los investigadores» (Granda-Orive et al., 2003, p. 766).

Así, las palabras clave se convierten en un insumo importante para identificar las temáticas de la producción académica en los trabajos de grado de maestría y las tesis de doctorado. En este sentido, se tiene que, en las trecientas diecisiete tesis y trabajos de grado, se reportan 1673 PC de la siguiente manera:

- Maestría en Educación de la UTP, 449 PC en cien trabajos de grado. 
- Maestría en Pedagogía y Desarrollo Humano de la UCP, 173 PC en 31 trabajos de grado.

- Maestría en Educación y Desarrollo Humano de la UM-C, 488 PC en 76 trabajos de grado.

- Maestría en Educación desde la Diversidad de la UM-C, 411 PC en 80 trabajos de grado.

- Doctorado en Ciencias Sociales, Niñez y Juventud de la UM-C, 152 PC en 30 tesis.

Con la intención de identificar, clasificar y analizar las temáticas de los trabajos de grado de maestría y las tesis de doctorado en el Eje Cafetero, se toman las palabras clave reportadas en dichos documentos. En términos generales, la Figura NRO. 8 , presentada a continuación, muestra el paisaje de palabras que describen el contenido de las producciones académicas de los investigadores y que, seguramente, resultarían de utilidad para las búsquedas de aquellos interesados en temáticas parecidas.

FIGURA NRO. 8. Palabras clave en el Eje Cafetero.

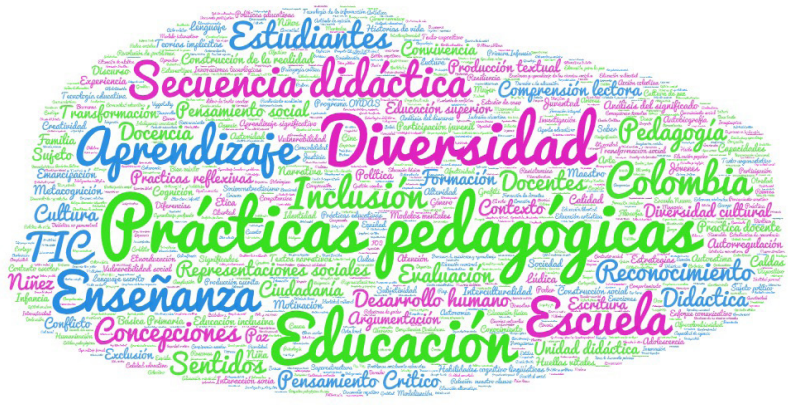

Elaboración propia.

Tal como se muestra en la figura, las temáticas de los trabajos de grado y las tesis de doctorado en el Eje Cafetero se nuclearizan en torno a claves conceptuales y teóricas como prácticas pedagógicas 
(cuarenta y dos), siendo la más destacada del paisaje de palabras clave en los programas estudiados. En el panorama sobresalen también palabras claves ligadas a procesos, actores y conceptos tales como diversidad (treinta y tres), educación (veinticinco), secuencia didáctica (veinticinco), aprendizaje (veintiuno), enseñanza (dieciocho) y escuela (diecisiete), las cuales dan sentido y cuerpo al contexto de las prácticas pedagógicas.

Las palabras claves utilizadas por los tesistas evidencian que, el foco de interés en educación y pedagogía, se sitúa en el espacio escolar con sus actores; especialmente, en los estudiantes y los docentes, de quienes interesan los procesos que realizan, las apuestas puestas en juego para atender situaciones que experimentan y, con ello, lograr transformaciones en el pensamiento, las actitudes, los comportamientos y los mismos contextos de los cuales hacen parte.

Ahora, una mirada relacional de las palabras clave, desde la cual se dejan de lado los plurales, adjetivos y otros acompañantes de la palabra inicial (aspectos que claramente dan contexto e intencionalidades), devela otro paisaje de las temáticas de los trabajos de grado de maestría y las tesis de doctorado, tal como se hace evidente en la TABLA NRO. 10. 
Tabla NRO. 10. Nuclearización de las palabras clave por palabra inicial en el Eje Cafetero.

\begin{tabular}{ll}
\hline Palabra inicial & Apariciones \\
\hline Educación & 85 \\
\hline Práctica & 77 \\
\hline Diversidad & 43 \\
\hline Aprendizaje & 36 \\
\hline Enseñanza & 36 \\
\hline Pensamiento & 29 \\
\hline Estudiantes & 23 \\
\hline Desarrollo & 23 \\
\hline Escuela & 21 \\
\hline Competencias & 21 \\
\hline Concepciones & 20 \\
\hline Formación & 20 \\
\hline Representación & 20 \\
\hline Inclusión & 18 \\
\hline Modelo & 18 \\
\hline Pedagogía & 16 \\
\hline Didáctica & 16 \\
\hline Relación & 16 \\
\hline Texto & 16 \\
\hline Docencia & 15 \\
\hline Contexto & 15 \\
\hline Construcción & 15 \\
\hline &
\end{tabular}

Elaboración propia.

La palabra educación (85 apariciones) está relacionada con los actores, contextos, dimensiones, propósitos y medios con los cuales se adjetiva, vehicula y acciona. Es el caso de educación superior, educación inclusiva, educación artística, educación física, educación popular, educación para la paz, educación alternativa, educación ambiental, educación básica, educación bilingüe intercultural, educación emocional, educación escolar, educación experiencial, educación inicial, educación innovadora, educación liberadora, educación libertad, educación media, educación moral, educación musical, educación no formal, educación política, educación primaria, educational practices, educación de adultos, educación de la primera infancia, educación de niños, educación física para niños, educación para adultos, educación para el desarrollo, educación para la ciudadanía, educación por internet, educación y empleo, y educación y enseñanza. 
La educación aparece entonces con orientaciones distintas, contextos, áreas, relaciones, actores y marcos también diversos. Se encuentra orientada al desarrollo, a la ciudadanía y a la paz. Tiene lugar en contextos no formales y escolares (superior, inicial, media y primaria), desde áreas relacionadas principalmente con las ciencias sociales y humanas (ambiental, artística, bilingüe, física, musical, política, moral, emocional). Se relaciona con apuestas transformadoras (alternativa, experiencial, innovadora, liberadora, libertad, popular) y diferenciales (inclusiva); con actores concretos (universitarios, niños, infantes, adultos) y con el marco de la enseñanza y el empleo.

En el paisaje también se identifica la práctica (77 apariciones) como una tendencia temática fuerte. Esta, en tanto acción o praxis, adquiere la tendencia de asociarse con adjetivos y sustantivos tales como: prácticas pedagógicas (cuarenta y dos relaciones), practicas reflexivas, práctica docente, prácticas educativas, práctica no directiva, prácticas, prácticas de aula, prácticas de crianza, prácticas discursivas, prácticas evaluativas, prácticas juveniles, prácticas pedagógicas universitarias, prácticas políticas, prácticas socioculturales, práctica de valores, y prácticas universitarias. Desde estas clasificaciones se delimitan los actores, contextos y propósitos de la práctica. Los actores generalmente asumen papeles institucionales de estudiantes y docentes, así como papeles sociales; es el caso de los padres de familia y los jóvenes, todos ellos hacen parte y confluyen en contextos socioculturales, llámense escuela, universidad, Centro de Desarrollo Infantil (CDI), familia, comunidad, barrio; a los cuales los investigadores llegan con diversas intenciones: educativas, pedagógicas, formadoras, transformadoras, reflexivas, evaluativas y políticas.

La diversidad (43 apariciones), por su parte, solo se vincula con la cultura y la etnia; aunque también pude relacionarse con la inclusión, esta última en contextos sociales y educativos. 
Por otra parte, el aprendizaje (36 apariciones) hace referencia a los estudiantes escolarizados y al currículo de la educación formal. Así, por ejemplo, aparecen composiciones en clave como aprendizaje significativo, aprendizaje basado en problemas, aprendizaje activo, aprendizaje escolar, aprendizaje experiencial, aprendizaje formal, aprendizaje informal, y aprendizaje profundo. Si bien la mayoría de las veces es el aprendizaje en sí, también se muestra ligado a los saberes escolares y adjetivado en términos de significativo.

Con un número de relaciones igual (36 apariciones), la enseñanza se articula con los saberes escolares, los niveles educativos y las intenciones pedagógicas o didácticas. De esta manera, se presentan composiciones como: enseñanza y aprendizaje de las ciencias sociales, enseñanza y aprendizaje, enseñanza ciencias naturales, enseñanza aprendizaje, enseñanza de la contabilidad, enseñanza de la escritura, enseñanza de las ciencias naturales, enseñanza de las matemáticas, enseñanza del sistema de numeración decimal, enseñanza mutua, enseñanza para la comprensión, enseñanza secundaria y enseñanza superior.

La enseñanza aparece enmarcada tanto con los saberes escolares, desde propuestas didácticas, como con los aprendizajes, los cuales se espera, logren los estudiantes al igual que las propuestas. Estos últimos, generalmente, se vinculan con el pensamiento, el desarrollo y las competencias. Específicamente, el pensamiento (29 apariciones) se compone de diferentes maneras: pensamiento crítico, pensamiento social, pensamiento creativo, pensamiento autónomo, pensamiento complejo, pensamiento histórico, pensamiento aleatorio y sistema de datos. Por su parte el desarrollo (23 apariciones) adopta matices, actores, esferas y adjetivos diferentes: desarrollo humano, desarrollo cognitivo, desarrollo participativo, desarrollo de capacidades, desarrollo integral, desarrollo emocional, desarrollo de la carrera, desarrollo de las habilidades, desarrollo del niño, y desarrollo del pensamiento. Una situación similar experimenta las competencias (21 
apariciones) en las cuales se hallan competencias ciudadanas, competencias ciudadanas emocionales, competencia científica, competencia ciudadana emocional, competencia comunicativa, competencia emocional, competencia lingüística, competencia social, competencias cognitivas, competencias comunicativas, competencias comunicativas e integradoras, competencias de lectura comprensiva, competencias del docente y competencias y afirmaciones.

Respecto a las propuestas educacionales, aparece la secuencia didáctica (25 presentaciones), como estrategia para articular la práctica de la enseñanza y el aprendizaje, así como los actores del proceso, es decir, los estudiantes (23 apariciones) y los docentes (15 apariciones); además del contexto institucional en el que converge la escuela (21 apariciones). De manera concreta, los estudiantes son principalmente estudiantes, estudiantes de secundaria, estudiantes universitarios y, en menor medida, estudiante profesor, estudiantes con Necesidades Educativas Especiales (NEE), estudiantes de primaria, y estudiantes sordos universitarios. La escuela puede aparecer sola y, en menor frecuencia, como Escuela Nueva o escuela pública. Desde estas propuestas, actores y contexto escolar se visualizan en el paisaje con otras claves temáticas tales como:

La formación (25 apariciones): formación de docentes, formación ciudadana, formación integral, formación crítico social, formación de agentes culturales, formación de docentes de educación especial, formación de maestros, formación inicial de maestros, formación investigativa y formación profesional. Esta se constituye en el principal foco de interés al momento de hablar de la formación de los profesionales en educación.

En igual número de relaciones sigue la representación (20 apariciones) y las concepciones (20 apariciones). La primera se encuentra vinculada a representaciones sociales, representación de la química, representación gráfico espacial, representación social, 
representaciones y representaciones semióticas; y la segunda, a concepciones docentes y concepción de sujeto. Allí, representaciones sociales cuenta con el mayor interés temático.

Respecto al conocimiento y dominio de sí mismo, emerge autorregulación, autoestima, autobiografía, autoeficacia, autoformación docente, autonomía, autonomía intelectual, autoridad, autorrealización y autorretrato. En este sentido, la autorregulación se establece como la mayor apuesta. Con el mismo número de apariciones está la inclusión (18 apariciones) y el modelo (18 apariciones), la primera vinculada a la inclusión educativa y la inclusión social; y el segundo en relación con modelos mentales, modelo interactivo, modelo conceptual, modelo pedagógico, modelo pedagógico crítico social, modelos de gestión, modelos explicativos, modelos Multinivel, y modelos pedagógicos.

Finalmente, están presentes la didáctica (16 apariciones), la pedagogía (16 apariciones), la relación (16 apariciones), el texto (16 apariciones), la construcción (15 apariciones) y el contexto (15 apariciones). La primera se enlaza con didáctica del lenguaje, didáctica alternativa, didáctica constructivista, didáctica de las matemáticas, didáctica musical, didáctica no parametral, didácticas y didactomorfosis. La segunda se adjetiva de dos formas llegando a ser pedagogía crítica y pedagogía de la incertidumbre. La tercera se particulariza como relación maestro alumno, relaciones de poder, relaciones interpersonales, relación pedagógica, relación familia escuela, relaciones, relaciones institucionales, relaciones intergeneracionales, relaciones sociales. La cuarta se diversifica como textos narrativos, texto argumentativo, texto expositivo, texto escolar, texto narrativo audiovisual, textos científicos. La quinta se muestra como construcción de la realidad, construcción social, construcción de conocimiento, construcción de imaginarios. Por último, el sexto puede evidenciarse como contexto escolar, contexto social, contexto educativo, contexto familiar, contexto situacional, contexto universitario, contexto y situación de comunicación. 
Ahora bien, dilucidar de manera más fiel este paisaje requiere una mirada más aguda en las particularidades de cada programa. Por tal razón, a continuación, se identifican y analizan las temáticas en clave de cada uno de ellos (ver Figura NRo. 9).

Figura NRO. 9. Palabras clave. Maestría en Educación, UTP.

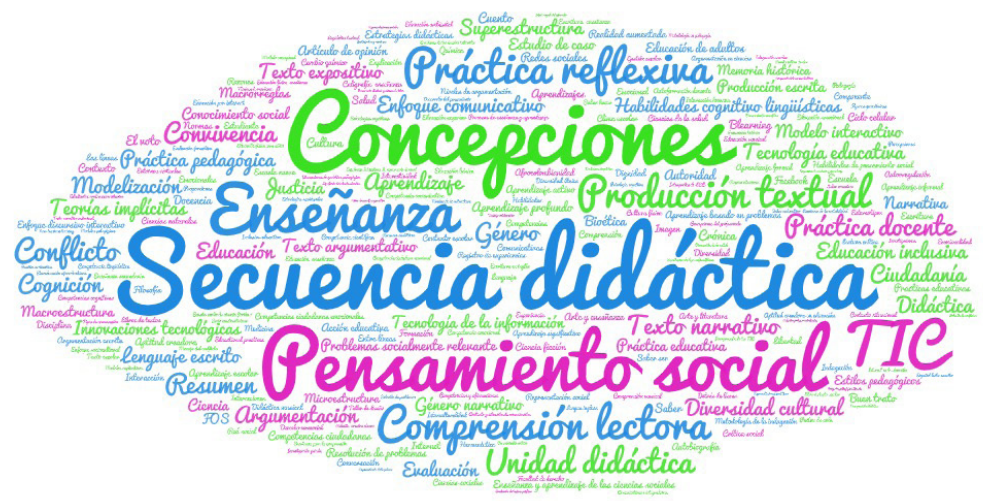

Elaboración propia.

En la Maestría en Educación de la UTP, la temática más referenciada en las palabras clave es la secuencia didáctica (14). También aparecen las concepciones (9) y el pensamiento social (9) como terminologías prevalecientes en el paisaje. De otro lado, hay cerca de ciento noventa palabras clave (entre las 449) que solo se mencionan una única vez. No obstante, para esto último habrá que considerar la nuclearización de las palabras, pues muchas de ellas se presentan como composiciones que particularizan, dan sentido intencional y subjetivan los sustantivos. Así lo muestra la TABLA NRO. 11: 
TABLA NRO. 11. Nuclearización de las palabras clave por palabra inicial, Maestría en Educación, UTP.

\begin{tabular}{ll}
\hline Palabra inicial & Apariciones \\
\hline Práctica & 25 \\
\hline Educación & 17 \\
\hline Enseñanza & 16 \\
\hline Texto & 15 \\
\hline Competencias & 14 \\
\hline Aprendizaje & 13 \\
\hline Pensamiento & 13 \\
\hline Producción & 12 \\
\hline Comprensión & 10 \\
\hline Concepciones & 10 \\
\hline Tecnología & 10 \\
\hline Habilidades & 9 \\
\hline Enfoques & 8 \\
\hline Argumentación & 6 \\
\hline Modelo & 6 \\
\hline Representaciones & 6 \\
\hline Ciencia & 5 \\
\hline Diversidad & 5 \\
\hline Lenguaje & 5 \\
\hline Saber & 5 \\
\hline
\end{tabular}

Elaboración propia.

$\mathrm{Al}$ respecto, el aprendizaje como término base, se encuentra ligado con aprendizaje activo, aprendizaje basado en problemas, aprendizaje escolar, aprendizaje formal, aprendizaje informal, aprendizaje profundo, aprendizaje significativo y aprendizajes. Esta composición, como muchas otras, es una muestra de los matices y la diversidad de apuestas en cuanto a los aprendizajes a los que apunta la educación; adquieren sentido y contexto teórico en el marco de las diferentes disciplinas y áreas del saber desde las cuales se busca contribuir en la formación de los estudiantes.

En este contexto se incluyen palabras clave ligadas a las disciplinas y áreas del saber escolar y disciplinar, por ejemplo: Ciencias de la salud, Ciencias naturales, Ciencias sociales, Lenguaje, Filosofía, Arte, Derecho comercial, Medicina, y Química. Desde ellas se busca el desarrollo de competencias de diverso tipo, a saber: competencia científica, competencia cognitiva, competencia comunicativa, competencia lingüística, competencias ciudadanas, 
competencia emocional, competencias ciudadanas emocionales, competencias y afirmaciones; las cuales se encuentran ligadas a los saberes como saber, saber comunicar, saber hacer, saber matemático y saber ser. Asimismo, se propende por el desarrollo del pensamiento como pensamiento creativo, pensamiento crítico, pensamiento histórico, pensamiento social, pensamiento aleatorio y sistema de datos.

Estos desarrollos en el contexto escolar están mediados por la práctica, la cual adquiere diversidad de matices y objetos. Es el caso de práctica docente, práctica educativa, práctica no directiva, práctica pedagógica, práctica reflexiva y prácticas educativas.

Todas estas temáticas se enmarcan en el contexto educativo, principalmente en el formalizado e institucionalizado, donde la educación adquiere diversas miradas: educación enseñanza, educación ambiental, educación básica, educación de adultos, educación emocional, educación física y enseñanza, educación física para niños, educación inclusiva, educación musical, educación por internet, educación superior y educational practices; y la didáctica que se ubica como acompañante y atributo para algunas intencionalidades y apuestas educativas: transposición didáctica, unidad didáctica, secuencia didáctica y estrategias didácticas.

Dichas intencionalidades se encuadran en intereses particulares de los autores y las especificidades de las mismas didácticas y saberes escolares, tal como se mencionó en las líneas del programa. En ellas, el aprendizaje y la enseñanza tienen amplia presencia. Esta última en contextos diferenciados: enseñanza de la contabilidad, enseñanza de las ciencias naturales, enseñanza de las matemáticas, enseñanza del sistema de numeración decimal, enseñanza para la comprensión, enseñanza secundaria, y enseñanza y aprendizaje de las ciencias sociales.

Finalmente, el paisaje de temáticas del programa deja ver el predominio de la didáctica. Esto puede ser por la misma razón 
de las líneas y grupos de investigación que lo sostienen, pues todos ellos pueden relacionarse con las didácticas de los saberes escolares. Así, por ejemplo, emergen los saberes del lenguaje relacionados con los procesos de comprensión y producción de textos, y amparan su enseñanza desde enfoques discursivosinteractivos y socioculturales. También aparece la enseñanza y el aprendizaje de la ciencia en relación con el desarrollo de habilidades como la argumentación, además de la identificación, profundización y ampliación de las representaciones, y los modelos mentales sobre los fenómenos y realidades físicas y naturales.

En suma, las temáticas que nuclearizan la investigación de los tesistas del programa indican que el interés está puesto en la enseñanza de los saberes escolares y, por ello mismo, se vuelve la atención al aprendizaje, las competencias y el pensamiento desde el diseño de intervenciones didácticas que tienen al estudiante y al docente como sus principales actores.

Las palabras clave en la Universidad Católica son como se muestra en la FigURA NRO. 10.

Figura NRo. 10. Palabras clave. Maestría en Pedagogía y Desarrollo Humano, UCP.

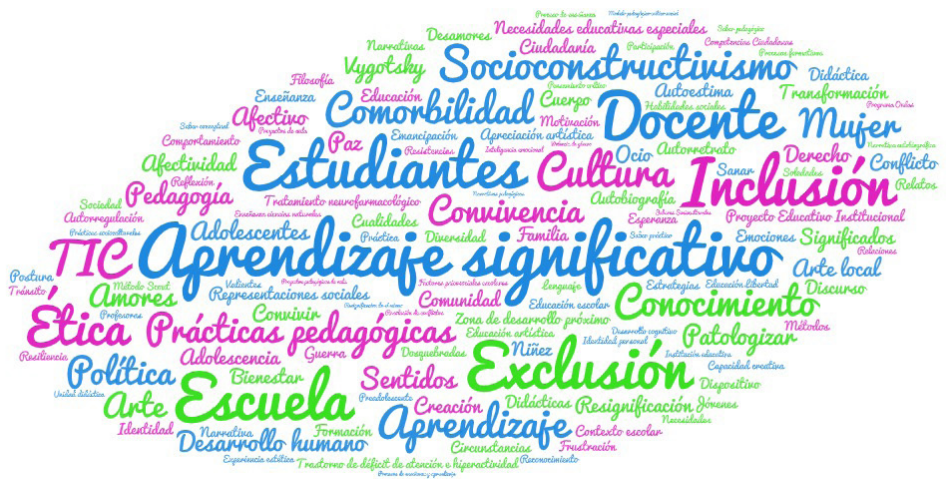

Elaboración propia. 
Las temáticas de mayor frecuencia en las palabras clave de los trabajos de grado de la Maestría en Pedagogía y Desarrollo Humano de la UCP son: aprendizaje significativo, docente, escuela, estudiantes, exclusión, inclusión, prácticas pedagógicas y socioconstructivismo; cada una de ellas contiene tres recurrencias. Por otra parte, ciento dos de las 173 palabras clave reportadas en las treinta y un tesis, solo se menciona una única vez. De esta manera existe una amplia llanura, que puede estar relacionada con la poca presencia de líneas de investigación (en 23 tesis) y convertirse en un marco, con el cual se circunscriben las temáticas de la producción académica de los autores del programa.

De la llanura mencionada hacen parte palabras como: amores, apreciación artística, bienestar, circunstancias, comportamiento, comunidad, contexto escolar, convivir, cualidades, cuerpo, derecho, desamores, desarrollo cognitivo, discurso, dispositivo, diversidad, Dosquebradas, emancipación, emociones, esperanza, estrategias, experiencia estética, factores psicosociales escolares, familia, filosofía, formación, frustración, guerra, habilidades sociales, institución educativa, inteligencia emocional, jóvenes, lenguaje, modelo pedagógico crítico social, motivación, necesidades, niñez, ocio, participación, paz, pensamiento crítico, postura, profesoras, Programa Ondas, reconocimiento, reflexión, relaciones, relatos, resignificación de sí mismo, resiliencia, resistencias, sanar, sociedad, soledades, tránsito, unidad didáctica, valientes, violencia de género, entre algunas otras.

Ahora, una mirada desde la composición de la palabra, particularmente la inicial, permite ampliar un poco el panorama (ver TABLA NRO. 12). 
TABLA NRO. 12. Nuclearización de las palabras clave por palabra inicial, Maestría en Pedagogía y Desarrollo Humano, UCP.

\begin{tabular}{ll}
\hline Palabra inicial & Apariciones \\
\hline Aprendizaje & 5 \\
\hline Práctica & 5 \\
\hline Educación & 4 \\
\hline Narrativa & 4 \\
\hline
\end{tabular}

Elaboración propia.

La producción académica de los trabajos de grado de maestría del programa se encuentra orientada a la comprensión del fenómeno educativo, tal como se manifiesta desde las maneras en que los actores involucrados hacen evidente su aprendizaje, desde las formas en que llevan a cabo su práctica y desde las narrativas (autobiográficas y pedagógicas), que construyen sobre la educación y la pedagogía en contextos principalmente formales.

Las palabras clave en la Maestría en Educación y Desarrollo Humano de la Universidad de Manizales y el CINDE son las que se muestran en la Figura NRO. 11.

Figura NRo. 11. Palabras clave. Maestría en Educación y Desarrollo Humano, UM-C.

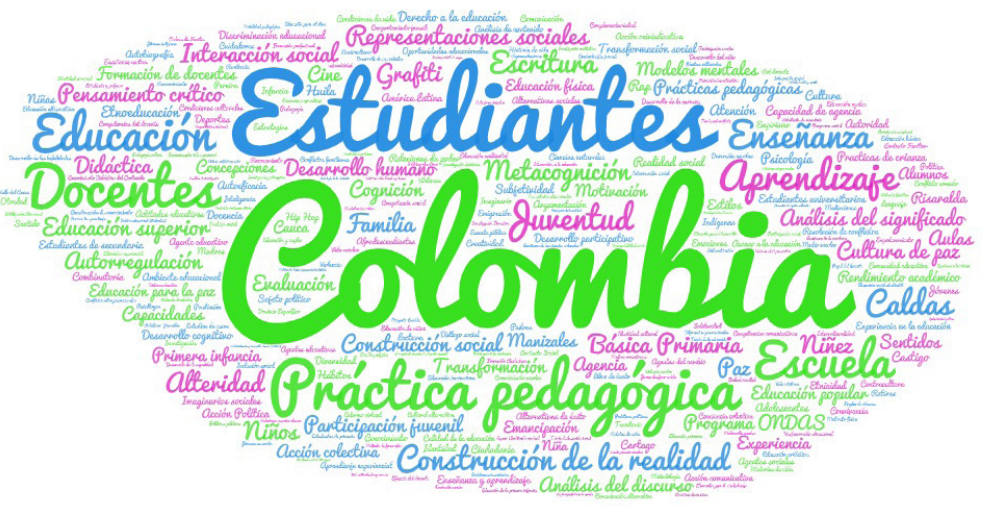

Elaboración propia. 
Allí, se ubica a Colombia (con 13 apariciones) como la temática de mayor uso en el programa de maestría. También aparecen palabras como estudiantes (11) y práctica pedagógica (9) en el paisaje temático. De otro lado, hay cerca de 230 palabras clave (entre las 488), las cuales se mencionan una única vez. Sin embargo, como en los anteriores programas, una clasificación desde la palabra inicial permite ampliar la vista del panorama. Así lo muestra la TABLA NRO. 13:

TABLA NRO. 13. Nuclearización de las palabras clave por palabra inicial, Maestría en Educación y Desarrollo Humano, UM-C.

\begin{tabular}{ll}
\hline Palabra inicial & Apariciones \\
\hline Educación & 35 \\
\hline Práctica & 19 \\
\hline Estudiantes & 18 \\
\hline Construcción & 13 \\
\hline Desarrollo & 12 \\
\hline Análisis & 10 \\
\hline Enseñanza & 10 \\
\hline Participación & 10 \\
\hline Aprendizaje & 8 \\
\hline Formación & 8 \\
\hline Jóvenes & 8 \\
\hline Niñez & 7 \\
\hline Relación & 7 \\
\hline Acción & 5 \\
\hline Investigación & 5 \\
\hline Programa & 5 \\
\hline
\end{tabular}

Elaboración propia.

Como indica dicha tabla, educación (con 35 formas de presentarse) es la palabra de mayor aparición en las composiciones temáticas, las cuales hacen los tesistas en sus producciones académicas. Esta clave suele asociarse al nivel, los propósitos, la diferenciación, las áreas y los destinatarios. En este sentido, aparecen principalmente: educación superior, educación para la paz, educación popular y educación física; así como educación alternativa, educación ambiental, educación artística, educación básica, educación de la primera infancia, educación de niños, educación experiencial, educación innovadora, educación media, educación para adultos, educación para el desarrollo, educación para la ciudadanía, educación primaria, y educación y empleo. 
En referencia a la palabra práctica (con diecinueve expresiones), se puede encontrar que la misma se diversifica y pluraliza, y por tanto aparece como práctica pedagógica, prácticas pedagógicas, prácticas de crianza, prácticas discursivas, prácticas juveniles, prácticas políticas y prácticas universitarias. Ligado a ello, se muestran los estudiantes (con dieciocho términos) en el marco de la educación formalizada, como lo son estudiantes de secundaria, estudiantes universitarios, estudiante y profesor y estudiantes de primaria.

También se exhibe (con 13 ejemplos), la locución construcción de la realidad social del conocimiento; ligadas ellas a educación, práctica y estudiantes, así como a desarrollo (con 12 manifestaciones) en sus múltiples esferas: desarrollo humano, desarrollo cognitivo, desarrollo de capacidades, desarrollo de la capacidad, desarrollo de la carrera, desarrollo de las habilidades, desarrollo del niño y desarrollo participativo. A este último tipo podría vincularse la participación (con 10 expresiones), la cual toma la forma de participación juvenil, participación de la mujer, participación de los estudiantes, participación escolary participación social.

Emerge además análisis (con 10 presentaciones), principalmente como análisis del significado, análisis del discurso y análisis de contenido. A este le sigue enseñanza (también con 10 expresiones), vinculada con procesos y áreas como la enseñanza de la escritura, la enseñanza de las ciencias naturales, la enseñanza mutua, y la enseñanza y el aprendizaje. Este último, es decir, aprendizaje (con ocho muestras) aparece en sí mismo como aprendizaje significativo. También se presenta la clave formación (8 ejemplos) con el maestro como principal destinatario: formación de docentes, formación ciudadana, formación de agentes culturales, formación de docentes de educación especial, formación investigativa y formación profesional. 
La palabra juventud (con 8 expresiones) también aparece como jóvenes, jóvenes en acción y jóvenes indígenas. Y niñez (7 ejemplares) se presenta como niños, niña, niñas, y niño en edad preescolar. Se incluyen, de igual forma, relaciones (7 locuciones) como relaciones de poder, relación familia y escuela, relaciones entre docentes y alumnos, relaciones interpersonales, relaciones maestro alumno y relaciones sociales. La acción, por su parte (con 5 ejemplos), se muestra como acción colectiva, acción comunicativa, acción política y acción reivindicativa. La investigación (también 5 ejemplos) como investigación, investigación cualitativa, investigación formativa, investigación histórica e investigación participativa. Y programa (5 expresiones), como Programa Ondas y programa social.

Así las cosas, las temáticas claves ponen el acento en el estudio de lo educativo desde variadas maneras de entenderlo: en la práctica misma de la educación y la pedagogía, en los actores que hacen parte del proceso y en los propósitos formativos del mismo.

Figura NRO. 12. Palabras clave. Maestría en Educación desde la Diversidad, UM-C.

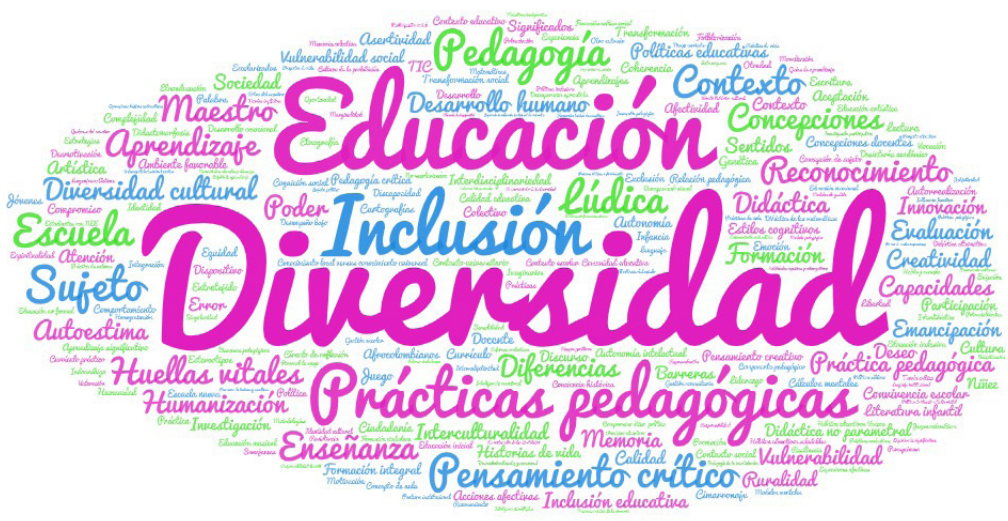

Elaboración propia. 
El paisaje temático de la Maestría en Educación desde la Diversidad de la Universidad de Manizales (ver Figura NRO. 12) deja ver que la palabra clave con mayor recurrencia es diversidad (con 30 apariciones). Igualmente, pero con una recurrencia menor, también aparecen palabras como educación (12 presentaciones), prácticas pedagógicas (12 muestras) e inclusión (10 ejemplos). Finalmente, se evidencia que cerca de 350 palabras clave se mencionan una única vez, asunto que deja en el pico a la diversidad y en una vasta llanura a una variedad de temáticas.

Ahora bien, respecto a aquellas expresiones mencionadas una única vez (cerca de 350 palabras clave, de las 411 reportadas en el programa), la clasificación de la composición de las temáticas, a partir de la palabra inicial, muestra un panorama diferente; tal como aparece en la TABLA NRO. 14.

TABLA NRO. 14. Nuclearización de las palabras clave por palabra inicial, Maestría en Educación desde la Diversidad, UM-C.

\begin{tabular}{ll}
\hline Palabra inicial & Apariciones \\
\hline Práctica & 24 \\
\hline Educación & 18 \\
\hline Pedagogía & 10 \\
\hline Contexto & 9 \\
\hline Pensamiento & 9 \\
\hline Didáctica & 8 \\
\hline Formación & 7 \\
\hline Política & 7 \\
\hline
\end{tabular}

Elaboración propia.

Desde la agrupación que subyace a la tabla anterior, la práctica (con 24 apariciones) se manifiesta también como prácticas pedagógicas, práctica pedagógica, práctica de valores, prácticas pedagógicas universitarias, prácticas, prácticas de aula y prácticas evaluativas. La educación, por su parte (con 18 expresiones), aparece principalmente como ella misma, pero también se amplia y se particulariza. Es el caso de educación artística, educación emocional, educación inclusiva, educación inicial, educación musical, y educación no formal. A este grupo puede 
sumarse pedagogía (con 10 apariciones), la cual, en el marco de discursos latinoamericanos, toma la forma de pedagogía crítica, y pedagogía de la incertidumbre. Esto último podría vincular la formación y desarrollo del pensamiento (9 ejemplos), donde aquel último es visto como pensamiento crítico, pensamiento creativo $\mathrm{y}$ pensamiento autónomo.

Igualmente, aparece la didáctica (con 8 ejemplares), la cual, al igual que pedagogía, también se reviste de otros discursos y toma la forma de didáctica no parametral, didáctica alternativa, didáctica de las matemáticas y didactomorfosis. Igual sucede con formación (7 ejemplos) que aparece con las especificidades de su acción y efecto, es decir, como formación integral, formación ciudadana, formación crítico social y formación inicial de maestros.

Así, todo ello guarda relación con política (7 apariciones), puesto que, las políticas educativas, políticas de atención a la diversidad, políticas inclusivas y políticas públicas como otras formas de política marcan algunos de los rumbos de las dinámicas educativas y pedagógicas del país; de ahí que el MEN sea la fuente de referencia de mayor relevancia. En este sentido, cobra relevancia la aparición de la clave temática contexto (con 9 presentaciones) tanto como él mismo - amplio y extenso-, como particularizado bajo formas de contexto educativo, contexto escolar, contexto social y contexto universitario. 
Figura nRo. 13. Palabras clave. Doctorado en Ciencias Sociales, Niñez y Juventud, UM-C.

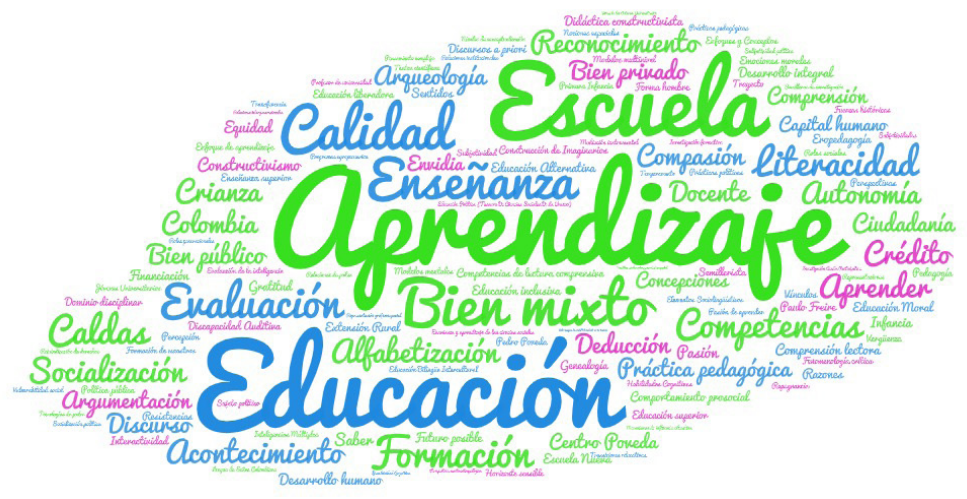

Elaboración propia.

El aprendizaje, la educación y la escuela (cada uno con tres menciones) aparecen como las temáticas predominantes en el paisaje de palabras clave en el Doctorado en Ciencias Sociales, Niñez y Juventud. Inmediatamente después (con dos menciones), registran terminologías como calidad, competencias, enseñanza, evaluación, formación, literacidad, reconocimiento y socialización (ver Figura NRO. 13).

Finalmente, se encuentran más de 120 palabras clave, de las 151 reportadas en las 30 tesis, mencionadas una única vez. Esta situación muestra un paisaje dominado por una llanura de términos como: acontecimiento, alfabetización, argumentación, arqueología, autonomía, Capital humano, ciudadanía, Colombia, compasión, comportamiento prosocial, comprensión, comprensión lectora, concepciones, crédito, crianza, deducción, discapacidad auditiva, dominio disciplinar, elementos sociolingüísticos, emociones morales, envidia, equidad, extensión rural, fenomenología crítica, forma hombre, fuerzas históricas, futuro posible, genealogía, gratitud, habilidades cognitivas, horizonte sensible, infancia, inteligencias múltiples, interactividad, jóvenes universitarios, lengua de señas 
colombiana, mecanismos de influencia educativa, mediación instrumental, niveles de conceptualización, nociones espaciales, Paulo Freire, pensamiento complejo, percepción, primera infancia, programas agropecuarios, razones, reivindicación de derechos, repugnancia, resistencias, saber, temperamento, textos científicos, transferencia, transiciones educativas, trayecto, vergüenza, videojuegos de realidad virtual no inmersiva, vínculos, voces de los actores universitarios, vulnerabilidad social, entre algunas otras.

La clasificación de las claves temáticas a partir de la palabra inicial da pie a la nuclearización evidenciada en la TABLA NRO. 15.

TABLA NRO. 15. Nuclearización de las palabras clave por palabra inicial, Doctorado en Ciencias Sociales, Niñez y Juventud, UM-C.

\begin{tabular}{ll}
\hline Palabra inicial & Apariciones \\
\hline Educación & 10 \\
\hline Bien & 4 \\
\hline Relaciones & 3 \\
\hline
\end{tabular}

Elaboración propia.

Como indica dicha tabla, educación (con 10 apariciones) se presenta como educación alternativa, educación bilingüe intercultural, educación inclusiva, educación liberadora, educación moral, educación política y educación superior. Por su parte, bien (con 4 ejemplos) se particulariza como bien mixto, bien privado y bien público. Y finalmente, relaciones (con 3 expresiones) aparece como relaciones de poder, relaciones institucionales y relaciones intergeneracionales.

El panorama descrito, aquel de palabras clave en el doctorado, no permite identificar temáticas fuertes o de implantación en las tesis analizadas, lo cual seguramente es cuestionable y llama la atención sobre la relevancia que tienen dichas palabras para ubicar y caracterizar las tesis y a sus autores. 
Desde esta perspectiva, es claro que la asignación de palabras clave a los informes de investigación, cuando son remitidos a los repositorios universitarios para su publicación, se constituye en un valor añadido para la recuperación, pues como es sabido, esos repositorios tienden a utilizarlas como índices para la búsqueda por parte de los usuarios. En este sentido, cobra relevancia su inclusión en las producciones académicas de los programas de maestría y doctorado, así como lo hace en las publicaciones de revistas indexadas, aunque claro está, con un lenguaje libre y natural para el usuario quien es el realizador de las búsquedas (Muñoz Martín, 2016)

Dicho esto, al tratarse de trabajos no publicados en una revista $\mathrm{y}$, por tanto, sin descriptores; es responsabilidad de los investigadores, así como de sus asesores - por eso extraña la aparición de diecinueve tesis sin palabras clave-, dotarlos de palabras clave significativas que representen el contenido y vayan más allá del título para, de esta forma, lograr un buen posicionamiento en los motores de búsqueda $y$, en consecuencia, ser consultados y citados.

Bajo esta mirada, es importante considerar que las palabras clave, en sí mismas, son una herramienta de doble vía: de quienes escriben y de quienes buscan la información (Mattar y González Tous, 2012). Por lo expuesto, una adecuada elección de las palabras clave puede hacer más fácil encontrar la publicación y generar mayores probabilidades de ser citada. Esto porque la intención de los autores cuando publican su obra

...es que su trabajo sea consultado y en el mejor de los casos, citado. Ése es el verdadero reconocimiento de su investigación, así se construyen comunidades académicas. Pero para ello es condición indispensable que sea recuperado de entre otros trabajos similares (Muñoz Martín, 2016, p. 182). 


\subsection{A manera de cierre}

El análisis de las 18025 referencias destaca la prevalencia de las alusiones al Ministerio de Educación Nacional (con 404 apariciones) como la autoridad de mayor consulta, principalmente en las tesis de maestría. También aparecen con frecuencia las referencias a César Coll (presentado 195 veces), y Paulo Freire (con 172 veces). Y, con menor predominancia, se mencionan referencias de la UNESCO (119 veces), Juan Ignacio Pozo (117 veces) y Lev Semiónovich Vygotsky (con 103 veces).

El predominio de estas referencias en los programas indica dos asuntos: En primer lugar, que los grupos, líneas y seminarios a los cuales asisten los tesistas proporcionan los insumos de fuentes "cabecera», lo que hace que marquen una tradición y construyan maneras particulares de entender los fenómenos ligados a la educación y la pedagogía; esto es un modo de proceder que también puede advertir, sobre cómo existe una forma en que los autores se van insertando en las comunidades discursivas académicas (Swales, 2004), además de irse dotando de los elementos teóricos, prácticos, metodológicos, epistemológicos y del decir para participar con pleno derecho en dichas comunidades de práctica (Lave y Wenger, 1991). En segundo lugar, indica que la procedencia de los tesistas y sus asesores es un factor a considerar en el análisis, pues los primeros son principalmente profesionales de la educación, maestras de la básica, la media y la universidad, quienes acuden a formarse a los posgrados y enmarcan sus apuestas investigativas desde los planteamientos del MEN; asunto que podría explicar la preponderancia de esta fuente en el paisaje de la zona. Por otro lado, habrá que considerar la formación de los asesores. Como se dijo, ellos también direccionan las fuentes bibliográficas a sus tutorados, las cuales posiblemente develan sus posiciones teóricas e ideológicas, y el origen de sus procesos de formación. De ahí la aparición frecuente de autores de referencia pertenecientes a España y Brasil. 
Finalmente, estas referencias permiten destacar algunas urgencias en el panorama de la producción académica en los programas de la zona. La primera de ellas tiene que ver con la necesidad de comenzar a realizar lecturas más polifónicas y contextuales de las problemáticas relacionadas con la educación y la pedagogía, puesto que si bien el MEN es la normativa nacional, la cual reglamenta y encuadra la educación; su sentido, propósitos y desafíos, como marco, también restringen y sesgan la mirada hacia otros discursos y visiones que podrían aportar elementos para entender los fenómenos relacionados con la educación en sus diversos niveles y expresiones.

Ligado a lo anterior, es imperativo el fortalecimiento de la capacidad investigativa y difusora de los programas, los investigadores y los grupos de investigación del territorio; de manera que puedan contar con el equipamiento necesario para construir explicaciones y maneras de entender la educación, las cuales se muestren más cercanas y contextualizadas a las dinámicas propias de dichos espacios. Es de vital importancia entonces, darle mayor reconocimiento social y académico a las investigadoras e investigadores locales, pues son ellos quienes conocen de cerca los problemas particulares que enfrenta la educación en las comunidades; son ellos quienes pueden hacer una lectura contextualizada de las situaciones experimentadas por profesores, estudiantes y la comunidad educativa; y son ellos quienes están formando una tradición investigativa y científica en la zona. Ese reconocimiento, tal como advierte Muñoz Martín (2016), se da en la medida en que su trabajo sea consultado y citado.

Ahora bien, en cuanto a las palabras clave en la zona (1 672 específicamente), una mirada relacional que deje de lado los plurales, los adjetivos y otros acompañantes de la palabra inicial, los cuales claramente dan contexto e intencionalidades a las temáticas, devela que, las de mayor frecuencia en los trabajos de grado de maestría y las tesis de doctorado son educación (con 85 apariciones) y práctica (con 77). La educación es entonces la 
montaña discursiva del paisaje, una formación plagada de dobleces dados por diversidad de adjetivos que la personalizan, le otorgan contextos, la hacen multidimensional, le dan sentido, y le brinda propósitos y medios. Así el panorama, la educación no solamente es alta en términos cuantitativos (número de recurrencias), sino también ancha en términos cualitativos (diversidad de adjetivaciones).

Las temáticas de los trabajos de grado de maestría y tesis de doctorado, al igual que los autores referidos, están advirtiendo la emergencia de otras formas de entender la educación y la pedagogía, y, en el mismo sentido, de otras apuestas en relación con la práctica. Estas últimas parecen estar ligadas al pensamiento crítico de las pedagogías latinoamericanas, y estar en comunión con maneras más ecológicas y amplias de entender la educación y de orientar su experiencia en el contexto escolar. El paisaje indica que, si bien el fundamento se realiza desde la perspectiva del MEN, se están escuchando otras voces críticas y constructivistas, las cuales entregan otros papeles a los actores educativos, a los actores sociales vinculados con la educación y a la misma sociedad como garante de esta.

\section{Referencias bibliográficas}

Arbeláez Gómez,M.C.(2014)Concepcionesdeconstructivismoen la revista colombiana «Educación y cultura» durante el período 1984-2005. [Tesis de doctorado, Universitat de Barcelona]. https://www.tdx.cat/bitstream/handle/10803/666310/ MCAG_TESIS.pdf? sequence $=1$ \&isAllowed $=\mathrm{y}$.

Bonilla Murcia, M. N. y Rosero Prado, A. L. (2011). Emergencias de la actividad investigativa en educación y pedagogía de la maestría en educación universidad del valle entre el 2000 y el 2009. Revista Latinoamericana de Estudios Educativos, 7(1), 99-122. https://www.redalyc.org/articulo. oa? id=134125447006. 
De Del Castillo, J. C. (2007). Conversando con tutores y asesores de tesis. Visión Gerencial, 16-32. https://www.redalyc.org/ pdf/4655/465545877006.pdf.

De la Cruz Torres, J. (2013). Relación de tutoría y promoción del desarrollo de habitus científicos en estudiantes de doctorado en educación. Perfiles Educativos, 35(140), 8-27. https://reader.elsevier.com/reader/sd/pii/

Fresán Orozco, M. (2001). Formación doctoral y autonomía intelectual. Relaciones causales. Universidad Anáhuac.

. (2002). La asesoría de la tesis de doctorado. Una influencia permanente en la vida del investigador independiente. Revista de la Educación Superior, 31(124), 103-122.

García Pérez, M. y García Aretio, L. (2014). Líneas de investigación y tendencias de la educación a distancia en América Latina a través de las tesis doctorales. RIED. Revista Iberoamericana de Educación a Distancia, 17(1), 201-230. http://revistas.uned.es/index.php/ried/article/ view/11581/11048.

Granda-Orive, J. I.; García Río, F. y Callol Sánchez, L. M. (2003). Importancia de las palabras clave en las búsquedas bibliográficas. Revista Española de Salud Pública, 77(6), 765-767.

Johnson, L.; Lee, A. \& Green, B. (2010). The Ph.D. and the Autonomous Self: Gender, Rationality and Postgraduate Pedagogy. Studies in Higher Education 25(2), 135-147. 
Lave, J. \& Wenger, E. (1991). Legitimate Peripheral Participation in Communities of Practice. In Situated Learning. Legitimate Peripheral Participation (pp. 89-118). Cambridge University Press.

López GiL, M. (Coord.) (2017). Las citas y las referencias bibliográficas: sentido, necesidad y procedimiento. Universidad de Cádiz.

Mattar, V. S. y González Tous, M. (2012). Las claves de las palabras clave en los artículos científicos. Revista Medicina veterinaria y zootecnia, 17(2), 2955-2956.

Ministerio de Educación Nacional [MEN]. (2015). Una mirada a los graduados de posgrado en Colombia: características $e$ indicadores de mercado. Boletín Educación Superior en Cifras. https://ole.mineducacion.gov.co/1769/ articles-380203_recurso_1.pdf. . (2017). Paso a paso hacia la equidad salarial: educación y mercado laboral en Colombia. Educación superior, Boletín No. 1. https://ole.mineducacion.gov.co/1769/ articles-380208_recurso_1.pdf.

Muñoz Martín, B. (2016). Descriptores y palabras clave. Revista de la Sociedad Otorrinolaringológica de Castilla y León, Cantabria y La Rioja, 7(3), 179-183. https:// revistas.usal.es/index.php/2444-7986/article/view/ orl201673.14814/15565.

Murcia-Peña, N.; Murcia-Gómez, N. y Urbina, J. E. (2011). Tendencias investigativas en educación y pedagogía: estudio de las regiones investigativas de la maestría en educación de la UIS. Revista Latinoamericana de Estudios Educativos (Colombia), 7(1), 81-98. https://www.redalyc. org/pdf/1341/134125447005.pdf. 
Murcia-Peña, N.; Ramírez, C. A. y Ospina, H. F. (2012). La investigación en educación y pedagogía en el eje cafetero. Revista Latinoamericana de Estudios Educativos (Colombia), 8(1), 11-38. https://www.redalyc.org/ pdf/1341/134129256002.pdf.

Repiso Caballero, R.; Torres Salinas, D. y Delgado López, E. (2013). La investigación científica sobre cine en España a partir de sus tesis doctorales: análisis de redes sociales (1978-2007). Revista ICONO14, 11(2), 385-404. https:// doi.org/10.7195/ri14.v11i2.530.

Revilla FigueroA, D. (2017). Expectativas y tensiones en la asesoría de tesis en la Facultad de Educación de la Pontificia Universidad Católica del Perú. REDU. Revista de Docencia Universitaria, 15(1), 277-303. DOI: https:// doi.org/10.4995/redu.2017.6057.

Sánchez Amaya, T. y Arias Murillo, F. (2012). La herramienta arqueológica. En H. F. Ospina Serna y N. Murcia Peña. (Ed.). Regiones investigativas en educación y pedagogía en Colombia: construcción de un mapa de la actividad investigativa de tesis de maestrías y doctorados en el periodo 2000-2010 (pp. 87-109). Editorial Zapata.

Swales, J. (2004). Research Genres: Explorations and Applications. Cambridge University Press.

Sime Poma, L. y Revilla FigueroA, D. (Comp.). (2014). Aportes a los procesos de asesoría de tesis en posgrados en educación. Lima: Escuela de Posgrado PUCP. Pontificia Universidad Católica del Perú.

Sмith, L. C. (1981). Citation analysis. Library Trends. 
Urbano Salido, C. (2000). El análisis de citas en publicaciones de usuarios de bibliotecas universitarias: un estudio de las tesis doctorales en informática de la Universidad Politécnica de Cataluña, 1996-1998. [Tesis de doctorado, Universidad de Barcelona]. https://www. tdx.cat/bitstream/handle/10803/2891/urbano-tesis 1 . PDF? sequence $=1 \&$ isAllowed $=\mathrm{y}$.

Valarino, E.; Meneses, R.; Yáber, G. y Pujol, L. (1996). Optimización de la gerencia de investigaciones en postgrado. Revista Latinoamericana de Psicología, 28(1), 63-82. https://www.redalyc.org/articulo.oa?id=80528104. 


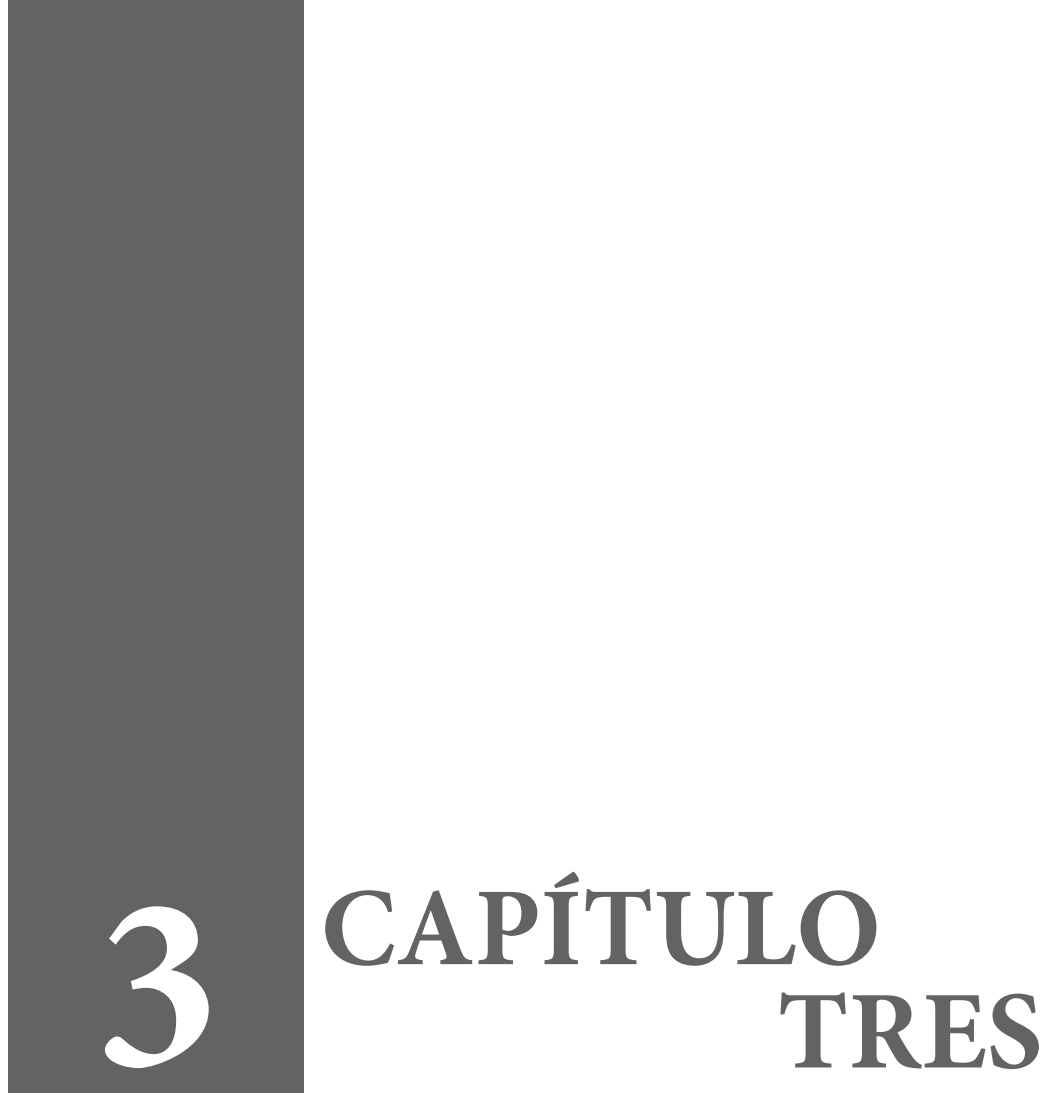





\title{
Alcances y metodologías en investigaciones de educación y pedagogía en la zona del Eje Cafetero (2010-2017)
}

\author{
Luz Stella Montoya Alzate \\ Elizabeth Gallego Correa ${ }^{8}$ \\ Jhon Wilmar Toro ${ }^{9}$
}

La metodología es uno de los apartados de los trabajos de grado y las tesis el cual fue analizado en esta investigación. Aquí se presentan los objetivos propuestos por los investigadores y, en consecuencia, las técnicas y métodos para alcanzarlos y definir cómo abordar cada una de las actividades las cuales hacen parte del estudio. Además, se determina la forma en que el investigador obtiene, ordena y analiza los datos o información recolectada, proceso que cumple la función de dar validez y rigor a los resultados.

El capítulo presenta los procedimientos y las técnicas utilizadas en los procesos de investigación realizados en las maestrías y doctorado de algunas universidades de la zona Eje

7 Universidad Tecnológica de Pereira.

8 Universidad Católica de Pereira.

9 Universidad Católica de Pereira. 
Cafetero. Este proceso permitió generar resultados teóricamente válidos al funcionar como soporte conceptual y como forma que rige la manera en que se aplicaron los procedimientos.

Para el análisis metodológico de las trescientas quince investigaciones se abordaron los siguientes tópicos: alcance de los de objetivos, paradigmas y enfoques, técnicas e instrumentos, y autores. En primera instancia, se presenta un análisis general de la zona del Eje Cafetero para, luego, proceder a un desglose por universidades con el fin de hacer una descripción y explicación de cada uno de los tópicos analizados.

\subsection{Tópico: alcance de los objetivos}

Los objetivos aspiran establecer con claridad lo que se pretende con la investigación. Así, algunos procesos investigativos buscan contribuir a la resolución de un problema, mientas otros tienen la pretensión de probar una teoría o aportar evidencias empíricas a favor de la suposición que requieren validar. Estos deben ser claros, precisos, medibles y coherentes según el problema a estudiar.

Los objetivos determinan la intencionalidad que tiene el investigador, es decir, que, si el propósito es comprender o evaluar una situación, dan cuenta de esta manera, del paradigma o del enfoque el cual se va a utilizar. Además, orientan el cómo se va a desarrollar el proceso investigativo; convirtiéndose así, en una guía de estudio la cual facilita la ruta que se ha de seguir en su desarrollo.

Además, permiten identificar el alcance de la investigación y delimitan hasta dónde se quiere llegar en el proceso. Esta característica aclara que no se debe pensar en una sola tipología tal como lo explica Hernández Sampieri et al. (2014), quienes plantean que los alcances «más que ser una clasificación, constituyen un continuo de "causalidad" que puede tener un 
estudio» (p. 90), dando claridad a la estrategia de investigación e indicando el alcance de los resultados que el investigador espera obtener del estudio.

Para el análisis de los objetivos se tuvo en cuenta las recurrencias encontradas en la cartografía. En este sentido, se identificaron aquellos con diversas intencionalidades como las comprensivas, las analíticas, las correlacionales, las descriptivas, las evaluativas, las exploratorias, las interpretativas, las explicativas, las experimentales, las reflexivas, y las biográficas o propositivas.

Este tópico permitió reconocer, en primera instancia, que los objetivos son nombrados de distintas formas; algunas veces como objetivos y otras, como pretensiones y/o propósitos. Si bien estos conceptos están relacionados, la diversidad en nombrarlos depende del estilo de quien asesora el trabajo de grado o de las preferencias de los investigadores. En segundo lugar, en algunos estudios no se logró ubicar con precisión cuál o cuáles eran los objetivos, estos se infirieron según el discurso y, en especial, conforme a lo descrito en los resultados, situación que se convierte en tema de análisis y de reflexión en tanto no da claridad sobre lo cual se quiere lograr en el proceso investigativo. Esto afecta su coherencia, validez y rigor en el procedimiento.

A partir de estas claridades, se realiza la descripción y el análisis del tópico objetivo tanto de la zona Eje Cafetero como de cada una de las universidades participantes. 
FigurA Nro. 14. Alcance del objetivo, zona Eje Cafetero.

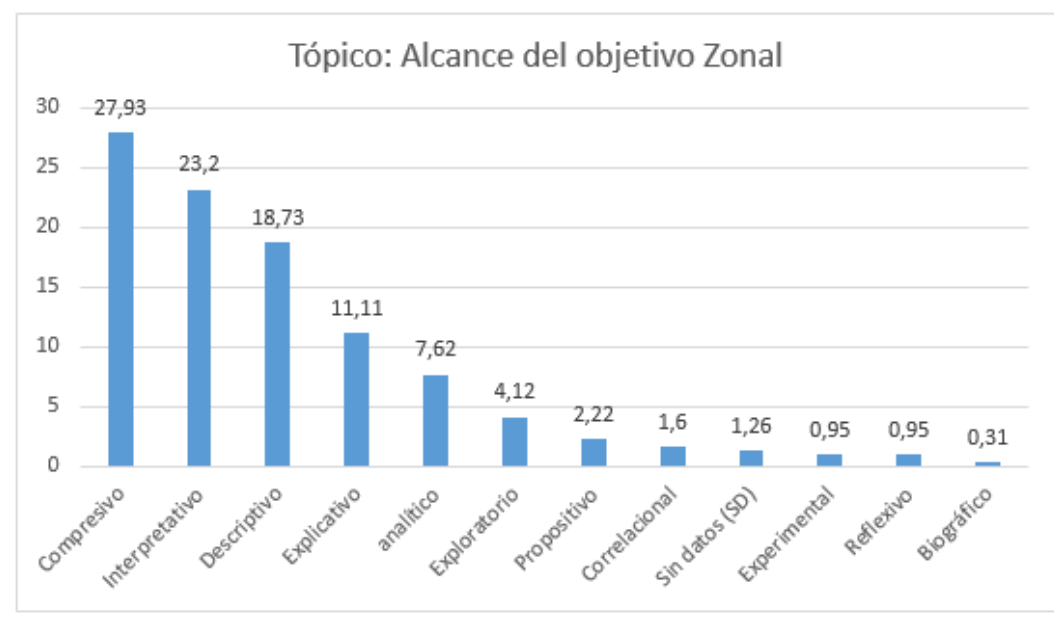

Elaboración propia

En la FIGURA NRO. 14, se muestran las principales relevancias de la zona del Eje Cafetero. Allí, se identifican doce clasificaciones, de las cuales once, corresponden a los objetivos identificados y una a un registro sin datos. Como pico, se encuentran los objetivos comprensivos, con un $27.93 \%$; le sigue la montaña, representada por lo interpretativo con un $23.2 \%$; una meseta, donde lo descriptivo ocupa un $18.13 \%$; una colina, conformada por objetivos explicativos con el $11.11 \%$; una llanura desde lo exploratorio con el $4.12 \%$, acompañada por lo propositivo en 2.22 $\%$; y, finalmente, se presentan las opacidades, las cuales se mueven entre lo experimental, lo reflexivo, lo biográfico y sin datos por debajo del $1 \%$.

Estos resultados permiten reconocer la existencia de una tendencia muy marcada hacia aquellos objetivos cuya intencionalidad se dirige a la comprensión del fenómeno. En ella se encuentra el interpretar, describir, explicar y explorar; lo cual 
indica la apertura y la flexibilidad por parte de los investigadores, sobre reconocer nuevas miradas frente al objeto de estudio en las cuales prevalezca la voz de las personas directamente involucradas en el proceso, fenómeno propio de la investigación cualitativa.

Sin embargo, aunque prevalecen los objetivos comprensivos, también se evidencian objetivos cuya intencionalidad es la medición de un fenómeno, tal es el caso de lo experimental ubicado como una opacidad, dado que solo en el $1 \%$ de los secesos, se emplean análisis estadísticos para validar postulados teóricos u otro tipo de situaciones. Este dato permite inferir la necesidad de ahondar en los procesos investigativos con enfoque cuantitativo.

Otras opacidades que llaman la atención son los objetivos reflexivos y biográficos. En cuanto a los primeros, se puede decir que son un proceso inmerso en todo el transcurso investigativo, ya que implican la conexión que tiene el investigador con el objeto de estudio. Así, frente a las reflexiones realizadas por el investigador, puede inferirse el alcance del procedimiento. En cuanto a los segundos, se generan confusiones debido a que lo biográfico se emplea más como técnica o instrumento, dado que son procedimientos destinados a indagar información para describir y/o explicar los diferentes momentos de la vida de una persona o de un grupo social en su contexto.

En general, se puede plantear que el alcance de los objetivos en la zona del Eje Cafetero se centra en la profundización del fenómeno estudiado. Esto, debido a que se dirige a la comprensión e interpretación, lo cual indica que se indaga detalladamente el fenómeno o situación estudiada, y en este sentido, se reconoce directamente de los implicados su pensar, su sentir y sus vivencias.

A continuación, en la TABLA NRO. 16, se presentan los tipos de objetivos formulados por cada una de las universidades participantes. 
TABLA NRo. 16. Tópico: alcance del objetivo por universidades.

\begin{tabular}{|c|c|c|c|c|c|c|c|c|c|c|}
\hline \multirow[t]{2}{*}{$\begin{array}{l}\text { Alcance del } \\
\text { objetivo }\end{array}$} & \multicolumn{2}{|c|}{$\begin{array}{l}\text { Universidad de } \\
\text { Manizales y el } \\
\text { CINDE } \\
\text { (Maestrías) }\end{array}$} & \multicolumn{2}{|c|}{$\begin{array}{l}\text { Universidad de } \\
\text { Manizales y el } \\
\text { CINDE } \\
\text { (Doctorado) }\end{array}$} & \multicolumn{2}{|c|}{$\begin{array}{l}\text { Universidad } \\
\text { Tecnológica } \\
\text { de Pereira }\end{array}$} & \multicolumn{2}{|c|}{$\begin{array}{l}\text { Universida } \\
\text { d Católica } \\
\text { de Pereira }\end{array}$} & \multicolumn{2}{|c|}{ Totales } \\
\hline & $\mathrm{F}$ & $\%$ & $\mathrm{~F}$ & $\%$ & $\mathrm{~F}$ & $\%$ & $F$ & $\%$ & $\mathbf{F}$ & $\%$ \\
\hline Compresivo & 60 & 38.71 & 14 & 48.2 & 14 & 14 & & & 88 & 27.93 \\
\hline Interpretativo & 21 & 13.55 & & & 48 & 48 & 4 & 15 & 73 & 23.2 \\
\hline Descriptivo & 37 & 23.87 & 5 & 17.3 & 5 & 5 & 12 & 40 & 59 & 18.73 \\
\hline Explicativo & 4 & 2.58 & & & 28 & 28 & 3 & 10 & 35 & 11.11 \\
\hline Analítico & 14 & 9.03 & 6 & 20.6 & 1 & 1 & 3 & 10 & 24 & 7.62 \\
\hline Exploratorio & 12 & 7.74 & 1 & 3.4 & & & & & 13 & 4.12 \\
\hline Propositivo & 2 & 1.29 & 2 & 6.9 & 3 & 3 & & & 7 & 2.22 \\
\hline Correlacional & 3 & 1.94 & 1 & 3.4 & 1 & 1 & & & 5 & 1.6 \\
\hline Sin datos & 2 & 1.29 & & & & & 2 & 4 & 4 & 1.26 \\
\hline Experimental & & & & & & & 3 & 10 & 3 & 0.95 \\
\hline Reflexivo & & & & & & & 3 & 10 & 3 & 0.95 \\
\hline Biográfico & & & & & & & 1 & 1 & 1 & 0.31 \\
\hline Totales & 155 & 100 & 29 & 100 & 100 & 100 & 31 & 100 & 315 & 100 \\
\hline
\end{tabular}

Elaboración propia.

En la Maestría de la Universidad de Manizales y el CINDE se presenta el siguiente relieve en el tópico de objetivos. En el pico, se encuentra aquellos comprensivos con un porcentaje del $38.7 \%$, en la montaña están los descriptivos con un $23.8 \%$, en la meseta los interpretativos con un $13.55 \%$, en la colina los analíticos con un $9.03 \%$, en la llanura los exploratorios con un $7.74 \%$; como opacidades se establecen los correlacionales con un $1.94 \%$, y los propositivos y el registro sin datos con un $1.29 \%$.

En el doctorado de la misma universidad, el pico está representado por objetivos de tipo comprensivo con un $48.2 \%$; le sigue una montaña, en la cual se ubican los objetivos analíticos con un $20.6 \%$; una meseta con los descriptivos, donde su porcentaje alcanza el $17.3 \%$; en la colina se ubican los propositivos con un $6.9 \%$; y en la llanura, se encuentran los correlacionales y los exploratorios con un $3.4 \%$.

Por su parte, en la Maestría de la Universidad Tecnológica de Pereira, el pico está constituido por los objetivos interpretativos con un $48 \%$; en la montaña, se encuentran los explicativos con un $28 \%$; en la meseta, los comprensivos con un $14 \%$; en la colina, 
los descriptivos con un $5 \%$; en la llanura, los propositivos con un $3 \%$; y, como opacidades, se establecen los objetivos analíticos y correlacionales con tan solo el $1 \%$.

En la Maestría de la Universidad Católica de Pereira, el relieve presenta las siguientes características; el pico corresponde a los objetivos descriptivos con un porcentaje del $40 \%$; la montaña la constituyen los interpretativos con el $15 \%$; en la meseta están los analíticos, los explicativos, los experienciales y los reflexivos con un $10 \%$; en la colina, se halla el registro sin dato con un $4 \%$; y, finalmente, como opacidad se encuentran los objetivos biográficos, con un $1 \%$.

Estos datos permiten reconocer la diversidad de objetivos los cuales se emplean en las investigaciones en cada una de las universidades. Estos van desde lo comprensivo hasta lo correlacional y lo propositivo. Sin embargo, si se suman los porcentajes de los picos y las montañas, las cuales representan los porcentajes más altos, se puede inferir que, en primer lugar, están los objetivos comprensivos con un $86.2 \%$, situación que indica la preferencia de los investigadores en los estudios cuya intencionalidad se centra en la interpretación a profundidad de un fenómeno, de los contextos, de los actores sociales o pedagógicos, involucrados en la investigación.

En segundo lugar, se encuentran los objetivos descriptivos e interpretativos con el $63.8 \%$ y $63 \%$, respectivamente. Estos primeros se centran en reconocer las características de lo estudiado, donde los resultados se basan en la exploración y la descripción de la situación abordada; y, los segundos, buscan profundizar el conocimiento y la comprensión del porqué de una realidad educativa y/o social; $y$, en tercer lugar, se localizan los explicativos y los analíticos con cifras de $28.8 \%$ y $20.6 \%$, respectivamente. Los primeros hacen parte de una de las pretensiones del campo comprensivo, pero su alcance va hasta explicar la situación o fenómeno estudiado; y los segundos, dan cuenta de su ubicación 
en paradigmas positivistas de carácter hipotético deductivo, los cuales buscan la validación o refutación de hipótesis, las causas de los fenómenos sociales, y sus consecuencias o implicaciones.

En términos generales, priman los objetivos que buscan comprender las prácticas e interpretar las transformaciones y/o las experiencias educativas, pedagógicas y sociales de las situaciones abordadas en cada una de las investigaciones. Es importante reconocer que, aunque la tendencia es frente a lo cualitativo, algunos investigadores optan por lo cuantitativo, lo cual busca medir y validar teorías. Es el caso de los objetivos correlacionales, los cuales se presentan en el doctorado con un porcentaje del 3.4 \%; en las maestrías de la Universidad de Manizales, con un $1.94 \%$; y, en la maestría de la Universidad Tecnológica de Pereira, con un simple $1 \%$. Dicha situación reafirma lo planteado anteriormente sobre la necesidad de profundizar y motivar las investigaciones de tipo cuantitativo, ya que estas permiten otra mirada de la situación estudiada, siendo un complemento en los procesos investigativos.

\subsection{Tópico: paradigmas y enfoques}

Históricamente, se habla de dos paradigmas o posturas científicas las cuales ayudan a comprender teóricamente la construcción de las investigaciones y sus alcances. El primer lugar, se encuentra el paradigma positivista, el cual indica una tendencia hacia las ciencias exactas. El segundo lugar está el constructivista, aquel direccionado hacia las ciencias humanas y el cual invita a reconocer lo relevante desde lo cualitativo en miras de dar explicaciones a los fenómenos que se quieren intervenir. El abordaje de los paradigmas en la investigación tiene una gran importancia. Estos representan el sistema de creencias o supuestos axiológicos de partida a la hora de llevar a cabo un proceso investigativo en educación. Dicho de otra manera, son los lentes con los cuales se aproxima a un estudio sistemático y a una indagación coherente de la realidad educativa - no solo escolar-(Sánchez, 2013), donde lo ontológico, lo epistemológico 
y lo metodológico se conjugan como lo menciona Guba y Lincoln (como se citó en Ramos, 2015) en un lente para ayudar a entender el campo u objetivo de investigación desde una postura crítica.

En cuanto a los enfoques, se puede decir que se reconocen como las formas en la cuales el investigador se ubica desde una escuela de pensamiento para agudizar su objetivo en la consecución de unos resultados. El enfoque es la manera concreta, de cómo los paradigmas logran mostrarse en una investigación. Estos son conocidos tradicionalmente como lo cuantitativo y cualitativo, buscan una especie de diálogo mostrando las bondades de cada uno en el buen sentido de la investigación y, para darle realce y validez de los resultados a los datos encontrados, brindan sentido a lo mixto como enfoque (Monje Álvarez, 2011).

En este sentido, hablar de paradigmas es hablar de lentes y enfoques. Es mencionar que existe un ojo el cual mira a través del lente, es decir, el que hace su ejercicio positivista y constructivista como lupa bajo una perspectiva ontológica, epistemológica y metodológica; lo cual se ve reflejado en los enfoques (lentes) cuantitativo, cualitativo y mixto, y llega a veces a confundirse en la terminología, haciéndolos valer como iguales. Estas perspectivas ayudan a leer el punto fijo de donde se parte para hacer la lectura y el trabajo de campo en una investigación. Un trabajo de grado el cual no tenga un paradigma y un enfoque definido corre el riesgo de perderse en el discurso o de no encontrar sustentos sólidos de defensa de sus postulados. En este sentido, puede hacer perder al lector cuando se encuentre con el texto.

Partiendo de esta perspectiva, se presentan los paradigmas y los enfoques de la zona del Eje Cafetero. Para su análisis, se tuvieron en cuenta los porcentajes y las frecuencias de la utilización recurrente de estos por parte de los investigadores, los cuales van desde lo cualitativo, pasando por lo cuantitativo y lo mixto. Además, este tópico permite reconocer que, el discurso de los paradigmas, los enfoques y los diseños se entrelazan; a saber, 
en unos momentos se da mención al primero, en otros casos, se entiende todo desde la perspectiva del segundo y, en otros sucesos, se perciben estos como diseño y todos lo leen desde el aspecto metodológico, el cual da luces para comprender las formas de lectura de las investigaciones. A partir de estas claridades, se realiza la descripción y análisis del tópico paradigmas y enfoques, tanto de la zona del Eje Cafetero, como de cada una de las universidades participantes.

En la Figura NRO. 15 se muestran las principales relevancias de la zona del Eje Cafetero y se identifican dieciséis categorías entre paradigmas y enfoques. En este sentido, el pico se encuentra en el paradigma cualitativo descriptivo con una recurrencia del $15.23 \%$; seguido por la montaña en lo hermenéutico con $9.5 \%$; la meseta en lo positivo empírico-analítico con $8.25 \%$; la colina compartida por lo cualitativo-comprensivo, lo constructivointerpretativo y lo interpretativo con una cifra del $7.61 \%$; lo etnográfico, descriptivo y hermenéutico reflexivo con un $6.03 \%$; la llanura, la cual se encuentra en la teoría fundada, con un 5.71 $\%$; el estudio de caso con el $4.4 \%$; y, finalmente, las opacidades las cuales se evidencian en lo cuasiexperimental, lo fenomenológico, el análisis de contenido y en lo analítico con el $1.9 \%$.

Estos resultados permiten leer que existe una fuerte tendencia por los paradigmas constructivistas, entendidos desde la perspectiva de Ramos (2015) cuando dice: «el saber del mundo real se basa en procesos de interacción social y de movilización de recursos y su interés se enmarca al cómo se producen los significados» (p. 15). Así, "Lo constructivista se [encuadra] en los enfoques cualitativos, los cuales buscan la comprensión de los fenómenos en su contexto natural» (p. 16). Pero, al ubicar un enfoque descriptivo propio del positivismo y de la investigación con enfoque cuantitativo, en palabras de Hernández Sampieri et al. (2010), se busca medir conceptos e identificar variables. Si bien como se plantea el enfoque es cualitativo y puede ser su dominancia, hay intenciones de vincular lo cuantitativo a 
buscar la validez y finalidad de las investigaciones, los cuales son utilizados en un $15.23 \%$, siendo interesante esta lectura sobre la combinación de paradigmas.

Seguido de este, se enmarca lo hermenéutico con el $9.5 \%$ y revisado desde el enfoque cualitativo con propiedad de las ciencias sociales. Según Arráez et al. (2006), es este la ciencia de la interpretación, devela sentidos y brinda captación de los mismos sobre los textos que se revisan. Situación que lleva a intuir que, si bien son importantes los ejercicios que involucran lo humano, se hace necesario revisar la literatura la cual se escribe con fines de descubrir sentidos a través de la historia.

El paradigma positivista se ve desde lo positivo empírico analítico con el $8.25 \%$, el positivismo y post-positivismo, según Ramos (2015), son aquellos que orientan la investigación cuantitativa y su objeto principal es la explicación de los fenómenos con fines de predecirlos y controlarlos. Un estudio empíricoanalítico se encarga de racionalizar, sistematizar y comprueba hipótesis por medio de la estadística para, así, determinar parámetros de las variables mediante la expresión numérica.

Lo cualitativo-comprensivo, constructivo-interpretativo y lo interpretativo contienen cada uno el $7.61 \%$; por su parte, lo etnográfico, lo descriptivo y lo hermenéutico reflexivo cuenta con un $6.03 \%$, siguen mostrando la tendencia de la zona Eje Cafetero, dadas las puestas constructivistas. Esto porque se denota en lo comprensivo las claridades sobre lo que se quiere leer, esto es, lo interpretativo como parte de los procesos inductivos (Hernández Sampieri et al., 2010), los cuales buscan explicaciones y significaciones. Así, lo etnográfico, leído desde Creswell (2009), muestra que impera la descripción e interpretación profunda de un grupo o sistema social. 
Por otro lado, y no menos importante, se encuentra la teoría fundada o fundamentada con una recurrencia $5.71 \%$. Según Ramos (2015), esta ayuda a construir una teoría sustantiva la cual ayuda a leer la subjetividad y, según Hernández Sampieri et al. (2010), esta abarca elementos narrativos y fenomenológicos. El estudio de caso, por su parte, cuenta con el $4.4 \%$. Según Martínez (2006), se considera una herramienta valiosa en la investigación dado que, a través del mismo estudio, se mide y se registra la conducta de los involucrados en el fenómeno estudiado.

Como se observa en la Figura NRO. 15, se demuestra la gran flexibilidad que tienen los investigadores de la zona del Eje Cafetero; esto, debido a que colocan en diálogo los paradigmas positivista y constructivista desde lo cualitativo-descriptivo. Pero sigue siendo fuerte el impulso de las metodologías al interior de las investigaciones desde el constructivismo.

Figura NRo. 15. Paradigmas y enfoques, zona Eje Cafetero.

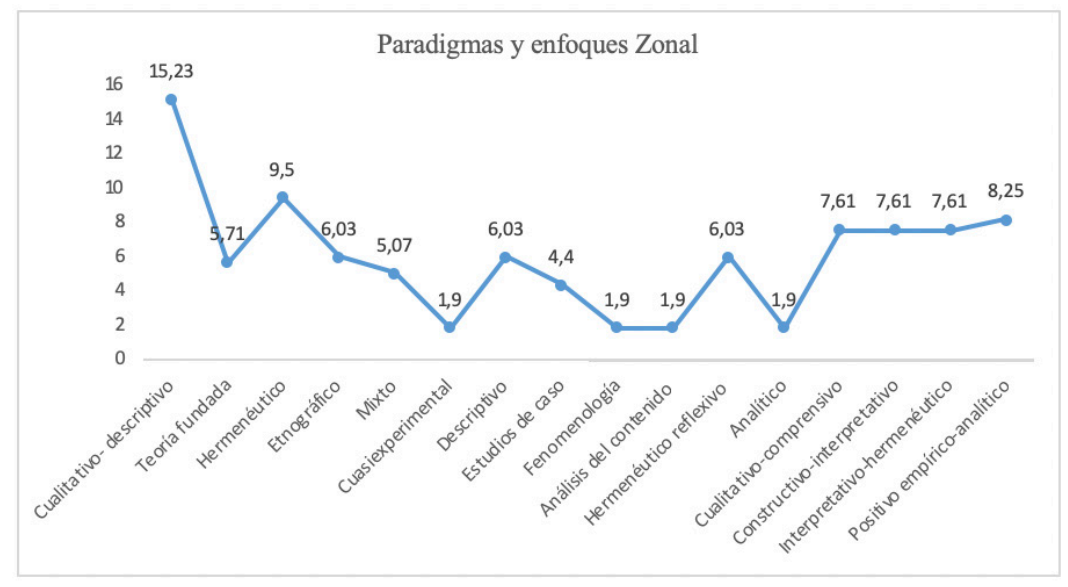

Elaboración propia.

A continuación, se presentan los resultados obtenidos por cada una de las universidades participantes, tal como se indica en la TABLA NRO. 17. 
TABLA NRO. 17. Paradigmas y enfoques por universidades.

\begin{tabular}{|c|c|c|c|c|c|c|c|c|c|c|}
\hline \multirow[t]{2}{*}{$\begin{array}{l}\text { Paradigmas y } \\
\text { enfoques }\end{array}$} & \multicolumn{2}{|c|}{$\begin{array}{l}\text { Universidad } \\
\text { de Manizales } \\
\text { y el CINDE } \\
\text { (Maestrías) }\end{array}$} & \multicolumn{2}{|c|}{$\begin{array}{l}\text { Universidad } \\
\text { de } \\
\text { Manizales y } \\
\text { el CINDE } \\
\text { (Doctorado) }\end{array}$} & \multicolumn{2}{|c|}{$\begin{array}{l}\text { Universidad } \\
\text { Tecnológica } \\
\text { de Pereira }\end{array}$} & \multicolumn{2}{|c|}{$\begin{array}{l}\text { Universidad } \\
\text { Católica de } \\
\text { Pereira }\end{array}$} & \multicolumn{2}{|c|}{ Totales } \\
\hline & $\mathrm{F}$ & $\%$ & $\mathrm{~F}$ & $\%$ & $\mathrm{~F}$ & $\%$ & F & $\%$ & $\mathbf{F}$ & $\%$ \\
\hline Cualitativo-descriptivo & 41 & 26.4 & 7 & 24.2 & & & & & 48 & 15.23 \\
\hline Teoría fundada & 18 & 11.6 & & & & & & & 18 & 5.71 \\
\hline Hermenéutico & 16 & 10.3 & 2 & 6.9 & & & 13 & 40.0 & 31 & 9.9 \\
\hline Etnográfico & 15 & 9.6 & 1 & 3.4 & & & 3 & 10.0 & 19 & 6.0 \\
\hline Mixto & 7 & 4.5 & 7 & 24.2 & 2 & 2.0 & & & 16 & 5.0 \\
\hline Cuasiexperimental & 6 & 3.9 & & & & & & & 6 & 1.9 \\
\hline $\begin{array}{l}\text { Sistematización de } \\
\text { experiencias }\end{array}$ & 5 & 3.2 & & & & & & & 5 & 1.6 \\
\hline Descriptivo & 5 & 3.2 & 1 & 3.4 & & & 3 & 10.0 & 9 & 2.8 \\
\hline Complementariedad & 5 & 3.2 & & & & & & & 5 & 1.6 \\
\hline Correlacional & 4 & 2.6 & 1 & 3.4 & & & & & 5 & 1.6 \\
\hline Estudios de caso & 4 & 2.6 & 2 & 6.9 & & & & & 6 & 1.9 \\
\hline Fenomenología & 4 & 2.6 & & & & & 6 & 20.0 & 10 & 3.2 \\
\hline Histórico-hermenéutico & 3 & 1.9 & & & & & & & 3 & 1.0 \\
\hline $\begin{array}{l}\text { Investigación acción } \\
\text { participativa }\end{array}$ & 3 & 1.9 & & & & & & & 3 & 1.0 \\
\hline Análisis del contenido & 1 & 0.64 & 1 & 3.4 & & & & & 2 & 0.6 \\
\hline Análisis del discurso & 1 & 0.64 & 1 & 3.4 & & & & & 2 & 0.6 \\
\hline Análisis documental & 1 & 0.64 & & & & & & & 1 & 0.3 \\
\hline Análisis semiótico & 1 & 0.64 & & & & & & & 1 & 0.3 \\
\hline Biográfico-narrativo & 1 & 0.64 & & & & & & & 1 & $\mathbf{0 . 3}$ \\
\hline Etnografia reflexiva & 1 & 0.64 & & & & & & & 1 & 0.3 \\
\hline Etnometodología & 1 & 0.64 & & & & & & & 1 & 0.3 \\
\hline Experimental & 1 & 0.64 & & & & & & & 1 & 0.3 \\
\hline Explicativo-descriptivo & 1 & 0.64 & & & & & & & 1 & 0.3 \\
\hline Fenomenología social & 1 & 0.64 & & & & & & & 1 & 0.3 \\
\hline $\begin{array}{l}\text { Fenomenológico- } \\
\text { hermenéutico }\end{array}$ & 1 & 0.64 & 2 & 6.9 & & & & & 3 & 1.0 \\
\hline $\begin{array}{l}\text { Hermenéutico } \\
\text { dialógico }\end{array}$ & 1 & 0.64 & & & & & & & 1 & 0.3 \\
\hline Hermenéutico reflexivo & 1 & 0.64 & & & & & & & 1 & 0.3 \\
\hline Histórico crítico & 1 & 0.64 & & & & & & & 1 & 0.3 \\
\hline Investigación acción & 1 & 0.64 & & & & & & & 1 & 0.3 \\
\hline Micro etnografía & 1 & 0.64 & & & & & & & 1 & 0.3 \\
\hline Positivista & 1 & 0.64 & & & & & & & 1 & 0.3 \\
\hline Sociocríticos & 1 & 0.64 & & & 1 & 1.0 & & & 2 & 0.6 \\
\hline $\begin{array}{l}\text { Cualitativo- } \\
\text { comprensivo }\end{array}$ & & & & & 24 & 24.0 & & & 24 & 7.6 \\
\hline $\begin{array}{l}\text { Arqueológico- } \\
\text { genealógico }\end{array}$ & & & 2 & 6.9 & & & & & 2 & 0.6 \\
\hline Analítico & & & & & & & 6 & 20.0 & 6 & 1.9 \\
\hline $\begin{array}{l}\text { Constructivo- } \\
\text { interpretativo }\end{array}$ & & & & & 24 & 24.0 & & & 24 & 7.6 \\
\hline $\begin{array}{l}\text { Interpretativo- } \\
\text { hermenéutico }\end{array}$ & & & & & 24 & 24.0 & & & 24 & 7.6 \\
\hline $\begin{array}{l}\text { Positivo empírico- } \\
\text { analítico }\end{array}$ & & & & & 25 & 25.0 & & & 25 & 7.9 \\
\hline Sin datos & 1 & 0.64 & 2 & 6.9 & & & & & 3 & 1.0 \\
\hline Totales & 155 & 100 & 29 & 100 & 100 & 100 & 31 & 100 & 315 & 100 \\
\hline
\end{tabular}

Elaboración propia. 
En el doctorado de la Universidad de Manizales y el CINDE, el pico se encuentra en lo cualitativo descriptivo y mixto con el $24.2 \%$; la montaña, la cual va en el orden de lo hermenéutico, estudio de caso, fenomenológico-hermenéutico, arqueológicogenealógico, cuenta con una cifra del 6.9\%; y una meseta la cual se devela en lo etnográfico, lo descriptivo, lo correlacional, el análisis de contenido y el análisis de discurso con el $3.4 \%$.

El CINDE y la Universidad de Manizales con sus maestrías presentan un pico en lo cualitativo descriptivo con la suma de 26.4 $\%$; la montaña se encuentra ligada a la teoría fundada con el 11.06 $\%$; la meseta se presenta entre dos tendencias, por un lado, lo hermenéutico con el $10.3 \%$ y, por otro, lo etnográfico con el $9.6 \%$; la colina se refleja en lo mixto con un $4.5 \%$; la llanura se extiende desde lo cuasiexperimental con el $3.9 \%$, la sistematización de experiencias, lo descriptivo y la complementariedad con el $3.2 \%$, seguido de lo correlacional, el estudio de caso y lo fenomenológico con el $2.6 \%$; las opacidades, por su parte, se encuentran en lo histórico hermenéutico y la investigación acción participativa con el $1.9 \%$, y el análisis del contenido, el análisis del discurso, el análisis documental, el análisis semiótico, lo biográficonarrativo, la etnografía reflexiva, la etnometodología, lo experimental, lo explicativo-descriptivo, la fenomenología social, lo fenomenológico-hermenéutico, lo hermenéutico dialógico, lo hermenéutico reflexivo, lo histórico crítico, la investigación acción, la micro etnografía, lo positivista, lo socio-crítico y lo sin datos con una cifra de tan solo el $0.64 \%$.

Según los datos en la TABla NRo. 17, se puede decir que la Universidad de Manizales, desde las maestrías, dinamiza sus procesos investigativos con paradigmas constructivistas y positivistas $y$, en los enfoques, su tendencia se inclina hacia lo cualitativo; situación compartida con el doctorado, en la cual se muestra una cohesión como universidad en los alcances investigativos desde la parte metodológica. 
En la Universidad Tecnológica de Pereira, el pico está en lo cualitativo con un gran total del $72 \%$, este porcentaje es la sumatoria de lo comprensivo, lo constructivo-interpretativo, lo interpretativo-hermenéutico; la montaña está representada con un $25 \%$; desde lo positivo empírico no se referencian mesetas y colinas; sin embargo, se presenta una llanura en lo mixto con el $2 \%$ y una opacidad en el enfoque sociocrítico con el $1 \%$. La Universidad Tecnológica de Pereira presenta su mayor realce en el paradigma constructivista desde los enfoques cualitativos en orden de lo comprensivo, lo constructivo, lo interpretativo y lo hermenéutico; para luego dar paso a lo positivista desde los enfoques cuantitativos, con lo empírico analítico. Si bien su tendencia mayor es hacia lo cualitativo, esta tiene flexibilidad en la ruta metodológica para que los estudiantes de posgrado puedan pensar en las metodologías acordes a las necesidades de los programas o a los intereses investigativos.

En la Universidad Católica de Pereira, el pico se encuentra en lo hermenéutico con un $40 \%$; la montaña se halla en la fenomenología y lo analítico con un $20 \%$; la meseta se localiza en lo etnográfico y lo descriptivo con un $10 \%$; en ella no se referencian colinas, llanuras y opacidades. Su apuesta está en los diseños hermenéuticos y su tendencia está hacia el enfoque cualitativo y el paradigma constructivista; lo cual se direcciona desde lo fenomenológico, lo analítico, lo etnográfico y lo descriptivo.

Las opacidades, las cuales suman en recurrencia el $2.15 \%$, se encuentran con mayor frecuencia en la Universidad de Manizales (y sus maestrías); con una menor frecuencia, en la Universidad Tecnológica de Pereira; y no presentes, en el doctorado, como tampoco en la Universidad Católica de Pereira. El tema sin datos solo aparece en un $0.64 \%$, lo cual indica que existe un cuidado especial en los trabajos de grado para que la información sea clara y así evitar que los lectores de los mismos se pierdan en las lecturas; un cuidado especial de los cartógrafos para plasmar la ruta de lo que concierne a paradigmas y a enfoques. 
En términos generales, se parte de la idea de que hay una condensación de percepciones al respecto lo que se comprende por paradigmas, enfoques y diseños. Al revisar el aspecto teórico, se encuentra que existe coherencia con las apuestas investigativas desde las metodologías en relación a los enfoques cuantitativos y cualitativos, y los diseños obedecen a estos postulados; es decir, aunque no se especifican, los paradigmas se ven desde los enfoques o diseños planteados en la investigación. Prevalece en la zona del Eje Cafetero, la relación de paradigmas constructivistas en consonancia con lo positivistas, se presenta una perspectiva mixta entre las dos formas tradicionales de hacer investigación, esto con dominancia cualitativa. Otra relevancia se encuentra en el paradigma constructivista desde el enfoque cualitativo con diseño hermenéutico, lo cual sigue mostrando una especial tendencia hacia el contacto con lo humano y el conjunto de relaciones las cuales se tejen alrededor de él. El trabajo de campo en este sentido involucra el contacto directo con el fenómeno, las personas y las comunidades, lo cual sigue siendo una prioridad.

\subsection{Tópico: técnicas}

En el proceso de investigación, la recolección de los datos exige rigurosidad y fidelidad, y ellos dan cuenta del hecho o fenómeno estudiado. Algunas investigaciones se basan en fuentes primarias, es decir, van a la obra de origen, mientras otras, aprovechan los datos previamente recolectados por otros investigadores $\mathrm{u}$ organismos, con el fin de dar respuesta a las preguntas formuladas en los trabajos de grado y en las tesis.

Para la recolección de los datos se emplean diferentes elementos. Por un lado, las técnicas, las cuales responden al cómo, o aspecto que implica reconocer el conjunto de reglas y procedimientos los cuales le permiten al investigador establecer la relación con el objeto o sujeto de estudio; por ejemplo, la entrevista, la encuesta, los registros y la observación. Y por otro, los instrumentos, aquellos que responden al con qué, es decir, a los 
mecanismos empleados por el investigador para recolectar, filtrar y codificar la información; por ejemplo, la entrevista estructurada, semiestructurada o abierta; el diario de campo, las pruebas de personalidad, entre otros.

Otro aspecto para tener en cuenta es la necesidad de diferenciar las formas o maneras con las cuales se realiza la recolección de la información en las investigaciones cualitativas y cuantitativas. En las cualitativas, la recolección de los datos busca proveer de un mayor entendimiento los significados y las experiencias de las personas, condición la cual hace que los instrumentos más utilizados, sean la observación y la descripción; aquellos que permiten reconocer las condiciones iniciales para luego perfeccionar y seleccionar los que posibilitan la profundización y comprensión de la situación indagada. En las investigaciones cuantitativas, en cambio, la recolección de los datos se basa en instrumentos estandarizados; es decir, los datos se obtienen por observación, medición y documentación. Además, deben ser válidos y confiables. Estas condiciones garantizan que los resultados del estudio se puedan generalizar o llevar a normas y leyes con el fin de comprobar y/o validar la teoría.

Una vez clarificado este tópico, se presentan por separado las técnicas e instrumentos. A continuación, se desarrollan las primeras: para esto se realizó el análisis desde las frecuencias (F), es decir, se tuvo en cuenta el número de veces que se repiten las técnicas en los trabajos de grado y en las tesis doctorales, ya que se pueden utilizar varias técnicas en un solo proyecto. Esto, con el fin de establecer un criterio más objetivo y así poder determinar, con mayor claridad, cómo se asumen las técnicas tanto en la zona del Eje Cafetero como en cada una de las universidades participantes. Es importante aclarar que este criterio se aplicó de igual manera para el análisis de los instrumentos. 
Figura nRo. 16. Técnicas, zona Eje Cafetero.

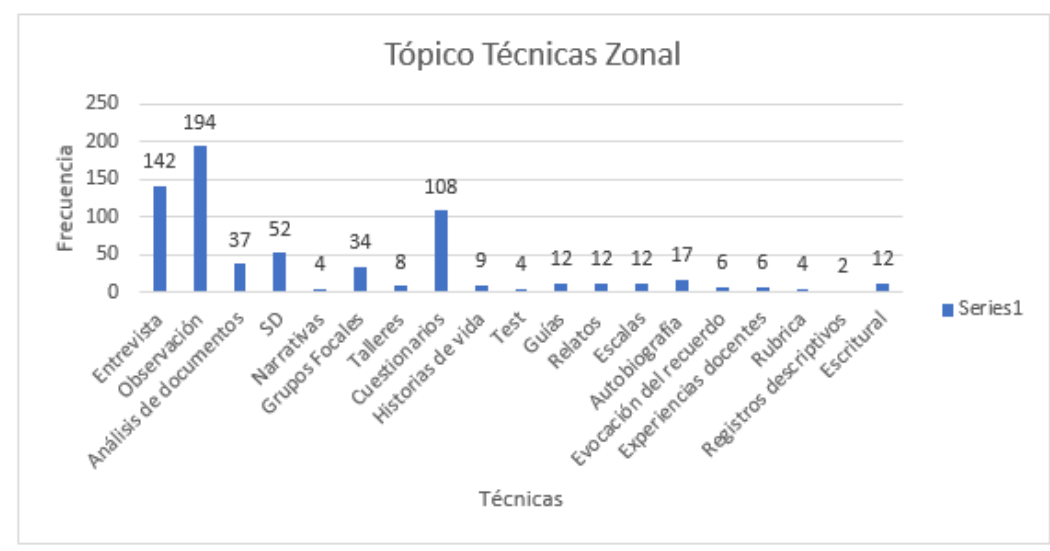

Elaboración propia.

En la zona Eje Cafetero, se evidencia una diversidad de técnicas, tal como lo muestra la Figura NRO. 16. El pico lo representan dos técnicas: la observación, con una frecuencia de 194 veces, y la entrevista con una constancia de 142; en la montaña se encuentra los cuestionarios, con una reiteración de 108 veces; le siguen algunas mesetas, donde una de ellas registra sin datos y con una frecuencia de 52, otra tal como análisis de documentos, con una frecuencia de 37 , y los grupos focales con una frecuencia de 34; En la colina se plasma la autobiografía con una frecuencia de 17; como llanura están las guías, los relatos, las escalas y lo escritural con una frecuencia de 12; y, como opacidad se reconocen las historia de vida con una frecuencia de 9, los talleres con una frecuencia de 8 , la evocación del recuerdo y las experiencias docentes con una frecuencia de 6, las narrativas, los test y las rubricas con una frecuencia de $4 \mathrm{y}$, finalmente con una frecuencia de 2 , se encuentran los registros descriptivos.

Teniendo en cuenta este relieve, se reconoce como lo más sobresaliente en el pico y la montaña aquellas técnicas como la observación, la entrevista y los cuestionarios. Por tanto, se puede 
considerar que, a través de la observación, los investigadores establecen una relación directa con el objeto de estudio, con el fin de descubrir cómo funciona, lo cual les permite conocer de primera mano la situación; además, profundizan este acercamiento cuando abordan los relatos de la situación observada, lo cual se despliega con la entrevista. Con el cuestionario, intentan precisar la información, esto al captar reacciones del informante ante las preguntas escritas. Estas características evidencian una tendencia hacia las técnicas que se emplean en la investigación de tipo cualitativo, aunque los cuestionarios son más empleados en las investigaciones cuantitativa. En general, las técnicas mencionadas revelan la intención del investigador, esto al acercarse a las fuentes de información, y por tanto, al reconocer sus comportamientos, sus acciones, sus ideas y sus opiniones, ya sea de manera directa $\mathrm{o}$ indirecta.

Sin embargo, teniendo en cuenta que los cuestionarios hacen parte de las técnicas más utilizadas, se podría inferir que estos proveen una información más precisa y objetiva, propia de las investigaciones cuantitativas donde el investigador toma distancia del fenómeno estudiado con el fin de garantizar un mayor nivel de confiabilidad y objetividad en sus interpretaciones.

De otro lado, al analizar las técnicas que configuran la meseta, la colina y la llanura, se reconoce la diversidad de procedimientos asumidos por los investigadores; sin embargo, estos presentan confusión pues bien pueden ser asumidos como instrumentos, por su especificidad y porque responden con mayor precisión a los mecanismos empleados por autores para recolectar, filtrar y codificar la información. Ejemplo de ello es el análisis documental, los grupos focales, la autobiografía, las escalas de medición, entre otros.

En este relieve, llama la atención las técnicas ubicadas como opacidades, tales como las historias de vida, la evocación del recuerdo y las experiencias de los docentes. Esto, en cuanto que 
permiten recoger información, la cual enriquece la comprensión de la situación o grupo estudiado y, por tanto, potencian las investigaciones cualitativas, las cuales son más relevantes en la zona del Eje Cafetero.

Queda abierta la posibilidad para seguir la profundización en cada una de las técnicas - tanto en su concepción como en su diferenciación con los instrumentos-, sin desconocer que cada decisión pasa por los intereses y el conocimiento de quien asesora $\mathrm{y}$ de quien investiga.

TABLA NRO. 18. Técnicas por universidades.

\begin{tabular}{|c|c|c|c|c|c|}
\hline Técnicas & $\begin{array}{l}\text { Universidad de } \\
\text { Manizzles y el CINDE } \\
\text { (Maestrías) }\end{array}$ & $\begin{array}{l}\text { Universidad de } \\
\text { Manizales y el } \\
\text { CINDE (Doctorado) }\end{array}$ & $\begin{array}{l}\text { Universidad } \\
\text { Tecnológica de } \\
\text { Pereira }\end{array}$ & $\begin{array}{l}\text { Universidad } \\
\text { Católica de } \\
\text { Pereira }\end{array}$ & Totales \\
\hline & $\mathbf{F}$ & & $\mathbf{F}$ & $\mathbf{F}$ & $\mathbf{F}$ \\
\hline Entrevista & 93 & 20 & 29 & & 142 \\
\hline Observación & 108 & 11 & 63 & 12 & 194 \\
\hline Análisis de documentos & 15 & 10 & 12 & & 37 \\
\hline Sin datos & 49 & 3 & & & 52 \\
\hline Narrativas & 2 & 2 & & & 4 \\
\hline Grupos focales & 28 & & 6 & & 34 \\
\hline Talleres & 8 & & & & 8 \\
\hline Cuestionarios & 63 & & 45 & & 108 \\
\hline Historias de vida & 7 & & 2 & & 9 \\
\hline Test & 4 & & & & 4 \\
\hline $\begin{array}{l}\text { Encuestas, } \\
\text { Guias, }\end{array}$ & 12 & & 10 & 2 & 24 \\
\hline $\begin{array}{l}\text { Relatos, } \\
\text { Escalas }\end{array}$ & & & & & 12 \\
\hline Pruebas, & 2 & & & & \\
\hline $\begin{array}{l}\text { Diario de campo, } \\
\text { Didactobiografia }\end{array}$ & $\begin{array}{l}2 \\
2\end{array}$ & & & & 2 \\
\hline Autobiografia & 15 & & 2 & & 17 \\
\hline Evocación del recuerdo & 3 & & 3 & & 6 \\
\hline Experiencias docentes & 3 & & & 3 & 6 \\
\hline Rúbrica & 2 & & 2 & & 4 \\
\hline Registros descriptivos & 2 & & & 2 & 2 \\
\hline $\begin{array}{l}\text { Autobiografia sociológica, autoinforme, } \\
\text { carta asociativa, cuadernos y registro de } \\
\text { evidencia, diálogo de saberes, experiencias } \\
\text { significativa, foro, fotografia, imagen } \\
\text { narrativa, interpretación de imágenes, } \\
\text { investigación en archivos y bibliotecas, } \\
\text { lectura crítica de materiales y bibliografias, } \\
\text { matriz de análisis, planeación docente, } \\
\text { preguntas base, revisión documental, } \\
\text { situación matemática, tablas de frecuencias } \\
\text { y porcentajes para variables cualitativas o } \\
\text { categóricas, y trabajo de campo }\end{array}$ & $1 \mathrm{c} / \mathrm{u}$ & & & & $1 \mathrm{c} / \mathrm{u}$ \\
\hline $\begin{array}{l}\text { Imágenes, técnica documental, relatos de } \\
\text { vida, relatos autobiográficos, protocolos de } \\
\text { pensamiento en voz alta, mapeo de } \\
\text { instituciones educativas, papas de redes, } \\
\text { grupos de discusión, foto lenguaje, estudio } \\
\text { colectivo de casos, encuesta, documentos, } \\
\text { diario de campo, diálogos generativos, } \\
\text { complementación de frases, y archivo } \\
\text { documental. }\end{array}$ & $1 \mathrm{c} / \mathrm{u}$ & & & & $1 \mathrm{c} / \mathrm{u}$ \\
\hline Escritural & & & & 12 & 12 \\
\hline
\end{tabular}

Elaboración propia 
Ahora, analizando las técnicas empleadas en cada una de las universidades, se puede reconocer la diversidad y variedad, tal como se muestra en la TABLA NRO. 18 cuyo relieve se describe a continuación.

En las Maestrías de la Universidad de Manizales y el CINDE, el pico está en la observación con una frecuencia de 108 y en la entrevista con una frecuencia de 93; como montaña, se encuentran los cuestionarios con 63 recurrencias; como meseta, existen los registros sin datos con una frecuencia de 49 y los grupos focales con 28 .

En el Doctorado -de la misma universidad, la entrevista representa el pico con una frecuencia de 20; la montaña corresponde a la observación con una frecuencia de 11; como meseta, está el análisis documental con una frecuencia de 10; en la colina, el registro sin datos se evidencia con una frecuencia de 3; y finalmente, como llanura están las narrativas con una frecuencia de 2 .

Por su parte, en la Universidad Tecnológica de Pereira, el pico se encuentra en la observación y el cuestionario, con frecuencia de 63 y 45, respectivamente; la montaña la representa la entrevista con una frecuencia de 29; la meseta corresponde al análisis documental con una frecuencia de 12; en la colina, se encuentran la encuesta, las guías, los relatos y las escalas con una frecuencia de 10; y como opacidades, están la evocación del recuerdo, las historias de vida y las rúbricas con una frecuencia de 3 y 2 correspondientemente.

En la Universidad Católica de Pereira, el pico se encuentra en la observación y lo escritural con una frecuencia de 12 cada una; la montaña corresponde a las experiencias de los docentes con una frecuencia de 3 y la meseta con las encuestas, guías, relatos, escalas y registros descriptivos con una frecuencia de 2 . 
Al realizar un análisis con los picos más altos en cada una de las instituciones educativas, se evidencia que, en el doctorado, la técnica más usada es la entrevista y le sigue la observación - presente en las tres universidades-. En el doctorado se emplea esta técnica, pero con menor frecuencia lo cual indica que el investigador establece una relación directa con el objeto o fenómeno de estudio; esto, con el fin de obtener información directamente de la fuente, y así recuperar su sentir y significado frente al fenómeno estudiado.

En la UTP y en la UCP, además de la observación, se emplean técnicas como el cuestionario, lo escritural y la experiencia docente. Estas indican que la forma como se decide la recolección de datos en una investigación oscila entre el paradigma cualitativo y el cuantitativo. Así, las técnicas mencionadas dan cuenta de lo subjetivo, es decir, de todo aquello que sucede con los sujetos investigados. De este modo, la observación permite conocer detalladamente el objeto de estudio y lo escritural; y recoge la experiencia docente donde este plasma su pensar, su sentir y su actuar. El cuestionario busca cuantificar los datos para poder hacer análisis más objetivos y, de esta forma, validar los hechos o las teorías.

Otro dato que amerita atención en los procesos investigativos es el registro sin dato (SD). Aquel corresponde a la meseta presente en los trabajos de grado y las tesis de la Universidad de Manizales y el CINDE; situación que debe ser superada, ante todo, por el nivel de exigencia y rigurosidad, el cual se presenta en los procesos de formación avanzada como las maestrías y los doctorados, donde se espera no presentar estas situaciones.

\subsection{Tópico: instrumentos}

Los instrumentos responden al con qué, es decir, a los mecanismos empleados por el investigador para recolectar, filtrar y codificar la información. En la recolección de datos es 
importante diferenciar los instrumentos según la intencionalidad del investigador, la cual guiará el estudio hacia un enfoque cuantitativo o cualitativo. Teniendo estas claridades, se presenta a continuación el análisis del tópico instrumentos en la zona del Eje Cafetero.

En términos generales, tal como se evidencia en la Figura NRO. 17, se presentan múltiples alternativas en el empleo de instrumentos. En este sentido, se crea un paisaje con gran diversidad de formas, donde confluye y se confunden las colinas con las llanuras, y se crea una opacidad por la variedad de aspectos los cuales alberga.

Figura NRo. 17. Instrumentos, zona Eje Cafetero.

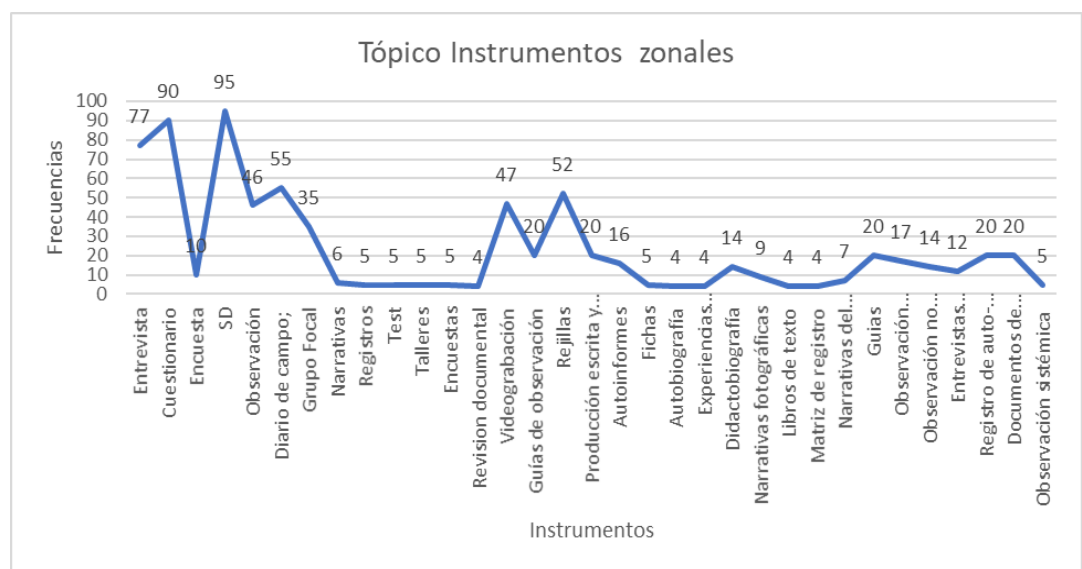

Elaboración propia

Así, se reconocen tres grandes picos donde el más sobresaliente es el de los registros sin datos con una frecuencia de noventa y cinco; le siguen los cuestionarios con una frecuencia de 90; y, finalmente, se encuentran las entrevistas, con una frecuencia de setenta y siete. 
Las montañas están representadas por los diarios de campo con una frecuencia de cincuenta y cinco; y las rejillas con una frecuencia de cincuenta y dos; como meseta se ubican las vídeo grabaciones con una frecuencia de cuarenta y siete, la observación con una frecuencia de cuarenta y seis y el grupo focal con una frecuencia de treinta y cinco.

La colina se expresa con variedad de instrumentos, se presentan en este caso de mayor a menor frecuencia y entre paréntesis se coloca su valor - esto en aras de facilitar la comprensión del relieve-. En primera instancia, están las guías de observación, producción escrita, dibujos, registro de auto observación y documentos de experiencias pedagógicas (veinte cada una); le siguen las guías - preguntas de trabajo y preguntas del relato-, y la observación participante (diecisiete cada una); luego están los auto informes (con dieciséis), la didactobiografia (con catorce) y la entrevista semiestructurada (con doce).

La llanura, la cual parece ser la continuación de la colina, está conformada por la encuesta con una frecuencia de diez; las narrativas fotográficas con frecuencia nueve; las narrativas auto biográficas; con frecuencia de siete; y la observación sistemática, el análisis documental, los libros, textos, fichas autobiográficas, experiencias pedagógicas, registro de talleres y los test, con una oscilación de la frecuencia entre cinco y cuatro.

En las opacidades - las cuales por su variedad y concentración no se representan en la gráfica-, se encuentran las pruebas, los diarios de campo, los foros, la planeación docente, la investigación de archivos, las imágenes, el complemento de frases, los diálogos generativos, los protocolos de pensamiento en voz alta, los mapas, entre otros. Todos ellos presentan una frecuencia de 3 a 1.

Este paisaje nos muestra un relieve muy diverso, al punto que se entremezclan $y$ en ocasiones se confunden unos con otros instrumentos de investigación. Sin embargo, es importante 
resaltar cómo el pico más alto está conformado por los registros $\mathrm{SD}$, lo cual evidencia una la necesidad de establecer criterios más rigurosos y cuidadosos en las asesorías de los proyectos y en la elaboración del informe final.

Otros picos para destacar son el cuestionario y la entrevista. Aunque, con cada uno de ellos se recolecta información de manera distinta, se evidencia que se le da mayor uso a las respuestas que los sujetos dan por escrito y a preguntas también escritas. Esto hace que las respuestas sean concretas y limiten la expresión de quien responde; sin embargo, con la entrevista, se supera dicha limitante, pues esta permite abordar los relatos, los sentires y percepciones de los sujetos desde su experiencia, condición que enriquece los datos recolectados.

En la montaña se encuentra el diario de campo y la rejilla. Esta situación evidencia que los investigadores optan por registrar y sistematizar hechos educativos y/o sociales los cuales son susceptibles de ser interpretados. Aun cuando no queda claro, quién registra y para qué se registra la información. Respecto a la rejilla, la información es muy difusa ya que puede adaptarse a diversas áreas de aplicación tal como la evaluación individual, la grupal, la familiar y la de pareja. No obstante, por ocupar un lugar significativo en este relieve, se deduce que hay un interés por parte de los investigadores en captar la forma en la cual una persona, en sus propios términos, da sentido a su experiencia.

De otro lado, la meseta, la colina y las opacidades presentan tanta variedad que ameritan un análisis más minucioso. Esto debido a que incluyen instrumentos los cuales son derivados y hasta sinónimos de algunos de ellos, como es el caso de la observación, la cual se presenta - con diferentes frecuencias-, como auto observación, guías de observación, observación participante, observación sistemática, entre otras formas; lo cual dificulta su ubicación, y lleva a que, en otras ocasiones, se confundan con las técnicas como la entrevista, la observación y las narrativas. 
Esta variedad indica que los investigadores emplean múltiples y diversas herramientas para recolectar la información, esto en aras de explorar nuevas posibilidades las cuales permitan recuperar la voz de los sujetos investigados.

Luego de hacer el recorrido por todo el relieve, se presenta el análisis de los instrumentos en cada una de las universidades. En términos generales, la Universidad de Manizales y el CINDE, y la Universidad Tecnológica de Pereira emplean instrumentos como la entrevista y el cuestionario; la Universidad Católica de Pereira usa instrumentos diferentes como la autoobservación y la experiencia pedagógica; instrumentos presentados como picos. A continuación, se detalla el realce de cada una, tal como se muestra en la TABLA NRO. 19.

TABLA NRO. 19. Instrumentos por universidad.

\begin{tabular}{|c|c|c|c|c|c|}
\hline Instrumentos & $\begin{array}{l}\text { Universidad } \\
\text { de } \\
\text { Manizales y } \\
\text { el CINDE } \\
\text { (Maestrías) }\end{array}$ & $\begin{array}{l}\text { Universidad } \\
\text { de } \\
\text { Manizales y } \\
\text { el CINDE } \\
\text { (Doctorado) }\end{array}$ & $\begin{array}{l}\text { Universidad } \\
\text { Tecnológica } \\
\text { de Pereira }\end{array}$ & $\begin{array}{l}\text { Universidad } \\
\text { Católica } \\
\text { de Pereira }\end{array}$ & Totales \\
\hline & $\mathbf{F}$ & $\mathbf{F}$ & $\mathbf{F}$ & $\mathbf{F}$ & $\mathbf{F}$ \\
\hline Entrevista & 65 & 12 & & & 77 \\
\hline Cuestionario & 50 & 6 & 34 & & 90 \\
\hline Encuesta & 5 & 5 & & & 10 \\
\hline Sin datos & 83 & 4 & & 8 & 95 \\
\hline Observación & 43 & 3 & & & 46 \\
\hline Diario de campo, & 32 & 2 & 21 & & 55 \\
\hline Grupo focal & & 3 & & & 35 \\
\hline Narrativas & 6 & & & & 6 \\
\hline $\begin{array}{l}\text { Registros, test, talleres y } \\
\text { encuestas }\end{array}$ & 5 & & & & 5 \\
\hline $\begin{array}{l}\text { Expresiones, diálogos, } \\
\text { expresiones y relatos }\end{array}$ & 3 & & & & 3 \\
\hline Análisis de experiencias, & 3 & & & & 3 \\
\hline $\begin{array}{l}\text { Conversatorio } \\
\text { Revisión documental }\end{array}$ & 3 & & 1 & & 4 \\
\hline Videograbación & 24 & & 23 & & 47 \\
\hline Guías de observación & 20 & & & & 20 \\
\hline Rejillas & 26 & & 26 & & 52 \\
\hline Producción escrita y dibujos & 10 & & 10 & & 20 \\
\hline Autoinformes & 8 & & 8 & & 16 \\
\hline $\begin{array}{l}\text { Fichas, autobiografias y } \\
\text { experiencias pedagógicas }\end{array}$ & 4 & & & & 4 \\
\hline Didactobiografia & 4 & & & 10 & 14 \\
\hline Narrativas fotográficas & 4 & & & 5 & 9 \\
\hline $\begin{array}{l}\text { Libros de texto y matriz de } \\
\text { registro }\end{array}$ & 2 & & 2 & & 4 \\
\hline
\end{tabular}




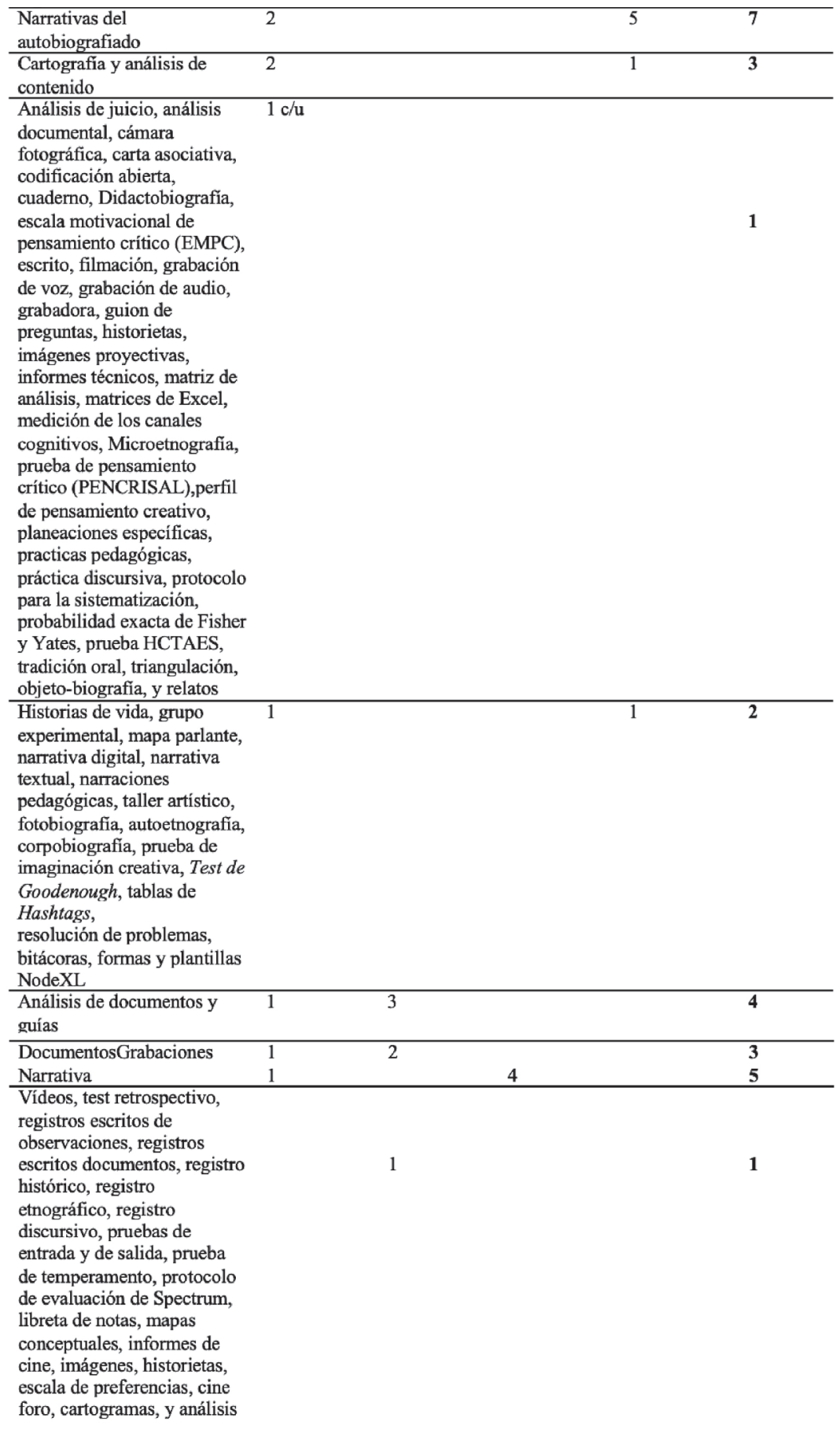




\begin{tabular}{lll} 
de contenido curricular & & 17 \\
\hline $\begin{array}{l}\text { Guías de autoinformes, de } \\
\text { observación, de preguntas, } \\
\text { de trabajo, del relato, entre } \\
\text { otros }\end{array}$ & & $\mathbf{1 7}$ \\
\hline Observación participante & 17 & $\mathbf{1 7}$ \\
\hline Observación no participante & 14 & $\mathbf{1 4}$ \\
\hline $\begin{array}{l}\text { Entrevistas } \\
\text { semiestructuradas }\end{array}$ & 12 & $\mathbf{1 2}$ \\
\hline Registro fotográfico & 2 & $\mathbf{2}$ \\
\hline Entrevistas a profundidad & 2 & $\mathbf{3}$ \\
\hline $\begin{array}{l}\text { Test, audios, actividades, y } \\
\text { organizadores de texto }\end{array}$ & 1 & $\mathbf{1}$ \\
\hline Registro de autobservación & & $\mathbf{2 0}$ \\
\hline $\begin{array}{l}\text { Documentos de experiencias } \\
\text { pedagógicas }\end{array}$ & & $\mathbf{2 0}$ \\
\hline $\begin{array}{l}\text { Relatos autobiográficos } \\
\text { Observación sistémica }\end{array}$ & & $\mathbf{2 0}$ \\
\hline
\end{tabular}

Elaboración propia.

La Universidad de Manizales y el CINDE presentan un pico en tres instrumentos: el primero, es el registro sin datos con una frecuencia de ochenta y tres; lo cual ratifica lo planteado anteriormente en cuanto a la necesidad de establecer criterios más rigurosos en las asesorías y elaboración de informes de los proyectos de investigación y las tesis doctorales; le sigue la entrevista con una frecuencia de sesenta y cinco; y el cuestionario, con una frecuencia de cincuenta.

En la montaña se encuentran la observación con una frecuencia de cuarenta y tres, y el diario de campo con frecuencia treinta y dos. En la meseta, están las rejillas con frecuencia de veintiséis, las videograbaciones con frecuencia de veinticuatro y las guías de observación con frecuencia de veinte. En la colina se encuentran instrumentos tales como la producción escrita y los dibujos con una frecuencia de diez, y los autoinformes con una frecuencia de ocho. La llanura se mezcla con las opacidades, por esto se hace complejo reconocer una de otra donde se encuentran los demás instrumentos como los libros de texto, la matriz de registro, las narrativas autobiográficas, la cartografía y el análisis de contenido, entre otros, estos con una frecuencia de dos y uno. 
En el doctorado de dicha universidad, el pico lo conforma la entrevista con una frecuencia de doce, la montaña la representa el cuestionario con una frecuencia seis y, la encuesta, con frecuencia cinco; la meseta la conforman los registros sin dato con una frecuencia de cuatro; la colina, constituida por la observación y el diario de campo, con una frecuencia de tres y dos respectivamente; y finalmente, la llanura se convierte en una opacidad, formada por instrumentos como vídeos, test, registros (escritos, históricos, etnográficos, discursivos), rejillas, mapas conceptuales y análisis de películas entre otros, esto con una frecuencia de uno.

En la Universidad Tecnológica de Pereira, el relieve se presenta de la siguiente manera: el pico lo conforma el cuestionario con una frecuencia de treinta y cuatro; la montaña está representada por la rejilla con una frecuencia de veintiséis, la videograbación con frecuencia veintitrés y el diario de campo con frecuencia veintiuno; en la meseta se encuentran las guías (de relatos, de informes, de preguntas y de observaciones) y la observación participante, con una frecuencia de diecisiete, y la observación no participante con una frecuencia de catorce; en la colina se evidencian la entrevista semiestructurada con una frecuencia de doce y la producción de escritura y dibujos con una frecuencia de diez; en la llanura estarían los autoinformes, con una frecuencia de ocho; y, como opacidad, se hallan las narrativas con una frecuencia de cuatro, los registros fotográficos, los libros de texto y las matrices con una frecuencia de dos, y las pruebas de imaginación, los test y las bitácoras con una frecuencia de uno.

En la Universidad Católica de Pereira, el pico se encuentra en el registro de auto-observación y los documentos de experiencias pedagógicas con una frecuencia de veinte. La montaña está conformada por la didactobiografia con una frecuencia de diez $y$ el registro sin dato con una frecuencia de ocho. La meseta está constituida por la narración fotográfica, la autobiografía y la observación sistemática con frecuencia de cinco cada una. Y, como opacidad, se identifican instrumentos como la cartografía, el análisis de contenido y las historietas con una frecuencia de uno. 
Teniendo en cuenta las recurrencias más altas (picos), presentes en las universidades, se reconoce que la entrevista y el cuestionario ocupan un lugar significativo en este relieve, en especial en la Universidad de Manizales y el CINDE, y la Universidad Tecnológica de Pereira; lo cual indica que los instrumentos empleados para la recolección de la información posibilitan un encuentro directo con los sujetos participantes en el estudio.

Sin embargo, no se logra reconocer el tipo de entrevista y cuestionario usados, lo cual lleva a inferir que, por descuido o falta de claridad, no se diferencian las técnicas de los instrumentos y se asumen como sinónimos. Aunque, la UTP registra la entrevista semiestructurada, la cual aparece como colina con una recurrencia de doce. En la Universidad Católica de Pereira, el pico está en la auto-observación y en las experiencias pedagógicas; instrumentos con los cuales se permite recolectar información, a partir de las vivencias y las percepciones de los sujetos en sus experiencias como docentes.

En este gran relieve, se reconoce en la montaña y en la UM, instrumentos como la observación y los diarios de campo; las rejillas y vídeo grabaciones en la UTP y las didactobiografías en la UCP. Con este tópico se reafirma la tendencia de establecer una relación directa con los sujetos de estudio y se ratifica la tendencia en los paradigmas cualitativos.

La diversidad de instrumentos presentes en la meseta, la colina y la llanura - tales como las rejillas, las videograbaciones, la producción escrita, los dibujos, el diario de campo, las guías, entre otras-, evidencian la recursividad de los investigadores y los asesores en cuanto emplean múltiples instrumentos para la recolección de la información - y aunque no especifican el uso de cada una de ellas-, y dan cuenta del interés de ellos al momento de recoger los datos, los cuales les permitan conocer más en detalle y con mayor profundidad lo sucedido con los actores y los distintos 
escenarios donde se investiga. Además, ratifica la preferencia por los paradigmas cualitativos cuya intencionalidad se encuentra en la comprensión de fenómeno estudiado.

La UTP y la UCP registran una serie de instrumentos (narrativas, registro fotográfico, libros, textos, matrices, percepción de imagen, test, bitácoras, cartografía, análisis de contenido e historietas), los cuales se ubican como opacidades y ratifican lo mencionado en párrafos anteriores respecto a la creatividad sobre la diversidad de instrumentos que se usan, la tendencia por el encuentro directo con los sujetos y/u objetos de estudio y el interés por lo subjetivo lo cual implica la posibilidad de recuperar y dar sentido a la voz de los que son investigados, además de llenar de sentidos los escenarios donde se teje la vida de cada uno de los actores del proceso investigativo.

\subsection{Tópico: autores}

El tópico autores da cuenta de los referentes teóricos los cuales sustentan metodológicamente las investigaciones analizadas. Es un tránsito por lugares insospechados, por senderos en medio de montañas de información y de autores por los cuales se camina en conjunto con los asesores y directores; aquellos que orientan y guían, ya sea a través de los clásicos de la investigación o a través de nuevas fronteras las cuales permiten la creación de nuevos caminos y finalmente llevan a comprender como se analizan los datos recolectados.

Es importante resaltar que, en la actualidad, hay tantos investigadores como formas de investigar. En este sentido, se podría decir que no existe un camino único y ya transitado el cual permita que un mapa sea definitivo y/o estático; más bien cada topografía y su planteamiento permite llegar a un lugar en común con sus pliegues de picos y llanuras discursivas con el fin de generar nuevo conocimiento científico a medida que se recorren lugares profundos y por descubrir. 
Los autores mencionados en una investigación, específicamente en el apartado de la metodología, ayudan a los investigadores a abrir senderos nuevos, sentidos distintos en cuanto a la visión de nuevas rutas las cuales encaminen la posibilidad de visibilizar un fenómeno y novedades en lo cual se quiere indagar. A continuación, se presenta el tópico de autores el cual acompañan los trabajos de grado y las tesis de las universidades de la zona del Eje Cafetero participantes de esta apuesta investigativa.

En total aparecen ciento veintinueve autores citados y un porcentaje significativo sin datos; asunto sobre lo cual se pueden tener varias miradas: la primera, una preocupación por dejar fuera del discurso metodológico a los autores que soportan dichas propuestas, situación que, más allá de contener dilemas éticos, es dejar un vacío por falta de soporte de los autores, es decir, plantear sus ideas y no evidenciar su autoría; la segunda, una mirada desde aquellos investigadores los cuales han encontrado luz en medio de la penumbra, permite dar cuenta de las formas en las cuales muchas veces se escribe una tesis doctoral o un trabajo de maestría, donde se rompen los esquemas clásicos establecidos y se resalta una escritura en clave poética; narrativas las cuales sensibilizan los aportes investigativos e incluyen, de múltiples maneras, a los coinvestigadores en los procesos de escritura.

En la Figura NRO. 18, se muestran los autores más referenciados en las tesis y trabajos de grado en la zona del Eje Cafetero. Se presentan los dieciséis autores con mayor porcentaje, entre ellos el de mayor relevancia es Hernández et al. con un 81.8 \%, seguido Creswell con el $29.2 \%$, Stake con el $21.3 \%$, Yin con el $21 \%$, Taylor y Bogdan con el $17.7 \%$, Corbin y Strauss con el $17.5 \%$, y Martínez con el $15.8 \%$. Otras citaciones la comparten autores como Imbernon con el 11.0 \%; Coll, Ericsson y Simón, Gardner, Geertz, Hernández, y Tamayo con el 10.3 \%; Flick con el $9.3 \%$; Deslauriers con el $8.82 \%$; Van Dijk, Gadamer, Foucault, y Pérez con el 8.80 \%; Bisquerra con el 7 \%. Y otros en porcentajes menores como Sandoval, Freire, Alvarado y Ospina, 
Guber, Elliot, Serres, entre otros autores referenciados (ver totales en la TABla Nro. 20). Estos autores dan cuenta de los énfasis ontológicos, epistemológicos y metodológicos expresados por los investigadores tanto en los objetivos y enfoques asumidos, como en los diseños, las técnicas e instrumentos, los cuales reflejan las apuestas cualitativas, comprensivas, interpretativas y criticas transformadoras, como las cuantitativas positivistas y mixtas.

Figura NRo. 18. Autores, zona Eje Cafetero.

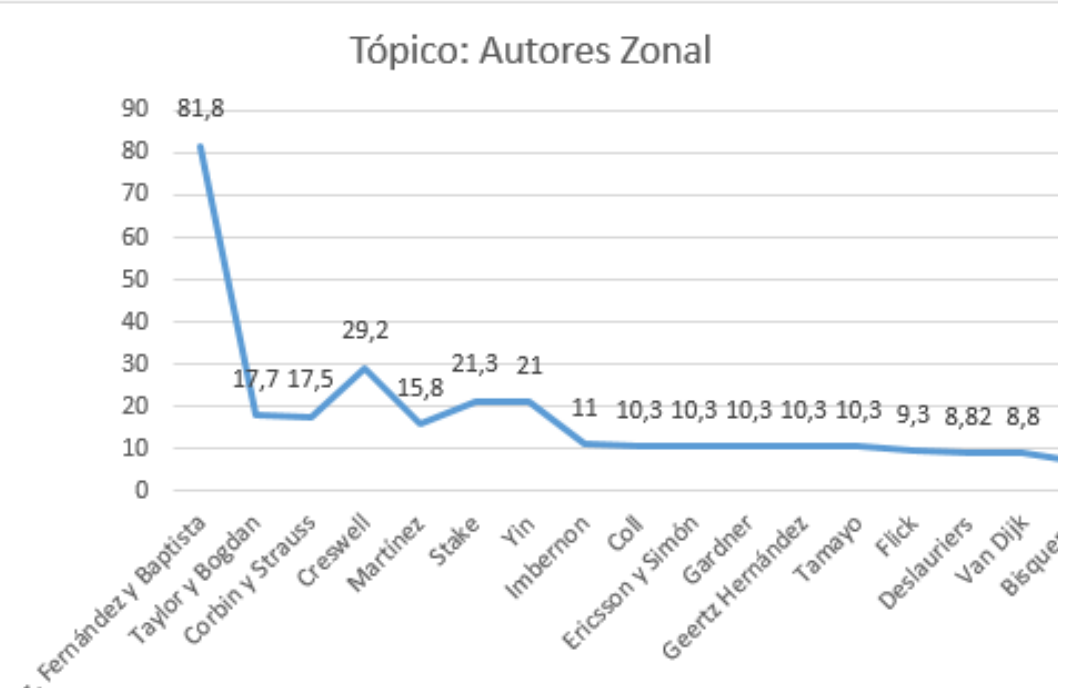

Elaboración propia.

La cantidad y diversidad de autores devela las capacidades que tienen los estudiantes de posgrado de utilizar en sus investigaciones diferentes perspectivas y posturas metodológicas, las cuales, a su vez, dan cuenta de la diversidad de caminos que pueden ser recorridos y que, indiscutiblemente, conducen al encuentro de nuevas formas de comprender y explicar la educación y la pedagogía en la zona del Eje Cafetero.

Cabe resaltar el pico presentado particularmente para las maestrias por Hernández Sampieri et al. con un $81.8 \%$. Esto quizás 
sea porque su texto de referencia explica de manera detallada el proceso de la investigación y aporta elementos procedimentales para investigadores nóveles, los cuales permiten no solo aprender a investigar, sino, además, marcar una tendencia en el enfoque que este nivel académico tiende a enseñar, guiar, mostrar y aplicar en sus diferentes formas de investigar y de abordar los contextos.

La segunda elevación zonal está representada con Creswell y sus planteamientos metodológicos, particularmente a la hora de dar claridad a los estudiantes de posgrado en el nivel de doctorado. Esto sobre las posibles formas de investigar, ya que ha aportado a los métodos mixtos de investigación en ciencias sociales, aportes significativos y la comprensión de las diversas formas de investigar sobre la educación y la pedagogía. Es por tanto que se convierte en un referente a la hora de plantear una investigación.

Otro número de elevaciones, las cuales se pueden denominar menores, muestran aspectos específicos en la metodología. Entre ellas están los autores Corbin y Strauss los cuales desarrollan la teoría fundamentada o, Stake y Yin, quienes brindan los diseños del estudio de caso, y Martínez en los diseños etnográficos. El resto de los autores con porcentajes bajos demuestran la cantidad de caminos los cuales pueden ser transitados en enfoques, diseños, técnicas e instrumentos y que siguen siendo importantes a la hora de plantear opciones metodológicas.

Dando continuidad al trabajo cartográfico sobre los autores en la metodología, se hace una mirada general de este por universidades como se observa en la TABLA NRO. 20. 
TABLA NRO. 20. Autores por universidades.

\begin{tabular}{|c|c|c|c|c|c|}
\hline Autores & $\begin{array}{l}\text { Universidad } \\
\text { de Manizales } \\
\text { y el CINDE } \\
\text { (Maestrías) }\end{array}$ & $\begin{array}{l}\text { Universidad } \\
\text { de Manizales } \\
\text { y el CINDE } \\
\text { (Doctorado) }\end{array}$ & $\begin{array}{l}\text { Universidad } \\
\text { Tecnológica } \\
\text { de Pereira }\end{array}$ & $\begin{array}{l}\text { Universidad } \\
\text { Católica de } \\
\text { Pereira }\end{array}$ & Totales \\
\hline & $\%$ & $\%$ & $\%$ & $\%$ & $\%$ \\
\hline Sin datos (SD) & 72.4 & 27.6 & & & 100 \\
\hline Hernández et al. & 14.8 & & 27.0 & 40.0 & 81.8 \\
\hline Taylor y Bogdan & 7.7 & & 8.0 & 2.0 & 17.7 \\
\hline Freire & 5.8 & & & & 5.8 \\
\hline Guber & 3.9 & & & 0.82 & 4.72 \\
\hline Corbin y Strauss & 3.2 & 10.3 & 4.0 & & 17.5 \\
\hline Sandoval & 3.2 & & 2.0 & 0.82 & 6.2 \\
\hline $\begin{array}{l}\text { Bertaux, González, } \\
\text { Martínez, Murcia y } \\
\text { Jaramillo, Restrepo }\end{array}$ & 2.6 & & & & 2.6 \\
\hline $\begin{array}{l}\text { Bajtín, Fernández, } \\
\text { Rodríguez, Skliar, } \\
\text { Van Dijk, } \\
\text { Gadamer, } \\
\text { Foucault, } \\
\text { Pérez }\end{array}$ & $1.9 \mathrm{c} / \mathrm{u}$ & $\begin{array}{l}6.9 \\
6.9 \\
6.9 \\
6.9\end{array}$ & & & $\begin{array}{l}1.9 \\
8.8 \\
8.8 \\
8.8 \\
8.8\end{array}$ \\
\hline $\begin{array}{l}\text { Agreda, Alvarez, } \\
\text { Aristizábal, Bolívar, } \\
\text { Domínguez y } \\
\text { Fernández, Castro, } \\
\text { Cornejo, Mendoza y } \\
\text { Rojas, Cruz, Cordero, } \\
\text { Cháriez, Coll, Pérez, } \\
\text { Cornejo, Denzin, }\end{array}$ & $1.3 \mathrm{c} / \mathrm{u}$ & & & & 1.3 \\
\hline $\begin{array}{l}\text { Decroly, Dewey; } \\
\text { Ferrarotti, Gimeno, } \\
\text { Guarín, Hernández, } \\
\text { Leal, Madriz, } \\
\text { Manosalva, Morín, } \\
\text { Robles, Rivas, Serna, } \\
\text { Vallés, Zabala, } \\
\text { Ricoeur, } \\
\text { Cerda, } \\
\text { Flick }\end{array}$ & & & $\begin{array}{l}2.0 \\
8.0\end{array}$ & 0.82 & $\begin{array}{l}3.3 \\
2.13 \\
9.3\end{array}$ \\
\hline Creswell & & 17.2 & 2.0 & 10.0 & 29.2 \\
\hline Martínez & & 13.8 & 2.0 & & 15.8 \\
\hline $\begin{array}{l}\text { Coll, Ericsson y } \\
\text { Simón, Gardner, } \\
\text { Geertz, Hernández, } \\
\text { Tamayo, } \\
\text { Stake }\end{array}$ & & $10.3 \mathrm{c} / \mathrm{u}$ & 11.0 & & $\begin{array}{l}10.3 \\
21.3\end{array}$ \\
\hline $\begin{array}{l}\text { Alvarado y Ospina, } \\
\text { Ángel y Herrera, } \\
\text { Bauman, Díaz, } \\
\text { Galeano, González, } \\
\text { Herrera, Hine, } \\
\text { Hutchins, Jiménez, } \\
\text { Maturana, Morse, } \\
\text { Moreno, Parra, Ríos, } \\
\text { Serres, Tesch, } \\
\text { Vasilachis, } \\
\text { Yin }\end{array}$ & & $6.9 \mathrm{c} / \mathrm{u}$ & $\begin{array}{l}2.0 \\
21.0\end{array}$ & & $\begin{array}{l}2.0 \\
21.0\end{array}$ \\
\hline Imbernon & & & 11.0 & & 11.0 \\
\hline Deslauriers & & & 8.0 & 0.82 & 8.82 \\
\hline Bisquerra & & & 7.0 & & 7.0 \\
\hline
\end{tabular}




\begin{tabular}{lll}
\hline Elliot & 5.0 & $\mathbf{5 . 0}$ \\
\hline Goez, Bonilla y & 4.0 & $\mathbf{4 . 0}$ \\
Rodríguez, Hueso y & & $\mathbf{3 . 0}$ \\
Cascant & 3.0 & \\
\hline Torres, Coll y & & $\mathbf{2 . 0}$ \\
Monereo, Mardones, \\
Briones & 2.0 & \\
\hline Denzin y Lincoln, & & \\
Carry y Kemis, & & \\
Carcamo, Dankhe, \\
Sandín, Latorre, \\
Rodríguez \\
\hline Quintar, Giacomo, \\
Rodríguez Gómez, Gil \\
Flores, García \\
Jiménez, Romero \\
Sánchez, Connelly y \\
Clandinni, Sánchez, \\
Cisterna, Troncoso, \\
Daniele, Fontas, \\
Concalves, Vitale, \\
Viglietta, Cabrera, \\
Artigue, Aguirre \\
García, Jaramillo, \\
Echeverri, Luna, \\
Merleau, Bolivar, \\
Bertaux, Sanz \\
Hernández, Rodriguez, \\
Gil y García, Villalta, \\
y Martinic, Reyes, \\
Monje, Valles, \\
Bresson, De Miguel; \\
Álvarez \\
\hline
\end{tabular}

Elaboración propia.

En las maestrías de la Universidad de Manizales y el CINDE el pico está en los sin datos con el $72.4 \%$. Esto no permite su ascenso a la cumbre con el fin de responder a los interrogantes sobre el por qué se han perdido los autores transitados en el sendero de la opción metodológica, lo cual se presenta como una revisión para las maestrías en el acompañamiento a estos ejercicios investigativos.

Como montaña aparece Hernández Sampieri et al. con el $14.8 \%$, estos poseen varias ediciones del libro Metodología de la Investigación (2014), lo cual hace que se tomen como autores de mayor referencia en la medida que - en muchos casos-, sirven como punto de partida para las guías que acompañan el trasegar investigativo en medio de la incertidumbre que suscita empezar este camino. 
En menor elevación se encuentran autores dedicados a investigar la educación y la pedagogía como Paulo Freire. Ellos, desde sus posturas particulares, han aportado en gran medida a la comunidad académica del mundo sobre dichos temas, y han mostrado una gran relevancia a la hora de realizar análisis de la información sistematizada.

Existe una tendencia en las maestrías de la UM-C por la búsqueda de información la cual permita aprender a investigar. Para esto se citan y se utilizan diferentes autores - tanto clásicos de las metodologías como pedagogos-, educadores y experiencias exitosas de otros investigadores. Lo anterior da cuenta de la importancia de las maestrías para que los estudiantes de posgrado revisen tantos autores como les sirva, y de esta manera, encuentren el sendero que los conduzca al encuentro de las respuestas particulares a las cuales quieren llegar.

En el doctorado de la misma institución, el pico lo presenta la opción sin datos con el $27.6 \%$. Así, vuelve y aparece el aspecto -el cual se deja para la reflexión-, sobre si se presenta de manera intencional y como formas de escritura, o como descuidos en el trasegar investigativo, lo cual vale la pena revisar.

En montañas de diferentes tamaños aparecen autores como Creswell y sus planteamientos metodológicos sobre los métodos mixtos de investigación en las ciencias sociales con el $17.2 \%$; Martínez, investigador español el cual ha aportado significativamente a la comprensión, a dar luz en la investigación cualitativa y etnográfica en educación con el $13.8 \%$; otros como Coll, Ericsson y Simón, Gardner, Geertz, Hernández, Stake, Strauss y Corbin, y Tamayo con el 10.3 \% cada uno; y, Alvarado y Ospina, Ángel y Herrera, Bauman, Díaz, Foucault, Gadamer, Galeano, González, Herrera, Hine, Hutchins, Jiménez, Maturana, Morse, Moreno, Parra, Pérez, Ríos, Serres, Tesch, Van Dijk, Vasilachis y Yin con el $6.9 \%$. Al mostrar la variedad del paisaje de autores tanto nacionales como extranjeros-, se muestra que aquellos no 
se ciñen a las formas tradicionales de investigación y metodologías clásicamente empleadas en los diferentes niveles académicos, sino que marcan tendencias en las cuales el doctorado hace partícipes a los coinvestigadores - en sus contextos-, a través de sus relatos, sus historias de vida, sus narrativas y las expresiones de lo que se desean investigar.

Para la UTP, el relieve de autores se observa entre el pico representado en el $27.2 \%$ con Hernández Sampieri et al. y las llanuras de $2.0 \%$ figuradas por autores como Denzin y Lincoln, Carry y Kemis, Carcamo, Dankhe, Sandín, Latorre, y Rodríguez. Con una presencia de aproximadamente veintinueve autores en el total de las cien investigaciones analizadas, lo que demuestra es una concentración de los investigadores, sus asesores y maestría en unos autores que preferiblemente han dado las orientaciones metodológicas para los estudios de tipo cualitativo. En este sentido, vuelve y aparece Hernández Sampieri et al., por lo que se asume la explicación planteada anteriormente respecto a un autor, el cual puede ser punto de partida para la formación investigativa en las maestrías. Las montañas del relieve con Yin en el $21 \%$ y con Stake en el $11 \%$ dan luces para los diseños de los estudios de caso aplicados muy frecuentemente en las investigaciones realizadas, en aquellos los grupos escolares de las instituciones educativas de convierten en el caso. Se inicia el descenso a la llanura, esto lo comparten autores como Taylor y Bogdan, Robles, Rivas, Serna, Vallés, Zabala, Ricoeur, y Cerda y Flick en un $8 \%$; Bisquerra en un $7 \%$; Elliot en un $5 \%$; Corbin y Strauss en un $4.0 \%$; y Torres, Coll y Monereo, Mardones, y Briones con el $3 \%$. Allí, en el caminar investigativo, se evidencia una influencia de autores exógenos.

En la UCP, el pico de autores se repite con Hernández Sampieri et al. en el $40 \%$. Solo aparece una pequeña montaña con Creswell en un $10 \%$, y una extensa llanura la cual inicia en un porcentaje de $2.0 \%$ con Taylor y Bogdan; y continúa extendiéndose con porcentajes de $0.82 \%$ cada uno, representados por Quintar (2015), Di Giacomo (1987), Cerda (1991), Rodríguez 
(1999), Sandoval (2002), Rodríguez (1996), Romero (2015), Connelly y Clandinni (1995), Sánchez (2013), Cisterna (2005), Troncoso y Daniele (2013), Fontas et al. (s.f.), Bal (1990), Cabrera (2005), Artigue (1995), Guber (2001), Aguirre y Jaramillo (2012), y Luna (2004). Esta gran variedad de autores orienta diferentes miradas metodológicas. Así, por ejemplo, para el abordaje de la fenomenología de la percepción se cita a Merleau (1993), y para el método biográfico se referencia a Bolívar et al. (2001), seguido en esta temática por Bertaux (1999) y Sanz (2005).

En el análisis básico de datos cualitativos se propone a Rodríguez (1996); en los modelos de interacción didáctica se sugiere a Villalta y Martinic (2009); para la investigación cualitativa desde las guías prácticas se referencia a Deslauriers (2005), Reyes (1999), Taylor y Bogdan (1990), y Monje Álvarez (2011); para las entrevistas cualitativas Valles (2014) y para la investigación biográfico-narrativa en educación, De Miguel (2013).

El reporte metodológico da cuenta del diseño que se piensa para cada uno de los trabajos de grado, aquellos que en su mayoría pertenecen a la investigación cualitativa y los cuales hacen saber sobre la pedagogía y, a su vez, guardan coherencia con los paradigmas y alcances de los objetivos para ayudar a su cumplimiento desde los distintos enfoques a los cuales dieron lugar.

La gran variedad de autores en lo metodológico muestra la posibilidad que tiene el estudiante de maestría de moverse en distintas escuelas de pensamiento y, por ende, de lograr los objetivos trazados. Esta experiencia muestra por un lado, la tendencia que tiene la maestría en Pedagogía y Desarrollo Humano por los ejercicios influyentes en el ámbito escolar, y por otro, cómo los abordajes cualitativos son relevantes para dar cuenta de los fenómenos que ocurren en este espacio y que merecen ser colocados en evidencia para ser reconocidos o repensados, y 
para evidenciar también la profundidad de ellos; esto al explicar y describir detalladamente sus alcances o desafíos, dejándolos como retos para las instituciones o para los mismos maestros.

Se enuncia la importancia, en la zona del Eje Cafetero, de fundamentar la marcha en las metodologías. Esto desde los planteamientos hechos por Hernández Sampieri et al., los cuales ofrecen rutas pedagógicas claras y ejemplificadas las cuales ayudan al investigador a entender su proyecto, y por ende, a lograr caminos posibles para llegar a su meta con el rigor que debiera tener su intervención.

En un segundo aspecto, Creswell sigue como uno de los mayores referentes en las metodologías al interior de las tesis y los trabajos de grado donde logra ser orientador de procesos, de horizontes y de posibilidades para llegar a los objetivos planteados. Este autor de la década de los noventa se preocupa por mostrar las bondades de los enfoques cualitativos - sin desconocer la fortaleza que tiene una perspectiva cuantitativa al igual que la investigación mixta-, convirtiéndose en una experiencia digna de contrastar con lo que enuncia Hernández et al. - con un discurso más próximo a la época-, sobre la lectura de las investigaciones las cuales forman parte de este estudio. Quizás los años de la publicación de las rutas investigativas de estos autores son los que ayudan a situarlos en primer y segundo lugar en la zona del Eje Cafetero.

En un tercer lugar, se encuentran Stake y Yin, quienes presentan una ruta investigativa desde los estudios de caso; apuesta alternativa la cual es posible si se mira desde un enfoque cualitativo. Estos retos, los cuales comparten en la zona un valor relevante, siguen mostrando la tendencia y la preocupación por develar lo que le acontece al ser humano, situación que está al interior de las propuestas y del interés investigativo de cada universidad, donde se miran comportamientos, reacciones, sentimientos, dinamismo desde sus preocupaciones o movilizaciones individuales y sociales. 
En términos prácticos, Hernández et al., Creswell, Stake y Yin son la muestra clara de un paradigma investigativo propio de la zona del Eje Cafetero. Exponen una línea clara de trabajo, una ruta donde los planteamientos - leídos desde estos autores-, dinamizan lo cualitativo, lo cuantitativo y lo mixto; y donde el estudio de caso, como una manera de hacer investigación, se convierte en el sello propio de la UM-C, la UTP y la UCP.

La referencia a estos autores - con cifras tan altas en las tesis y los trabajos de grado-, indica la claridad de sus explicaciones para ser situadas en marchas de topógrafos, y en aras de su contribución en la resolución de problemáticas en el ámbito educativo y social. No se desconoce con esta propuesta, que existen otros autores referenciados; sin embargo, es este grupo el más relevante, aquel que, con sus perspectivas, brinda elementos para leer las distintas problemáticas de la zona - con sus diversos matices-, y aportan a la solución de las mismas.

\subsection{Cierres}

La ruta de investigación propuesta por la zona del Eje Cafetero, desde el doctorado y maestrías, se preocupa por problematizar sobre los fenómenos los cuales atañen el ámbito escolar, y presenta su prioridad en la apuesta por lo humano, donde el sujeto y el objeto de estudio se tienen en cuenta con el fin de darle sentido a lo que se investiga. Esta condición se convierte en un reto al direccionar los posgrados en sus distintos grupos de investigación, ya que da lectura a las indagaciones con sus proyectos, lo cual busca ayudar en la resolución de una situación la cual merece ser revisada desde las tesis doctorales o los trabajos de grado.

La diversidad empleada en las apuestas investigativas desde los objetivos, las metodologías, los paradigmas y enfoques, los instrumentos y los autores, denota el espíritu de libertad el cual debiera acompañar los procesos. Este fenómeno puede ser benéfico en la medida de la variedad de rutas a seguir con el propósito final, 
lo cual resulta con la entrega de la tesis o los trabajos de grado; y puede ser negativo porque no se demarca una línea de trabajo o autores, los cuales respalden la propuesta de manera fuerte. La distinción de estas particularidades debe estar al interior de cada posgrado, es decir, sobre las conveniencias de la utilización de dichos caminos los cuales conllevan a la investigación.

Se observa una coherencia y coincidencia investigativa en las tres universidades, sobre todo en el alcance de los objetivos y los autores. Esto al aclarar que, en la zona del Eje Cafetero, aunque son universidades distintas, hay una unión en lo investigativo a través de los intereses, lo cual deja una consigna la cual indica lo siguiente: lo importante es la lectura de lo educativo para la comprensión de lo humano.

Como apertura y gran preocupación se enuncia el vacío existente (SD) en las tesis y los trabajos de grado de la Universidad de Manizales y el CINDE - tanto en el doctorado como de las maestrías-, y en los autores los cuales respaldan las apuestas investigativas. Esta situación impide descubrir algunas rutas y deja una relevancia muy fuerte, sobre los estilos escriturales los cuales deben incluir la subjetivad para la comprensión, o un descuido de los investigadores para incluirlos como ruta pedagógica y comprensión de los textos.

Esta subjetividad o descuido por parte de los estudiantes de posgrado igual genera confusión en las técnicas e instrumentos; se entremezclan los conceptos, tanto en su conceptualización como en el uso, siendo difícil reconocer las diferencias y similitudes entre uno y otro.

Es así que conceptos como la entrevista, la encuesta, el cuestionario, el diario de campo y la observación, entre otros, tienen cabida tanto en las investigaciones cuantitativas como cualitativas y se ubican unas veces como técnica y otras como instrumento dentro del mismo o diferente documento; situación 
la cual genera confusión a la hora de realizar el análisis. De allí la importancia de poder profundizar y aclarar cada uno de los conceptos, esto con el fin de lograr mayor claridad y comprensión frente a su significado y uso dentro del proceso investigativo.

\section{Referencias bibliográficas}

Aguirre, J. y Jaramillo, G. (2012). Aportes del método fenomenológico a la Investigación Educativa. Revista latinoamericana de Estudios Educativos. 8(2), 51-74. https:// www.redalyc.org/pdf/1341/134129257004.pdf.

Artigue, M. (1995). Ingeniería didáctica. En: Artigue, M.; Douady R. y Moreno, L. Ingeniería didáctica en educación matemática. Un esquema para la investigación y la innovación en la enseñanza y el aprendizaje de las matemáticas (ed. P. Gómez). (pp. 33-60). Grupo Editorial Iberoamérica, una empresa docente.

Arráez, M.; Calles, J. y Moreno de Tovar, L. (2006). La Hermenéutica: una actividad interpretativa. Sapiens. Revista Universitaria de Investigación, 7(2), 171-181. https://www. redalyc.org/pdf/410/41070212.pdf.

BAL, M. (1990). Teoría de la Narrativa (Una Introducción a la Narratología). Ediciones Catedra. http:// dspace.universia.net/bitstream/2024/1271/1/ Bal+Mieke+Teoria+De+La+Narrativa.pdf.

Bertaux, D. (marzo 1999). El enfoque autobiográfico: su validez metodológica, sus potencialidades. Proposiciones, 29(69), $1-21$.

Bolívar, A., Domingo, J. y Fernández, M. (2001). La investigación biográfico- narrativa en Educación. La Muralla. 
CABrera, C. (2005). Categorización y triangulación como procesos de validación del conocimiento en investigación cualitativa. Revista Theoria, 14(1), 61-71.

Cerda, H. (1991). Los elementos de la investigación. El Búho.

Cisterna, F. (2005). Categorización y triangulación como procesos de validación del conocimiento en investigación cualitativa. Revista Theoria, 14(1), 61-71.

Connelly, M. y Clandinni, J. (1995). Relatos de experiencia e investigación. Narrativa Laertes.

Creswell, J. (2009). Mapeo del campo de la investigación de métodos mixtos. Revista de Investigación de Métodos Mixtos, 3(2): 95-108.

Deslauriers, P. (2005). Investigación Cualitativa. Guía Práctica. $2^{\text {a }}$ Edición. Papiro.

De Miguel, L. (2013). La investigación artística a través de la investigación basada en las artes: narrando una historia, compartiendo experiencias. Revista Sonda: Investigación y Docencia en Artes y Letras, (2), 61-84.

Di Giacomo, J. (1987) Teorías y métodos de análisis de las representaciones sociales. En: D. Páez Róvira. Pensamiento, individuo y sociedad: cognición y representación social (pp. 278-295). Editorial Fundamentos.

Guber, R. (2001). La etnografía. Método, campo y reflexividad. Norma. 
Fontas, C., Concalves, F., Vitale, M. \& Viglietta, D. (s.f.). La técnica de los grupos focales en el marco de la investigación socio cualitativa. http://www.fhumyar.unr.edu.ar/escuelas/3/ materiales $\% 20 \mathrm{de} \% 20$ catedras/trabajo $\% 20 \mathrm{de} \% 20$ campo/ profesoras.htm.

Hernández Sampieri. R.; Fernández Collado, C. y Baptista Lucio, M. P. (2010). Metodología de la investigación (5. a ed.). McGraw-Hill Interamericana.

(2014). Metodología de la investigación (6. ${ }^{\mathrm{a}}$ ed.). McGraw-Hill Interamericana.

LunA, F. (2004). investigación cualitativa descriptiva. Ediciones Aljibe.

Martínez, P (2006). El método de estudio de caso: estrategia metodológica de la investigación científica. Pensamiento \& Gestión, (20),165-193. https://www.redalyc.org/ pdf/646/64602005.pdf.

Merleau, M. (1993). Fenomenología de la percepción. Planeta de Agostini S. A.

Monje Álvarez, C. A. (2011). Metodología de la investigación cuantitativa y cualitativa. Guía didáctica. Universidad Surcolombiana.

QuintaR, B. E. (2015, 28 de febrero). Referentes epistemológicos para la investigación de Ciencias humanas y sociales. [Seminario. Maestría en Pedagogía y Desarrollo Humano]. Universidad Católica de Pereira.

Ramos, C. (2015). Los paradigmas de la investigación científica. Av. psicol, 23(1), 9-17. https://www.researchgate.net/ publication/282731622. 
Reyes, T. (1999). Métodos cualitativos de investigación: Los grupos focales y el estudio de caso. In Forum empresarial 4(2), 75-87.

Romero, M. (2015). Investigación en educación artística: narrativas, realidades y ficciones. (A. A. Visuales, Editor). http://ocs.editorial.upv.es/index.php/ANIAV/ANIAV2015/ paper/viewFile/1262/646.

Rodríguez, G. (1996). Metodología de la investigación cualitativa. Editorial Aljibe. Archidona.

Sandoval, A. (2002), "Investigación cualitativa". Programa de especialización en teoría, métodos y técnicas de investigación social. Instituto Colombiano para el fomento de la educación superior.

SÁnchez, J. (2013). Paradigma de investigación educativa: de las leyes subyacentes a la modernidad reflexiva. Entelequía: revista interdisciplinar, (16), 91-102. https:// www.researchgate.net/publication/257842598_Paradigmas de_Investigacion_Educativa_Paradigms_on_Educational_ Research.

SANZ, A. (2005). El método biográfico en la investigación social: potencialidades y limitaciones de las fuentes orales y los documentos personales. Asclepios, LVII, 99-115.

TAYlor, S. \& Bodgan, R (1990) Introducción a los métodos cualitativos de investigación. Paidós. 
Troncoso, C., y Daniele, E. (2013). Las entrevistas semiestructuradas como instrumentos de recolección de datos: una aplicación en el campo de las ciencias naturales. Anuario Digital de Investigación Educativa, (14), 543-555 http://www.uccor.edu.ar/paginas/REDUC/troncoso.3.pdf.

Valles, S. M. (2014). Cuadernos Metodológicos. Entrevistas cualitativas. CIS-Centro de Investigaciones Sociológicas.

Villalta Páucar, M. y Martinic Valencia, S. (2009). Modelos de estudio de la interacción didáctica en la sala de clase. Investigación y Postgrado, 24(2), 6176. $\quad$ http://www.scielo.org.ve/scielo.php?script=sci arttext \& pid=S 131600872009000200004 \& lng=es\&nrm=iso $>$. ISSN 1316-0087. 



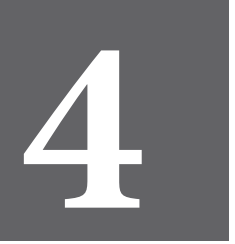

CAPÍTULO

CUATRO 



\title{
Aproximación conceptual: regiones, educación y pedagogía en el Eje Cafetero
}

\author{
Martha Lucía Garzón $n^{10}$ \\ Claudia Liliana Sánchez Sánchez ${ }^{11}$ \\ Juan David Lalinde Sánchez $z^{12}$
}

El presente capítulo expone la aproximación conceptual sobre las regiones de educación y pedagogía, las cuales emergen de trecientos quince trabajos de grado de maestría y tesis de doctorado pertenecientes a los programas de posgrado de tres universidades de la zona del Eje Cafetero: Universidad Tecnológica de Pereira (Maestría en Educación), Universidad Católica de Pereira (Maestría en Pedagogía y Desarrollo Humano) y Universidad de Manizales y el Centro de Estudios Avanzados en Niñez y Juventud (CINDE) (Maestría en Educación desde la Diversidad, Maestría en Educación y Desarrollo Humano y Doctorado en Ciencias Sociales, Niñez y Juventud).

10 Maestría en Educación de la Universidad Tecnológica de Pereira. malucia@utp.edu.co

11 Maestría en Educación y Desarrollo Humano de la Universidad de Manizales y el Centro de Estudios Avanzados en Niñez y Juventud. lilosan24@gmail.com

12 Maestría en Educación y Desarrollo Humano de la Universidad de Manizales y el Centro de Estudios Avanzados en Niñez y Juventud. juanlalynde@gmail.com 
En la TABla NRO. 21 se presenta el número y porcentaje de trabajos de grado de maestría y tesis de doctorado analizadas por cada universidad:

TABLA NRO. 21. Número y porcentaje de trabajos de grado de maestría y tesis de doctorado por universidad.

\begin{tabular}{lllll}
\hline Datos & $\begin{array}{l}\text { Universidad } \\
\text { Tecnológica de } \\
\text { Pereira }\end{array}$ & $\begin{array}{l}\text { Universidad } \\
\text { Católica de } \\
\text { Pereira }\end{array}$ & $\begin{array}{l}\text { Universidad de } \\
\text { Manizales y el } \\
\text { CINDE }\end{array}$ & $\begin{array}{l}\text { Total Eje } \\
\text { Cafetero }\end{array}$ \\
\hline Nro. de tesis & 100 & 31 & 184 & 315 \\
\hline$\%$ de tesis & 31.74 & 9.84 & 58.41 & 100 \\
\hline
\end{tabular}

Elaboración propia.

Como se puede observar en la tabla, la Universidad de Manizales y el Centro de Estudios Avanzados en Niñez y Juventud (UM-C) aportó el $58.41 \%$ de los trabajos de grado de maestría y tesis de doctorado analizadas, la Universidad Tecnológica de Pereira (UTP) aportó el 31.74 \% y la Universidad Católica de Pereira (UPC) el $9.84 \%$ restante. Es de anotar que la UM-C presenta un mayor número de investigaciones ya que se integran al análisis dos maestrías y un doctorado, mientras que para la UTP y la UCP se incluyen trabajos de una sola maestría.

Para efectos del presente análisis se desarrolla un consolidado que da cuenta de los resultados cuantitativos y cualitativos de los programas de posgrado de la zona del Eje Cafetero. Es importante señalar que, para una adecuada lectura y comprensión de las conclusiones obtenidas, se utilizan las metáforas concertadas para el proyecto, las cuales asumen un escenario de conversación entre las instituciones y actores.

Este capítulo se desarrolla en tres apartados: análisis por universidades de la zona del Eje Cafetero, análisis de los reportes conceptuales por universidades y las conclusiones que se derivan de los resultados encontrados. 


\subsection{Análisis de las regiones, educación y pedagogía en la zona del Eje Cafetero}

Para el análisis presentado a continuación, no se toma en consideración el número de trabajos de grado de maestría y tesis de doctorado, sino la frecuencia (f) de presentación de los tópicos globales, los cuales emergen de ambas regiones. En el presente capítulo corresponden a un total de 479 f; y respecto a ello, se observa que, en las investigaciones del Eje Cafetero la teorización ha estado dirigida hacia la región pedagogía con un total de $311 \mathrm{f}$ $(65.76 \%)$, mientras la menor prevalencia se evidencia en la región educación, con tan solo $168 \mathrm{f}$ correspondientes al $34.24 \%$ del total. Es de anotar, que en dicha zona se ha estado construyendo una tradición conceptual, principalmente con acercamientos teóricos ligados a la pedagogía; sin embargo, la conceptualización de educación se encuentra articulada a los contextos formales de enseñanza y aprendizaje. Para el cálculo de las frecuencias fueron tenidas en cuenta el número de repeticiones o recurrencias de los datos (tópicos) en cada una de las regiones. En el siguiente apartado, se desarrolla dicho reporte conceptual.

\subsubsection{Región pedagogía}

En la TABLA NRO. 22 se presentan los tópicos globales de la región pedagogía en relación con las frecuencias (f) y los porcentajes (\%) encontrados en el Eje Cafetero. 
TABLA NRO. 22. Región pedagogía por tópicos globales en las universidades del Eje Cafetero.

\begin{tabular}{|c|c|c|c|c|c|c|c|c|}
\hline \multirow[t]{2}{*}{ Tópicos globales } & \multicolumn{2}{|c|}{$\begin{array}{l}\text { Universidad } \\
\text { Tecnológica de } \\
\text { Pereira } \\
\end{array}$} & \multicolumn{2}{|c|}{$\begin{array}{l}\text { Universidad } \\
\text { Católica de } \\
\text { Pereira } \\
\end{array}$} & \multicolumn{2}{|c|}{$\begin{array}{l}\text { Universidad de } \\
\text { Manizales y el } \\
\text { CINDE }\end{array}$} & \multicolumn{2}{|c|}{$\begin{array}{l}\text { Total Eje } \\
\text { Cafetero }\end{array}$} \\
\hline & $\mathbf{F}$ & $\%$ & $\mathbf{F}$ & $\%$ & $\mathbf{F}$ & $\%$ & $\mathbf{F}$ & $\%$ \\
\hline Didáctica/enseñanza & 89 & 28.62 & 5 & 1.61 & 12 & 3.86 & 106 & 34.08 \\
\hline Práctica pedagógica & 28 & 9.00 & 4 & 1.29 & 35 & 11.25 & 67 & 21.54 \\
\hline Enfoque pedagógico & 25 & 8.04 & 2 & 0.64 & 7 & 2.25 & 34 & 10.93 \\
\hline Aprendizaje & 23 & 7.40 & 0 & 0 & 9 & 2.89 & 32 & 10.29 \\
\hline $\begin{array}{l}\text { Uso pedagógico de las } \\
\text { TIC }\end{array}$ & 13 & 4.18 & 3 & 0.96 & 2 & 0.64 & 18 & 5.79 \\
\hline Maestro & 9 & 2.89 & 2 & 0.64 & 8 & 2.57 & 19 & 6.11 \\
\hline Concepciones & 8 & 2.57 & 0 & 0 & 1 & 0.32 & 9 & 2.89 \\
\hline Competencias & 1 & 0.32 & 1 & 0.32 & 0 & 0 & 2 & 0.64 \\
\hline Autobiografía & 0 & 0 & 7 & 2.25 & 0 & 0 & 7 & 2.25 \\
\hline Estrategias & 0 & 0 & 4 & 1.29 & 1 & 0.32 & 5 & 1.61 \\
\hline Procesos & 0 & 0 & 1 & 0.32 & 1 & 0.32 & 2 & 0.64 \\
\hline Cognición & 0 & 0 & 0 & 0 & 9 & 2.89 & 9 & 2.89 \\
\hline Estudiantes & 0 & 0 & 0 & 0 & 1 & 0.32 & 1 & $\mathbf{0 . 3 2}$ \\
\hline $\begin{array}{l}\text { Total de recurrencias } \\
\text { y porcentajes }\end{array}$ & 196 & 63.02 & 29 & 9.33 & 86 & 27.65 & 311 & 100 \\
\hline
\end{tabular}

Elaboración propia.

Tal como se observa en la tabla, para la región pedagogía, emerge un total de trece tópicos globales con una frecuencia de trecientos once datos, de los cuales la UTP reporta el $63.02 \%$, la UM-C el $27.65 \%$ y la UCP el $9.33 \%$. Sobre la investigación de la región en la zona se abordan cuestiones que hacen referencia en primer lugar a los tópicos globales (conceptos) de los trabajos de grado de maestría y tesis de doctorado con mayor frecuencia (más de $30 \mathrm{f}$ ), en segundo lugar, a los tópicos los cuales emergen con mediana frecuencia (entre 5 y $29 \mathrm{f}$ ) y, por último, los de baja frecuencia en su presentación (menores de $5 \mathrm{f}$ ).

La primera mirada ha estado puesta en los tópicos conceptuales los cuales emergen como pico en relación con la didáctica/enseñanza (106 f correspondientes al 34.08\%), y una montaña que se erige para comprender la práctica pedagógica (67 f las cuales se traducen en un $21.54 \%$ ). Así mismo emergen como mesetas los tópicos de enfoque pedagógico (34 $\mathrm{f}$ equivalentes a un $10.93 \%$ ) y el aprendizaje ( $32 \mathrm{f}$ las cuales se ajustan a un 10.29 $\%)$. Este asunto da cuenta que las investigaciones han centrado 
su interés en la conceptualización de aquellos elementos que nuclearizan las intervenciones didácticas para la construcción de aprendizajes alrededor de un saber.

De manera particular, en las investigaciones que teorizan sobre didáctica (106f), se incluyen áreas concretas como: lenguaje, ciencias sociales, ciencias naturales y, con menor prevalencia, áreas como las matemáticas, la tecnología y las artes - las dos últimas como un interés particular de la UCP-. Las didácticas de los saberes específicos se definen desde variados enfoques y diversos autores, entre los cuales pueden enunciarse a Chevallard (1985; 1991), Brousseau (1986), Camps (2003a), Litwin (2008), Tamayo (2009), Coll (1990; 2001), Comenio (1998), Villada (2014), León (1997) y Cassany (1990). Se resalta además que en los trabajos de la UM-C, se asume el enfoque la didáctica no parametral (Quintar, 2002).

Respecto a las investigaciones que conceptualizan la práctica pedagógica $(67 \mathrm{f})$, son diferentes las maneras en que esta se nombra y se define, es decir, se puede encontrar como práctica pedagógica, práctica docente, práctica educativa y práctica reflexiva. Ellas, si bien podrían estar relacionadas con espacios educativos formales, informales y no formales, todas se asumen en el contexto escolar regular. Algunas de las perspectivas a las cuales se acude para entenderla se concretan desde aportes teóricos como los de Zabala (2007), Carr y Kemmis (1998), Perrenoud (2007), Schön (2002) y Rodríguez (2013).

En relación con lo anterior, la práctica pedagógica se fundamenta en construcciones teóricas sobre la pedagogía, en tanto, son estas las que guían el quehacer de los maestros, su acción y su gestión en los espacios áulicos para la formación de aquellos seres humanos que demanda la sociedad. Por su parte, la práctica docente destaca el valor subjetivo del maestro y su quehacer en el orden humano, ético, político y profesional. La práctica educativa se relaciona con el compromiso del maestro para la 
formación de sujetos sociales que participen democráticamente en la trasformación social y cultural del entorno; y finalmente, la práctica reflexiva hace alusión a una elección del docente, la cual le permite realizar autoanálisis de la acción y sobre la acción, para así tomar decisiones sobre sus prácticas de enseñanza.

Ahora bien, el concepto de enfoque pedagógico, el cual emerge en todas las universidades con $34 \mathrm{f}$, representa un mayor interés para la UTP con trabajos que buscan comprender el proceso de enseñanza y aprendizaje; esto con sumo énfasis desde una perspectiva socioconstructivista, inspirada en las ideas y planteamientos de Vygotsky (1979). A esta situación la siguen la UM-C y la UCP, universidades que, desde una lectura de la pedagogía crítico social y emancipadora (Freire, 1970), reconocen a la escuela como un espacio democrático para pensar escenarios de conocimiento y transformación social.

En cuanto al abordaje teórico del tópico aprendizaje (32 f) es necesario resaltar que, este se presenta como una relevancia que no permea la conceptualización en todas las instituciones que componen la zona. Ahora, las formas en las cuales se le define son un tanto símiles en las investigaciones desarrolladas; dado que se asumen con mayor recurrencia a partir de una perspectiva constructivista desde la cual se comprende como un proceso constructivo de carácter interpersonal, social y cultural; el cual está gobernado tanto por factores cognitivos como por factores situacionales y contextuales (Colomina et al., 2004). Además, desde este tópico se abordan diversas nociones que se inscriben en el marco de las didácticas específicas ya mencionadas, algunas de las cuales se relacionan con el aprendizaje significativo (Ausubel, 1983), experiencial y por indagación (Dewey, 1975) y, aprendizaje colaborativo y basado en problemas desde la perspectiva de autores como Vygotsky (1979), Rogoff (1993) y Mercer (1997).

En relación con los tópicos de mediana relevancia en orden de frecuencia, emergen conceptos como maestro (19 f, $6.11 \%$ ), 
uso pedagógico de las TIC ( $18 \mathrm{f}, 5.79 \%$ ), concepciones ( 9 f, 2.89 \%), cognición (9f, $2.89 \%$ ), y finalmente, autobiografía (7f, 2.25 $\%)$. Ahora bien, respecto a los tópicos globales mencionados, la noción de maestro abordada en todas las universidades lleva a considerarlo como un ser activo; competente desde el saber, el hacer y el ser; con valores, intereses y postura política; y cuyas subjetividades repercuten en sus prácticas pedagógicas del aula. Espacio en el cual se articula la teoría y la práctica, y se crean las condiciones contextuales necesarias y adecuadas para el intercambio y construcción del conocimiento. Al respecto, la UTP pone especial énfasis en los aspectos conceptuales y procedimentales relacionados con el acto de enseñar, la UCP centra sus comprensiones en el reconocimiento y la significación de la actividad docente desde la dimensión humana del maestro y la UM-C hace referencia al sujeto para la creación y transformación de realidades. Para ello dichas instituciones fundamentan sus investigaciones en autores como Tardif (2004), Honneth (1996; 2007), Acaso (2012), Feixas (2010) y González-González (2014).

Por otra parte, el uso pedagógico de las TIC posee un soporte teórico desde autores tales como Coll (2007), Coll y Onrubia (2008), Coll y Monereo (2008), Castells (2006), Ponce (2012), Lévy (2004), Piscitelli et al. (2010), De Haro (2010), Castañeda y Adell (2012), Levis (2007), entre otros. Las TIC son comprendidas como herramientas de interacción comunicativa y mediación entre los docentes, los estudiantes y el contenido para la resolución de la tarea propuesta. Adicionalmente, la inclusión de las nuevas tecnologías (internet, redes sociales, realidad virtual, fotografía) permiten al estudiante partir de un contexto real, motivante y significativo para la construcción del saber. Así mismo, emerge una relación de la educación virtual con el papel que tiene en el mejoramiento de la educación rural y la formación técnica y tecnológica.

La noción de concepciones -entendidas como teorías implícitas-, tal como lo plantea Pozo et al. (2006), hacen hincapié 
en que estas se encuentran instaladas en el inconsciente de los docentes y surgen de las experiencias e interacciones tenidas respecto a una situación específica. Así, los educadores asumen un estilo de enseñanza, el cual depende de las ideas que posean en relación con la forma de aprender de sus estudiantes.

Como particularidad de la UM-C, el concepto de cognición hace referencia al estudio de las características y desarrollo de la metacognición en la sociedad actual; esto para comprender cómo pueden las personas desarrollar la capacidad de reflexionar sobre sus propias acciones y pensamientos, y generar procesos de regulación en respuesta a las diferentes situaciones presentes en la vida cotidiana para las cuales exigen soluciones asertivas $\left(\mathrm{EC} / 051-02 / 060 / \mathrm{M}^{13}\right)$. Por su parte, en la UCP emerge la noción de autobiografía, la cual se enmarca en las narrativas de las vivencias sobre las prácticas pedagógicas y su importancia para comprender y comprenderse; estas lecturas se hacen desde Bolívar et al. (2001), Vygotsky (1979), Bruner (1991) e Imbernon et al. (1992).

En relación con las llanuras discursivas que se comparten en la región pedagogía con frecuencias inferiores a $5 \mathrm{f}$, emergen tópicos como la estrategia, los procesos, las competencias y los estudiantes. Aquellos buscan complejizar, desde lo social, lo cognitivo y lo emocional, las formas que deberían utilizarse para la enseñanza y el aprendizaje en las áreas de ciencias naturales y sociales, para lo cual los trabajos de grado y las tesis se apoyan en autores como Bisquerra (2000), Chaux et al. (2004) y Villada (2007).

\subsubsection{Región educación}

En la TABLa NRo. 23 se presentan los tópicos globales de la región educación en relación con las frecuencias (f) y los porcentajes (\%) encontrados en la zona del Eje Cafetero.

13 La nomenclatura utilizada para esta y otras citaciones, corresponde al código asignado a los trabajos de grado de maestría y tesis de doctorado analizadas, los cuales varían de acuerdo con el programa y ciudad. 
TABLA NRO. 23. Región educación por tópicos globales en las universidades del Eje Cafetero.

\begin{tabular}{|c|c|c|c|c|c|c|c|c|}
\hline \multirow[t]{2}{*}{ Tópicos globales } & \multicolumn{2}{|c|}{$\begin{array}{l}\text { Universidad } \\
\text { Tecnológica de } \\
\text { Pereira }\end{array}$} & \multicolumn{2}{|c|}{$\begin{array}{l}\text { Universidad } \\
\text { Católica de } \\
\text { Pereira }\end{array}$} & \multicolumn{2}{|c|}{$\begin{array}{l}\text { Universidad de } \\
\text { Manizales }\end{array}$} & \multicolumn{2}{|c|}{$\begin{array}{l}\text { Total Eje } \\
\text { Cafetero }\end{array}$} \\
\hline & $\mathrm{F}$ & $\%$ & $\mathrm{~F}$ & $\%$ & $F$ & $\%$ & $F$ & $\%$ \\
\hline $\begin{array}{l}\text { Educación } \\
\text { emancipadora }\end{array}$ & 9 & 5.36 & 2 & 1.19 & 5 & 2.98 & 16 & 9.52 \\
\hline $\begin{array}{l}\text { Educación y desarrollo } \\
\text { humano integral }\end{array}$ & 0 & 0 & 0 & 0 & 18 & 10.71 & 18 & 10.71 \\
\hline $\begin{array}{l}\text { Educación para la } \\
\text { formación de sujetos } \\
\text { sociales }\end{array}$ & 7 & 4.17 & 3 & 1.79 & 31 & 18.45 & 41 & 24.40 \\
\hline $\begin{array}{l}\text { Educación inclusiva y } \\
\text { diversidad }\end{array}$ & 6 & 3.57 & 1 & 0.59 & 17 & 10.12 & 24 & 14.29 \\
\hline Educación emocional & 2 & 1.19 & 0 & 0 & 4 & 2.38 & 6 & 3.57 \\
\hline Educación de adultos & 2 & 1.19 & 0 & 0 & 1 & 0.59 & 3 & 1.79 \\
\hline Currículo & 2 & 1.19 & 0 & 0 & 2 & 1.19 & 4 & 2.38 \\
\hline Evaluación & 2 & 1.19 & 0 & 0 & 2 & 1.19 & 4 & 2.38 \\
\hline Formación & 1 & 0.60 & 0 & 0 & 6 & 3.57 & 7 & 4.17 \\
\hline $\begin{array}{l}\text { Educación y cambios } \\
\text { fisicos }\end{array}$ & 0 & 0 & 1 & 0.59 & 1 & 0.59 & 2 & 1.19 \\
\hline Educación artística & 0 & 0 & 2 & 1.19 & 4 & 2.38 & 6 & 3.57 \\
\hline $\begin{array}{l}\text { Educación y } \\
\text { metodología por } \\
\text { proyectos }\end{array}$ & 0 & 0 & 1 & 0.59 & 0 & 0 & 1 & 0.59 \\
\hline $\begin{array}{l}\text { Educación y desarrollo } \\
\text { cognitivo }\end{array}$ & 0 & 0 & 1 & 0.59 & 4 & 2.38 & 5 & 2.98 \\
\hline $\begin{array}{l}\text { Educación y factores de } \\
\text { riesgo }\end{array}$ & 0 & 0 & 1 & 0.59 & 0 & 0 & 1 & 0.60 \\
\hline Escuela & 0 & 0 & 0 & 0 & 5 & 2.98 & 5 & 2.98 \\
\hline Etnoeducación & 0 & 0 & 0 & 0 & 2 & 1.19 & 2 & 1.19 \\
\hline Pensamiento crítico & 0 & 0 & 0 & 0 & 4 & 2.38 & 4 & 2.38 \\
\hline Poder & 0 & 0 & 0 & 0 & 4 & 2.38 & 4 & 2.38 \\
\hline Sentido de la educación & 0 & 0 & 0 & 0 & 3 & 1.79 & 3 & 1.79 \\
\hline $\begin{array}{l}\text { Educación } \\
\text { transformadora }\end{array}$ & 0 & 0 & 0 & 0 & 4 & 2.38 & 4 & 2.38 \\
\hline Educación para la paz & 0 & 0 & 0 & 0 & 3 & 1.79 & 3 & 1.79 \\
\hline Educación propia & 0 & 0 & 0 & 0 & 3 & 0.595 & 1 & 0.59 \\
\hline Educación experiencial & 0 & 0 & 0 & 0 & 2 & 1.19 & 2 & 1.19 \\
\hline Gestión educativa & 0 & 0 & 0 & 0 & 1 & 0.59 & 1 & 0.59 \\
\hline $\begin{array}{l}\text { Cultura juvenil/cultura } \\
\text { estudiantil }\end{array}$ & 0 & 0 & 0 & 0 & 1 & 0.59 & 1 & 0.59 \\
\hline $\begin{array}{l}\text { Total por frecuencias y } \\
\text { porcentajes }\end{array}$ & 31 & 18.45 & 12 & 7.14 & 121 & 74.40 & 168 & 100 \\
\hline
\end{tabular}

Elaboración propia.

En cuanto a la región educación se puede observar que el concepto que mayor relevancia tiene como tópico global de la zona del Eje Cafetero, es el de la educación para la formación de sujetos sociales. Así mismo, se evidencian otros tópicos con escasas frecuencias y una dispersión notoria en relación con las llanuras que emergen. 
En esta misma región se establecieron 27 tópicos globales con 168 frecuencias en donde la UM-C relaciona el $74.40 \%$ de las frecuencias, la UTP el $18.45 \%$ y la UCP el $7.14 \%$. En el caso de las tres universidades, los tópicos con mayor frecuencia fueron: educación para la formación de sujetos sociales ( $41 \mathrm{f}$ con un $24.40 \%$ ), educación inclusiva y diversidad (24 f con un $14.29 \%$ ), educación y desarrollo humano integral (18 f con un $10.71 \%$ ), y educación emancipadora (16 f con un $9.52 \%$ ).

Además, aparecen tópicos de mediana relevancia como: formación ( $7 \mathrm{f}$ con el $4.17 \%$ ), educación emocional ( $6 \mathrm{f}$ con el $3.57 \%$ ), educación artística (6 f con el $3.57 \%$ ), educación y desarrollo cognitivo ( $5 \mathrm{f}$ con el $2.98 \%$ ), escuela ( $5 \mathrm{f}$ con el 2.98 $\%$ ), pensamiento crítico ( $4 \mathrm{f}$ con el $2.38 \%$ ), currículo ( $4 \mathrm{f}$ con el $2.38 \%$ ), evaluación ( $4 \mathrm{f}$ con el $2.38 \%$ ), poder ( $4 \mathrm{f}$ con el $2.38 \%$ ) y educación transformadora ( $4 \mathrm{f}$ con el $2.38 \%$ ).

En otro momento se presentan llanuras como: educación de adultos ( $3 \mathrm{f}$ con el $1.79 \%$ ), sentido de la educación ( $3 \mathrm{f}$ con el 1.79 $\%$ ), educación para la paz ( 3 f con el $1.79 \%$ ), educación y cambios físicos ( $2 \mathrm{f}$ con el $1.19 \%$ ), etnoeducación ( $2 \mathrm{f}$ con el $1.19 \%$ ), educación experiencial ( $2 \mathrm{f}$ con el $1.19 \%$ ) y con una frecuencia de $0.59 \%$ se encuentran tópicos tales como: educación y metodología por proyectos, educación y factores de riesgo, educación propia, gestión educativa y cultura juvenil/cultura estudiantil.

Así, en la geografía del Eje Cafetero, para el caso de la UMC, el énfasis se centra en educación para la formación de sujetos sociales ( $31 \mathrm{f}$ con el $18.45 \%$ ), educación y desarrollo humano integral (18 f con el $10.71 \%$ ), y educación inclusiva y diversidad (17 f con el 10.12\%). En el caso de la UTP las mayores frecuencias se enfocan en la educación emancipadora ( 9 f con el $5.36 \%$ ) y la educación para la formación de sujetos sociales ( $7 \mathrm{f}$ con el 4.17 $\%)$. Y finalmente, la UCP tiene un realce marcado en la educación para formación de sujetos sociales ( 3 f con el $1.79 \%$ ), la educación emancipadora ( $2 \mathrm{f}$ con el $1.19 \%$ ) y la educación artística ( 2 f con el $1.19 \%)$. 
Lo anterior permite resaltar la importancia que se le está dando, en el Eje Cafetero, a la formación de sujetos comprometidos con los contextos, las libertades, y los escenarios sociales, con perspectivas emancipadoras, los cuales promueven la construcción social a partir de la escuela como institución que congrega, educa, transforma, vincula e incluye actores en los procesos de transformación de las sociedades.

Adicionalmente, la educación inclusiva permite que las universidades pongan especial interés en las políticas gubernamentales las cuales derivan en investigaciones de los programas de posgrado, donde se reconoce la diversidad en sus diferentes perspectivas. Se resalta la labor de un maestro, el cual tenga la capacidad de transformar las prácticas pedagógicas desde currículos respetuosos y comprensivos con la diversidad.

En cuanto a la educación y desarrollo humano integral, tópico registrado únicamente en la UM-C gracias a su maestría en Educación y Desarrollo Humano, se puede decir que, este ha puesto su interés en la construcción de condiciones favorables al desarrollo de los potenciales humanos para alcanzar una sociedad incluyente equitativa y libre.

Ahora bien, en cuanto a la educación emancipadora, se refleja la búsqueda por una formación de sujetos autónomos con capacidad de reflexión y acción colectiva, y con amplio sentido de transformación social desde las pedagogías liberadoras, siguiendo la línea de pensamientos de Paulo Freire.

Adicional a los tópicos anteriores, se presentan algunos con bajas frecuencias como es el caso del currículo (4 f), la evaluación (10 f) y la formación (4 f). Desde ellas se edifica la lectura a la evaluación con el papel que tiene en la formación integral y en la construcción de un currículo para la emancipación. 
Las llanuras particulares de la UTP se relacionan con conceptos como la educación emocional, generalmente asociada a las competencias ciudadanas y la educación de adultos ligada a la formación académica para el trabajo.

En el caso de la UCP, emerge la noción de educación y cambios físicos relacionados con las etapas de desarrollo y su influencia en los procesos cognitivos de los estudiantes. Aparece también el concepto de educación artística para adquirir aprendizajes significativos en ciencias naturales, educación y TIC. Además, el tópico educación y metodología por proyectos surge como una apuesta para la convivencia escolar y la construcción de paz. Finalmente, la educación y el desarrollo cognitivo se observan desde la captación de los riesgos psicosociales y su implicación en el aprendizaje al interior del aula.

La UM-C tiene la particularidad de abordar el concepto de gestión educativa donde los tópicos como política educativa y proyectos educativos perfilan la gestión como posibilidad de construir escenarios para la diversidad y la inclusión. Asimismo, el pensamiento crítico y el sentido de la educación se relacionan con una educación más humana. Por último, es la educación propia la cual permite el reconocimiento del diálogo de saberes entre las instituciones, y el conocimiento ancestral y tradicional de comunidades étnicas específicas.

\subsection{Análisis. Reporte conceptual por universidades}

En el presente apartado se exponen los resultados correspondientes a la aproximación conceptual de las regiones educación y pedagogía en cada una de las universidades participantes en el estudio. 


\subsubsection{Reporte conceptual Universidad Tecnológica de Pereira}

(UTP)

De los cien trabajos analizados en la Maestría en Educación de la UTP, emergen 16 tópicos globales distribuidos en 8 para la región pedagogía y 8 para la región educación, los cuales agrupan un total de 227 tópicos locales. De la primera región emergen 196 tópicos locales (86.3\%), y de la segunda los 31 restantes (13.6\%), lo cual indica que, en el programa prevalece la investigación en pedagogía. A continuación, se expone la aproximación teórica de cada una de las regiones.

\subsubsection{Región pedagogía.}

La geografía de la región pedagogía se fundamenta en conceptos que tejen relaciones entre tópicos globales, locales y relacionales, los cuales abordan la interactividad que se gesta en el proceso de enseñanza y aprendizaje. En este entramado, de los 196 datos hallados para la región, surge como pico de mayor relevancia la noción de didáctica/enseñanza ( $89 \mathrm{f})$; con mediana relevancia las prácticas pedagógicas ( $28 \mathrm{f}$ ), el enfoque pedagógico $(25 \mathrm{f}$ ) y el aprendizaje (23 f); con baja relevancia emerge el uso pedagógico de las TIC (13 f), el maestro (9 f) y las concepciones ( $8 \mathrm{f}$ ), y como una opacidad la noción de competencias emocionales (1 f). Por tal motivo, en los siguientes apartados se esboza la postura teórica asumida en cada uno de los tópicos mencionados.

4.2.1.1.1. Didáctica/enseñanza. En los trabajos de grado de maestría analizados, la didáctica, con $89 \mathrm{f}$, es comprendida como un campo que se encuentra en construcción y que permite explicar la compleja configuración de los saberes en el marco de la interactividad que se gesta entre quien enseña, quien aprende y los contenidos enseñados y aprendidos. Respecto a ello, las investigaciones a partir de diferentes autores (Chevallard, 1985; Guba, 1990; Zambrano, 2005; Litwin, 2008; y Tamayo, 2009), coinciden en que la didáctica no puede ser pensada como una 
colección de técnicas de enseñanza, sino como el resultado de una relación pedagógica intencionada la cual busca la generación de criterios para describir, explicar, reflexionar, comprender y transformar el proceso de enseñanza y de aprendizaje de saberes escolares (lenguaje, ciencias sociales, ciencias naturales y matemáticas).

En relación con la didáctica del lenguaje, emergen tópicos locales desde las propuestas de Rincón (2009), Solé y Teberosky (2001), Pérez y Roa (2010), y Camps (2003a, 2003b), autores que entienden la enseñanza del lenguaje como una práctica social y cultural la cual pone en juego propósitos claros de comunicación, aquellos que median las interacciones entre quienes hablan y escuchan, y quienes escriben y leen. Este entramado de relaciones se fundamenta teóricamente desde tres enfoques para la enseñanza del lenguaje, los cuales en orden de frecuencia son: el enfoque comunicativo planteado por Hymes (1971; 1996), el enfoque discursivo interactivo propuesto por Martínez-Solís (2000; 2002; 2005), y el enfoque sociocultural de Cassany (1999) y Cassany et al. (2007).

Por otra parte, en las investigaciones orientadas al estudio de la didáctica de las ciencias sociales, se enfatiza la construcción del conocimiento y del pensamiento social a partir de problemas socialmente relevantes. Desde autores como Santisteban (2004; 2011), Pagés (1997; 2007; 2009); Pagés y Santisteban (2011), Benejam (1997a) y Pipkin (2009), la enseñanza de dichas ciencias se orienta al análisis de hechos sociales, históricos, geográficos, políticos y culturales en contextos reales, lo cual conlleva a la formación de estudiantes autónomos, aquellos que comprenden y actúan sobre su realidad social para edificar un futuro personal y colectivo en una sociedad democrática e incluyente.

Respecto a la didáctica de las ciencias naturales, los procesos investigativos acuden al concepto de investigación dirigida (Ruíz, 2007), la cual asume que, para desarrollar el pensamiento 
científico desde lo conceptual, lo metodológico y lo actitudinal, es preciso situar a los alumnos en un contexto de actividad similar al que vive un científico. Esto bajo la dirección del profesor quien refuerza, matiza y cuestiona las hipótesis y conclusiones obtenidas por los estudiantes en la construcción y solución de problemas auténticos del entorno (Jorba y Sanmartí, 1996).

Con menor representatividad, emerge la didáctica de las matemáticas la cual, a partir de los postulados de Duval (1999), Macedo et al. (2006), Castorina (1996) y Polya (1963), propone la enseñanza del área desde una construcción social que permita a los estudiantes conjeturar, aplicar información, descubrir, inventar, comunicar y probar ideas a través de la reflexión crítica y la argumentación; aquellos elementos que parten del planteamiento de problemas los cuales son comprendidos, redefinidos y aplicados en situaciones cotidianas.

4.2.1.1.2. Práctica pedagógica. Para el tópico en cuestión no existe una postura teórica única toda vez que se acude a un sinnúmero de definiciones para fundamentar las prácticas pedagógicas (28 f) de los maestros. En primer lugar, la noción de práctica educativa, se entiende como aquella que implica procesos de enseñanza desarrollados en instituciones sociales como la familia, la ciudad, la iglesia, entre otras. Dichas prácticas, las cuales siguen estando - en gran proporción-, en manos de los profesores, implican un análisis del impacto social y político de su quehacer educativo y una revisión permanente de los valores morales, éticos y políticos presentes en sus pensamientos y acciones cotidianas (Korthagen y Zeichner citados en Rodríguez, 2013), máxime si se tiene en cuenta que se relacionan con una forma de poder la cual actúa a favor del cambio social (Carr y Kemmis, 1998). Esta situación pone en evidencia la forma como los docentes, de manera crítica, dan cuenta de la razón de ser del conocimiento construido socialmente (Freire, 2005). 
En segundo lugar, emerge la práctica pedagógica, aquella concebida como la labor del maestro en ejercicio, quien en su cotidianidad debe confrontar diversas situaciones las cuales exigen una reflexión —-más allá del hacer repetitivo-, surgida de la relación dinámica del devenir continuo entre la teoría y la práctica (Lanza, 2007) para así posibilitar nuevas formas de enseñanza y aprendizaje, y de esta forma proyectar el mejoramiento de la calidad de vida de la comunidad.

En tercer lugar, las investigaciones que analizan la enseñanza de la ciencia asumen el concepto de práctica docente, la cual, en concordancia con Ruíz et al. (2014), se relaciona con las concepciones, la reflexión y la comprensión del ejercicio profesional; además de las acciones que, mediadas por el conocimiento científico, implementa el educador en el aula.

Finalmente, la práctica reflexiva abordada conceptualmente desde autores como Schön (2002) y Perrenoud (2007) es comprendida como una elección pedagógica la cual parte de la experiencia personal y profesional del docente, y le permite la autorreflexión, el autoanálisis, y la toma de posturas críticas y propositivas para la construcción de propuestas de mejora en los procesos de planificación, ejecución (en la acción), evaluación de su clase (sobre la acción) y del impacto social y político de su quehacer educativo.

4.2.1.1.3. Enfoque pedagógico. En relación con el enfoque pedagógico (25 f), se privilegia la comprensión del proceso de enseñanza y aprendizaje desde una postura socioconstructivista. En ella se resalta la interacción, el lenguaje, la mediación y el contexto sociocultural, como elementos claves para el desarrollo individual de las capacidades psicológicas humanas (Vygotsky, 1979), las cuales tal como lo plantean Coll et al. (1992; 1995), Coll (1990; 2001), Coll et al. (2008) y Daza-Pérez y Moreno-Cárdenas (2010), se dan gracias a una actividad productiva conjunta entre 
el alumno, el contenido, y el profesor quien ayuda al alumno a construir significados y a dotar de sentido los contenidos culturalmente establecidos.

Adicionalmente y con una menor tendencia, emerge la pedagogía sociocrítica. Esta, desde los postulados de Freire (1970; 2004) y Blyth (1976), se centra en la formación de un ser humano libre, de pensamiento autónomo y crítico, dado que se encuentra permeado por la subjetividad del mundo que le rodea; aquel mundo con el cual debe dialogar no solo para reconocerse como un sujeto con compromiso político y social en el proceso de transformación de su contexto, sino para comprender empáticamente al otro. Finalmente, y de manera tímida, surge el concepto de constructivismo cognitivo el cual concibe el pensamiento, el aprendizaje y en general los procesos psicológicos como fenómenos que tienen lugar en la mente de las personas $\left(\mathrm{RDA} / 133 / 061 / \mathrm{M}^{14}\right)$.

4.2.1.1.4. Aprendizaje. Con una frecuencia menor (23 f) y a partir de autores como Vygotsky (1976), Coll (1990), Rogoff (1993) y Mercer (1997), los trabajos de grado asumen que el aprendizaje escolar y el desarrollo cognitivo cuentan con un proceso de base biológica elemental, y un proceso superior de origen sociocultural, cuyo instrumento de mediación para la comunicación, la autorregulación, la apropiación del mundo externo y la construcción de los saberes de la cultura, es por excelencia el lenguaje. Otra de las posturas, señala que el sujeto aprendiz no solo obedece a operaciones intelectuales, sino que se enfrenta a la subjetividad inmersa en los múltiples actos de comunicación tejidos en un aula de clase. Así, en la medida que el estudiante reflexiona en colectivo, interioriza y comprende la multiplicidad de saberes, crea la necesidad de transformar su propia vida y su realidad (Freire, 1970; 2004).

14 En adelante, se hace alusión a los trabajos de grado a través de sus respectivos códigos. Estos acompañan la correspondiente referencia bibliográfica en el último apartado del capítulo [N. de E.]. 
Adicionalmente, algunas de las investigaciones plantean el aprendizaje desde la perspectiva de Dewey (1910), quien parte de la premisa de «aprender haciendo», mientras que otras lo relacionan con la transformación de las estructuras cognitivas del estudiante a partir de la significatividad que adquieren los contenidos y de la relación entre los conceptos previos con la nueva información adquirida, propuesta sustentada en Ausubel (1983).

Desde las anteriores perspectivas, se establecen diferentes estrategias las cuales permiten el aprendizaje de los saberes escolares, tales como el aprendizaje colaborativo, privilegiado por las áreas de lenguaje y filosofía; el aprendizaje basado en problemas, por las ciencias sociales; el aprendizaje por investigación orientada y por descubrimiento, enfatizado en las ciencias naturales; $y$, el aprendizaje por indagación en el área de matemáticas.

4.2.1.1.5. Uso pedagógico de las TIC. Para este tópico, algunas investigaciones, representadas (13f), partiendo de Coll (2007), Coll et al. (2008), Coll y Monereo (2008), proponen el estudio de la interactividad y los mecanismos de influencia educativa que se generan a partir de la inclusión de las TIC en el ámbito escolar. Estas — las TIC —, se entienden como mediadoras, no solo desde las relaciones entre los participantes y los contenidos de aprendizaje, sino desde las interacciones y los intercambios comunicativos para planificar, regular y orientar la actividad productiva conjunta. Asimismo, en otros estudios, soportados en autores como Castells (2006), Ponce (2012), Lévy (2004), Piscitelli (2010), De Haro (2010), y Castañeda y Adell (2012), se plantean las bases teóricas las cuales se dirigen hacia los usos pedagógicos de las redes sociales para mejorar los procesos de enseñanza y aprendizaje.

4.2.1.1.6. Maestro. Desde este tópico (9 f), el maestro es considerado como un actor competente y un sujeto activo poseedor de saberes disciplinares, quien, en una articulación permanente con la práctica, le permiten movilizar, transformar 
y producir otros saberes (Tardif, 2004; Shulman, 2001). En este sentido, el maestro como mediador entre el estudiante y el conocimiento, crea las condiciones necesarias y adecuadas para el intercambio y la ampliación de significaciones (RDA/133/035/M). En este proceso, él pone en juego sus saberes, habilidades, valores, intereses, normas, principios y juicios, los cuales marcan las relaciones dentro del aula de clase.

\subsection{Concepciones y competencias emocionales. Como} una llanura se rastrean los conceptos de concepciones ( $8 \mathrm{f}$ ) y competencias emocionales ( $1 \mathrm{f})$. Las primeras se plantean como teorías implícitas, y herencias culturales perdurables las cuales solo se modifican en el nivel de la consciencia y determinan las posturas de los maestros frente a lo que enseñan, la manera de hacerlo y el tipo de evaluación empleado; situación que conlleva al docente a asumir bien sea posturas transmisionistas o relativistas y constructivistas sobre el proceso de enseñanza y aprendizaje (Pozo et al., 2006). Las segundas se entienden en términos de Chaux et al. (2004) y Bisquerra (2003), como las capacidades necesarias para tomar consciencia, identificar y responder constructivamente a las emociones propias, a las de los demás y al clima emocional de un contexto determinado.

A partir de los hallazgos evidenciados en la región pedagogía, se pone en evidencia que, si bien los trabajos de grado de la Maestría en Educación de la UTP, con mediana frecuencia, acuden a algunos conceptos relacionados con la pedagogía sociocrítica; con un amplio margen de relevancia las investigaciones se ubican conceptualmente en una postura teórica socioconstructivista, y permean de manera importante cada uno de los tópicos globales.

\subsubsection{Región educación}

Desde esta región, las investigaciones consideran que la educación tiene un compromiso con la solución de los problemas sociales, desde apuestas que permitan la resignificación de las 
acciones dentro y fuera de las aulas de clase, en las cuales adquiere relevancia la formación de valores para aprender a vivir juntos. Desde allí, en la geografía de la región educación, prevalecen tópicos relacionados con la educación emancipadora (9 f), educación para la formación de sujetos sociales $(7 \mathrm{f})$ y educación inclusiva (6 f). Luego, con escasa frecuencia aparecen educación emocional (2 f), educación de adultos (2 f), currículo (2 f) y evaluación (2 f). Y como llanura emerge la noción de formación $(1 \mathrm{f})$. A continuación, se presenta la fundamentación teórica de cada uno de los tópicos.

4.2.1.2.1. Educación emancipadora. De la educación emancipadora hacen parte trabajos de investigación los cuales se refieren a la educación liberadora. Esta es comprendida desde la perspectiva de Freire (2004), quien propone que el diálogo es condición para la liberación del pensamiento autónomo y crítico, la aceptación de la subjetividad del otro y su inclusión. Así, toda acción educativa tiene como finalidad romper las relaciones de poder por medio del reconocimiento del papel activo de los sujetos, configurados subjetivamente desde la libertad. En relación con lo anterior, las investigaciones destacan a la práctica educativa como una forma de poder, por lo que el docente debe profesionalizar la función vital que desempeña, de manera que pueda promover el cambio de las condiciones del mundo en el que se habita (Carr, 1996).

\subsection{Educación para la formación de sujetos sociales.} En relación con este tópico, se resalta el papel fundamental que tiene la enseñanza de la historia, dado que, se convierte en un vehículo para analizar y reflexionar sobre los hechos y las causas de los fenómenos históricos y sobre la sociedad y sus dinámicas polifónicas, esto con el fin de comprender el inicio de los problemas actuales. Así, la apuesta está en permitir el desarrollo del pensamiento social para contribuir a la democratización, la participación, la autonomía, al cuidado de los otros y de sí mismo sobre la base de la comprensión, el análisis crítico y la transformación de la realidad (RDA/133/077/M). 
4.2.1.2.3. Educación inclusiva. Las investigaciones analizadas la asumen este tipo de educación como un asunto de derechos humanos que, mediante una creciente participación en el aprendizaje, la cultura y las comunidades, permite responder a la diversidad escolar. Al respecto varios autores como Echeita y Duck (2008), Unesco (2008), López Melero (2011), Blanco (2006; 2011), Ainscow et al. (2006), Ainscow y Miles (2008) y Ainscow (2012) coinciden en que todos los estudiantes tienen derecho a educarse juntos y en igualdad de condiciones, independientemente de su lengua, cultura, condiciones individuales o sociales. Ello implica la identificación y reducción de barreras para acceder a una educación que respeta la diferencia y se enriquece ella misma.

De manera complementaria al concepto de educación inclusiva, surge el tópico de formación entendida como un elemento clave para la profesionalización del quehacer docente y la transformación de la práctica educativa. Lo anterior se referencia desde autores como Stainback y Stainback (2007), Vélez (2013) e Imbernon y Jarauta (2012), quienes señalan la necesidad de la formación de los docentes para atender las características diversas de los estudiantes. Situación que supone pensar en seres que, en relación consigo mismos, con los demás y con el entorno, creen y recreen lo histórico, lo social, lo cultural, lo político y lo económico.

4.2.1.2.4. Educación emocional. Con una frecuencia menor, esta se asume como un proceso educativo, continuo y permanente, el cual pretende potenciar el desarrollo emocional como complemento indispensable de lo cognitivo; con el objetivo de prevenir los efectos nocivos de las emociones negativas, desarrollar la habilidad de automotivarse y adoptar una actitud positiva ante la vida (Bisquerra, 2000; 2003). Estos desarrollos deberán permitir que el ciudadano actúe de manera constructiva en una sociedad democrática (Chaux et al., 2004). 
4.2.1.2.5. Educación de adultos. Para este tópico, además de la educación de adultos se incluye también la educación emprendedora. En cuanto a la primera, desde la perspectiva de la Unesco (1976) se considera como un espacio para la búsqueda de alternativas educativas innovadoras dirigidas a personas que no han cursado o abandonaron sus estudios, y que han desarrollado aptitudes, conocimientos y competencias técnicas o profesionales las cuales les hacen evolucionar y participar en el desarrollo socioeconómico y cultural del contexto (RDA/133/063/M). Respecto a la segunda, se concibe como una oportunidad para promover el desarrollo de capacidades y actitudes como la curiosidad, la apertura al aprendizaje continuo, la actitud proactiva, la autonomía y la creatividad; aspectos útiles a lo largo de toda la vida, tanto en el campo personal como en el profesional y el social (RDA/133/062/M).

4.2.1.2.6. Currículo. Cuando se aborda el currículo, en las investigaciones consultadas se adjetiva como oculto y emancipador, sin citar autores para su definición. En relación con el currículo oculto, se indica que se concreta en aquellos conocimientos, mensajes, actitudes, posturas y valores, entre otros, no formalizados explícitamente, ni contemplados en planes de estudios o normativas institucionales y que, por sus contenidos y fuerte carga de sus funciones morales y de reproducción social posee un importante componente de orden económico, político, social, cultural e ideológico. Lo anterior está ligado a una mirada del currículo emancipador, lo cual hace necesario que los actores implicados en el proceso áulico realicen una reflexión en el sentido de que la organización de un currículo no susceptible a cambios, ejerce control sobre la libertad (RDA/133/047/M; RDA/133/057/M, y RDA/133/074/M).

4.2.1.2.7. Evaluación. Los trabajos de grado consultados conciben la evaluación como un proceso de la planeación para elaborar, de forma anticipada, las estrategias necesarias que permitan establecer diálogos entre los participantes, los saberes 
y los contextos, y lleven a determinar las acciones suficientes y oportunas para emitir juicios y emprender planes de mejoramiento (Villada, 1997) en función del logro de los objetivos propuestos. Situación que la configura en una herramienta reguladora de los procesos educativos, en tanto posibilita el análisis de las situaciones actuales y la toma de decisiones para reorientar o reorganizar el quehacer educativo.

En la geografía de la región educación de la UTP, prevalece un panorama rico en recursos discursivos donde se observa el diálogo como condición de la educación liberadora del pensamiento autónomo y crítico, y la aceptación de la subjetividad del otro y su inclusión. De esta manera se comprende que, toda acción educativa tiene como finalidad romper las relaciones de poder, esto por medio del reconocimiento del papel activo de las personas configuradas subjetivamente desde la libertad. Así, la educación juega un papel preponderante a la hora de constituir sujetos para el cambio y la transformación social, por tanto, ha de ser una formación orientada a la consolidación de contratos didácticos más humanos y dignificantes, y especialmente, hacia la autonomía como valor intrínseco de cualquier proceso educativo: familiar, escolar, comunitario y social.

Es por ello que la enseñanza está llamada a constituirse en puente entre la cultura y el desarrollo humano, y entre el saber cultural y el saber disciplinar. Esto, con el fin de que, en una reflexión constante, el diálogo de saberes sea transversal al desarrollo del pensamiento crítico y al crecimiento de un sujeto, el cual contribuya a la construcción de una sociedad democrática y participativa.

\subsubsection{Reporte conceptual Universidad Católica de Pereira} (UCP)

De treinta y un trabajos de grado de maestría analizados, emergen cuarenta y un tópicos de los cuales veintinueve pertenecen a la región pedagogía equivalentes al $70.33 \%$ y doce 
pertenecen a la región educación los cuales equivalen al $29.67 \%$. La mayoría de los proyectos de los estudiantes evocan el sentir pedagógico, siendo las prácticas y la autobiografía las que mayor relevancia poseen. Por su parte, las narrativas pedagógicas y la conceptualización realizada por cada persona sobre sí misma son las constantes en los trabajos de maestría, convirtiéndose en la oportunidad de búsquedas de sentidos para luego ser replicados en los ámbitos escolares.

\subsubsection{Región pedagogía}

En la geografía de la región pedagogía se enmarcan 22 investigaciones equivalentesal $71 \%$ de todos los trabajos analizados. En ellas se aborda lo didáctico desde temas relacionados con la acción pedagógica para el bienestar de la comunidad, los aportes del desarrollo humano a la reflexión pedagógica, la apropiación de un modelo pedagógico crítico, y las estrategias pedagógicas aplicadas en el aula. Particularmente desde las ciencias naturales, las experiencias docentes las cuales ayudan a la comprensión de las prácticas desde lo político y lo pedagógico, la autobiografía como manera de intervenir la subjetividad del maestro y el actuar desde sus sentires para comprender sus acciones en el aula escolar.

Cada una de estas temáticas abona a la construcción de sentidos del quehacer pedagógico, e involucra al docente en su cotidianidad para hacer efectiva su labor. Así, más que lo teórico, se resalta la necesidad de estudiantes de la maestría por comprender lo práctico y lo humano en el ámbito escolar. A continuación, se describen, en orden de frecuencia, cada uno de los conceptos emergentes en la maestría a partir de los tópicos globales de la región pedagogía.

4.2.2.1. Autobiografía. La autobiografía como tópico de mayor relevancia es entendida como un método de estudio y estrategia pedagógica abordada desde Bolívar (2001), Vygotsky (1979), Bruner (1991) e Imbernon et al. (2002); como relatos 
de experiencias los cuales permiten reconocer al otro desde sus diferencias y contextos de vida, los cuales contribuyen a la construcción de significados y edificación sensible de cada momento transcurrido en la existencia de quien se involucra; esto, al conocer su historia, y de esta forma, al redescubrir sus horizontes, comprenderse y comprender las actitudes de otros.

4.2.2.1.2. Didáctica/enseñanza. Este concepto se retoma desde el área de la tecnología y la informática en relación con los resultados de aprendizaje y el comportamiento de los estudiantes. Esta postura se asume desde Honneth (1997) y Arresé (2009). En el mismo sentido, emerge el concepto de secuencia didáctica el cual rescata la educación en línea como la concepción pedagógica apoyada en las TIC, donde el problema de formación y/o investigación se centra en la educación y la pedagogía y no dichas herramientas (RDA/018/020/M).

4.2.2.1.3. Práctica pedagógica. Es concebida como aquella que promueve el desarrollo de actividades las cuales conduzcan a mejorar el bienestar de la comunidad educativa, partiendo de la reflexión y autoevaluación realizadas por el docente frente su quehacer pedagógico (RDA/018/019/M). La práctica pedagógica se entiende, además, como el camino emprendido por el maestro para comprender lo humano y propender por el cambio (Honneth, 1997). Por otra parte, desde la maestría se propone el abordaje del concepto desde el Ministerio de Educación Nacional, en relación con la Ley 115 de 1994 (Ley General de Educación 1994), donde se concibe como un "proceso de autorreflexión que se convierte en espacio de conceptualización investigación y experimentación didáctica» (p. 5).

Se resalta el desarrollo de la práctica docente desde propuestas de aprendizaje significativo de Ausubel (1976), y el Método Scout reconocido como un sistema de educación de carácter no-formal el cual pretende que los jóvenes desarrollen sus capacidades 
físicas, intelectuales, emocionales, sociales y espirituales, como individuos y como miembros de la sociedad, para que contribuyan a construir un mundo mejor.

Por otro lado, la investigación RDA/018/011/M centra su interés en la reflexión hecha por un docente de su propia práctica para la convivencia escolar. Considera además que las experiencias estéticas forman parte del discurso desde la resignificación de sí mismo y su repercusión en los procesos de enseñanza. Aparece el concepto de ensoñación el cual desde Bachelard (1982) incluye un momento de vigilia que permite mover el pensamiento, la memoria y las imágenes, con las cuales el poeta lleva a rememorar al uso poético del lenguaje.

En la investigación RDA/018/027/M, se da la mirada a una práctica pedagógica en la cual el maestro, como recolector de historias, da cabida a la apertura de espacios de diálogo, debate y encuentro de narraciones. Aquel se convierte en la persona que converge en realidades compartidas, y permite el reconocimiento del otro en sus formas de sentir, pensar y conocer. Opciones para el reencuentro, la resignificación y la construcción del saber a partir de los intereses.

4.2.2.1.4. Estrategias pedagógicas. Las estrategias pedagógicas son pensadas para la atención educativa en estudiantes con el Trastorno por Déficit de Atención e Hiperactividad (TDAH), en el área de las ciencias naturales. Estas se pueden replicar en otras áreas del conocimiento mediante la implementación de secuencias didácticas las cuales contemplen la estética y la producción de textos narrativos; estrategias las cuales moldean las miradas frente a lo pedagógico en contextos escolares (RDA/018/022/M; RDA/018/023/M; RDA/018/024/M).

4.2.2.1.5. Uso pedagógico de las TIC. En el trabajo de grado $\mathrm{RDA} / 018 / 028 / \mathrm{M}$, se aborda la noción de nativos digitales desde la implementación de la fotografía como herramienta pedagógica. 
Por su parte, la investigación RDA/018/012/M relaciona estos mismos nativos desde las artes plásticas, convirtiéndolos en una estrategia de enseñanza que facilita la construcción de competencias ciudadanas. Así mismo, la tecnología es comprendida como la herramienta que permite la movilización de distintas estrategias pedagógicas, actuando desde los lenguajes modernos, los cuales van más allá de la utilización de la internet para propiciar un aprendizaje significativo (RDA/018/030/M).

4.2.2.1.6. Enfoques pedagógicos. Desde este tópico, se promueve la apropiación de un modelo pedagógico crítico social el cual reconoce la escuela como espacio democrático y humano, donde los estudiantes, los maestros, los padres y la comunidad en general se encuentran para pensar en escenarios de conocimiento, ciencia, tecnología y todas aquellas expresiones artísticas las cuales contribuyan a desplazar la violencia por una convivencia, ya generar relaciones interpersonales de respeto, amor y transformación cultural (RDA/018/031/M; RDA/018/017/M).

4.2.2.1.7. Maestro. El tópico maestro se concibe desde su ser y de cómo éste repercute en sus prácticas pedagógicas en el aula, así como desde el reconocimiento como actor político (RDA/018/001/M). Por otra parte, se evidencia el rol de la mujer docente y su influencia en lo pedagógico (RDA/018/014/M). En la investigación $\mathrm{RDA} / 018 / 021 / \mathrm{M}$, se permite una reflexión acerca de la importancia de valorar a la persona que subyace al interior de las prácticas de enseñanza; esto al reconocer que es humano, que tiene potencialidades y también situaciones de mejora, al igual que aspectos que permean sus prácticas en el aula.

4.2.2.1.8. Procesos. Los procesos escolares median lo social, lo cognitivo y la inteligencia emocional a través de las secuencias didácticas las cuales dotan de sentidos el aprendizaje. Estos procesos buscan emancipar el rol pedagógico a partir de la transformación y su afectación positiva en la convivencia escolar (RDA/018/018/M). 
Lo pedagógico desde la perspectiva de la maestría, se constituye en una introspectiva la cual ayuda al futuro magister a ser consciente sobre la realidad en la que, para realizar cambios externos, debe procurarse en su interior las significaciones de la soledad de la mujer docente, las narrativas pedagógicas, los sentidos de las prácticas docentes, entre otros aspectos presentes en la acción pedagógica.

\subsubsection{Región educación}

La educación, tal como lo refiere Campos Campos (1998), no solamente se trata de conducir, guiar y orientar, ya que el término en sí se puede vincular con la palabra exducere o "conducir hacia fuera». En este sentido, existe una estrecha relación entre la educación y la escuela. Dicha relación es analizada en siete de los treinta y un trabajos, los cuales se enmarcan en la construcción de saberes guiados en torno a temáticas, tales como: la búsqueda de significados para comprender la naturaleza del ser humano en espacios culturales, la convivencia escolar, las estrategias para la inclusión, la violencia de género, las metodologías para el trabajo de aula a través de la educación artística, las libertades para mirar lo educativo a través del discurso y la resignificación de un Proyecto Educativo Institucional (PEI). Estos y otros tópicos globales se profundizan en los párrafos siguientes. Así, se comienza por los picos con mayores frecuencias, se transita hacia las mesetas las cuales emergen con mediana frecuencia y se finaliza con las llanuras.

\subsection{La educación para la formación de sujetos} sociales. Para la UCP este tópico emerge con mayor pico. En él, la educación para la convivencia y los procesos formativos se pueden comprender desde el abordaje teórico propuesto por Maslach y Pines (1977) en relación con el Síndrome de Burnout, el cual es complementado con la concepción de frustración desde la perspectiva de Freud (1912) y Dollard et al. (1939), quienes vinculan el término con una interferencia en la secuencia 
del comportamiento la cual se gesta debido al estado en el que se encuentra un sujeto cuando se le niega o se le prohíbe la satisfacción de una demanda de origen pulsional. Situación que se podría interpretar como la reacción a la no consecución de algo que se está buscando.

4.2.2.2.2. Educación emancipadora. La educación emancipadora, desde la perspectiva de Freire (1999; 2004), enfatiza en las libertades que, desde el análisis del discurso de los estudiantes, emergen para conocer sus expectativas de vida, sus experiencias y sus afectaciones positivas y negativas y, así llegar a comprender, de una manera más contextualizada, los sentidos del PEI en una población determinada. Desde esta mirada, la libertad se comprende como uno de los primeros cambios con los cuales se encontrarán los estudiantes en una nueva etapa que trae consigo una mayor libertad; y en la búsqueda de identidad, la exigencia de mayor independencia y nuevos intereses. Así, la libertad es la posibilidad de soñar con un cambio cuando hay nuevas expectativas al llegar a la básica secundaria. La escuela prepara tímidamente para estos cambios.

En el trabajo de grado RDA/018/004/M se determina la resistencia como el mecanismo de reacción que tiene el ser humano ante cada situación que se le presenta. En este sentido, "pone en evidencia las variantes, en las resistencias desde el punto de vista ético-político que cada docente ha asumido y la manera como ha tomado posición de su propia realidad» (RDA/018/004/M, p. 4).

4.2.2.2.2. Educación inclusiva y artística. La educación e inclusión (RDA/018/007/M) piensa en alternativas como formación por el arte, es decir, el proceso de creación para conseguir que los individuos sean capaces de crear por sí mismos en cualquier momento de la vida, en el trabajo, en el estudio y, sobre todas las cosas, en el hogar; porque es ahí donde empieza la expresión del niño (Socas Duarte, 2015). Este sentir se enmarca en la necesidad de complejizar sobre el mundo de los jóvenes. 
4.2.2.2.3. Educación y cambios físicos. Se plantean los cambios físicos hormonales en niños y niñas escolares. También el papel de la escuela y los procesos formativos, esto al tener en cuenta la oportunidad que tiene el ámbito escolar para pensar en la integralidad de sus estudiantes (RDA/018/010/M).

4.2.2.2.4. Educación y desarrollo cognitivo. El desarrollo cognitivo se piensa en el marco del riesgo psicosocial y sus implicaciones al interior del aula; factor a considerar en los procesos formativos, para atender oportunamente a los estudiantes y construir procesos de paz desde las estrategias de aula (RDA/018/009/M).

4.2.2.2.5. Educación y factores de riesgo. Este concepto se plantea desde la representación social como el conjunto de tradiciones, normas y valores presentes en la memoria colectiva la cual es expresada muchas veces por formas simbólicas a través del lenguaje y acumuladas por la historia, donde se busca la representación de muchas circunstancias, y de cómo estas repercuten en las acciones de los estudiantes.

Se concluye que la tendencia de la Maestría en Pedagogía y Desarrollo Humano, respecto a su geografía, propende por la región pedagogía y enfatiza en las prácticas pedagógicas desde la autobiografía y las narrativas pedagógicas en las cuales el concepto de escritura emocional adquiere especial relevancia. Dicha mirada involucra al investigador y lo relaciona con las prácticas docentes desde lo didáctico y lo educativo en el escenario escolar, así como con sus procesos formativos, enmarcados en la búsqueda de sentidos y en procura de una transformación, la cual beneficie, no solo las acciones emprendidas en el contexto áulico, sino aquellas llevadas a cabo en el entorno institucional. Esto, a través de la resignificación de los PEI y la necesidad de blindar la convivencia escolar para el mejoramiento continuo y la construcción de la paz. En definitiva, lo anterior promueve la mejora en la calidad educativa. 


\subsubsection{Reporte conceptual Universidad de Manizales y Centro de Estudios Avanzados en Niñez y Juventud (UM-C)}

De los 184 trabajos de grado y las tesis analizadas en la UM-C, 80 corresponden a la Maestría en Educación desde la Diversidad, 75 a la Maestría en Educación y Desarrollo Humano y 29 al Doctorado en Ciencias Sociales Niñez y Juventud. En la región educación, se presenta no solo el mayor número de tópicos, sino además el mayor número de frecuencias con 125 equivalentes al $59.24 \%$. 86 corresponden a la región pedagogía con el $40.76 \%$, lo cual demuestra el interés prevalente que tienen los posgrados de dicha institución en la educación y su importancia en la actualidad.

\subsubsection{Región pedagogía}

La región pedagogía tiene un pico muy marcado en la práctica pedagógica. En un segundo plano de su geografía, aparece una mayor relevancia en la correlación de la pedagogía con la cognición y la relación didáctica/enseñanza. También emergen tópicos como el aprendizaje y el papel de los profesores, y el enfoque pedagógico y la pedagogía emancipadora. Como tópicos con bajas frecuencias aparecen el uso educativo de las TIC, las concepciones, las estrategias, los estudiantes y los procesos.

4.2.3.1.1. Práctica pedagógica. La práctica pedagógica se observa en relación con la lectura de la interactividad presente en el aula de clase y como mecanismo de influencia educativa en la enseñanza y el aprendizaje desde los procesos de la argumentación, aquellos en los cuales el maestro asume un papel generador de prácticas incluyentes. Así mismo, se teoriza sobre la práctica educativa, entendida esta como potencial de creación de la acción docente, las relaciones de poder y la organización de ambientes de aprendizaje favorables en los cuales se consolidan expresiones afectivas potenciadoras de la construcción del conocimiento. 
Otro aspecto fundamental que emerge de las investigaciones estudiadas es la necesidad de reflexionar la práctica pedagógica desde los saberes escolares; especialmente, en las afectaciones que permean los procesos de enseñanza. Esto, sin dejar de lado los distintos saberes del maestro los cuales tienen que ver con lo experiencial y lo profesional (EC/051-01/019/M).

4.2.3.1.2. Didáctica/enseñanza. Este tópico se plantea en términos de la educación artística la cual pretende potenciar las habilidades y destrezas, así como la contemplación y apreciación propia de las dimensiones artísticas, lo cual favorece el desarrollo sensitivo, cognitivo, creativo, expresivo y práctico en los estudiantes. En este sentido, la educación artística implica transformaciones en la escuela y en las prácticas educativas, y además supone la construcción de nuevos espacios y formas de producción y circulación de los conocimientos.

4.2.3.1.3. Cognición. El concepto cognición se aborda desde diferentes concepciones. Inicialmente, el desarrollo lingüístico y las competencias comunicativas se ven como el puente para que las personas no oyentes realicen elaboraciones cognitivas avanzadas, primordialmente a través de la lengua de señas complementada con el acceso comprensivo a los textos escritos.

Por otro lado, la sensitividad cognitiva funciona por medio del reconocimiento que tiene dentro del discurso de un tipo específico de patrones lingüísticos y, ante todo, por la identificación de que estos implican una formulación explícita de la argumentación en el lenguaje articulado utilizado en la lógica formal (EC/043/032/D).

Otra línea de abordaje de la cognición se refiere a la teoría de Gardner (1997) sobre las inteligencias múltiples. Esta se toma como una perspectiva orientada a detectar los talentos de los estudiantes, en donde los maestros son quienes direccionan sus habilidades hacia posibilidades más productivas (EC/05102/003/M). 
En relación con el tópico surge, además, la noción de estilos cognitivos, los cuales se fortalecen a través de los hábitos de estudio, y los procesos de formación influenciados por el capital sociocultural y las prácticas pedagógicas en los contextos y territorios.

Finalmente, las investigaciones contemplan el tópico de regulación metacognitiva. Sobre ella, se resalta el papel que tienen los entornos virtuales como mediadores para que el estudiante pueda mejorar su rendimiento académico al indagar nuevas formas de aprender (EC/051-02/051/M). Adicionalmente, los entornos virtuales de aprendizaje se constituyen en una mediación la cual privilegia la sincronía entre el enseñar y el aprender.

4.2.3.1.4. Aprendizaje. Una primera lectura asocia directamente al aprendizaje con la pedagogía y ubica al educador como un facilitador (EC/043/002/D). Allí, dicho aprendizaje se enfatiza desde las experiencias vividas por los sujetos, una relación con la calidad de experto o novato frente a las situaciones y con la formación previa que tenga la persona (Erausquin et al., 2006).

En segunda medida se contempla el fortalecimiento de habilidades metacognitivas, las cuales motivan y sirven como motor para el aprendizaje a través de la didáctica no parametral (Quintar, 2002) como estrategia que resulta apropiada, y que se debe favorecer desde el hogar y la escuela.

Finalmente, emerge una lectura sobre los estilos de aprendizaje, los cuales revelan el pensamiento integral y creativo en los niños y que, a su vez, se relacionan con las estrategias de aprendizaje de los estudiantes.

4.2.3.1.5. Maestro. Desde este tópico, se concibe al maestro como un mediador el cual, desde sus prácticas pedagógicas, aproxima a los estudiantes no solo al conocimiento sino a la diversidad. Esto al asumir la educación desde la inclusión, 
tanto en el aula como en la institución educativa (EC/05101/059/M). Además, este actor aporta una serie de actividades que, con fundamentos científicos y metodológicos, se orientan a la consolidación de conocimientos, habilidades, destrezas, valores y actitudes para lo cual parte de la dialéctica de crítica en su forma reflexión-acción-transformación-reflexión (EC/05101/061/M). Así mismo, un maestro que incita a la búsqueda de la transformación de la realidad de una manera más humana (EC/051-01/058/M) que, en términos de Freire (1970), se traduce en profesores y educandos los cuales aprenden entre sí mediante una interacción dialógica.

4.2.3.1.6. Enfoque pedagógico. Este enfoque se observa desde la perspectiva de la pedagogía activa y el papel del maestro, la pedagogía de la resistencia y la necesidad del «otro» para transformar y hacer frente a las demandas del país (EC/05101/055/M; EC/051-01/069/M). De igual manera, se plantea la necesidad de lo organizacional y la institucionalidad de figuras tales como la escuela y el colegio; escenarios para la interacción, relación y vínculo de los individuos. Adicionalmente, emerge la pedagogía del arte (Dewey, 1975) y el papel que esta juega en la educación de los niños, como posibilidad de hacer frente a la deshumanización del otro como ser humano.

4.2.3.1.7. Pedagogía emancipadora. Desde este tópico se aborda conceptualmente la pedagogía liberadora como aporte sobre la relación horizontal entre el maestro y el estudiante (Freire, 1970). En ella se resalta el papel que tiene el diálogo (EC/05101/031/M). Y complementariamente, se asocia el ejercicio de autonomía que cada persona debe emprender (Nussbaum, 1995) en la medida en que aprende a ser libre; ya que no podrá existir una plena salud mental cuando existen desigualdades y opresión en el esquema de libertad y las prácticas discursivas que conducen a lograrla (EC/051-02/017/M). 
4.2.3.1.8. Uso educativo o pedagógico de las TIC. Se concibe, en primer lugar, desde la posibilidad de enseñanza y aprendizaje de la geometría a partir de sistemas de realidad virtual (Levis, 2007), las cuales permitan al sujeto interactuar intuitivamente con los objetos (EC/043/007/D); y, en segundo lugar, desde la perspectiva de la educación virtual, la cual tiene un papel en el mejoramiento de la educación rural y la formación técnica y tecnológica como un modelo de educación del campo para el desarrollo en dichos espacios.

4.2.3.1.9. Tópicos con bajas frecuencias. Tópicos como concepciones, estrategias, procesos y estudiantes emergen como llanuras en los planos discursivos de las investigaciones analizadas. En relación con las estrategias, estos son comprendidos desde la pedagogía experiencial al reconocer a los sujetos en sus cotidianidades, experiencias y concepciones. A partir de allí, se busca establecer reflexiones y conceptualizaciones las cuales permitan la transformación de las prácticas educativas, de las instituciones y del marco relacional en el cual está inmersa la escuela, y la relación enseñanza y aprendizaje.

En el tópico procesos se abordan los mecanismos de influencia educativa como procedimientos para construcción de significados y la atribución de sentido a los saberes construidos en el proceso de enseñanza y de aprendizaje, espacio en el cual el profesor se convierte en un facilitador de la instrucción activa (EC/043/012/D).

En el último tópico se hace relación a las necesidades del estudiante en el nivel de básica, en términos de generar mayor intensidad del vínculo maestro-estudiante en la primaria, y disminuir el nivel de conexiones hacia la secundaria (EC/043/015/D). 


\subsubsection{Región educación}

Esta se asocia principalmente con la formación de sujetos sociales, la educación y el desarrollo humano e integral, así como con la inclusión y la diversidad. Evidencia la relación de los programas de doctorado y maestría involucrados con sus objetos de estudio, aquellos centrados en la relación de la educación con las ciencias sociales, el desarrollo humano y la diversidad.

Desde otra mirada, se encuentra una lectura a la escuela como el escenario para una educación emancipadora. De esta manera, se marca el papel que tiene la educación popular en los procesos formativos de las maestrías participantes; y, así mismo, se enfatiza sobre el papel de la sociedad como escenario formativo. Otra lectura hace referencia a las relaciones de poder, y al sentido de la formación para comprender la educación propia, artística, transformadora y emocional. Finalmente, como llanuras se encuentran la evaluación, la educación experiencial, la educación de adultos, la gestión educativa, y la educación y los cambios físicos.

4.2.3.2.1. Educación y formación de sujetos sociales. Cuando se habla de la educación para la formación de sujetos sociales, se hace desde los aportes teóricos de Canals et al. (2008) y Benejam (1997b), quienes enfatizan en dicha formación desde el desarrollo de habilidades, las cuales posicionan al individuo como un ciudadano con un fuerte compromiso social, preparado para responder a las exigencias y cambios de la actual sociedad. Además, se aborda desde planteamientos que comprenden la educación como acontecimiento ético, lo cual significa asumirla como una relación con el otro desde la alteridad, más allá de los discursos técnicos y especializados (EC/051-02/073/M).

También se plantea una pedagogía basada en la praxis (Freire, 1970). Desde esta, el trabajo y la relación con el conocimiento permite la construcción de agentes sociales y políticos con la 
suficiente capacidad para cambiar y transformar su realidad social; esto, al romper su subjetividad o conciencia, saber popular o cultura (EC/051-02/056/M). A lo anterior, se suma la noción de formación en ciudadanía, la cual plantea como requerimiento la generación de espacios específicos donde se desarrollarán las habilidades y competencias necesarias para la participación, los derechos humanos, la formación moral y los valores; elementos que no se conciben de manera aislada sino, por el contrario, con fuertes conexiones entre ellos.

Ahora bien, una mirada desde la sociología, específicamente desde Durkheim (1985), entiende la educación articulada a la sociedad como socialización, como aquella que reproduce relaciones sociales de clase. Además, se establece su rol (Sen, 1999a; 1999b; Sen y Brundtland,1999) para impulsar el desarrollo tanto de manera individual como colectiva, y para desarrollar las capacidades de los educandos de ejercer sus derechos y libertades, de impulsar sus proyectos de vida, de avanzar y recrear su cultura y de trabajar por el progreso de sus comunidades.

Finalmente, se plantea la capacidad de agenciamiento la cual se extiende al punto de impactar también a otros estudiantes de la institución a través del intercambio de experiencias, sentimientos y significados en la medida que pueden compartir y contrastar discursos sobre las formas de acción colectiva (EC/051-02/020/M).

4.2.3.2.2. Educación y desarrollo humano integral. Este tópico se edifica desde diversas posturas teóricas. En primer lugar, parte de pilares como la utopía y el sueño de equidad, libertad, responsabilidad, sociedades incluyentes y condiciones favorables al desarrollo de los potenciales humanos (EC/043/006/D). En segundo lugar, al seguir a Gardner (1997), propone al maestro como potencializador de la inteligencia y sugiere una lectura más compleja sobre el desarrollo humano en términos del rechazo de la enseñanza uniforme y la apuesta por una enseñanza centrada en la persona. 
Desde otra perspectiva, se aborda a Morin (1982) para señalar la educación como unidad y diversidad humana. Allí, se resaltan aspectos de la educación del futuro que velará por la idea de unidad de la especie humana sin obviar o borrar su diversidad - y viceversa - . Por otra parte, se plantea (Ausubel, 1983) que la educación permite preparar a las nuevas generaciones para que, además de vivir como personas en sociedad -las cuales crean y transforman su cultura-, asuman las responsabilidades que ello implica (EC/051-01/049/M).

Finalmente, surge la necesaria relación entre escuela y familia. En ella los seres humanos se sumergen en un extenso proceso educativo el cual va desde el entorno familiar de protección, hasta el entorno social de la adultez en donde existan condiciones de educabilidad (EC/043/008/D).

4.2.3.2.3. Educación inclusiva-diversidad. Se concibe como pluralidad y cambio estructural en el sistema educativo. Esta permite la manifestación de las diferencias, de la variedad, de formas de pensar y ver el mundo a través de la concepción de un ser humano complejo y diverso. Además, se plantea que la educación debe dar respuesta a la diversidad; primero al facilitar la interpretación y el entendimiento de ella, y segundo, en la operacionalización del currículo en la praxis pedagógica (EC/05101/029/M).

4.2.3.2.4. Formación. El concepto es abordado desde la formación profesional por la influencia de las vivencias personales, familiares y la participación en grupos sociales; así mismo, por el influjo de maestros en la escuela (EC/051-02/004/M). La formación se concibe en el marco de condiciones éticas, las cuales implican su ejercicio y asuntos, que deberían fundamentarse en los criterios de calidad y desarrollo humano. 
4.2.3.2.5. Educación emancipadora. Es aquella que abre posibilidades, caminos y nuevos sentidos desde la interioridad particular de cada individuo; desde su riqueza interior, su sensibilidad, sus talentos y valores; así como desde la valoración de los aspectos negativos que bien pueden convertirse en un referente de cambio (EC/051-01/010/M).

4.2.3.2.6. Escuela. Se presenta como relaciones de poder, de dominioy de sometimiento a las voluntades impuestas por el adulto; frente a las cuales los jóvenes reaccionan, demandan autonomía y buscan que se tenga en cuenta sus maneras particulares de pensar el mundo, su cultura y sus estéticas (EC/051-02/018/M).

Adicionalmente, desde la Ley 115 de 1994 se relaciona con darle un papel más participativo a la familia en la escuela, lo cual ha permitido avanzar en los esfuerzos por constituir las escuelas de padres.

4.2.3.2.7. Tópicos con bajas frecuencias. El primer tópico emergido con baja frecuencia es la educación artística, la cual se concibe como una práctica pedagógica en la formación de sujetos diversos en donde se concluye que la pedagogía tiene la finalidad de educar a los sujetos desde la experiencia y desde la didáctica, la cual guía el proceso de enseñanza.

En cuanto al pensamiento crítico, como otro concepto con baja frecuencia, se trasciende de la superación de la mirada individual a la formación de sujetos capaces de reflexionar de manera colectiva, la escuela y el contexto social que los rodea. Además, el abordaje del pensamiento crítico desde el poder, se relaciona con las fuerzas, las cuales logran disciplina de los cuerpos de los estudiantes en la escuela; se considera que el dispositivo pedagógico es de control de los sujetos (Foucault, 2002). Así, el poder es visto desde las transformaciones y los cambios propuestos por los colectivos de jóvenes; aquellos que deconstruyen las relaciones jerárquicas para dar paso a encuentros de reconocimiento propio y del otro, de solidaridad y construcción colectiva de su cultura, su identidad y sus prácticas particulares. 
En cuanto a la educación emocional, se piensa en relación con el comportamiento necesario para la convivencia escolar. En la misma línea, se conceptualiza la educación emocional desde los componentes de autoconocimiento, de autorregulación, de motivación, de empatía y de sociabilidad (EC/051-02/016/M).

Por otra parte, la educación para la paz se entiende como un conjunto de acciones orientadas a generar procesos de socialización, los cuales permitan la convivencia con equidad. Se trata sobre todas las acciones y procesos en la educación formal y la educación popular, las cuales se integran para ayudar a formar ciudadanos capaces de reconocer y potenciar la diferencia (EC/051-02/030/M).

La etnoeducación teorizada como un enfoque educativo de construcción colectiva, dirigido a los grupos indígenas y afrocolombianos, busca, desde un diálogo intercultural, fortalecer la autonomía y promover la apropiación y producción de conocimientos, costumbres y valores que le son propios a la realidad cultural y al proyecto global de vida de los grupos étnicos (MEN, 2019).

El sentido de la educación se enfoca en una crítica en torno a enfoques economicistas, influenciados por los intereses burocráticos gubernamentales, así como a los sistemas económicos, los cuales la limitan a un enfoque poco humanista, poco creativa y distante de las realidades que viven los estudiantes (EC/051-01/069/M). De manera alternativa, se plantea la necesidad de dotar de otro sentido más pertinente a la educación con la exigencia de procesos más contextualizados que respondan no solo a necesidades globales, sino que partan de las necesidades locales.

La evaluación se asocia más con un proceso formativo en donde el estudiante se prepara para ella, y no para la vida (EC/051-02/058/M, EC/051-02/066/M). Es entonces cuando la 
evaluación formativa se configura en una herramienta reguladora de los procesos educativos, en tanto posibilita el análisis de las situaciones actuales y la toma de decisiones para reorientar o reorganizar el quehacer educativo.

La lectura a la educación experiencial desde la sistematización —en calidad de modalidad de investigación cualitativa, crítica, participativa y formativa-, permite que se reconstruyan, se reflexionen, se analicen y se interpreten sistemáticamente las prácticas y experiencias de una colectividad. Aquella privilegia los saberes y puntos de vista de sus propios integrantes en la búsqueda del reconocimiento de los sentidos y las lógicas que la constituyen.

En otra línea, la educación es el lugar de la relación del encuentro con el otro. Por tanto, es necesario pensar y vivir la educación desde lo que sugieren las propias palabras de «experiencia»y de «alteridad» para que esta sea un encuentro a una experiencia nueva de ser y de saber (Skliar y Larrosa, 2009).

\subsubsection{Conclusiones}

El presente estudio ha permitido comprender el panorama conceptual que se viene construyendo en las regiones de educación y pedagogía desde los programas de formación posgradual de la Universidad Tecnológica de Pereira, la Universidad Católica de Pereira y la Universidad de Manizales y el Centro de Estudios Avanzados en Niñez y Juventud (CINDE). Cada universidad ha encauzado esfuerzos para entrever los tópicos globales que, como picos, montañas, mesetas y llanuras de la geografía, emergen de sus investigaciones. Esto posibilita comprender la urdimbre que se viene tejiendo en relación con la conceptualización, y las principales formas de abordar la educación y la pedagogía en el Eje Cafetero. 
En cuanto a la región pedagogía en dicha zona, su potencialidad se encuentra en una investigación centrada en la elaboración y el desarrollo de propuestas pedagógicas y didácticas que apuntan a la transformación de las prácticas de enseñanza, de los aprendizajes de los estudiantes, de los papeles de los docentes y demás actores educativos, los cuales interactúan en el contexto escolar, con una mirada comprensiva puesta en mejorar la calidad de la educación, ofrecida en la zona.

El análisis realizado en la región pedagogía permite identificar picos relevantes en la zona del Eje Cafetero. Estos son representados en tópicos como didáctica/enseñanza, prácticas pedagógicas y enfoques pedagógicos, los cuales se centran en la conceptualización de los elementos inherentes a las intervenciones didácticas para la construcción de aprendizajes en torno a los saberes escolares.

Desde este contexto y partiendo de la postura teórica asumida por los cartógrafos, se pueden establecer diferentes estrategias las cuales permiten la construcción de los saberes disciplinares y, por ende, el aprendizaje escolar, siendo las de mayor relevancia las que, desde los postulados de los enfoques pedagógicos socioconstructivista y critico social, teorizan sobre la didáctica y el entramado de relaciones gestadas en torno a esta.

Respecto a las investigaciones que conceptualizan la práctica pedagógica, se evidencia que para la zona del Eje Cafetero, esta se asume desde diversas perspectivas: en primer lugar, desde la práctica reflexiva como el proceso de enseñanza de un docente que reflexiona y se autoevalúa para entender y transformar su quehacer; en segundo lugar, se destaca la práctica educativa como una forma de poder que permite promover el cambio de las condiciones del mundo en el que se habita; en tercer lugar, desde la práctica docente, relacionada con el ejercicio profesional, mediado por el conocimiento científico; finalmente, la práctica pedagógica, la cual vincula la reflexión entre la teoría y la práctica, 
en aras de posibilitar nuevas formas de enseñanza y aprendizaje para el mejoramiento de la calidad de vida de las comunidades.

Otros tópicos emergentes, que pueden considerarse como llanuras dentro de este relieve, corresponden al uso pedagógico de las TIC como mediadoras potentes para lograr la interactividad y la construcción del conocimiento; las concepciones frente a las formas de aprender de los estudiantes, las cuales surgen de las experiencias de los docentes; así como el tópico maestro, donde aquel es considerado un sujeto activo, competente desde el saber, el hacer y el ser, con valores, intereses y postura política respecto al acto de enseñar.

Ahora bien, desde la Maestría en Educación de la Universidad Tecnológica de Pereira se puede evidenciar que la región pedagogía se erige con mayor relevancia para el estudio $y$, desde ella, se intenta explicar la trama de relaciones gestadas en el acto de enseñar y aprender en el contexto áulico. En esta geografía emerge como tópico de mayor relevancia la noción de didáctica, la cual es concebida como un campo en construcción el cual busca comprender la interactividad dada entre el docente y el estudiante en torno a los contenidos escolares; subsidiariamente, y con mediana relevancia, los conceptos de práctica pedagógica, el enfoque pedagógico y de aprendizaje permean de manera importante la didáctica general y las de los saberes específicos; con baja representatividad, aparecen tópicos como el uso pedagógico de las TIC, y el maestro y sus concepciones; y como una llanura, nace el concepto de competencias emocionales.

En general, todas estas situaciones, inherentes al acto educativo, intentan entender conceptualmente cuestiones relacionadas con la elaboración e implementación de apuestas de intervención en el aula, fundamentadas principalmente desde el enfoque pedagógico socioconstructivista con la intención de propiciar la transformación de los procesos de enseñanza del docente y la construcción de aprendizajes desde el desarrollo 
cognitivo, emocional y social del estudiante, lo cual es posible gracias a los procesos reflexivos realizados por los docentes sobre sus prácticas.

En el caso de la Universidad Católica de Pereira se encuentra una predominancia en las cartografías orientadas al análisis de la región pedagogía. Allí se resaltan los tópicos de prácticas pedagógicas y la autobiografía como los picos sobresalientes, siendo en estos donde las narrativas pedagógicas y las autoconceptualizaciones se ven intervenidas por las subjetividades de los maestros, el actuar desde sus sentires para comprender sus acciones y la aplicación de estrategias pedagógicas en el aula.

En esta región, desde las investigaciones, se aborda lo didáctico en temas relacionados con la acción pedagógica para el bienestar de la comunidad y se aporta a partir del desarrollo humano a la reflexión pedagógica desde la apropiación de un modelo pedagógico crítico.

La Universidad de Manizales y el CINDE tienen un pico marcado en las prácticas pedagógicas según las cuales se concibe al docente desde sus distintos saberes, no solo como mediador entre los estudiantes y el conocimiento, sino como generador de ambientes de aprendizaje consolidados por las expresiones afectivas. Además, en la geografía de dichas instituciones se concibe la práctica educativa como potencial de creación para una práctica docente, la cual propicia relaciones de poder; aquellas que permean los procesos de enseñanza en relación estrecha con la lectura y la interacción en el aula.

En relación con la región educación para la zona del Eje Cafetero, es relevante mencionar que esta se articula a la región pedagogía en tanto se enmarca en los contextos formales de enseñanza y aprendizaje de los distintos saberes escolares. Desde allí se ha considerado que la educación tiene un compromiso con el logro de objetivos para la solución de los problemas sociales 
desde apuestas por el respeto, la comunicación y la concertación, las cuales permitan la resignificación de las acciones dentro de las aulas de clase. En tal sentido, se evidencia que los conceptos de mayor relevancia, reflejados en los tópicos globales de la zona, hacen referencia a la educación para la formación de sujetos sociales y educación inclusiva.

En cuanto a la educación para la formación de sujetos sociales, se resalta la comprensión de los hechos y las causas de los fenómenos históricos y, con ello, el reconocimiento de los problemas actuales. Así pues, la apuesta está en propiciar un contexto de reflexión y diálogo constante para el desarrollo de habilidades intelectuales y de pensamiento crítico, el cual posicione al estudiante como un ciudadano con un fuerte compromiso social y preparado para responder a las demandas de la actual sociedad. Este aspecto exige el conocimiento profundo de la realidad y su comprensión desde diversas miradas y saberes; justamente porque todo ejercicio crítico es un ejercicio político y ciudadano; ante esto, es la educación la que juega un papel preponderante a la hora de constituir sujetos para el cambio y la transformación social.

Por su parte, la educación inclusiva es asumida en las investigaciones como el derecho que tienen todos los seres humanos a una educación de calidad independientemente de sus condiciones individuales, culturales, sociales, económicas y geográficas, es decir, aquellos aspectos inherentes a la diversidad humana. Adicionalmente, como lectura a los hallazgos encontrados en las tres universidades, el tópico genera una reflexión en torno a dos posibles miradas: la primera de tipo político-institucional y la segunda del momento histórico de la educación.

Como llanuras, emergen la noción de educación de adultos desde un papel político y social al dirigirse a personas que, a pesar de no haberse vinculado al sistema educativo, han desarrollado competencias las cuales les permiten evolucionar e incluirse en 
contextos sociales y económicos. Así mismo, en medio de la geografía de la región educación de la zona, se aborda el currículo oculto y emancipador, así como la evaluación entendida desde la planificación de estrategias e instrumentos para recopilar información sobre la práctica educativa con el fin de emitir juicios y tomar decisiones al respecto.

En la geografía de la región educación, particularmente, en la Universidad Tecnológica de Pereira, es evidente que el pliegue sobre el cual discurren los discursos teóricos alcanza sus mayores picos en relación con una educación, la cual se encuentra estrechamente ligada a las condiciones políticas, sociales, culturales y económicas de la actual sociedad. Este contexto exige de la institución educativa una respuesta emancipadora y transformadora para la resolución de problemáticas y situaciones propias de los espacios donde transcurre la vida de los estudiantes. En este sentido, las investigaciones analizadas abogan por una educación liberadora que permita la formación de seres humanos libres y comprometidos con la transformación de su entorno, $y$ que, además, asuman posturas críticas frente a la construcción de una sociedad democrática y participativa en la que la diferencia se convierta en una oportunidad de enriquecimiento de todos los actores sociales, una sociedad donde la garantía de los derechos permita una convivencia armónica.

Así, la cartografía de universidad considera que es tarea de la educación establecer un puente entre el saber disciplinar y el saber cultural desde el desarrollo del pensamiento crítico; aspecto que implica entenderla como un proceso de formación del ser humano, el cual comprende no solo la dimensión cognoscitiva y racional, sino también la espiritual, emocional y axiológica; una formación integral que permita a los estudiantes comprender la realidad social y actuar sobre ella para transformarla en el presente y el futuro. 
En la geografía de la región educación de la Universidad Católica de Pereira, es de resaltar que la educación liberadora se concibe desde diferentes miradas: en primer lugar, desde el diálogo como vehículo para el desarrollo del pensamiento autónomo y crítico; en segundo lugar, desde la aceptación del otro, donde se afirma que toda acción educativa y su inclusión tienen como finalidad romper las relaciones de poder y se reconoce el papel activo desde la libertad. Adicionalmente, se advierte el papel de los docentes en una educación liberadora; allí, se destaca la práctica educativa como una forma de poder por lo que el docente debe comprender sus actuaciones y profesionalizar su quehacer con el fin de promover el cambio en el mundo académico en el cual se desempeña.

Otro de los hallazgos de la región educación de las cartografías de la UCP es aquel que concibe el desarrollo cognitivo desde el riesgo psicosocial y sus implicaciones al interior del aula; factor a considerar en los procesos formativos para atender oportunamente a los estudiantes y construir procesos de paz desde las estrategias del aula. Por otro lado, se plantea la educación inclusiva como un proceso en el cual los individuos sean capaces de crear por sí mismos en cualquier momento de la vida, en el trabajo, en el hogar y, por supuesto, en el estudio.

La geografía de la región educación de la Universidad de Manizales y el CINDE devela la riqueza de paisajes que, desde la concepción de educación, muestra su pico más alto, estrechamente relacionado con la formación de sujetos con compromiso social. Esto, a partir del desarrollo de habilidades individuales y del reconocimiento del otro, lo cual construye y transforma las realidades desde sus prácticas en los contextos. Personas cuyo papel social y político implica el compromiso de asumir una postura crítica para promover cambios estructurales en la sociedad. 
También, se observa un pico marcado en la educación inclusiva desde la diversidad, concebida como un proceso de construcción y reconstrucción del conocimiento a través de la interacción de personas distintas, las cuales favorecen las formas conscientes y autónomas de identidad y pensamiento. En la geografía de la universidad también se proponen estrategias de enseñanza y aprendizaje diversificados y flexibles; esto, con la doble finalidad de dar respuesta a una realidad heterogénea, $y$ contribuir a la mejora y el enriquecimiento de las condiciones educativas, las relaciones sociales y culturales de los sujetos.

Por otro lado, la educación y el desarrollo humano integral busca la necesaria relación entre la escuela y la familia, aquella que permita la educabilidad de estudiantes conscientes de su papel y sus compromisos en la sociedad. Lo anterior, se logra a partir de potencializar las inteligencias múltiples para el desarrollo humano en términos de una enseñanza que no es uniforme sino, más bien, centrada en las particularidades de los individuos. Finalmente, se pretende formar personas que creen y transformen la cultura con el fin de impactar en los contextos en los cuales se desarrollan.

\section{Referencias bibliográficas}

Acaso, M. (2012). Pedagogías Invisibles: el espacio de aula como discurso. Catarata.

Ainscow, M. (2012). Haciendo que las escuelas sean más inclusivas: lecciones a partir del análisis de la investigación internacional. Revista de Educación Inclusiva, 5(1), 39-49.

Ainscow, M. y Miles, S. (2008). Por una educación para todos que sea inclusiva: ¿hacia dónde vamos ahora? Perspectivas, 38(1), 17-44. 
Ainscow, M.; Booth, T. \& Dyson, A. (2006). Improving Schools, Developing Inclusion. Routledge.

Arrese Igor, H. O. (2009). La teoría del reconocimiento de Axel Honneth como un enfoque alternativo al cartesianismo. Universidad Nacional de la Plata.

Ausubel, D. P. (1976). Psicología educativa. Un punto de vista cognoscitivo. Editorial Trillas.

.(1983). La teoría del aprendizaje significativo. Universidad de Río Grande.

Bachelard, G. (1982). La poética de la ensoñación. Fondo de Cultura Económica.

Benejam, P. (1997a). Las finalidades de la educación social. En P. Benejam y J. Pagés. (Eds.). Enseñar y aprender ciencias sociales, geografía e historia en la educación secundaria (pp. 151-168). Horsori.

(1997b). La selección y secuencia de los contenidos sociales. En P. Benejam y J. Pagés. (Eds.). Enseñar y aprender ciencias sociales, geografía e historia en la educación secundaria (pp. 71-95). Horsori.

Bisquerra, A. R. (2003). Educación emocional y competencias básicas para la vida. Revista de Investigación Educativa, 21(1), 7-43.

. (2000). Educación emocional y bienestar. Praxis.

Blanco, R. (2006). La equidad y la inclusión social: uno de los desafíos de la educación y la escuela hoy. REICE. Revista iberoamericana sobre calidad, eficacia y cambio en educación, 4(3), 1-15. 
. (2011). De la inclusión en la escuela a la inclusión en el aprendizaje. Palabra Maestra: publicación del premio compartir al maestro, 11(28), 3-4.

Blyth, W. A. L. (1976). Place, Time and Society 8-13: Curriculum Planningin History, Geography and Social Science. Collins.

Bolívar, A.; Domingo, J. y Fernández, M. (2001). La investigación biográfica-narrativa en educación. Editorial la Muralla.

Brousseau, G. (1986) Fundamentos y métodos de la didáctica. Facultad de Matemática, Astronomía y Física. Universidad de Córdoba.

Bruner, J. S. (1991). The Narrative Construction of Reality. Critical Inquiry, 18(1), 1-21.

Campos Campos, Y. (1998) Hacia un concepto de educación y pedagogía en el marco de la tecnología educativa. Tecnología educativa/pedagogía, 1-16. http://www.camposc. net/0repositorio/ensayos/98educacionypedagogia.pdf.

CAmps, A. (2003a). Miradas diversas a la enseñanza y el aprendizaje de la composición escrita. Lectura y Vida, 24(4), $2-11$.

. (Comp.). (2003b). Secuencias didácticas para aprender escribir. Grao.

Canals, A.; Boisot, M. H.; MacMillan, I. (2008). The spatial dimension of knowledge flows: a simulation approach. Cambridge Journal of Regions, Economy and Society, 2(1), 175-204. 
CARr, W. y Kemmis, S. (1998). Teoría crítica de la enseñanza. La investigación-acción en la formación del profesorado. Martínez Roca.

CARr, W. (1996). Una teoría para la educación: hacia una investigación educativa crítica. Ediciones Morata.

Casas, M.; Bosch, D. y González, N. (2005). Las competencias comunicativas en la formación democrática de los jóvenes: describir, explicar, justificar y argumentar. Enseñanza de las Ciencias Sociales, (4), 39-52. https://www.redalyc.org/ pdf/3241/324127616006.pdf.

Cassany, D. (1990). Enfoques didácticos para la enseñanza de la expresión escrita. Comunicación, Lenguaje y Educación, 6, 63-80. https://dialnet.unirioja.es/servlet/ articulo? codigo $=126193$.

(1999). Los enfoques comunicativos: elogio y crítica. Lingüística y literatura, 36(37), 11-33. https://repositori. upf.edu/bitstream/handle/10230/21223/cassany_enfoques. pdf?se.

(2001). La sociedad red. Alianza Editorial.

(2006) Tras las líneas. Sobre la lectura contemporánea. Anagrama.

Cassany, D.; Luna, M. y SAnZ, G. (2007). Enseñar lengua. Grao.

Castañeda, L. y Adell, J. (Eds.). (2012). Entornos Personales de Aprendizaje: clave para el ecosistema educativo en red. Marfil. http://www.edutec.es/sites/default/files/publicaciones/ castanedayadelllibrople.pdf 
CASTELLS, M. (2006). La sociedad red: una visión global. Alianza Editorial.

Castorina, J. (1996). El debate Piaget-Vygotsky: la búsqueda de un criterio para su evaluación. En J. A. Castorina; E. Ferreiro; M. Col de Olivera y D. Lerner. (Eds.). Piaget-Vygotsky: contribuciones para replantear el debate (pp. 9-44). Paidós.

Chaux, E.; Lleras J. y Velásquez, A. M. (2004). Competencias ciudadanas: de los estándares al aula. Ministerio de Educación Nacional, CESO, Ediciones Uniandes.

Chevallard, Y. (1985). La transposition didactique. Du savoir savant au savoir enseigné. La Pensée Sauvage.

. (1991). La transposición didáctica: del saber sabio al saber enseñado. Aique.

Coll, C. (1990). Aprendizaje escolar y construcción del conocimiento. Paidós.

. (2001). Constructivismo y educación: la concepción constructivista de la enseñanza y del aprendizaje. En C. Coll; J. Palacios y A. Marchesi. (Comps.). Desarrollo psicológico y educación. Psicología de la educación escolar (pp. 157-186). Alianza Editorial.

- (2007). TIC y prácticas educativas: realidades $y$ expectativas. Fundación Santillana.

Coll, C.; Colomina, R.; Onrubia J. y Rochera, M. (1992). Actividad conjunta y habla: una aproximación al estudio de los mecanismos de influencia educativa. Infancia $y$ Aprendizaje, 59(60), 189-232. 
. (1995). Actividad conjunta y habla: una aproximación al estudio de los mecanismos de influencia educativa. En P. Fernández y M. Melero (Eds.). La interacción social en contextos educativos (pp. 193-326). Siglo xx Editores.

Coll, C. y Monereo, C. (Eds.). (2008). Psicología de la educación virtual. Aprender y enseñar con las tecnologías de la información y la comunicación. Ediciones Morata.

Coll, C.; Mauri, T. y Onrubia, J. (2008). La utilización de las tecnologías de la información y la comunicación en la educación: de diseño tecno-pedagógico a las prácticas de uso. En C. Coll Salvador y C. Monereo (Coords.). Psicología de la educación virtual (pp. 74-103). Morata.

Colomina, R.; Onrubia, J. y Rochera, M. J. (2004). Interactividad, mecanismos de influencia educativa $y$ construcción de conocimiento en el aula. En Desarrollo psicológico y educación. Psicología de la educación escolar (pp. 437-460). Alianza Editorial.

Comenio, J. A. (1998). Didáctica Magna. Porrúa.

Daza-Pérez, E. y Moreno-Cárdenas, J. (2010). El pensamiento del profesor de ciencias en ejercicio. Concepciones sobre la enseñanza y el aprendizaje de las ciencias naturales. Revista Electrónica de Enseñanza de las Ciencias, 9(3), 549-568. http:// reec.uvigo.es/volumenes/volumen9/ART4_Vol9_N3.pdf.

De Haro, J. J. (2010). Redes sociales para la educación. Anaya multimedia.

Dewey, J. (1910). How We Think. Carbondale. Southern Illinois University Press. 
(1975). Democracia y educación. Ediciones Morata.

Dollard, J.; Dobb, L. W.; Miller, N. E.; Mower, O. H. y Sears, R. R. (1939). Frustration and agression. Yale University Press.

Durkheim, É. (1985). La división del trabajo social. PlanetaAgostini.

Duval, R. (1999). Semiosis y pensamiento humano: Registros semióticos y aprendizajes intelectuales. Universidad del Valle.

Echeita Sarrionandia, G. y Duk Homad, C. (2008). Inclusión Educativa. REICE. Revista Electrónica Iberoamericana sobre Calidad, Eficacia y Cambio en Educación, 6(2), 1-8. https:// www.redalyc.org/pdf/551/55160201.pdf.

Erausquin C.; Basualdo M. E. y González D. (2006). Heterogeneidad de giros y tensiones en los modelos mentales de "psicólogos en formación» sobre la intervención profesional en problemas situados. Hacia una dialéctica de la diversidad. Anuario de Investigaciones, 13, 105-123. https:// www.redalyc.org/articulo.oa?id=369139942011.

Feixas, M (2010). Enfoques y concepciones docentes en la universidad. Revista electrónica de investigación y evaluación educativa, 16(2), 1-27. https://www.researchgate. net/profile/Monica_Feixas/publication/315338988 Enfoques_y_concepciones_docentes_en_la_universidad/ links / 5 d62 c489299bf 1 f7 0b 0d 842a/Enfoques - y concepciones-docentes-en-la-universidad.pdf.

Foucault, M. (2002a). Vigilar y castigar: nacimiento de la prisión. Siglo Xxi Editores.

Freire, P. (1970). Pedagogía del oprimido. Tierra Nueva, Siglo XXI Editores. 
. (1999). Educação como prática da liberdade. Paz e Terra.

. (2004) Pedagogía de la autonomía. Paz y Tierra.

. (2005). Pedagogía de la Esperanza. Un reencuentro con la pedagogía del oprimido. Siglo XxI Editores.

Freud, S. (1912). Sobre la dinámica de la trasferencia. En S. Freud, Obras completas, Tomo XII (pp. 93-106). Amorrortu Editores.

Gardner, H. (1997). La mente no escolarizada. Cómo piensan los niños y cómo deberían enseñar las escuelas. Paidós Ibérica S. A.

González-González, M. A. (2014). Metáforas y paradojas de los miedos en los sujetos docentes. Revista Latinoamericana de Ciencias Sociales, Niñez y Juventud, 12(1), 355-370. http:// www.scielo.org.co/pdf/rlcs/v12n1/v12n1a22.pdf.

GubA, E. G. (1990). The Alternative Paradigm Dialog. En E. G. Guba (Ed.). The Paradigm Dialog (pp. 17-26). Sage.

Honneth, A. (1996). Reconocimiento y obligaciones morales. Revista Internacional de Filosofía Política, 8, 5-17. http://e-spacio.uned.es/fez/eserv/bibliuned:filopoli1996-8-6443431F-2BE8-F544-3A97-47F0DA074DF8/ reconocimiento_obligaciones.pdf.

. (1997). La lucha por el reconocimiento. Por una gramática moral de los conflictos sociales. Crítica Grijalbo. http://asj. sagepub.com/content/47/4/351.full.pdf+html.

- (2007). Reificación. Un estudio en la teoría del reconocimiento. KATZ Editores. 
Hymes, D. (1971). On Communicative Competence. University of Pennsylvania.

. (1996). Acerca de la competencia comunicativa. Forma y función, 9, 13-37. https://revistas.unal.edu.co/index.php/ formayfuncion/article/view/17051/17909.

IMBERNON, F. (2002). Reflexiones globales sobre la formación y el desarrollo profesional del profesorado en el Estado español y latino América. Revista Educar, (30), 15-25. https://dialnet. unirioja.es/servlet/ articulo? codigo $=440773$.

Imbernon, F. y Jarauta, B. (2012). Pensando el futuro de la educación una nueva escuela para el siglo XXII. Grao.

Imbernon, F.; Parcerisa Aran, A.; Zabala Vidiella, A.; Antúnez Marcos, S.; Del Carmen Martín, L. M. (1992). Del proyecto educativo a la programación aula (El trabajo de cada día). Grao.

Jorba, J. y SANMARTí, N. (1996). Enseñar, aprender y evaluar: un proceso de regulación continua. Propuesta didáctica para las áreas de Ciencias de la Naturaleza y Matemáticas. Ministerio de Educación y Cultura.

Lanza, C. L. (2007). Núcleo de práctica. Departamento de Psicopedagogía. Universidad Tecnológica de Pereira.

LeÓN, D. I. (1997). La didáctica de las disciplinas en la educación básica. Universidad Externado de Colombia.

LEVIS, D (2007). Enseñar y aprender con informática/enseñar y aprender informática. Medios informáticos en la escuela argentina. En D. Levis y R. CABello. Medios informáticos en la educación (pp.21-50). Prometeo. 
LÉvy, P. (2004). Inteligencia colectiva. Por una antropología del ciberespacio. (F. M. Álvarez, Trad.). http:// inteligenciacolectiva.bvsalud.org/public/documents/pdf/es/ inteligenciaColectiva.pdf.

LEY 115 DE 1994. (1994, 8 de febrero). Congreso de la República de Colombia. Diario oficial Nro. 41.214. http://www. secretariasenado.gov.co/senado/basedoc/ley_0115_1994. html.

Litwin, E. (2008). El oficio de enseñar. Condiciones y contextos. Paidós.

López Melero, M. (2011). Barreras que impiden la escuela inclusiva y algunas estrategias para construir una escuela sin exclusiones. Innovación Educativa, (21), 37-54. https:// minerva.usc.es/xmlui/bitstream/handle/10347/6223/ pg_039-056_in21_1.pdf?sequence=1\&isAllowed=y.

Macedo, B.; Katzkowicz, R. y Quintanilla, M. (2006). La educación de los derechos humanos desde una visión naturalizada de la ciencia y su ciudadanía a través de la educación científica. Ariel.

Martínez-Solís, M. C. (2000). Análisis del discurso y práctica pedagógica: una propuesta para leer, escribir y aprender mejor. Editorial Homo Sapiens.

. (2002). Propuesta de intervención pedagógica para la comprensión y producción de textos académicos. Universidad del Valle, Escuela de Ciencias del Lenguaje.

. (2005). La construcción de los procesos argumentativos en el discurso. Perspectivas teóricas y trabajos prácticos. Universidad del Valle, Escuela de Ciencias del lenguaje. 
MASLACH, C. y PINES, A. (1977). The burnout syndrome in the day care setting. Child Care Quartely, 6(2), 100-113. https:// www.researchgate.net/publication/226884500_The_BurnOut_Syndrome_in_the_Day_Care_Setting.

Mercer, N. (1997). La construcción guiada del conocimiento. El habla de profesores y alumnos. Paidós.

MINISTERIO DE EDUCACIÓN NACIONAL (1996). La etnoeducación: realidad y esperanza de los pueblos indígenas y afrocolombianos, lineamientos de etnoeducación $y$ proyectos etnoeducativos institucionales. Editorial El Ministerio.

Morin, E. (1982). La unidad del hombre como fundamento y aproximación interdisciplinaria. En L. Apostel, Interdisciplinariedad y ciencias humanas (pp. 188-212). Tecnos/Unesco.

Nussbaum, M. y Glover, J. (Ed.). (1995). Women, Culture and Development: A Study of Human Capabilities. Clarendon Press.

Pagés, J. (1997). La formación del pensamiento social. En P. Benejam y J. Pagés. (Eds.). Enseñar y aprender ciencias sociales, geografía e historia en la educación secundaria (pp. 151-168). Horsori.

- (2007). La enseñanza de las ciencias sociales y la educación para la ciudadanía. Didáctica Geográfica, 3. época, 9, 205-214. 
(2009). El desarrollo del pensamiento histórico como requisito para la formación democrática de la ciudadanía. Reseñas de Enseñanza de la Historia, (7), 69-91. https:// pagines.uab.cat/joan_pages/sites/pagines.uab.cat.joan_ pages/files/2009_Pages_Rese\%c3\%b1as_7.pdf.

Pagés, J. y Santisteban, A. (2011). Las cuestiones socialmente vivas y la enseñanza de las ciencias sociales. Bellaterra.

Pérez, M. y RoA, C. (2010). Herramienta para la vida: hablar, leer y escribir para comprender el mundo. Referentes para la didáctica del lenguaje en el primer ciclo. Secretaría de Educación Distrital.

Perrenoud, P. (2007). Desarrollar la práctica reflexiva en el oficio de enseñar. Editorial Grao.

Pipkin, D. (2009). Pensar lo social. La Crujía Ediciones.

Piscitelli, A.; Adaime, I. y Binder, I. (2010). El proyecto Facebook y la posuniversidad. Sistemas operativos sociales y entornos abiertos de aprendizaje. Editorial Ariel S. A.

Polya G. (1963). Cómo plantear y resolver problemas. Trillas.

Ponce, I. (2012). Redes sociales. http://recursostic.educacion. es/observatorio/web/ca/internet/web-20/1043-redessociales? format $=$ pdf.

Pozo, J. I., Scheuer, N., Pérez, M. P., Mateos, M., Martín, E.; De La Cruz, M. (2006). Nuevas formas de pensar la enseñanza y el aprendizaje: las concepciones de profesores $y$ alumnos. Grao.

Quintar, E. (2002). La enseñanza como puente a la vida. Universidad Nacional del Comahue, UPN. 
Rincón, G. (2009). La didáctica de la lengua castellana: Reconceptualización y retos actuales. Universidad del Valle.

Rodríguez, R. (2013). El desarrollo de la práctica reflexiva sobre el quehacer docente, apoyada en el uso de un portafolio digital, en el marco de un programa de formación para académicos de la Universidad Centroamericana de Nicaragua [Tesis de Doctorado en Educación y Sociedad, Universitat de Barcelona].

Rogoff, B. (1993). Aprendices del pensamiento. Desarrollo cognitivo en el contexto social. Paidós.

Ruíz, F. (2007). Modelos didácticos para la enseñanza de las ciencias naturales. Revista Latinoamericana de Estudios Educativos (Colombia), 3(2), 41-60. https://www.redalyc.org/ pdf/1341/134112600004.pdf.

Ruíz Ortega, F. J.; Tamayo, O. E. y Márquez Bargalló, C. (2014). Cambio en las concepciones de los docentes sobre la argumentación y su desarrollo en clase de ciencias. Enseñanza de las ciencias, 32(3), 53-70.

Santisteban, A. (2004). Didáctica del conocimiento del medio social y cultural en la educación primaria: ciencias sociales para comprender, pensar y actuar. Síntesis.

Santisteban, A. (2011). Las finalidades de la enseñanza de las ciencias sociales. En A. Santisteban y J. Pagés. (Coords.). Didáctica del conocimiento del medio social y cultural en la educación primaria: ciencias sociales para aprender, pensar y actuar (pp. 63-84). Síntesis.

Schön, D. (2002). La formación de profesionales reflexivos. Hacia un nuevo diseño de la enseñanza y el aprendizaje en las profesiones. Editorial Paidós. 
Sen, A. (1999a). Desarrollo y libertad. Editorial Planeta.

. (1999b). El futuro del Estado de Bienestar. Conferencia pronunciada en el «Círculo de Economía» de Barcelona. La Factoría. http://www.lafactoriaweb.com/articulos/amartya. htm.

. (2000). Desarrollo y libertad. Planeta.

Sen, A. y Brundtland, G. H. (1999). Romper el ciclo de la pobreza: invertir en la infancia. Conferencias magistrales. Banco Interamericano de Desarrollo.

Shulman, L. S. (2001). Conocimiento y enseñanza. Estudios públicos, 83, 163-196. https://www.cepchile.cl/cep/site/ docs/20160303/20160303184436/rev83_shulman.pdf.

Skliar, C. y Larrosa, J. (2009). Experiencia y alteridad en educación. Homo Sapiens Ediciones.

Socas Duarte, M. (2015). Ensayo sobre creación y pedagogía. Expresión plástica infantil en la escuela pos-moderna. Tomo III. Editorial Dunken

Solé, I. y Teberosky, A. (2001). La enseñanza y el aprendizaje de la alfabetización. Alianza.

Stainback, S. y Stainback, W. (Coord.). (2007). Aulas inclusivas. Un nuevo modo de enfocar y vivir el currículo. Narcea Ediciones.

Tamayo, O. (2009). Didáctica de las ciencias: la evolución conceptual en la enseñanza y el aprendizaje de las ciencias. Universidad de Caldas.

TARdif, M. (2004). Los saberes del docente y su desarrollo profesional. Narcea. 
Organización de LAS NACIONES UNIDAS PARA LA EdUCACión, LA Ciencia y la Cultura [UNESCO]. (1976). Recomendación de la Unesco sobre educación de adultos, aprobada en la $19^{a}$ reunión de la Conferencia General en Nairobi el 26 de noviembre de 1976.

. (2008). Conferencia Internacional de Educación. La Educación inclusiva: el camino hacia el futuro. Unesco. http://www.ibe.unesco.org/fileadmin/user_upload/Policy_ Dialogue/48th_ICE/CONFINTED_48-3_Spanish.pdf.

VéLEZ, L. (2013). La educación inclusiva en los programas de formación docente. Folios Segunda época, (37), 95-113.

Villada, D. (1997). Evaluación integral de los procesos educativos. Artes Gráficas Tizán.

Villada, D. (2007) Competencias. Sintagma.

Villada, D. (2014). Perspectiva del desarrollo humano desde la persona. UCP.

Vygotsky, L. S. (1979). El desarrollo de los procesos psicológicos superiores. Crítica.

Zabala, A. (2007). Práctica educativa. Editorial Graó.

Zambrano, A. (2005). Didáctica, pedagogía y saber. Editorial Magisterio. 
Trabajos de grado de maestría y tesis de doctorado citados

EC/043/002/D. Patiño-Giraldo, L. E. (2010). La lengua de señas colombiana como mediadora en el proceso de conceptualización de nociones relacionadas con las ciencias sociales en niños y niñas no oyentes [Tesis de Doctorado en Ciencias Sociales, Niñez y Juventud, Universidad de Manizales]. http://biblioteca.clacso.edu.ar/Colombia/ alianza-cinde-umz/20130225050457/tpatino.pdf.

EC/043/006/D. Palacios Mena, N. (2010). Derechos, socialización y subjetividad política en la escuela [Tesis de Doctorado en Ciencias Sociales, Niñez y Juventud].

EC/043/007/D. Mejía Franco, D. N. (2012). Elementos estructurales de los videojuegos potencialmente educativos para el desarrollo de temáticas escolares relacionadas con el pensamiento espacial en niños y niñas entre ocho y diez años [Tesis de Doctorado en Ciencias Sociales, Niñez y Juventud, Universidad de Manizales]. https:// repository.cinde.org.co/bitstream/handle/20.500.11907/511/ MejiaFrancoDivaNelly2012.pdf? sequence $=1 \&$ isAllowed $=\mathrm{y}$.

EC/043/008/D. Moromizato Izu, R. (2012). Transiciones educativas en comunidades indígenas de la amazonia peruana: del hogar a los programas educativos [Tesis de Doctorado en Ciencias Sociales, Niñez y Juventud, Universidad de Manizales]. http://biblioteca.clacso. edu.ar/Colombia/alianza-cinde-umz/20130401060539/ TesisReginaKMoromizatoIzu.pdf. 
EC/043/012/D. Rosero Prado, A. L. (2012). Mecanismos de influencia educativa en la enseñanza y el aprendizaje de la argumentación en niños y niñas de cinco a seis años del nivel de transición de la educación preescolar [Tesis de Doctorado en Ciencias Sociales, Niñez y Juventud, Universidad de Manizales]. https://repository.cinde.org.co/bitstream/ handle/20.500.11907/499/RoseroPradoAnaLucia2012. pdf? sequence $=1 \&$ is Allowed $=\mathrm{y}$.

EC/043/015/D. Aguirre DÁvila, E. (2013). Relación entre prácticas de crianza, temperamento y comportamiento prosocial de niños de quinto y sexto grado de la educación básica, pertenecientes a seis estratos socioeconómicos de Bogotá, D. C. [Tesis de Doctorado en Ciencias Sociales, Niñez y Juventud, Universidad de Manizales]. http://biblioteca.clacso.edu.ar/Colombia/alianza-cindeumz/20140620113621/EduardoAguirreD.pdf.

EC/043/032/D. AcostA, D. A. (2017). La sensitividad cognitiva: hacia un modelo de su funcionamiento. Manizales: Doctorado en ciencias sociales, niñez y juventud. [Tesis de Doctorado en Ciencias Sociales, Niñez y Juventud, Universidad de Manizales]. http://biblioteca.clacso. edu.ar/Colombia/alianza-cinde-umz/20170925114012/ DavidArturoAcostaSilva.pdf.

EC/051-01/010/M MenJura-Escobar, M. I.; Orozco-Tobar, A. M.; Valladares-Ruiz, A. Y. y López-OrdóÑez, J. G. (2012). La diversidad en la escuela: una mirada desde las concepciones de los docentes de básica primaria en contextos educativos rurales [Tesis de Maestría en Educación desde la Diversidad, Universidad de Manizales]. 
EC/051-01/019/M. Garzón-Arcos, M. R.; Botina-Paz, M. F.; Benavides, J. S.; Ríos-Patiño, A. G. (2013). El miedo en las prácticas pedagógicas. [Tesis de Maestría en Educación desde la Diversidad, Universidad de Manizales].

EC/051-01/029/M. Gómez-Ordóñez, E.; Guerrero-Martínez, G.

D. R.; Buesaquillo, M.; González-González, M. A. (2013). Prácticas pedagógicas y diversidad. [Tesis de Maestría en Educación desde la Diversidad, Universidad de Manizales].

EC/051-01/031/M. Ayala Escobar, N. E.; Calvachi, R. E.; Guaranguay Benítez, N. R.; Hernández Benavides, D. A. y Trujillo-Caicedo, Z. R. (2013). Reflexiones que apoyan la transformación del componente pedagógico hacia la educación desde la diversidad [Tesis de Maestría en Educación desde la Diversidad, Universidad de Manizales].

EC/051-01/049/M. Mera-Prieto, I. Y.; Cortes-Solar, A. R.; JimÉnEz-GuZmÁn, C. P. (2015). El reconocimiento de los "otros" a través del juego en la didáctica de las matemáticas permite dinamizar las aulas inclusivas. [Tesis de Maestría en Educación desde la Diversidad, Universidad de Manizales].

EC/051-01/055/M. Escobar-Gómez, A. M.; García-Londoño, W. F.; Peláez-Buitrago, M. I.; Restrepo-Otálvaro, C. P. y DE GIL. G. I. (2015). La cuestión del sujeto desde las percepciones pedagógicas y didácticas de los docentes de escuela nueva. [Tesis de Maestría en Educación desde la Diversidad, Universidad de Manizales].

EC/051-01/058/M. Yonda, M, Obregón, J, y Quijano, O. (2015). La escuela como dispositivo de sujeción o espacio para la subjetivación. Una lectura en contextos locales. [Tesis de Maestría en Educación desde la Diversidad, Universidad de Manizales]. 
EC/051-01/059/M. Guapucal Cuasanchir, M. E. y Jaguandoy Chamorro, M. Y. (2015). La formación docente como estrategias pedagógicas para fortalecer la atención a estudiantes con necesidades educativas diversas en la Institución Educativa Luis Irizar Salazar del municipio de Barbacoas (NAR). [Tesis de Maestría en Educación desde la Diversidad, Universidad de Manizales].

EC/051-01/061/M. Arroyo-Estrada, L. Del C.; PalaciosDelgado, C.; Ramos-Ramos, M. Del S. y Cadavid-Marín, A. M. (2015). Las huellas vitales y su contribución en la potenciación de las inteligencias múltiples [Tesis de Maestría en Educación desde la Diversidad, Universidad de Manizales].

EC/051-01/069/M. Toro-Marín, S. P. y Quintar, E. B. (2016). El aula como espacio de reconocimiento: una mirada desde la sobreexigencia [Tesis de Maestría en Educación desde la Diversidad, Universidad de Manizales].

EC/051-02/003/M. Orozco Rubio, M. Del P. (2010). Confiabilidad y validez predictiva de la prueba de evaluación de inteligencias múltiples de las estudiantes de los grados séptimo y noveno del Colegio Eugenia Ravasco de Manizales [Tesis de Maestría en Educación y Desarrollo Humano, Universidad de Manizales]. https://repository.cinde.org.co/bitstream/ handle/20.500.11907/435/OrozcoRubioMariadelPilar2010. pdf? sequence $=1 \&$ is Allowed $=\mathrm{y}$.

EC/051-02/004/M. Robledo Castro, C. (2011). Desarrollo de competencias comunicativas en la formación del psicólogo, una perspectiva biográfica [Tesis de Maestría en Educación y Desarrollo Humano, Universidad de Manizales]. http://biblioteca.clacso.edu.ar/Colombia/alianza-cindeumz/20130318071735/TesisCarolina.pdf. 
EC/051-02/016/M Montoya Guzmán, A. (2014). Prácticas discursivas sobre agencia política de jóvenes en contextos de vulnerabilidad y violencia en la Institución Educativa Liceo Mixto Sinaí de la Comuna Nro.5 "Ciudadela del Norte» de la ciudad de Manizales-Caldas-Colombia [Tesis de Maestría en Educación y Desarrollo Humano, Universidad de Manizales]. https://repository.cinde.org.co/bitstream/ handle/20.500.11907/422/MontoyaGuzmanAlvaro2014. pdf? sequence $=1$ \&isAllowed $=\mathrm{y}$.

EC/051-02/017/M. Bermúdez Pacheco, A. (2013). Prácticas discursivas de la salud mental de los jóvenes de la Institución Educativa Belisario Peña Piñeiro IEBPP del municipio de Roldanillo Valle del Cauca [Tesis de Maestría en Educación y Desarrollo Humano, Universidad de Manizales]. https://repository.cinde.org.co/bitstream/ handle/20.500.11907/426/BermudezPachecoAndreina2013. pdf? sequence $=1$ \&isAllowed $=y$.

EC/051-02/018/M. Castañeda-Jiménez, A. F.; Salazar-Henao, M. (2014). Prácticas discursivas de la agonía institucional de niños en contexto de vulnerabilidad en la corporación superarse y el Centro Juvenil Amigoniano. [Tesis de Maestría en Educación y Desarrollo Humano, Universidad de Manizales].

EC/051-02/020/M Jiménez CÁrdenas, D. M. y Franco Zuluaga, J. M. (2014). Formas y expresiones de la capacidad de agencia de un grupo de jóvenes del servicio social estudiantil [Tesis de Maestría en Educación y Desarrollo Humano, Universidad de Manizales]. https://repository.cinde.org.co/bitstream/ handle/20.500.11907/1282/FrancoZuluagaJohannaM2015. pdf? sequence $=1$ \&isAllowed $=\mathrm{y}$. 
EC/051-02/030/M. Henao Ramírez, R.; López Peralta, D.; Mosquera Ortiz, E. y Pardo Rodríguez, N. (2014). Narrativas de jóvenes sobre los sentidos de convivencia pacifica en la escuela [Tesis de Maestría en Educación y Desarrollo Humano, Universidad de Manizales]. https:// repository.cinde.org.co/bitstream/handle/20.500.11907/403/ HenaoRamirezRubiela2014.pdf? sequence $=1$ \&isAllowed $=y$.

.EC/051-02/051/M. Osorio López, X.; Calderón Lindarte, L. K. y Rendón Monsalve, S. M. (2016). Estrategias de regulación metacognitiva en entornos virtuales de aprendizaje. [Tesis de Maestría en Educación y Desarrollo Humano, Universidad de Manizales].

EC/051-02/056/M. Zapata-Herrera, O. M.; Blandón-Henao, G.; Orrego-Noreña, J. F. (2016). El grafiti. Formas de comunicación emergentes en la escuela. [Tesis de Maestría en Educación y Desarrollo Humano, Universidad de Manizales].

EC/051-02/058/M Chamorro, H. A.; Camocho-Díaz, C. F. y Loaiza-Zuluaga, Y. E. (2017). Concepciones de los estudiantes sobre la evaluación del aprendizaje en la Fundación Universitaria Católica Lumen Gentium (Cali). [Tesis de Maestría en Educación y Desarrollo Humano, Universidad de Manizales].

.EC/051-02/066/M. Acosta Franco, I. C.; Jaramillo, J. M. y Valencia Abraham, D. A. (2017). Concepciones de evaluación en estudiantes, docentes y padres de familia de dos instituciones educativas públicas del Programa Ondas. [Tesis de Maestría en Educación y Desarrollo Humano, Universidad de Manizales]. https://repository.cinde.org. $\mathrm{co} / \mathrm{bitstream} / \mathrm{handle} / 20.500 .11907 / 2532 /$ Informe $\% 20$ final $\% 20$ de $\% 20$ investigaci $\%$ c3 $\%$ b3n $\% 20 \% 28$ Johana $\% 20$ Jaramillo\%2c\%20Isabel\%20Acosta $\% 20 y \% 20$ Didier $\% 20$ Valencia $\% 29$.pdf? sequence $=2 \&$ isAllowed $=y$. 
EC/051-02/073/M. Lamprea Chalarca, P. A. y Pineda Gaviria, A. L. (2017). Sentidos de alteridad en los docentes de educación media. [Tesis de Maestría en Educación y Desarrollo Humano, Universidad de Manizales]. https://repository.cinde.org.co/ bitstream/handle/20.500.11907/2525/Informe\%20Final. pdf? sequence $=1 \&$ isAllowed $=$ y.

EC-051-01-069-M. Toro-Marín, S. P. y Quintar, E. B. (2016). El aula como espacio de reconocimiento: una mirada desde la sobreexigencia. [Tesis de Maestría en Educación desde la Diversidad, Universidad de Manizales].

RDA/018/001/M. TrujILlo-GonzÁLez, A. L. (2015). Maestra en Obra. [Tesis de Maestría en Pedagogía y Desarrollo Humano, Universidad Católica de Pereira].

RDA/018/004/M. Gallego Galvis, B. L.; Melo Pineda, C. y Londoño Osorio, F. A. (2016). ¿De qué manera se configuran las resistencias ético políticas en el quehacer pedagógico de tres docentes de la ciudad de Pereira? [Tesis de Maestría en Pedagogía y Desarrollo Humano, Universidad Católica de Pereira]. https://repositorio.ucp. edu.co/bitstream/10785/4237/1/DDMPDH50.pdf.

RDA/018/007/M. GÁlvez-Torres, M. E. y Zuleta-SAlAZAR, L. M. (2016). Narrativas y expresión artística en educación. [Tesis de Maestría en Pedagogía y Desarrollo Humano, Universidad Católica de Pereira].

RDA/018/009/M. Martínez Torres, A. Y. y Guevara M. L. (2016). Representaciones pedagógicas de la paz de unas maestras de Pereira. [Tesis de Maestría en Pedagogía y Desarrollo Humano, Universidad Católica de Pereira]. https://repositorio.ucp.edu.co/bitstream/10785/4029/1/ DDMPDH37.pdf. 
RDA/018/010/M. Martínez Sotelo, A. (2016). Las narrativas pedagógicas y su contribución en el fortalecimiento de la autoestima. [Tesis de Maestría en Pedagogía y Desarrollo Humano, Universidad Católica de Pereira].https://repositorio. ucp.edu.co/bitstream/10785/4028/1/DDMPDH36.pdf.

RDA/018/011/M Grisales Vera, C. M. (2016). Amores y desamores pedagógicos de una docente e implicaciones en los procesos formativos. [Tesis de Maestría en Pedagogía y Desarrollo Humano, Universidad Católica de Pereira]. https://repositorio.ucp.edu.co/bitstream/10785/4027/1/ DDMPDH35.pdf.

RDA/018/012/M. Grisales Vera, C. M. (2016). Amores y desamores pedagógicos de una docente e implicaciones en los procesos formativos. [Tesis de Maestría en Pedagogía y Desarrollo Humano, Universidad Católica de Pereira]. https://repositorio.ucp.edu.co/bitstream/10785/4027/1/ DDMPDH35.pdf.

RDA/018/014/M. Arango-Ríos, M. S. (2015). La participaciónacción de la comunidad educativa de la institución "Sofía Hernández Marín" en la resignificación del proyecto educativo. [Tesis de Maestría en Pedagogía y Desarrollo Humano, Universidad Católica de Pereira].

RDA/018/017/M. Trujillo Trujillo, J.; Bernal García, K.; Corales Orozco, L. A. y Quiroga Zapata, S. P.; (2015). Proyecto pedagógico de aula basado en el arte, para el desarrollo de aprendizaje significativo. [Tesis de Maestría en Educación y Desarrollo Humano, Universidad Católica de Pereira]. https://repositorio.ucp.edu.co/ bitstream/10785/3159/3/DDMPDH22.pdf. 
RDA/018/018/M. Barrios Arroyave, F. A. y García Giraldo, C. L. (2015). Secuencia didáctica para el uso pedagógico de narrativas textuales o digitales. Una propuesta para otorgar sentido a la identidad personal de los estudiantes, en el marco de las competencias ciudadanas a partir de las experiencias de las instituciones educativas instituto Kennedy y Aquilino Bedoya. [Tesis de Maestría en Pedagogía y Desarrollo Humano, Universidad Católica de Pereira]. https://repositorio. ucp.edu.co/bitstream/10785/3155/1/SECUENCIA $\% 20$ DID \% c3\%81CTICA \%20PARA \%20EL\%20USO $\% 20$ DE\%20NARRATIVAS \%20TEXTUALES\%200\%20 DIGITALES.pdf.

RDA/018/019/M. Cardona Ortiz, A. M.; Vásquez Valencia, M. I. y ReY López M. L. (2015). Autorreconocimiento de la mujer maestra. [Tesis de Maestría en Pedagogía y Desarrollo Humano, Universidad Católica de Pereira]. https://repositorio.ucp.edu.co/bitstream/10785/3160/1/ AUTORRECONOCIMIENTO.pdf.

RDA/018/020/M. Gómez-LóPEz, J. I. (2015). Las didácticas como herramienta en la formación y transformación de los estudiantes desde sus procesos de aprendizaje. [Tesis de Maestría en Pedagogía y Desarrollo Humano, Universidad Católica de Pereira].

RDA/018/021/M. Bedoya-CeBallos, N. J. (2015) Las soledades en una mujer docente: reflexiones de un relato autobiográfico. [Tesis de Maestría en Pedagogía y Desarrollo Humano, Universidad Católica de Pereira]. 
RDA/018/022/M. Franco Acevedo, C. L. (2015). Resignificación del proyecto educativo institucional de la Institución Educativa San Francisco de Asís, a partir de las prácticas y los saberes socioculturales de su comunidad educativa. [Tesis de Maestría en Pedagogía y Desarrollo Humano, Universidad Católica de Pereira]. https://repositorio.ucp.edu.co/bitstream/10785/3152/1/ Resignificaci\%C3\%B3n\%20Proyecto\%20Educativo $\% 20$ Instituional $\% 20 \% 5$ BClaudia $\% 20$ Franco $\% 5$ D.pdf.

RDA/018/023/M. Romero Salazar, A. A.; Cardona Osorio, J. C.; SÁnchez Royo, L. Del C. y Aragón Palacios, S. (2015). Propuesta pedagógica socioconstructivista en ciencias naturales para atender a niños de grado quinto con trastorno de déficit de atención e hiperactividad. [Tesis de Maestría en Pedagogía y Desarrollo Humano, Universidad Católica de Pereira].

RDA/018/024/MArce Ortiz,C. G.; RamírezDimaté, F. y MUÑOZ, W. E. (2015). Narrar para Comprender. Una secuencia didáctica para la producción de textos narrativos con estudiantes de grado sexto. [Tesis de Maestría en Pedagogía y Desarrollo Humano, Universidad Católica de Pereira]. https://repositorio.ucp.edu.co/bitstream/10785/4838/1/ DDMPDH11.pdf.

RDA/018/027/M. Orozco B., Y. E. (2016). Experiencias estéticas en la re-significación de sí mismo y del proceso de enseñanza aprendizaje en un grupo de estudiantes de filosofía de grado décimo y once de la Institución Educativa Pablo Sexto en Dosquebradas: pedagogía que encanta. [Tesis de Maestría en Pedagogía y Desarrollo Humano, Universidad Católica de Pereira]. https://repositorio.ucp. edu.co/bitstream/10785/4835/1/DDMPDH8.pdf. 
RDA/018/028/M. Arboleda Mancilla, A. P.; Maturana Mosquera, C. y Narváez Cartagena L. A. (2016). Implementación de una unidad didáctica desde el socioconstructivismo para el manejo de conflictos en un contexto escolar. [Tesis de Maestría en Pedagogía y Desarrollo Humano, Universidad Católica de Pereira]. https://repositorio.ucp.edu. co/bitstream/10785/4833/1/DDMPDH6.pdf.

RDA/018/030/M. Rodríguez Botero, M. y Castaño Caicedo J. A. (2016). Formas de reconocimiento por medio de la experiencia de elaboración del autorretrato como medio estético en un grupo de jóvenes de la Vereda de San Isidro del municipio de Pereira. [Tesis de Maestría en Pedagogía y Desarrollo Humano, Universidad Católica de Pereira]. https://repositorio.ucp.edu.co/bitstream/10785/4830/1/ DDMPDH3.pdf.

RDA/018/031/M. Cárdenas Tabares, E. M.; Ceballos Calle, M. V. y García Muñoz, C. M. (2016). Representaciones sociales sobre violencia de género hacia las mujeres, en un grupo de estudiantes del grado sexto de la Institución Educativa La Inmaculada de Versalles Valle. [Tesis de Maestría en Pedagogía y Desarrollo Humano, Universidad Católica de Pereira]. https://repositorio.ucp.edu.co/ bitstream/10785/4829/1/DDMPDH2.pdf.

RDA/133/035/M. Guzmán Montiel, J. R. y Puerta Giraldo, C. E. (2011). La conversación en la clase de filosofía. [Tesis de Maestría en Educación, Universidad Tecnológica de Pereira]. 
RDA/133/047/M. Gómez Avendaño, L. S. y Forero Granados, L. I. (2011). Representaciones de género en las imágenes icónicas de los textos escolares de ciencias naturales de los grados sexto a noveno de básica secundaria publicados en el período 1995-2009. [Tesis de Maestría en Educación, Universidad Tecnológica de Pereira].

http://repositorio.utp.edu.co/dspace/bitstream/handle/11059 /1869/372412G633.pdf;jsessionid=D6E26AD3FE8C108C EA74C7849E6CF39A?sequence $=1$.

RDA/133/057/M. García Gallego, A. C. y García Quiroz, C. (2011). La educación artística: un estado del arte para nuevos horizontes curriculares en la Institución Educativa Mundo Nuevo de la ciudad de Pereira. [Tesis de Maestría en Educación, Universidad Tecnológica de Pereira]. http://repositorio.utp. edu.co/dspace/bitstream/handle/11059/1893/3725G216. pdf? sequence $=1$.

RDA/133/061/M. Marín Hernández, O. A. (2013). Estilos de enseñanza y prácticas pedagógicas en educación física: tensiones constitutivas en el Instituto Estrada de Marsella (Risaralda). [Tesis de Maestría en Educación, Universidad Tecnológica de Pereira]. http://repositorio.utp.edu.co/ dspace/bitstream/handle/11059/3387/37286132M337. pdf? sequence $=1$ \&isAllowed $=\mathrm{y}$.

RDA/133/062/M. Gallego Echeverry, L. D. (2014). El emprendimiento en estudiantes de la Institución Educativa Manuel Quintero Penilla del municipio de Cartago-Valle. Relatos de sueños y vivencias. [Tesis de Maestría en Educación, Universidad Tecnológica de Pereira]. http://repositorio.utp. edu.co/dspace/bitstream/handle/11059/4640/370118G166. pdf? sequence $=1$ \&isAllowed $=\mathrm{y}$. 
RDA/133/063/M. Zapata GómeZ, O. J. (2015). Concepciones de educación de adultos de los docentes del Instituto Comfamiliar. [Tesis de Maestría en Educación, Universidad Tecnológica de Pereira]. http://repositorio.utp.edu. co/dspace/bitstream/handle/11059/5504/374012Z35. pdf? sequence $=1 \&$ isAllowed $=y$.

RDA/133/074/M. Calderón Jaramillo, A. M. (2012). Los procesos de configuración de la subjetividad política en escenarios educativos. [Tesis de Maestría en Educación, Universidad Tecnológica de Pereira]. http://repositorio.utp. edu.co/dspace/bitstream/handle/11059/2860/37926C146. pdf? sequence $=1$ \&isAllowed $=y$.

RDA/133/077/M. Martínez Valencia, C. A. y Murillo Sandoval, J. A. (2015). Habilidades de pensamiento social en una práctica de enseñanza y aprendizaje del concepto de libertad con estudiantes del grado diez de la institución educativa La Graciela de Tuluá. [Tesis de Maestría en Educación, Universidad Tecnológica de Pereira]. http://repositorio.utp. edu.co/dspace/bitstream/handle/11059/4312/37283M385. pdf? sequence $=1 \&$ isAllowed $=y$. 



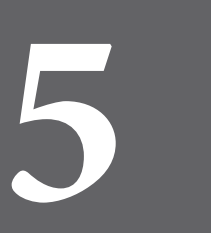

CAPÍTULO CINCO 



\title{
Hallazgos en educación, pedagogía y otras regiones de las tesis y los proyectos de grado del Eje Cafetero (2010-2017)
}

\author{
Héctor Fabio Ospina ${ }^{15}$ \\ Martha Cecilia Arbeláez ${ }^{16}$ \\ Clara Lucía Lanza ${ }^{17}$ \\ María Camila Ospina-Alvarado ${ }^{18}$ \\ Sara Victoria Alvarado ${ }^{19}$ \\ Claudia Patricia Jiménez $z^{20}$ \\ Jhon Fredy Orrego ${ }^{21}$ \\ María Alejandra Fajardo 22
}

En este capítulo se presentan los hallazgos de los trabajos de grado de maestría y tesis de doctorado de la zona del Eje Cafetero. Los resultados se presentarán integrados en tres regiones: educación ( $38.5 \%$ de los estudios revisados en la zona), pedagogía (56 \%) y otras regiones (5.5\%).

15 Centro de Estudios Avanzados en Niñez y Juventud, Universidad de Manizales-CINDE. 16 Universidad Tecnológica de Pereira.

17 Universidad Tecnológica de Pereira

18 Centro de Estudios Avanzados en Niñez y Juventud, Universidad de Manizales-CINDE.

19 Centro de Estudios Avanzados en Niñez y Juventud, Universidad de Manizales-CINDE.

20 Universidad de Manizales.

21 Centro de Estudios Avanzados en Niñez y Juventud, Universidad de Manizales-CINDE.

22 Centro de Estudios Avanzados en Niñez y Juventud, Universidad de Manizales-CINDE. 


\subsection{Región educación}

TABLA NRO. 24. Tópicos globales de la Región educación de las tesis en las universidades en la zona del Eje Cafetero.

\begin{tabular}{|c|c|c|c|c|c|c|c|}
\hline \multirow[t]{2}{*}{ Tópicos globales } & \multicolumn{2}{|c|}{$\begin{array}{l}\text { Universidad de } \\
\text { Manizales y el } \\
\text { CINDE } \\
\end{array}$} & \multicolumn{2}{|c|}{$\begin{array}{l}\text { Universidad } \\
\text { Católica de } \\
\text { Pereira } \\
\end{array}$} & \multicolumn{2}{|c|}{$\begin{array}{l}\text { Universidad } \\
\text { Tecnológica de } \\
\text { Pereira } \\
\end{array}$} & \multirow{2}{*}{$\begin{array}{l}\text { Total Eje } \\
\text { Cafetero } \\
\%\end{array}$} \\
\hline & $\mathbf{F}$ & $\%$ & $\mathbf{F}$ & $\%$ & $\mathbf{F}$ & $\%$ & \\
\hline $\begin{array}{l}\text { Educación para la paz y la } \\
\text { democracia }\end{array}$ & 31 & 9.8 & & & 1 & 0.3 & 10.1 \\
\hline Educación inclusiva & 15 & 4.8 & 1 & 0.3 & 7 & 2.2 & 7.3 \\
\hline Escuela & 17 & 5.4 & 2 & 0.5 & & & 5.9 \\
\hline Evaluación & 8 & 2.5 & 1 & 0.3 & 4 & 1.3 & 4.1 \\
\hline Pensamiento crítico & 6 & 1.9 & & & & & 1.9 \\
\hline Poder & 4 & 1.3 & & & & & 1.3 \\
\hline Políticas educativas & 4 & 1.3 & & & & & 1.3 \\
\hline Formación & 3 & 1 & & & 1 & 0.3 & 1.3 \\
\hline Currículo & 2 & 0.6 & 1 & 0.3 & 1 & 0.2 & 1.1 \\
\hline Proyecto educativo & 2 & 0.6 & 1 & 0.3 & & & 0.9 \\
\hline Sentido de la educación & 2 & 0.6 & & & & & 0.6 \\
\hline Educación propia & 2 & 0.6 & & & & & 0.6 \\
\hline Gestión educativa & 2 & 0.6 & & & & & 0.6 \\
\hline Educación ética y moral & 2 & 0.6 & & & & & 0.6 \\
\hline $\begin{array}{l}\text { Cultura juvenil/cultura } \\
\text { estudiantil }\end{array}$ & 1 & 0.3 & & & & & 0.3 \\
\hline Pensamiento social & & & 1 & 0.3 & & & 0.3 \\
\hline $\begin{array}{l}\text { Educación para el } \\
\text { emprendimiento }\end{array}$ & & & & & 1 & 0.3 & 0.3 \\
\hline Total de porcentaje & 31.9 & & 2.0 & & 4.6 & & 38.5 \\
\hline
\end{tabular}

Elaboración propia.

De las 315 tesis analizadas en la zona Eje Cafetero el 38.5\% de ellas abordan la región educación. Los tópicos de esta región que poseen mayor relevancia en los posgrados de las tres instituciones y que se toman como fuente de formación hacen referencia a la educación inclusiva (7.3\%), la evaluación (4.1\%) y el currículo (1.1\%).

Por otro lado, se encuentran aquellos tópicos no tan relevantes en toda la zona del Eje Cafetero, pero son compartidos al menos por programas de dos instituciones, algunos de los cuales en el porcentaje total de la zona presentan mayor proporción, a saber:

- Educación para la paz y la democracia: si bien este se presenta como el tópico con mayor porcentaje $(10.1 \%)$ de la región 
educación, es abordado prioritariamente por los postgrados de la Universidad de Manizales y el CINDE y la Universidad Tecnológica de Pereira.

- Escuela: este tópico se presenta tanto en la Universidad de Manizales y el CINDE como en la Universidad Católica de Pereira con un $5.9 \%$.

- Formación: tópico compartido por los postgrados de la Universidad de Manizales y el CINDE y la Universidad Tecnológica de Pereira con un $1.3 \%$ de los hallazgos.

- Proyecto educativo: tópico global el cual se encuentra en los postgrados de la Universidad de Manizales y el CINDE, y la Universidad Católica de Pereira. Este se encuentra representado con el $0.9 \%$ de los hallazgos.

Finalmente, se presentan aquellos tópicos los cuales son particularidad de cada una de las instituciones (ver TABLA NRO. 24). En este sentido, se representa un interés especial sobre estas temáticas dadas las especificidades de los programas:

- Universidad de Manizales y el CINDE: pensamiento crítico (1.9\%), poder (1.3\%). políticas educativas (1.3\%), sentido de la educación (0.6\%), educación propia (0.6\%), gestión educativa (0.6\%), educación ética y moral (0.6\%) y cultura juvenil/cultura estudiantil (0.3\%).

- Universidad Católica de Pereira: pensamiento social (0.3\%).

- Universidad Tecnológica de Pereira: educación para el emprendimiento (0.3\%).

Lo anterior nos permite comprender que la amplitud de tópicos en la región educación se debe a la diversidad de intereses que tienen los estudiantes-investigadores desde sus zonas e instituciones de procedencia. Se identifican algunas temáticas fuertes, mientras que otras requieren mayor atención y motivación 
en su desarrollo. Es una región que, aparentemente, tiene menores desarrollos. Sin embargo, la educación es vista en el contexto escolar, mayoritariamente desde la educación formal; en este sentido, el énfasis en la pedagogía y la didáctica no se entienden por fuera del campo de la educación.

\subsubsection{Tópico global: educación para la paz y la democracia}

De las dos maestrías analizadas en la Universidad de Manizales y el CINDE, una maestría en la Universidad Católica de Pereira, una maestría en la Universidad Tecnológica de Pereira y el Doctorado en Ciencias Sociales, Niñez y Juventud también de la Universidad de Manizales y el CINDE. Solo los programas ofrecidos por esta última institución y por la Universidad Tecnológica de Pereira presentan aportes significativos al tópico global de educación para la paz y la democracia.

La UTP presenta una tesis como único registro ubicado en el tópico global de educación para la paz y la democracia, este representa el $0.3 \%$ de los trabajos tenidos en cuenta en el estudio para esta zona, mientras en la UCP no se encontraron registros. Por su parte, la UM ha abordado el tópico global de educación para la paz y la democracia en las tesis de dos maestrías y un doctorado para el período de estudio comprendido entre el 2010 y el 2017 una de las maestrías y el doctorado en alianza con el CINDE-; allí, se encuentran 184 tesis aproximadas a la educación de las cuales, 27 de maestría y 4 de doctorado, correspondientes al $16.8 \%$ de las tesis revisadas en esta universidad, y al $9.8 \%$ del total de las tesis abordadas en el estudio en la zona del Eje Cafetero, las cuales se han preocupado por la educación para la paz y la democracia, incluyendo como tópicos locales relevantes subjetividad política $(2.5 \%)^{23}$, ciudadanía/ciudadanía y conciencia crítica (1.9\%). Mientras, otros tópicos tienen un poco menos de relevancia que los anteriores, pero siguen contando cierta importancia o recurrencia,

23 Estos porcentajes son calculados en función del total de tesis de la zona del Eje Cafetero y no de la Universidad de Manizales y el CINDE. 
estos son: convivencia (1.5 \%), participación/participación ciudadana (0.9\%) y conflicto/resolución de conflictos/pluralidad y conflicto $(0.9 \%)$. Varios tópicos se distribuyen en opacidades o temas poco abordados tales como: memoria $(0.3 \%)$, construcción de identidad (0.3\%), reintegración (0.3\%), sujeto autónomo y reflexivo $(0.3 \%)$ y sin tópico local (0.3\%). La investigación que no responde a ninguno de los tópicos locales es la de EC/051-02/067/ $\mathrm{M}^{24}$. Aun cuando tiene como subtópico la escritura para la paz, no aparecen desarrollados los hallazgos en la ficha.

Lo anterior nos permite comprender cómo la diversidad de intereses de los investigadores, de acuerdo con su formación y lugar de procedencia, genera amplitud en la configuración de tópicos locales desde los cuales también se identifican relevancias y tendencias; especialmente, en temáticas relacionadas con la subjetividad política, la ciudadanía, la convivencia, el conflicto y la participación (ver TABLA NRO. 25).

TABLA NRO. 25. Tópicos locales para el tópico global de educación para la paz y la democracia.

\begin{tabular}{lllllll}
\hline Tópicos locales & $\begin{array}{l}\text { Universidad } \\
\text { de Manizales y y } \\
\text { el -CINDE }\end{array}$ & $\begin{array}{l}\text { Universidad } \\
\text { Tecnológica de } \\
\text { Pereira }\end{array}$ & $\begin{array}{l}\text { Universidad } \\
\text { Católica de } \\
\text { Pereira }\end{array}$ \\
\cline { 2 - 7 } & F & $\%$ & F & $\%$ & F & $\%$ \\
\hline Participación/participación ciudadana & 3 & 0.9 & 0 & 0 & 0 & 0 \\
\hline Convivencia & 5 & 1.5 & 0 & 0 & 0 & 0 \\
\hline Ciudadanía/ciudadanía y conciencia crítica & 6 & 1.9 & 0 & 0 & 0 & 0 \\
\hline Subjetividad política & 8 & 2.5 & 0 & 0 & 0 & 0 \\
\hline Memoria & 1 & 0.3 & 0 & 0 & 0 & 0 \\
\hline Construcción de identidad & 1 & 0.3 & 0 & 0 & 0 & 0 \\
\hline Reintegración & 1 & 0.3 & 0 & 0 & 0 & 0 \\
\hline $\begin{array}{l}\text { Conflicto/resolución de conflictos/pluralidad y } \\
\text { conflicto }\end{array}$ & 3 & 0.9 & 0 & 0 & 0 & 0 \\
\hline Sujeto autónomo y reflexivo & 1 & 0.3 & 0 & 0 & 0 & 0 \\
\hline Sin tópico local & 1 & 0.3 & 0 & 0 & 0 & 0 \\
\hline
\end{tabular}

Elaboración propia.

24 En adelante, se hace alusión a los trabajos de grado a través de sus respectivos códigos. Estos acompañan la correspondiente referencia bibliográfica en el último apartado del capítulo [N. de E.]. 
La tesis de la UTP, la cual hace parte de este tópico global, no especifica en la ficha el desarrollo de tópicos locales; sin embargo, profundiza en la educación para la paz como un proceso educativo, continuo y permanente, fundamentado por los conceptos de paz positiva y perspectiva creativa del conflicto, y que pretende desarrollar un nuevo tipo de cultura;

...la cultura de paz, que ayude a las personas a desvelar críticamente la realidad compleja y conflictiva, para poder situarse ante ella y actuar en consecuencia. La educación para la paz pretende alcanzar la construcción de un nuevo orden internacional basado en un concepto de paz positivo, de modo que las relaciones (individuales, familiares, sociales, nacionales), en cualquier nivel (individual, familiar, social, nacional, internacional) tengan como resultado la solución no violenta de los conflictos y la justicia (Salguero, 2004, pp. 60-61).

En esta misma línea de ideas,

Jares (2001) menciona que la educación para la paz es un proceso educativo, dinámico continuo y permanente, que se fundamenta en los conceptos de paz y en la perspectiva creativa del conflicto, como elementos significantes, donde por medio de la aplicación de enfoques socioafectivos y problematizantes pretende desarrollar una cultura de paz que ayude a las personas a descubrir críticamente la realidad, situarse ante ella y actuar en consecuencia (Castillo Sánchez y Gamboa Araya, 2012, p. 125).

En esta medida, indica que las características de la paz positiva consisten en considerar a esta como un fenómeno amplio y complejo, el cual exige una comprensión multidimensional, así como uno de los valores máximos de la existencia humana. Asimismo, se debe contemplar que la paz afecta a todas las dimensiones de la vida; hace referencia a una estructura social de amplia justicia y reducida violencia; y hace alusión a tres conceptos ligados entre sí: el conflicto, el desarrollo y los derechos humanos, tal y como establece Galtung (como se citó en Ramos, 2003). 
Finalmente, cabe resaltar de esta tesis la aproximación que realiza en torno al tema de la subjetividad en donde, a partir del análisis de dicho tópico, se proponen cuatro puntos sobresalientes: 1) pensar al sujeto como agente de su propia formación, al entender que esta no solo ocurre en espacios educativos formales sino en la cotidianidad misma de habitar el mundo; 2) romper con la dicotomía entre lo social y lo individual para acercarse a la comprensión del fenómeno subjetivo a partir de la producción de sentidos; 3) los educadores y educandos construyen aprendizajes en la medida en que despliegan sus subjetividades sociales en espacios de interacción; y 4) potenciar los procesos de reflexividad los cuales configuran subjetividades políticas tanto en los educadores como en los educandos, lo cual lleva a estos a desarrollar una práctica educativa democrática.

A continuación, se desarrollan los tópicos locales encontrados en las tesis de la Universidad de Manizales.

\subsubsection{Participación/participación ciudadana}

Este tópico local es abordado por tres tesis, lo que equivale al 0.9 \% de los trabajos estudiados en el Eje Cafetero. Por un lado, la investigación C/051-02/032/M reconoce las posibilidades que encuentran los jóvenes en la institución académica para ejercer prácticas políticas, las cuales posibiliten un mundo de transformación social a partir de la movilización y participación en escenarios democráticos. Dichos escenarios de participación permiten entrever el desarrollo de procesos de sensibilización donde este agente asume de manera consciente un estilo de generar movilización a partir de experiencias significativas, su formación académica y el desarrollo social de su territorio. Esto afianza un escenario, el cual posibilita la intervención de escenarios más abiertos como los mecanismos de participación institucionales: el consejo directivo, elecciones a personeros y los consejos de gobierno, los cuales permiten la representación de comunidades sociales denominadas «Grupo educativos» (p. 130). 
Desde una perspectiva similar, y al tener en cuenta las concepciones de algunos de los agentes educativos, maestras y jardineras sobre las niñas y los niños, otra tesis (EC/05102/036/M) evidencia la concepción de la participación como un sinónimo de autonomía y libertad, donde se les permite a las niñas y a los niños decir qué quieren hacer, cómo lo quieren hacer y si están de acuerdo con los planteamientos que se les hacen.

Desde otra perspectiva, se acoge el tópico de participación ciudadana en relación con las prácticas pedagógicas, las cuales se encuentran limitadas debido a que algunos docentes presentan resistencia a la innovación, actualización y ruptura de paradigmas; los cuales proporcionen un cambio que genere viabilidad en los procesos de aprendizaje, así como una intervención a las dificultades presentadas con el fin de buscar la transformación del entorno, y forjar en los estudiantes actitudes que conlleven a vivir, enfrentar y modificar la realidad. En este sentido, se identifican como ejes fundamentales para la ruptura de los esquemas establecidos: la política, porque se debe dar prioridad a contextos en los cuales primen las necesidades básicas del ser humano y esto coarta un proceso de educación en contexto; la ética, porque el desarrollo humano es la pauta clave para garantizar una interacción sana y reciproca del educando consigo mismo, con sus semejantes, con el ambiente el cual le rodea y con la cultura; y la cultura, ya que su preservación ayuda a crear un vínculo entre el pasado, el presente y el futuro, es decir, a fortalecer la educación desde el contexto para prospectar horizontes los cuales permitan vivenciar una educación en contexto (EC/051-1/008/M).

\subsubsection{Convivencia}

Este tópico es trabajado por cinco tesis, lo que corresponde al $1.5 \%$ de los trabajos estudiados en la zona. Se afirma que «ni el autoritarismo ni las formas primarias de resolver discrepancias, agravios y abusos son la vía para superar las situaciones» de conflicto (Vidales y Maggi, 2007, p. 20). En tal sentido, afirman: 
«hay que fortalecer las prácticas y vías democráticas de solución a los problemas del país, en cuyo seno desarrollan su actividad las escuelas» (Vidales y Maggi, 2007, p. 20) con el fin de instaurar las bases para el reconocimiento y respeto del otro, donde la convivencia cotidiana propicie la creación de un clima escolar favorable y genere una nueva interacción social, basada en la participación democrática (EC/051-1/009/M).

En este sentido, se evidencia una tensión entre la responsabilidad de la familia y de la escuela en las dificultades de convivencia y adaptación presentes en los escolares. Algunos docentes consideran importante el papel de la escuela, tanto para que el currículo escolar propenda por fortalecer el uso adaptativo de las emociones, como para que el estudiante pueda adaptarse de forma más eficaz al medio que lo rodea. En este sentido, si la escuela es propugnada como un lugar idóneo para el desarrollo emocional de niños y niñas, el docente tiene que asumir el compromiso ético de dedicarse no solo a enseñar bien sino a aportar a la transformación de las capacidades emocionales y de las deficiencias afectivas de sus alumnos. Pero, para que el maestro pueda lograr esto, la condición es que se transforme a sí mismo $y$, de esta manera, ajuste sus propias competencias emocionales para proyectar una influencia positiva sobre los estudiantes en términos de motivación, de cambio de actitudes y de formación de personalidad. Por tal razón, dentro del proceso educativo, es importante focalizar el desarrollo humano para fortalecer y generar espacios de convivencia democrática (EC-051-1-017-M).

Al continuar con el abordaje de la convivencia en la escuela, se encuentra que las concepciones sobre esta que tienen los docentes y directivos se hallan inmersas en tres perspectivas, relacionadas con el conflicto, la conciliación; con los valores y el ideal de convivencia, los cuales actúan como facilitadores cuando promueven una sana convivencia, y como obstaculizadoras cuando afectan la dinámica interna de la institución educativa y sus resultados académicos y convivenciales. Aquellos sujetos hacen 
especial énfasis en factores externos - problemas familiares y del entorno social de la escuela-, los cuales afectan la convivencia escolar y desconocen la repercusión que tiene la misma escuela sobre lo que ocurre en su interior. Esto al no reconocer dicho espacio como una institución social, la cual posibilita la comunicación asertiva, la escucha activa, la creación de ambientes de aprendizaje enriquecidos y armónicos (Peña Figueroa et al., 2017, citado en EC/051-01/043/M). En consecuencia, invita a mirar la convivencia en una perspectiva multidimensional (EC/051-01/043/M).

Por otra parte,

las representaciones develadas frente a la escuela demuestran que la reflexión sobre la educación y los procesos institucionales son fundamentales, ya que se debe tener en cuenta que en su interior se viven procesos los cuales tienen como fin dar forma, instruir, dar dentro de un dispositivo algo que el sujeto no tiene, algo de lo cual carece. Es evidente que los significados, sentimientos, imágenes y prácticas sociales, constatadas al interior de la escuela -en calidad de internado-, muestran el desencuentro con el contexto y la historia del sujeto estudiante. Esto genera la secularización y descontextualización de los saberes expuestos, respecto a la realidad subjetiva y su vida cotidiana (EC/051-02/006/M, p. 89).

Este abordaje retoma una perspectiva de género desde la cual la escuela está presente para cumplir su papel normativo y normalizador, a partir del cual, las niñas deben seguir un comportamiento que obedezca a los principios y reglas dadas en su interior. Por ende, la norma denota las prohibiciones y cierra las posibilidades que puedan expresar, porque solo el adulto es quien conoce y tiene el poder. De esta manera, se legitima la manera «correcta» de comportarse, de ser y estar en el mundo en encuentro con otros (EC/051-02/006/M). 
Desde esta reflexión, trabajar las representaciones de la escuela implica develar la cultura escolar; no es sólo conocer las creencias, sentimientos y pensamientos los cuales se tejen al interior, a partir de las diversas prácticas cotidianas; implica un compromiso con la transformación de la acción educativa, iniciando con la comprensión del contexto socio-histórico y cultural en que éstos procesos se desarrollan; implica además, reflexionar frente a las nuevas y mejoradas prácticas educativas, que reconozcan al niño como un ser activo, en permanente construcción de su historia, en interacción con el mundo y con los otros, donde existe negociación y re-negociación de significados, de símbolos, de tradiciones personales y colectivas las cuales posibilitan la creación de su identidad (EC/051-02/006/M, p. 90).

A su vez, los juicios hechos por los estudiantes acerca de la convivencia escolar y la confianza que los caracteriza, se inclinan por creencias fervientes en el diálogo para alcanzar la paz y, con ello, una sana convivencia. Resaltan la gran importancia de la participación de los estudiantes en muchos de los eventos que involucren la sana convivencia (EC/051-02/030/M). Además, se evidencia la concientización existente en los jóvenes sobre el compromiso particular con la búsqueda de la convivencia escolar como camino y mecanismo para la construcción de la paz en el ámbito estudiantil; no sin antes advertir la necesidad de un acompañamiento por parte de los docentes, quienes comparten con ellos un espacio y a quienes su postura, apoyo y concejo son de gran valor e importancia por el ser representativo que es el maestro (EC/051-02/030/M).

\subsubsection{Ciudadanía/ciudadanía y conciencia crítica}

Este tópico local fue retomado por seis tesis, representadas en el $1.9 \%$ de trabajos estudiados en la zona. Desde un abordaje de la formación ciudadana en el contexto, se expresa el requerimiento de un cambio de concepción, al trascender los valores y principios en los cuales se ha fundamentado la escuela, hacia una ética cívica, conformada a partir de valores como la libertad, la igualdad, la 
solidaridad, el respeto activo y el dialogo; aspectos que permiten una mirada diferente hacia el sujeto, hacia la sociedad y hacia la solución de los conflictos, generados en la cotidianidad al entrar en relación con el otro. Así, se posibilita resolver los problemas comunes a través del diálogo, donde este se encuentra encaminado a reconocer la singularidad dentro de la diversidad. Por lo tanto, es imprescindible realizar prácticas de formación ciudadana las cuales penetren en el imaginario social para transformarlo con el fin de respetar la diversidad de culturas en el marco de una sociedad más democrática (EC/051-01/041/M).

Por otra parte, se considera que,

la educación debe ser un encuentro fraterno de pares donde se aprende y se enseña en doble vía. Esta debe dejar de ser un proceso de poder de unos (supuestamente los que saben más) sobre otros y donde el factor emotivo acerque y no ponga barreras en el espacio llamado escuela (EC/051-01/042/M, p. 77).

La escuela ideal para los jóvenes es aquella que permita la libre expresión; la que sea dinámica y se conciba por fuera de las aulas donde aprender no sea traumático, y se tenga en cuenta el arte y el deporte; además, donde prime el respeto a la diversidad. Los docentes y directivos siguen realizando cuestionamientos a la forma de vestir, de llevar el cabello, de sentarse (especialmente en las mujeres) hasta llegar a controvertir los pensamientos divergentes. Esta situación se ejemplifica por medio de la siguiente cita: «... mmm bueno que no haya restricciones para nuestras diferencias, diferencias para ninguno, que así vengamos como vengamos, respetarnos, hacernos valer por lo que somos, en los mismos estudiantes $\mathrm{mmm}$, tener más libertad, no tener uniforme» (Arcos, 2013, citado en EC/051-01/042/M, p. 77).

Sin embargo, «los jóvenes tienen la percepción de la no existencia de procesos políticos formadores en la escuela» (EC/051-01/042/M, p. 79). 
Frente a la solución de la problemática local y nacional, y dado el real ejercicio político de las instancias representativas en las cuales se organizan; pareciese que lo que se hace se lleva a cabo por cumplir un compromiso institucional, tal es el caso de las elecciones de representantes estudiantiles y de personero, las cuales cuentan con acompañamiento mínimo. Posteriormente, estas actitudes se proyectan en su edad adulta, cuando la política es considerada únicamente como una acción electoral (EC/05101/042/M, p. 79).

En este sentido, se aboga por una formación política y ciudadana la cual implica la formación para la participación, sin embargo, no toda formación para la participación involucra la ciudadanía (EC/051-01/042/M).

En relación con la diversidad cultural, durante el trabajo con comunidades en Turbo (Antioquia), se encontró que el nivel de apropiación que se tiene de las políticas educativas para el reconocimiento de la diversidad cultural afrocolombiana es casi nulo. En esa dirección, la estrategia Cátedra de Estudios Afrocolombianos, emprendida por el grupo étnico y aprobada en instancias del Estado, se encuentra a la deriva y sin concretar, todo ello debido a la obra del discurso comunicativo el cual tatuó no solo la piel de los grupos étnicos, sino además sus mentes al imposibilitarlos para llevar a feliz término con un propósito que les compete. En este mismo sentido, también se encontró que las estrategias de la política educativa los encauza como alimentadores de un sistema hegemónico el cual restringe posibilidades epistémicas para la igualdad de condiciones. De ahí la importancia de la representación política afrocolombiana en las instancias del poder con el fin de lograr una apropiada participación social e incidir de manera eficaz en la toma de decisiones. Así, una de las conclusiones relevantes es que los derechos educativos de la población afrocolombiana, desde las políticas educativas, han sido insuficientes para la dignificación de estos colectivos humanos. Se hace necesario considerar las concepciones a partir de una visión escolarizada y descontextualizada para superar las 
problematizaciones surgidas en las aulas y al mismo tiempo las injusticias en la cotidianidad social. Por ello, aunque Colombia posee una amplia legislación favorable a los grupos étnicos, la discriminación racial y la marginalidad socioeconómica impiden la participación social de estos actores en la solución de sus problemáticas. Se requieren acciones afirmativas para la reivindicación de derechos de las comunidades afrocolombianas que favorezcan la construcción de identidad a partir de las políticas de diversidad (EC/051-01/053/M).

Por otra parte, los resultados de otro ejercicio investigativo dan cuenta de la relación directa entre cultura de paz y educación, esto debido a que cada una potencia a la otra desde lo vocacional y desde los ejercicios propios de la ciudadanía pacífica. Han sido las prácticas universitarias propuestas por la Universidad de Manizales, específicamente por los programas de Derecho y Comunicación Social, las cuales han permitido este análisis, al descentralizar y poner en cuestión el saber impartido desde lo disciplinar, desde las teorías y desde los conceptos para llevarlo a un ejercicio real, aplicable, a un escenario social en el cual se permite construir con los demás y desarrollar en los estudiantes, no de manera magistral sino vivencial, los valores de la cultura de paz. Esa vivencia de experiencias reales, las cuales permiten las prácticas universitarias, son sin duda — como ya se ha explicitado en los apartados anteriores-, la misma esencia de la proyección social que la universidad construye y potencia a través de múltiples escenarios; pero fundamentalmente, son los pasos necesarios y significativos los cuales se dan hacia la responsabilidad social universitaria (EC/051-02/061/M).

$\mathrm{Al}$ abordar este tópico local desde la primera infancia, se encuentra que el reconocimiento del otro - como potencial para la construcción de paz-, implica fortalecer en los niños y niñas su capacidad de autoreconocerse en su individualidad y reconocerse en relación con los otros. Esto requiere del uso de estrategias pedagógicas que permitan evidenciar a ese otro como 
igual, pero singular en sus diferencias y, a partir de ello, construir nuevas formas de relación desde lo común. Se hace necesario el proporcionar múltiples y variadas experiencias a la población en primera infancia, las cuales conlleven a ocupar el lugar de los otros, y además, a generar acciones de respeto por su individualidad y fragilidad humana. En este sentido, como sujetos de derechos los cuales ejercen la ciudadanía; los niños y las niñas requieren ser considerados como interlocutores válidos con capacidad de expresar sentimientos y emociones, de dar sentido a su propia vida y de tomar pequeñas decisiones; esto, con la necesidad de grupos de referencia como la familia, los agentes educativos y los pares, los cuales contribuyan a consolidar patrones de relación con base en el respeto por el otro, la diversidad y su afecto como movilizadores de su realidad cotidiana (EC/051-02/063/M). Se argumenta que, en los procesos de construcción de paz de la primera infancia, juega un papel sustancial la corresponsabilidad de los diferentes actores involucrados; por lo cual, se abre la posibilidad de reivindicar a los agentes educativos como contadores de historias y coinvestigadores con el fin de generar estrategias de reflexión continua sobre la práctica pedagógica. Esto propiciará trascender esquemas basados en las prácticas tradicionales de enseñanza y de aprendizaje. Asimismo, posicionará al educador como un mediador y guía en los escenarios de formación de esta población (EC/051-02/063/M).

Finalmente, una tesis aborda el tópico de la ciudadanía desde la conciencia crítica en donde se establece como fundamental favorecer la autoestima en los niños y las niñas. Esto permitirá que ellos se sientan protagonistas de sus aprendizajes y aportará a la resolución de problemas comunitarios, así como contribuirá a la formación de ciudadanas y ciudadanos conocedores de sus derechos y deberes, responsables, y comprometidos con su transformación individual y social. Lo anterior tiene como principio fundamental la participación democrática, el trabajo colaborativo, la toma de decisiones, el diálogo con lo diferente, el respeto de las opiniones de los demás y la búsqueda de consenso (EC/043/028/D). 


\subsubsection{Subjetividad política}

Este tópico fue abordado por ocho tesis, lo cual representa el $2.5 \%$ de los proyectos abordados en el Eje Cafetero y lo ubica como el tópico local más relevante respecto al tópico global de educación para la paz y la democracia.

Por una parte, la educación se considera como un fenómeno social de continuo cambio dialéctico y trasformación. El proceso educativo está integrado por profundas redes a nivel social y cultural las cuales designan qué tipos de relaciones sociales se construyen en una comunidad, como proceso educativo de niños, niñas y jóvenes; se encuentra mediado principalmente por el escenario familiar, institucional y social. En este sentido,

una educación para la pazinicia con tener maestros comprometidos con el desarrollo socio-histórico de sus estudiantes, pues el trabajo docente «constituye uno de los fundamentos y pilares del sistema educativo por ser los depositarios de la fe pública en la construcción del sujeto social validado como proyecto humano» (Burbano y Muñoz, 2015, p. 65, citado en EC/051-01/044/M, pp. 24-25).

Así pues, la tarea docente se genera a través de posibilidades de discusión entre el pasado, el presente, y el futuro. Lo anterior permite el encuentro entre el conflicto y la memoria como horizontes para el empoderamiento de los estudiantes entendidos como agentes sociales (EC/051-01/044/M).

Por otro lado, en relación con las prácticas de educación no formal se hace necesario viabilizar la participación de las personas adultas en los procesos de emancipación y de participación social, esto para favorecer la construcción de pensamiento crítico y aportar a la configuración de sujetos integrales los cuales contribuyan al mejoramiento de sus entornos. Avanzar en este sentido implica escuchar las voces de los integrantes de las comunidades, indagar en sus opiniones respecto a las prácticas 
sociales, locales y globales y, analizar sus discursos respecto a las contribuciones que ellos consideran pueden hacerse para mejorar los escenarios comunitarios. De acuerdo con los hallazgos encontrados, es posible continuar con prácticas educativas basadas en la pedagogía crítica para formar sujetos reflexivos y dispuestos a comprender el sistema dominante para evitar su mantenimiento. En este sentido, indagar y buscar con mayor precisión posible formas de usar la educación no formal para intervenir en el mejoramiento de los contextos es una alternativa propicia para lograr condiciones de vida más favorables para todos y construir ambientes más armoniosos, lo cual aporta al desarrollo humano, porque a través de la educación basada en el pensamiento crítico es viable conseguir sostenibilidad económica y, por ende, mejores niveles de vida (EC/051-01/045/M).

Desde otra perspectiva, se encontró que en la escuela se desarrollan dos perfiles específicos, de la sujeción y de los espacios para la subjetivación. En primera instancia, la escuela a través de la implementación de las políticas educativas estatales y los diferentes discursos de poder en el orden económico, político y religioso, agencia diferentes dinámicas a través de sus prácticas educativas para moldear al individuo y someterlo de manera autómata con el fin de que responda más al sistema capitalista que a las necesidades y realidades vividas en los contextos educativos locales. En segunda instancia, dentro de este sistema educativo - por fuera de su política一, se pueden agenciar otras dinámicas como son los espacios de subjetivación, los cuales se dan en los contextos educativos locales, donde los individuos subvierten sus pensamientos de manera autónoma y crítica, puesto que sus conocimientos son planteados a partir del ejercicio reflexivo de la realidad en la cual se encuentran. En este sentido, su política se da en un escenario que potencia las habilidades y destrezas de las personas. Así, tanto los dispositivos de sujeción como los espacios de subjetivación están presentes en la escuela. Los primeros se presentan en la aplicación de políticas en el centro educativo, las cuales son diseñadas por el modelo capitalista y aplicadas por el 
Estado con la intención de formar personas para que produzcan en un régimen laboral que cada día demanda la explotación de más obreros, con el objetivo de generar riquezas a los grandes empresarios. En sentido contrario, los segundos obedecen más al ejercicio crítico del sistema, de los programas y de los currículos; esto, para transformar sus pensamientos de forma reflexiva, analítica, y propositiva; $y$, en este sentido, contribuyan al proceso formativo y educativo de la realidad de manera autónoma y no se convierta en un ser autómata, pasivo y momificado frente a los diferentes cambios y transformaciones las cuales se están gestando en la sociedad (EC/051-01/058/M).

Otra investigación presenta en sus hallazgos la identificación de "presencias ausentes» en la familia y la institución educativa. Los relatos entrevén esta concepción tanto por parte del núcleo familiar como por la misma institución. Así, se constituyen en contradicciones entre las prácticas realizadas por los adultos $\mathrm{y}$ aquellos aspectos que quieren imponer como norma de comportamiento al niño, es decir, el adulto impone al niño una norma que él no cumple. Esto se evidencia en las prácticas de crianza cuando al pequeño se le delegan responsabilidades del hogar, las cuales, si bien son propias del adulto, deben ser ejercidas por este como un aporte al hogar y como un medio de asumir actividades conjuntas. Por parte de la institución, esta presencia ausente se da cuando se ignora, sea por falta de control o capacitación, las prácticas de sus agentes institucionales, lo cual lleva abocar de esta forma al niño a un estado de indefensión que lo hace vulnerable y víctima de las mismas. Dentro de los hallazgos se evidencian posturas en los niños que se encuentran atravesadas por una identificación como sujetos políticos; a partir de sus prácticas, se visualizan resistencias frente a ciertas sujeciones de poder dadas a su alrededor pese a las condiciones impuestas por el eje social. Desde una dimensión social, las prácticas discursivas evidencian transformaciones presentes en los niños a partir de las experiencias vitales obtenidas durante su recorrido institucional. En este sentido, cada niño establece - a decir de Bustelo (citado 
en EC/051-02/018/M) -, una relación simétrica la cual parte de él hacia el adulto y no del adulto hacia el niño como se suele ver, de esta forma, el niño hace un acercamiento al adulto sea como agente institucional, o como parte de un núcleo familiar; así las cosas, define, describe o conceptúa no al adulto sino a sus prácticas. En lo referente a su familia no la señala, no la juzga, sino que la concibe a partir de las vivencias atravesadas por cada uno de sus integrantes, sea por razones de pobreza, violencia o presencia de sustancias psicoactivas; en el caso del agente institucional, el niño pone en cuestión no al docente como tal, sino a sus prácticas y la forma como ellas vulneran o contribuyen a la emancipación de su subjetividad (EC/051-02/018/M).

Al continuar con la búsqueda por el reconocimiento de los niños y niñas como sujetos de derechos, se reconoce el impacto de los contextos violentos. Se parte de la premisa de que el desarrollo humano teje fuertes vínculos con la educación en la medida en que los docentes asuman la responsabilidad ética, social y política; reflexionen y contribuyan a repensar el proceso educativo, como la posibilidad de iniciar procesos de transformación social y desarrollo humano; con el fin de propiciar, facilitar y acompañar a los estudiantes en su proceso de formación integral. Finalmente, esto generará en ellos, no solamente el aprendizaje de unos contenidos o la construcción del conocimiento disciplinar, sino el análisis y la reflexión como miembros activos de una sociedad en permanente construcción. Esta requiere cambios estructurales que propendan por la justicia y la equidad para todos (EC/05102/019/M).

Por otra parte, desde la perspectiva de los jóvenes, se llega a comprensiones en las cuales, a partir de la participación en el programa del servicio social estudiantil, se puede establecer que este servicio se constituye en una oportunidad para el despliegue y fortalecimiento de la capacidad de agencia de los y las jóvenes; si bien es cierto que esta capacidad se ha venido fortaleciendo en ellos desde la infancia temprana, en el contexto familiar y escolar 
donde se van adquiriendo las primeras pautas de solidaridad y participación, se hace necesario complementarla con políticas y programas los cuales vinculen a los estudiantes con acciones colectivas, de proyección comunitaria y de reconocimiento de su contexto inmediato. Así, el programa del servicio social del estudiantado se convierte en una posibilidad de agenciamiento de los jóvenes en el cual proyectan compromiso, responsabilidad social y un posible proyecto de vida (EC/051-02/020/M).

Otra tesis como EC/051-02/041/M, relaciona la configuración de subjetividad política con la construcción de identidad del sujeto, asegura que este proceso comienza en la primera infancia, basándose en las experiencias de vida las cuales se desarrollan en la familia; en las pautas de crianza las cuales promueven la tolerancia, el dialogo, la solidaridad, la confianza para expresar sus puntos de vista, la capacidad para compartir y entender fines colectivos. El impacto de estos procesos radica en el método utilizado por ser incluyente, lo suficientemente atractivo para que la participación sea activa y voluntaria; invitar a la reflexión y análisis de las situaciones cotidianas las cuales afectan al sujeto desde una vista ajena ya que se presentan como «juegos o retos» que son analogías de estas realidades. Otra fortaleza que tienen los procesos formativos experienciales es que involucran variadas herramientas mediadoras de la experiencia como el juego, el arte, el turismo, los retos, las técnicas narrativas, los vídeo foros; pero, sobre todo, comprometen - y deben hacerlo-, todos los canales de comunicación del sujeto: el auditivo, el kinestésico y el visual. Así, se fomenta el desarrollo de las habilidades cognitivas integrales por medio de la utilización de todo el cuerpo como parte del proceso de aprendizaje y análisis de la experiencia.

Finalmente, el estudio EC/043/022/D determinó que las subjetividades políticas implican condiciones y oportunidades, como aquellas ligadas a la transformación de relaciones de poder en sus escenarios de socialización. Así pues, develar las formas de constitución de subjetividad política y su incidencia 
sobre lo político en la escuela permiten comprender mejor las reivindicaciones de los jóvenes estudiantes los cuales pugnan por el reconocimiento político y por la inclusión de sus expectativas dentro de una relectura de la ciudadanía.

\subsubsection{Memoria}

La tesis EC/051-01/079/M aborda este tópico y representa el $0.3 \%$ de los trabajos estudiados. Esta tesis presenta la recuperación de la memoria realizada por el Colectivo «Cartografías en el Centro de Memoria Paz y Reconciliación» de la ciudad de Bogotá.

Desde esta perspectiva, la recuperación de la memoria, se constituye en un ejercicio pedagógico que aporta a retomar el papel de los individuos como ciudadanos, siendo una experiencia que se cualifica en la medida que se replique y se propicie la expresión lúdica y sanadora de los participantes, que debe apreciarse en su justa dimensión, como el esfuerzo y el aporte a la paz al relatar sus vivencias, compartirlas y convertirlas en insumo que perpetúa recuerdos para la sanación.

El conflicto destruyó gran parte del tejido social que sostenía la dinámica ciudadana, generó una población migrante y trastocó la cotidianidad en un cúmulo de historias que se entrelazan al azar, pero que a su vez tienen vínculos resultado de la violencia que los obligó a insertarse en lugares diferentes a los de su origen y a reinventarse bajo otros premisas, con las que las personas víctimas sobrevivientes, retoman su papel social; a través de la recuperación de la memoria sientan bases para superar la etapa de los encuentros y desencuentros del conocimiento de la verdad y avanzar en la disposición hacia una reflexión sobre el perdón, la reconciliación y la convivencia, haciendo gala de nuestra capacidad de resiliencia (EC/051-01/079/M, p. 109).

\subsubsection{Construcción de identidad}

La tesisEC/051-01/080/Maborda estetópico yrepresenta el0.3 $\%$ de los trabajos estudiados. En ella se reconocen transformaciones 
las cuales implican un transitar en la construcción de identidad del sujeto, desde la experiencia que el maestro tiene en el mundo de la vida cotidiana y que se orienta hacia la construcción de escenarios de lo posible. Esto implica una modificación del conocimiento del mundo hacia un reconocimiento de sí mismo, donde la persona asume un posicionamiento reflexivo-deliberante para determinar su manera de ser-estar en la historia; por último, se devela la transformación de un sujeto el cual se reconoce por medio de un lenguaje-fuerza el cual lo potencializa en las posibilidades de ser. Específicamente, para el docente corresponde a la posibilidad de ser sujeto maestro en el escenario del mundo (EC/051-01/080/M).

Se reconoce que los educadores otorgan mayor relevancia a las experiencias vividas en escenarios donde ellos han asumido el rol de aprendiz o maestro. Destacan experiencias de aprendizaje y de enseñanza, ya sea en escenarios relacionados con la educación como en otros escenarios de su cotidianidad. Estos realizan una construcción sobre el arquetipo de ser maestro, pero se vive como ideal posible en la medida que el sujeto asume su papel como maestro y se reconoce en ese ideal (EC/051-01/080/M).

Al visibilizar huellas, producto de experiencias vividas que son relevantes en la historia de cada sujeto, estas experiencias se transforman en un lenguaje experiencial producto de experienciarse, lo cual le posibilita al sujeto maneras de representary de significar su mundo. Así, en la medida que se realizan estas construcciones, se permite el despliegue de la subjetividad hacia nuevos horizontes de posibilidades. En este sentido, la construcción de este lenguaje experiencial, especialmente lenguaje-fuerza, provee al sujeto la posibilidad de reconocerse como posibilidades de cuestionarse a sí mismo y surcar los límites de las determinaciones propias de lo dado como significado (EC/051-01/080/M).

Se reconoce la existencia de un lenguaje-fuerza que corresponde a una forma particular del lenguaje experiencial el cual enriquece la capacidad del sujeto de mostrar el mundo y resignificarlo. 
El lenguaje-fuerza cobra relevancia en la construcción de lo posible mediante la capacidad poética del lenguaje, la cual permite al sujeto atravesar los límites de las determinaciones hacia nuevos horizontes de posibilidades. Así, se reconoce en los docentes la construcción de un ideal de ser maestro que se materializa como experiencia vivida, la cual vuelve a vivir en el presente histórico. De este modo, el educador puede experienciar-se como sujeto maestro en su historia y vivirla, como sujeto en el escenario del mundo, como espacio-tiempo de posibilidades (EC/05101/080/M, p. 172).

Finalmente, se reconocen transformaciones que implican un transitar en la construcción de identidad del sujeto. Aquellas surgen desde la experiencia que el docente tiene en el mundo de la vida cotidiana. Esta se orienta hacia la construcción de escenarios de lo posible e implica una transformación en lenguaje experiencial, en la cual el sujeto logra un enriquecimiento de su lenguaje y, por ende, de su subjetividad; por otra parte, implica una transformación del conocimiento de mundo hacia un reconocimiento de sí mismo, donde la persona asume un posicionamiento reflexivo-deliberante para determinar su manera de ser-estar en la historia (EC/051-01/080/M).

\subsubsection{Reintegración}

La tesis EC/051-02/008/M aborda este tópico y representa el $0.3 \%$ de los trabajos estudiados. La educación es uno de los factores más potentes para afrontar los cambios sociales que vienen con el fenómeno del postconflicto; sobre todo para que quienes han hecho parte directamente del conflicto armado (EC/051-02/008/M).

La temática trabajada en esta tesis es de gran pertinencia de cara al contexto del país y a la necesidad de la educación que tienen las comunidades que han participado directamente o han sido afectadas por el conflicto armado, como también, las comunidades de acogida de quienes provienen de escenarios de 
guerra; tal y como lo han propuesto Alvarado et al. (2012). Se trata de una opacidad para las líneas de investigación de educación de la Universidad de Manizales y el CINDE y sería un tema fundamental para seguir profundizando.

\subsubsection{Conflicto/resolución de conflictos/pluralidad y conflictos}

Tres tesis abordaron este tópico y representan el $0.9 \%$ de los trabajos estudiados. Desde el papel docente se pueden percibir casos de violencia familiar en los cuales es posible realizar un acompañamiento a las familias en la búsqueda de soluciones y orientación. Se destaca la prevención primaria que significa incentivar acciones dentro de la comunidad en donde se tome conciencia de la magnitud del problema; informar a la comunidad de los riesgos y buscar especialistas los cuales den conferencias sobre la temática. Con respecto a la violencia escolar, es posible llevar a cabo acciones que permitan prevenir el surgimiento de la misma en la institución escolar. Se precisa que debe haber una articulación más fina entre la escuela y la sociedad para poder evitar la violencia. No se trata solo de prevenirla al interior de la escuela sino generar los procesos formativos y el acompañamiento necesario para que, en ningún escenario, sea esta la forma de afrontar los conflictos (EC/051-02/016/M).

Por otra parte, otro estudio perteneciente a EC/051-02/037/M evidencia cómo los niños y niñas participantes del proyecto no se nombran a sí mismos como víctimas del conflicto armado; por el contrario, reconocen sus orígenes geográficos, la historia de conflicto que los llevo hasta el lugar donde se encuentran, y los cambios y transformaciones generadas por el desplazamiento forzado en la configuración de su familia y su entorno comunitario. Las narraciones de sí mismos se tejen con más fuerza alrededor del reconocimiento de sus cualidades; sus habilidades sociales y relacionales; y sus gustos escolares, artísticos y deportivos. Emerge también aquí la noción del otro como actor válido con 
el cual se construye subjetividad en una trama de prácticas relacionales puestas en escenarios de socialización como la familia y la escuela. Además, el entre nos — con sus pares y agentes educativos-, el cual aporta en la construcción de subjetividad desde las concepciones que estos construyen sobre el niño y la niña, los cuales ha vivenciado el conflicto armado, se encuentra mediado por algunas concepciones las cuales dan cuenta de una fuerte tendencia del agente educador a nombrarlo y referirlo como «victima», atribuyéndole características de indefensión, malestar en la relación con los pares y deseos de venganza.

Finalmente, los hallazgos de la investigación EC/043/029/D, dan cuenta de cómo los conflictos entre jóvenes en la universidad surgen principalmente a causa de las diferencias, por los problemas en la comunicación y por la presión académica. Por otra parte, se refuerza la idea de la universidad como escenario de socialización política donde se pone en juego todos los asuntos mencionados en relación con el conflicto: tensión, intereses, posiciones, actitudes, poder, pluralidad, contexto, entre otros. Se destaca el tema de género como un matiz específico del tópico, es decir, que los jóvenes perciben que las relaciones entre mujeres suelen ser más conflictivas por una suerte de naturaleza femenina la cual implicaría unos atributos más complejos para las relaciones. Desde esta perspectiva, se encuentra que las principales diferencias se hallan en el género, pero también aparecen exclusiones a causa de la raza, y otros fenómenos sociales que no son unidireccionales ni verticales, sino bidireccionales y horizontales.

\subsubsection{Sujeto autónomo y reflexivo}

La tesis de EC/043/011/D aborda este tópico y representa el $0.3 \%$ de los trabajos estudiados. En este se exponen

... las concepciones de participación de los estudiantes de Derecho en Colombia [y se retoman] las categorías como derecho fundamental, libertad, reflexividad y metaderecho las cuales 
permitieron sustentar concepciones sobre la participación, pues definen la práctica social del Estado Social de Derecho y el desarrollo del sujeto estudiante de leyes como ciudadano impecable. Sin embargo, llama la atención que junto a muchos conceptos sobre participación expresados por ellos aparecen entre paréntesis palabras como "utopía", "farsa", "esto no se da", y "en Colombia no existe". Con ello se expresa que la participación ciudadana es un concepto que se ha venido tratando de manera teórica y no se relaciona con la realidad del país, aunque ingresa en los discursos de los estudiantes (EC/043/011/D, p. 155).

En consonancia con una formación en Derecho a través de la pedagogía crítica es necesario conjugar las prácticas de los estudiantes con los procesos de aprendizaje, como escenario del ejercicio de la ciudadanía. Ello no es posible mientras la formación se siga dando en los espacios cerrados de cuatro paredes y en la lógica individualista de formación. Se requiere una formación autorregulada y flexible en el proceso de aprendizajes orientados por los estudiantes (autonomía), trabajo colaborativo (grupos de discusión, de investigación, de prácticas) (EC/043/011/D, p. 161).

\subsubsection{Miradas comunes en relación con la educación para la paz y la democracia}

Los análisis realizados en torno a los hallazgos en el tópico global educación para la paz y la democracia permiten dar cuenta de dos tópicos locales relevantes: subjetividad política $y$ ciudadanía/ciudadanía y conciencia crítica. Lo anterior obedece a la influencia ejercida por el Centro de Estudios Avanzado en Niñez y Juventud, en la Maestría en Educación y Desarrollo Humano y en el Doctorado en Ciencias Sociales, Niñez y Juventud al tener en cuenta la trayectoria presentada de estos tópicos desde diversas perspectivas, y el reconocimiento que actualmente tienen tanto a nivel nacional como latinoamericano, como fruto de este trabajo. Al ser la subjetividad política una categoría emergente de las discusiones de la línea de investigación de socialización política y constitución de subjetividades del doctorado en mención. Así mismo, los estudios son desarrollados en escenarios educativos 
tanto de tipo formal como informal, lo cual también evidencia la relevancia que tienen estos espacios para la constitución de sujetos críticos y participativos los cuales, desde sus decisiones, puedan aportar a la construcción de democracia y paz.

Por su parte, en el tópico de subjetividad política, identificado como el más relevante dentro del tópico global de educación para la paz y la democracia se encuentra que, desde un análisis general de los hallazgos presentados, hay un abordaje complejo de las relaciones tejidas en los contextos educativos en donde no es posible prescindir de otros espacios sociales, culturales y comunitarios que constituyen redes para el desarrollo humano de los sujetos. Así mismo, se destaca la importancia de visibilizar los procesos desarrollados en espacios de educación no formal en donde se generan procesos de participación social que, desde el pensamiento crítico, pueden aportar a la emancipación. En este sentido, y en relación con lo expuesto por Alvarado et al. (2012), dentro de la subjetividad política se ponen en juego aspectos relacionados con la autonomía; con la capacidad reflexiva; con la acción y con la forma como esta es narrada; con la renegociación del poder, el reconocimiento y la apropiación del espacio público. Esto es, al mismo tiempo, una oportunidad en donde convergen pluralidades desde donde se comparten cuestiones identitarias y se reconocen particularidades propias de cada biografía. De este modo, se trasciende el carácter reproductivo de la socialización para dar lugar a las posibilidades de transformación social, las cuales emergen de la pluralidad y la diversidad. Quizás el engranaje entre la educación y la socialización política como vía para la constitución de subjetividades políticas estaría en el diálogo propuesto por Alvarado et al. (2012) entre estas perspectivas de socialización política y la educación popular, en donde se busca pensar a las escuelas como territorios de paz, y los escenarios comunitarios como territorios de formación y educación. 
Respecto a la ciudadanía/ciudadanía y conciencia crítica, se encuentra que los estudios que hacen parte de este tópico son desarrollados en la escuela. Estos reconocen su importancia como escenario en donde los niños y las niñas permanecen la mayor parte del tiempo y, por lo tanto, donde establecen relaciones y concepciones correspondientes a sí mismos, a los otros, y al mundo que los rodea; situaciones desde las cuales empiezan a construir sentidos y significados que tocan sus subjetividades e identidades a partir del encuentro con la diversidad y la diferencia. Así también lo manifiesta Carreño (2007) al plantear la necesidad de llevar a cabo procesos educativos que incidan en los sujetos tanto de forma individual como colectiva. Estos permitirían el reconocimiento de sus funciones y responsabilidades como actores sociales en diversos escenarios como parte de la formación ciudadana, lo cual conduce a apreciar la participación como un elemento constitutivo del desarrollo humano, el cual permite reconocer al otro como legítimo y concertar intereses para la tramitación de conflictos.

Otro tópico trabajado fue el de convivencia. Desde este, se resalta la democracia como el mejor camino para la tramitación de conflictos en lugar del autoritarismo y de otras formas impositivas sobre el ser y el hacer. En este sentido, nuevamente se acude a los escenarios familiares y escolares por su relevancia y responsabilidad en la formación de niños y niñas como sujetos que logran responder asertivamente a las demandas sociales y relacionales. Se evidencia a la escuela como eje desde el cual se articulan diversas perspectivas que fundamentan procesos convivenciales a partir de la construcción de significados, sentidos y prácticas dentro de la vida cotidiana, pero sin caer en estrategias que pretendan lograr la convivencia a partir de la normalización y homogenización de los y las estudiantes.

Es así como, en los hallazgos de las tesis los cuales abordaron este tópico, se resalta la importancia de reflexionar en torno a prácticas educativas desde las cuales sea posible reconocer a los 
niños y las niñas como sujetos activos e inacabados que, a partir de su interacción con otros, negocian acciones dominantes que han naturalizado la violencia. Esto aportaría a la construcción de su propia identidad.

Por su parte, con una menor relevancia, fue abordado el tópico de participación/participación ciudadana, desde el cual se reconocen las apuestas que en este sentido se vienen desarrollando en las instituciones educativas para propiciar transformación social a partir de la movilización y participación en escenarios democráticos. De esta manera, este tipo de prácticas se relacionan con la autonomía y la libertad de los sujetos, los cuales también están inmersos en las prácticas pedagógicas, y logran replantear paradigmas en donde se da un lugar importante a la política y al desarrollo humano. Es importante establecer una relación entre estas apuestas participativas con aquello que concierne a lo político, lo cual también permite entender cómo aquellas prácticas se despliegan en la vida en común, en lo que implica ser ciudadano y en el ejercicio de la democracia tanto en su expresión formal como informal. Esto estaría en pro de la inclusión y el bien colectivo (Arias-Cardona y Alvarado, 2015).

Otro tópico que presenta una relevancia similar corresponde a conflicto/resolución de conflictos/pluralidad y conflictos. En este se aborda el conflicto desde diversas dimensiones: la violencia intrafamiliar y la violencia escolar, abordadas desde una perspectiva preventiva que requiere la articulación de sectores públicos y privados; y el trabajo mancomunado entre familia y escuela. También se hace alusión al entorno universitario como escenario de socialización política en donde se vivencian conflictos a causa de la pluralidad, específicamente, desde una perspectiva de género.

Igualmente, se destaca la aproximación de este tópico desde el conflicto armado. Allí se reconocen los cambios y transformaciones producto de este pero a partir de narraciones 
que permiten el reconocimiento de cualidades, habilidades y potencias relacionales; esto se logra a partir de una postura crítica y alternativa alrededor del desarrollo y de las vivencias, lo cual permite que en las narrativas la voz de los niños y las niñas tenga lugar y que, sin desconocer la afectación, se pueda forjar un ejercicio transformador y reflexivo en el que ellos, junto con sus agentes relacionales, logren reconocer sus recursos y potencialidades. Esto genera rupturas con el lugar pasivo que ha ocupado la niñez en la construcción de la realidad y del mundo social (Ospina-Alvarado et al., 2018). Se presenta como opacidad el tópico de reintegración - abordado solo por una tesis-, el cual permite establecer una conexión con la temática del conflicto armado, y es retomada desde la educación como posibilidad para hacer frente a los cambios propios del posconflicto. Esta opacidad representa un llamado a la Universidad de Manizales y al Centro de Estudios Avanzados en Niñez y Juventud a agenciar nuevas investigaciones las cuales permitan fortalecer la relación entre la educación y los procesos de reintegración.

Finalmente, es importante hacer alusión a otras opacidades o tópicos poco abordados los cuales, desde sus apuestas, presentan temáticas interesantes y dejan la invitación para continuar siendo abordadas y exploradas. Una de ellas es la memoria, tenida en cuenta como un recurso que se recupera a partir de un ejercicio pedagógico y el cual acercó a los participantes a una experiencia lúdica y sanadora luego de haber experimentado situaciones de conflicto y de afectación del tejido social a causa de la migración. Como lo presentan Ospina-Alvarado, Alvarado y Cardona (2018), y Ospina-Alvarado, Alvarado y Fajardo (2018, existe una necesidad social por llevar a cabo estudios en el campo de la memoria, especialmente con niños y niñas y sus agentes relacionales, como una práctica reivindicativa y conducente a la garantía de derechos y a la construcción de paz. Estos autores consideran además la memoria y sus narraciones como un proyecto político y un camino hacia la justicia (Sánchez et al., 2018). De cara al país, este sería un tópico fundamental para seguir profundizando a través del Centro de Estudios Avanzados en Niñez y Juventud. 
En relación a la construcción de identidad, tópico local abordado solo por un estudio, se identifica su abordaje a partir de la forma como los maestros construyen y reconstruyen su lugar en el mundo de la vida cotidiana, donde se privilegia el lugar del lenguaje y de la habilidad reflexiva para este proceso. Desde una perspectiva similar, se aborda el tópico sujeto autónomo y reflexivo para identificar las concepciones de práctica social, las cuales se establecen desde los estudiantes de Derecho en Colombia, en donde se establece como reto la construcción de una pedagogía crítica, mediada por la autorregulación y la flexibilidad a partir de la cual se puedan conjugar las prácticas de los estudiantes con los procesos de aprendizaje, como escenario del ejercicio de la ciudadanía. Este sería otro tema importante para seguir profundizando.

Finalmente, se presenta como oportunidad continuar investigando alrededor de temas como la educación para la paz desde metodologías abiertas, flexibles y plurales las cuales reconozcan el conflicto como parte de la cotidianidad y como oportunidad para identificar nuevos caminos que permitan la tramitación de los mismos sin acudir a las distintas formas de violencia. Esto permitiría desplegar dichas acciones en espacios de educación formal e informal.

\subsubsection{Tópico global: educación inclusiva}

Este tópico se presenta con mayor relevancia para la Universidad de Manizales y el CINDE (4.8\%); se debe al énfasis que la Maestría en Educación desde la Diversidad hace sobre esta temática. Por otro lado, para la Universidad Tecnológica de Pereira (2.2\%) presenta un crecimiento en este interés; mientras la Universidad Católica de Pereira $(0.3 \%)$ se presenta con mayor opacidad que en las otras instituciones. 
Ahora bien, la educación inclusiva se relaciona de manera particular con subtópicos de diversidad, pluralidad e interculturalidad, pero no se logra evidenciar una fuerte diferencia entre estos, pareciera en algunos casos como sinónimos de la inclusión como en el caso de diversidad o como sus características en el caso de la pluralidad y de la interculturalidad.

Este tópico global se presenta principalmente como una crítica a las prácticas tradicionales las cuales desconocen la diversidad en sus múltiples manifestaciones, más aún en la actualidad cuando la población escolar crece permanentemente (nacionalidades, prácticas culturales y sociales, familias, experiencias de vida, emociones, capacidades físicas y sensoriales, entre otras). En estos escenarios, a pesar de los discursos, aun se viven gran cantidad de procesos de discriminación y exclusión para con el otro, su lenguaje, sus ideologías, sus potencialidades, entre otros aspectos.

Ello exige grandes retos para la educación. El primero de ellos está relacionado con el tránsito del discurso a la práctica y a las actitudes; esto quiere decir que se deben superar los discursos sobre la inclusión y la diversidad para hacerlos más prácticos, generar espacios no solo de reflexión sino de inclusión verdadera; allí se exige que los futuros maestros se formen en estos espacios para que desde la vivencia directa desarrollen actitudes inclusivas; así mismo se requiere flexibilización curricular y didáctica en el contexto escolar, elementos que respondan a las necesidades particulares de los sujetos y generen mecanismos distintos de actuación y participación en el marco de las diversidades humanas.

Fue significativa la manera en la que la maestra incorporó estrategias que posibilitaron el trabajo grupal entre estudiantes, sin embargo, no se presentó aprendizaje cooperativo dado que no hubo responsabilidad compartida por parte de los estudiantes, a través del reconocimiento de las capacidades propias y de los demás (RDA/133/003/M). 
Todo lo anterior implica que el maestro, la institución y la misma sociedad tengan claro las diferencias conceptuales entre integración e inclusión y el recorrido histórico de cada región, esto para comprender verdaderamente el sentido real de la educación inclusiva. Por otro lado, se debe generar una actitud diferente del maestro que no solo busque hacer la inclusión sino que llegue él mismo a ser en inclusión, situación que le llevaría a construir una sensibilidad para sí y para con el otro; cuestionar las injusticias, adaptarse permanentemente y hacer coherentes sus actitudes y acciones con sus discursos sobre la inclusión educativa (Bourdieu, 2000; Ezcurra, 2008; Ezcurra, 2011; Jacinto y Terigi, 2007; López, 2007; Marquina y Chiroleu, 2015; Mayer, 2012; Mayer y Cerezo, 2016; Nirenberg, 2010; Tinto, 2006; Urresti, 1999).

\subsubsection{Tópico global: escuela}

El tópico escuela se presenta en un $5.9 \%$ de las tesis de la zona del Eje Cafetero. Este se encuentra en dos de las instituciones tenidas en cuenta para el estudio. Entre ellas, se muestra como relevante para la Universidad de Manizales y el CINDE con el 5.4 $\%$, mientras que, para la Universidad Católica de Pereira (0.5 \%), dos tesis han abordado este estudio.

Las investigaciones relacionadas con la escuela presentan una línea clara hacia las relaciones. Por un lado, se encuentran las relaciones las cuales debe fortalecer dicho espacio con la comunidad, relación que se puede ver desarrollada a través de prácticas académicas como el servicio social del estudiantado, o a partir de la promoción de la lectura para comprender los acontecimientos del contexto. En esta relación, la escuela busca dejar una huella en las comunidades y territorios de procedencia de sus estudiantes.

Así mismo, la otra forma de relación que se busca fortalecer es la familiar. Se reconoce que, a pesar de las normas estatales e institucionales las cuales proponen hacer efectiva la vinculación de 
la familia a los asuntos escolares, está lejos de cumplirse de forma óptima. Mientras los padres ceden cada vez más la responsabilidad de la formación de sus hijos a los maestros; estos, a su vez, exigen un mayor acompañamiento de los padres en este proceso.

Pero, la relación más fuerte que se ha buscado fortalecer es precisamente de la escuela y el maestro con los mismos jóvenes. Se evidencia cómo los niños, por su misma condición y el desconocimiento de las leyes, las cuales los cobijan, se presentan más sumisos ante las imposiciones de una escuela adultocéntrica; sin embargo, en el caso de los jóvenes, estos generan resistencias ante el poder otorgado al adulto y demandan ser escuchados y tenidos en cuenta, exigen escenarios de diálogo y de transformación. Esto lleva a pensar en una escuela viva, la cual se piensa permanentemente desde el diálogo intergeneracional e intercultural; esto implica generar estrategias de educación emocional las cuales no solo se dirijan a la formación del joven sino también a la del adulto que comparte el espacio escolar con ellos (Bauman, 2004; Contreras Domingo, 2017; Dubet, 1997; Espinosa, 2015; Jackson, 1980; Rockwell, 2005).

\subsubsection{Tópico global: evaluación}

La evaluación es un tópico que se presenta con poco interés de estudio en las instituciones. Aun así, sigue siendo relevante para la zona del Eje Cafetero, al encontrarse al menos una tesis en las universidades las cuales hacen parte del estudio. Para este caso, la evaluación da cuenta del $4.1 \%$ de las tesis incluidas en el estudio, presentándose con mayor frecuencia en la Universidad de Manizales y el CINDE (2.5 \%), en la Universidad Tecnológica de Pereira se plantea tímidamente con un $1.3 \%$, mientras que en la Universidad Católica de Pereira se muestra con una opacidad del $0.3 \%$ sobre el total de las tesis de la zona. 
El principal abordaje de este tópico se da en la crítica a las prácticas tradicionales de la evaluación sumativa y a partir de pruebas estandarizadas (Pruebas Saber y Pruebas Pisa), las cuales buscan el control del conocimiento y de la voluntad del estudiante. Es el tipo de evaluación que se representa a través de calificaciones y notas cuantificables.

Por otro lado, de estas críticas y de los resultados de evaluación se resaltan las propuestas por desarrollar otros tipos de evaluación más pertinentes a las necesidades educativas de los estudiantes. Ejercicios que pretenden una evaluación integral la cual busca dar cuenta del logro de competencias reflexivas, propositivas y argumentativas; pero que se constituyan en verdaderos ejercicios de diálogo para fortalecer la relación maestro-estudianteconocimiento (Black y William, 2009; Carlino, 1999; Camilloni, 2010; Eriksson, 2017; Farrell, 2018; Ferrer, 2006; Grinberg, 2015; Gysling, 2017; Guba y Lincoln, 1982; Guba y Lincoln, 1989; Hidalgo, 2018; Magnus, 2018; Motsenbocker, 2018; Pace, 2018; Peñaloza y Quiceno, 2017; Preal, 2008; Martínez Rizo, 2012; Stufflebeam, 1987).

Se podría pensar que no se muestra un mayor interés en los estudios sobre evaluación como una reacción a la orientación tecnológica educativa que ha tenido el campo de la evaluación en Colombia, lo cual compite con el interés pedagógico más fuerte en la zona del Eje Cafetero. Este intento de explicación se tendría que corroborar con estudios posteriores.

\subsubsection{Tópico global: pensamiento crítico}

Este tópico solo es abordado por la Universidad de Manizales y el CINDE con seis tesis, equivalentes al $1.9 \%$ de la totalidad de trabajos estudiados en la zona del Eje Cafetero.

A la escuela le corresponde formar sujetos críticos integrales (dos tesis) capaces de reflexionar sus contextos de vida cotidiana, 
pensar las situaciones de dominación y liberación que allí acontecen; así mismo, ganar las voces de los estudiantes y potenciar un pensamiento el cual contribuye a transformar las realidades sociales en corresponsabilidad con los otros (Adorno, 1998; Habermas, 1981). Esto supera la mirada individual del pensamiento crítico y se lanza a la formación de sujetos capaces de reflexionar de manera colectiva sobre la escuela y el contexto social que la rodea (EC/051-01/025/M); en este sentido, «La escuela se convierte así en el espacio propicio para la construcción del pensamiento crítico como una herramienta en la formación de sujetos transformadores» (EC/051-01/020/M, p. 26). En la formación de sujetos críticos, una de las tesis plantea la importancia de trabajar pedagogías críticas por parte de los profesores con apoyo de la educación musical a partir de lo cual se mejora la convivencia entre los estudiantes y con esto se contribuye a una sociedad mejor (EC/051-01/057/M). La cuarta tesis que aborda el pensamiento crítico lo hace desde una mirada distinta a las anteriores, se trata de analizar los niveles del pensamiento crítico cognitivo y encuentra que estos son bajos en los estudiantes, lo cual obliga a determinar estrategias de mejoramiento y la construcción de instrumentos más efectivos para su valoración (EC/051-02/014/M).

Las otras dos tesis las cuales abordan el pensamiento crítico lo hacen desde el poder. Una de ellas analiza las fuerzas de poder de disciplina hacia los cuerpos de los estudiantes en la escuela; considera que el dispositivo pedagógico es un dispositivo de control de los sujetos (Foucault, 2002a), por medio de lo que Foucault llamó técnicas de poder disciplinario (Castro, 2004). Plantea esta tesis, como la institución escolar estudia, excluye y estigmatiza a los alumnos. Una escuela distinta busca resolver estos problemas y ser incluyentes de los estudiantes (EC/043/005/D). La otra tesis aborda el ejercicio del poder sobre la primera infancia, considera que, entre la familia y la escuela, se juegan ciertos papeles de disciplinamiento en algunos casos, pues en la primera se tienen algunas reglas mientras que en la segunda se 
viven otras. Sin embargo, existen casos en donde, en el escenario familiar, se desconocen las normas presentes en la escuela y el niño puede hacer lo que desea siempre y cuando respete su lugar en la jerarquía del hogar. En estos términos, se asume que este espacio académico, desde una perspectiva foucaultiana, es un lugar en el cual se producen y ejercen formas de poder sobre los niños con el objeto de dominar su voluntad, de llevarlos a madurar dentro de las normas morales establecidas por la sociedad y respetar la autoridad (Foucault, 1983; 1995; 2002; EC/051-02/009/M).

Algo similar a lo propuesto en los estudios sobre escuela y en el proyecto pedagógico, se podría decir con relación a las dos tesis que abordan la formación de pensamiento crítico integral en los estudiantes y las tesis analizadas sobre formación; porque de qué otra cosa estamos hablando cuando se habla de formación en el concepto de educación alemana, heredera del pensamiento crítico frankfurtiano, que no sea de la formación del pensamiento crítico. Con esto se estaría aumentando el número de estudios sobre formación.

\subsubsection{Tópico global: poder}

El tópico poder es planteado por cuatro tesis, lo cual equivale al $1.3 \%$ de los trabajos del Eje Cafetero. Este solo se presenta en la Universidad de Manizales y el CINDE.

El poder es una condición social el cual marca las relaciones entre los sujetos, ya sean de género, ya sean de autoridad o de encuentros de dominación intergeneracionales. Así, se encuentra que, básicamente, toda relación social es una relación de poder (Foucault, 1966;1979; 2000a; 2000b; 2002a; 2002b; 2007a; 2007b; 2016). Para ejercer este, el maestro como figura de autoridad en el aula demanda disciplina, control y gobernabilidad con relación al niño (EC/051-02/049/M). Ahora bien, contra esta mirada, la condición juvenil se presenta como posibilidad permanente de ruptura frente a las ideologías dominantes las cuales desconocen 
los deseos, saberes y formas diferentes de afrontar el mundo (Adorno, 1998; 2005; Habermas, 1981). Así, los nuevos lenguajes juveniles buscan romper con la hegemonía de un mundo adulto el cual los quiere adoctrinar y homogenizar.

En este sentido, los sujetos-jóvenes reclaman cambios y transformaciones en las relaciones de poder ejercidas por el adulto para que se reconozcan otras subjetividades; para ello, la institución educativa debe abrirse cada vez más a estas miradas, lo cual permitiría una formación más potente de sujetos críticos los cuales respondan a las necesidades actuales de una sociedad que ellos mismos son los encargados de construir permanentemente; estas demandas no solo afectan a los jóvenes sino que toca las nuevas mentalidades de los niños, aquellos que están siendo impactados por los medios de comunicación y las redes y, sobre los que la escuela tiene gran responsabilidad, como el caso de los niveles iniciales de transición y preescolar (EC/051-02/049/M).

En otra perspectiva, el poder es visto desde las transformaciones y los cambios propuestos por los colectivos de jóvenes desde la educación, los cuales tiene relación con las diversidades entre la mirada de los jóvenes y las miradas adultas. Esto, desde un análisis decolonial, conduce a problematizar relaciones de dominación y sometimiento (Castro-Gómez, 2012a; 2012b; 2014; Escobar, 2011; 2012; 2016; Quijano, 1980; 1981; 1987; 1988; 1993; 2000; Reguillo, 1999a; 1999b; 2005). Desde allí, los jóvenes en pleno uso de su accionar político se organizan en colectivos juveniles a partir de los cuales hacen propuestas para cuestionan la realidad y las prácticas sociales imperantes (EC/05102/034/M); deconstruyen las relaciones jerárquicas para dar paso a encuentros de reconocimiento propio y del otro, de solidaridad y construcción colectiva de su cultura, su identidad y sus prácticas particulares. 
Esta mirada, se concreta en la educación popular como una alternativa frente a la educación tradicional. Tal educación fractura lo institucional, se abre hacia nuevas formas de comprender, de asumir el mundo y de adquirir saberes, destrezas y habilidades para afrontar los nuevos retos presentes en la sociedad; pensada así, la educación ya no es un lugar de transmisión, adoctrinamiento y homogenización, sino de construcción mutua y diversa de una realidad común para chicos, jóvenes y adultos (Apple, 2017; Arroyo, 2016; Bolívar, 2005; Cabaluz Ducasse, 2017; Cepal y Unesco, 1992; Dussel, 1980; Grinberg, 2008; Mejía, 2011; Ortiz et al., 2018; Walsh, 2014).

\subsubsection{Tópico global: políticas educativas}

Este tópico se presenta solo en la Universidad de Manizales y el CINDE, representa el $1.3 \%$ de los trabajos abordados en la zona del Eje Cafetero. Los trabajos encontrados allí se centran en cuatro aspectos:

- Sistemas de calidad: hace referencia a los factores motivacionales (autoestima/imagen propia) los cuales intervienen en los procesos de reintegración para la vinculación y permanencia en el sistema educativo (EC/051-02/008/M).

- Políticas públicas educativas: se busca una equidad para la educación a través de la política pública de educación superior, las cuales deben elaborarse de acuerdo a las necesidades del contexto. No a las políticas estandarizadas ya que de alguna manera son excluyentes.

- Niveles educativos: caracterizado por el componente institucional y de variables socioeconómicas no considerados en los trabajos de economía de la familia.

- Conocimiento del contexto social: se plantea la inexistencia de variables las cuales afectan la calidad de vida. 
En América Latina se ha producido una amplia literatura sobre política educativa la cual realiza críticas a las orientaciones propuestas a nivel internacional por distintos organismos y, en particular, a lo agenciado por los gobiernos en cada país (Flórez Petour, 2011; Piussi, 2013; Schwartzman y Cox, 2009; Torres, 2008).

\subsubsection{Tópico global: formación}

El tópico formación es de poco interés, si bien se presenta en las tesis de dos instituciones, estas tan solo representan el $1.3 \%$ de la totalidad de las tesis incluidas en el estudio ( $1 \%$ para la Universidad de Manizales y el CINDE y el $0.3 \%$ para la Universidad Tecnológica de Pereira).

Las tesis incluidas en este tópico se centran en estudiar la formación profesional. Por un lado, se encuentran las motivaciones para elegir una u otra formación, lo cual está mediado por diversidad de motivos como: el interés en la temática central de la profesión, las vivencias personales, las situaciones familiares, las relaciones, los grupos sociales, los duelos, las rupturas o la influencia de maestros.

Por otro lado, se buscó indagar sobre lo que implica este tipo de formación. Es decir, la formación profesional no se limita a la adquisición de saberes propios de la profesión, sino y sobre todo, al desarrollo de una actitud responsable, idónea y ética; la necesidad de proyectar la actualización permanente para mantenerse en altos rangos de calidad según los diferentes estándares determinados para ello. Todo esto pasa por entender que la formación profesional requiere superar los currículos encargados de las asignaturas y centrarse más en las prácticas y las experiencias las cuales forman a un profesional con sentido crítico, curioso, dialógico y propositivo. De esta manera, se busca una mayor coherencia entre el discurso y la práctica profesional. 
La concepción de la educación como formación es trabajada en Colombia por el profesor Andrés Klaus Runge-Peña y otros integrantes de su grupo de investigación, heredero de la concepción de formación del pensamiento educativo alemán, el cual se nutre epistemológicamente en la concepción de reflexión de la escuela de Frankfurt (Runge-Peña, 1996; 2002; 2005; 2011; 2012; 2014; Runge-Peña y Garcés-Gómez, 2010; 2011; Runge-Peña y MuñozGaviria, 2006; Runge-Peña et al., 2007).

\subsubsection{Tópico global: currículo}

Este tópico se presenta con un bajo porcentaje para la zona del Eje Cafetero (1.1\%) frente al total de las tesis tenidas en cuenta en el estudio. Se encuentra en los trabajos de las tres instituciones (0.6 \% para la Universidad de Manizales y el CINDE, $0.3 \%$ para la Universidad Católica de Pereira y $0.2 \%$ para la Universidad Tecnológica de Pereira).

Se aborda una crítica directa a los currículos tradicionales o mallas curriculares las cuales se disponen como un camino predeterminado y obligatorio a seguir sin dar la posibilidad de una movilidad más abierta. En estos elementos tan importantes como la formación investigativa se ve reducidas al cumplimiento de requisitos en los cuales pareciera que el estudiante debe desarrollar las habilidades y destrezas del experto, pero no la idoneidad, curiosidad y capacidad analítica del verdadero profesional.

Frente a estas críticas, emergen las propuestas de volver a currículos más flexibles en los cuales se vinculen las emociones, la sensibilidad, la corporeidad y el pensamiento estético. Todo ello se puede lograr a través de las artes para alcanzar un proceso de educación pertinente, el cual involucre la formación social, integral, ciudadana y para la vida en sociedad (Darling-Hammond, 2012; Ferrer, 1999; Dueñas, 2001; López, 1995; Lundgren, 1997; Posner, 2005). 


\subsubsection{Tópico global: proyecto educativo}

Este tópico tiene una baja representatividad, apenas un 0.9 $\%$ frente a la totalidad de los trabajos vinculados por parte de la zona del Eje Cafetero (0.6 \% para la Universidad de Manizales y el CINDE y $0.3 \%$ para la Universidad Católica de Pereira).

Las investigaciones relacionadas con el proyecto educativo parten de la crítica al estilo homogeneizador de los mismos. En contraposición a ello, emergen propuestas las cuales buscan un proyecto educativo el cual apunte a la diversidad de los sujetos que llegan a la escuela y que traen consigo toda una carga cultural y social la cual desfigura todo intento de hacer a todos iguales.

En este sentido, se plantea la necesidad de rediseñar y resignificar permanentemente los proyectos educativos para que cumplan sus fines, salir de la escuela para dirigirse a la comunidad educativa para responder a sus necesidades y expectativas. Para lograrlo, se hace ingente la participación activa de los maestros en su desarrollo.

El estudio del proyecto educativo puede ser incluido como parte de los estudios de escuela los cuales fueron propuestos teniendo en cuenta que son parte de esta; si se procede de esa manera, se aumenta un poco el porcentaje de los estudios sobre la escuela.

\subsubsection{Tópico global: sentido de la educación}

Las dos tesis, las cuales abordan este tópico global, equivalen al $0.6 \%$ de los trabajos proporcionados por la Universidad de Manizales y el CINDE en la zona del Eje Cafetero.

Tradicionalmente la educación se ha desarrollado desde una perspectiva economicista para responder a los intereses burocráticos del ministerio y de los sistemas económicos que 
la influencian; esto ha hecho de la educación un aspecto poco humanista, poco creativo y distante de las realidades vividas por los estudiantes (EC/051-01/069/M). Por otro lado, como alternativa a esta mirada se exige dotar de otro sentido más pertinente a la educación, es la exigencia de procesos más contextualizados, los cuales respondan no solo a necesidades globales, sino que partan de las necesidades locales y que se construyan desde los mismos sujetos (Caso y Hernández, 2010, citado en EC/051-01/015/M; Hernández y Moreno, 2007, citado en EC/051-01/015/M; Navarro, 2003, citado en EC/051-01/015/M). En este sentido, se da un giro en la búsqueda de la calidad de la educación puesta sobre indicadores medibles y cuantificables hacia una educación de calidad más humana, pertinente y contextualizada (EC/05101/015/M).

\subsubsection{Tópico global: educación propia}

La educación propia es el tópico presente como opaco con tan solo el $0.6 \%$ de las tesis de la Universidad de Manizales y el CINDE incluidas en el estudio para la zona del Eje Cafetero. Un primer trabajo propone analizar la extensión rural, a través de la comprensión de la educación rural incluyente y de las necesarias oportunidades productivas para los pequeños productores. Como lo plantea EC/043/019/D se requieren políticas públicas pertinentes al contexto rural, en las que se valore el conocimiento local.

Por otro lado, la investigación propone una concepción más integral, compleja e integradora, la cual cuente con la participación de múltiples actores, los cuales reconozcan los conocimientos, acciones y discursos de las comunidades; y recuperen su condición de ser humanos y en su cotidianidad «los enfoques que se construyan sobre Extensión Rural deben ser diversos y plurales» (EC/043/019/D, p. 16). 


\subsubsection{Tópico global: gestión educativa}

La gestión educativa es abordada por dos trabajos de la Universidad de Manizales y el CINDE (0.6\%). Esta se centra en el análisis de las políticas públicas educativas y de las instituciones; allí se propone que la escuela debe trascender la normatividad y generar dinámicas propias en las instituciones al involucrar toda la comunidad educativa.

\subsubsection{Tópico global: educación ética y moral}

La zona del Eje Cafetero abordó en total trescientas quince tesis de programas de posgrado, los cuales corresponden a cuatro maestrías (dos en la Universidad de Manizales, una en la Universidad Católica de Pereira y una en la Universidad Tecnológica de Pereira) y el doctorado en Ciencias Sociales, Niñez y Juventud de la Universidad de Manizales y el CINDE. Es importante tener en cuenta que, de estos programas, solo los ofrecidos por la UM presentan aportes para el tópico global de educación ética y moral.

La Universidad de Manizales ha abordado el tópico global de educación ética y moral en las tesis de dos maestrías y un doctorado para el período de estudio comprendido entre el 2010 y el 2017. En la zona del Eje Cafetero se encuentran 315 tesis las cuales se han aproximado a la educación y la pedagogía. De ellas únicamente dos de doctorado, correspondientes al $0.6 \%$ del total de trabajos tenidos en cuenta en el estudio para esta zona, se han preocupado por la educación ética y moral. En ellas se incluyen dos tópicos locales: sujeto trascendental kantiano/sujeto emancipado $(0.3 \%)$ y restaurar la confianza (0.3\%).

Lo anterior permite identificar opacidades tanto en el tópico global de educación ética y moral como en los dos tópicos locales los cuales representan, en el caso de la UM, lo que a su vez conduce a que las tesis, las cuales hacen parte de este tópico global, tengan poca representación en los porcentajes (ver TABLA NRO. 26). 
TABLA NRO. 26. Región educación-tópico global de educación ética y moral

\begin{tabular}{lllllll}
\hline Tópicos locales & $\begin{array}{l}\text { Universidad de } \\
\text { Manizales y el } \\
\text { CINDE }\end{array}$ & $\begin{array}{l}\text { Universidad } \\
\text { Tecnológica de } \\
\text { Pereira }\end{array}$ & $\begin{array}{l}\text { Universidad } \\
\text { Católica de Pereira }\end{array}$ \\
\cline { 2 - 7 } & F & $\%$ & F & $\%$ & F & $\%$ \\
\hline $\begin{array}{l}\text { Sujeto trascendental } \\
\text { kantiano/sujeto emancipado }\end{array}$ & $\mathbf{1}$ & 0.3 & 0 & 0 & 0 & 0 \\
\hline Restaurar la confianza & 1 & 0.3 & 0 & 0 & 0 & 0 \\
\hline
\end{tabular}

Elaboración propia.

\subsubsection{Sujeto trascendental kantiano/sujeto emancipado}

La tesis EC/043/001/D aborda este tópico y representa el $0.3 \%$ de los trabajos estudiados en la zona del Eje Cafetero. Con la intención de reconstruir el saber que sobre el hombre y la formación se ha constituido - específicamente sobre aquellos maestros licenciados en educación en Colombia-, y de esta forma, repensar la educación y la pedagogía, se realiza un abordaje histórico y filosófico del sujeto, cuya aparición se da en el siglo XVII, en los trabajos desarrollados por René Descartes, quien intentó encontrar un régimen de verdad el cual lograra aprehender este ser, a todas luces indomable, y que, de algún modo, habría que someter.

Lo extraño es que esta tendencia consigue infiltrarse en el cristianismo y, sin que se le resistiera, encontró en él asidero. Por este camino parece completarse el esquema moderno el cual suplanta al hombre natural y subjetivo, al traer a la existencia el sujeto trascendental kantiano (Arias, 2010, p. 717 ).

El sujeto kantiano se funda en el ideal de la realización del hombre, ya no en un más allá en el que no se tenían certezas, sino en el más acá en su concreción histórica. Este trabajo, sabiamente desarrollado por Kant en la moral que le da sustento, encuentra en el carácter societario del hombre su referente. La «felicidad» solo ha de ser posible para el hombre en la medida que sea procurada no en el individuo sino en el sujeto, dado que este 
último representa, encarna y carga con la responsabilidad de la realización del hombre en su condición histórica; pero como esta responsabilidad no puede ya descansar en un individuo - por ejemplo, el soberano en los trabajos de Foucault-, ha de fundarse sobre un sujeto abstracto, esto es, trascendental, el cual no puede ser otro que el Estado (EC/043/006/D).

El sujeto tiene carácter social y, por esto, ha de organizarse partiendo de sus condiciones particulares, de los insumos reales los cuales posee, de las características las cuales le son propias, lo que le identifica y hace que sea semejante a los otros, es decir, la lengua o idioma, sus costumbres, sus tradiciones, sus formas de organización interna, lo que produce, su forma de verse y ver el mundo, su modus vivendi o ethos, su cultura. «Todo ello hace que el ciudadano o ciudadana termine asociado y busque constituir una comunidad en la que pueda reconocerse y en la que sus valores sean los valores de los otros» (Arias, 2010, p. 717).

La existencia del Estado ha de estar legitimada por los ciudadanos, por esto, los sujetos conforman un Estado Social de Derecho y delegan en sus representantes, reconocidos por el derecho, su acción y decisión.

Todo este trabajo implica una tarea educativa-formativa hasta hacer que los individuos declinen su condición y se integren a la sociedad en calidad de sujetos; sujetos que en el Estado Social de Derecho han de hallar quién hable por ellos, quién les represente y signe en su nombre, en su voluntad. En este sentido el sujeto moderno es, necesariamente, un sujeto regulado, normado, disciplinado, estructurado, representado y delegatario, a lo que no escapa el maestro o maestra en su proceso educativo y formativo. (Arias, 2010, p. 717).

Los discursos educativos muestran la necesidad de intervenir al hombre para que no sea más el que es, y se abra para que se le constituya otro diferente, disciplinado, formado, al punto que se valora en la medida en que somete su naturaleza en aras de la 
constitución de una realidad quele es “ajena”. Hayun extrañamiento del hombre en los discursos de y sobre la educación y, desde ella, en los programas de formación de maestros y maestras; allí se hace evidente su negación para acceder a su positivización: disciplinarización, sujeción, normalización, regulación. Todo esto le hace permeable, dócil, obediente, fraterno, solidario, ecuánime, humano (Arias, 2010, p. 717).

Los discursos educativos posteriores a la Segunda Guerra Mundial están mediados por el discurso de los derechos humanos. El horror que produjo la guerra condujo al posicionamiento del discurso sobre lo humano, como aquello contra lo que no hay que atentar porque de hacerlo se estaría labrando la propia destrucción, su aniquilamiento; el imperativo de la convivencia y el compromiso con la paz mundial anida y se instala en los discursos sobre educación. Se ponen como condición para la ayuda y el apoyo internacional, de tal manera que los países los cuales no hacen público este reconocimiento sobre los valores intrínsecos de los derechos humanos, quedan por fuera del derecho a la ayuda de la comunidad internacional. En función esto se retira el derecho (EC/043/006/D).

El maestro, a través de los programas que propician su formación, emerge como dispositivo de normalización. Él es agente del discurso, encargado de objetivarlo, concretarlo en actividades observables, mensurables, y pareciera que el resultado de su actuar profesional arroja el comportamiento de los sujetos en la sociedad (EC/043/006/D).

La formación del maestro hoy es asumida como tarea profesional; en este sentido, el trabajo el cual se viene haciendo para hacer de la pedagogía una disciplina con campos de trabajo como los de la enseñanza, la didáctica, el aprendizaje y la formación, es cada vez más importante, pues ello ha de emancipar al maestro de la sujeción y ambigüedad en que se le ha sumido y pasará a ser un profesional de la educación como gestor, creador, cultor, en la especialidad en que se desempeña, a lo cual ha de contribuirle la pedagogía en su reconfiguración discursiva (EC/043/006/D). 
La constitución del sujeto, como se ha mostrado, es el fundamento de los programas de formación de maestros. En este espacio formativo pareciera no tener cabida el hombre en cuanto individuo o subjetividad. ¿No será preciso repensar al sujeto que tanto se defiende y abrirse a pensar la subjetividad como componente más cercano a la realidad del hombre? (EC/043/006/D).

El trabajo empírico que buscó describir el saber sobre el hombre, realizado sobre los programas y textos formativos de maestros y maestras licenciados en la Universidad Santo Tomás, evidencia que el hombre colombiano se comporta de modo más subjetivo (individual) y menos subjetivo (colectivista). Estas prácticas, al parecer mediadas por el conocimiento situacional e histórico del hombre -humano- que se ha constituido en la realidad colombiana, generan otros tipos de saberes -posiblemente aún no explorados- y producen otros discursos relacionales que marcan tendencias hacia adentro y hacia afuera, lo que ha de llevar a producir cambios -más temprano que tarde- en las formas de acceder y producir su conocimiento; estas prácticas cada vez más ponen su interés en el hombre en su condición de individuo, por ejemplo en su experiencia personal, lo que a su vez conduce a nuevas formas (Arias, 2010, p. 718).

En la perspectiva teórica aquí trabajada, se está al atisbo de la ruptura, hay que disponerse para «replantearnos nuestra voluntad de verdad; restituir al discurso su carácter de acontecimiento; borrar finalmente la soberanía del significante» (Foucault, 2005, p. 51).

Posiblemente hayamos de volver al hombre que cultiva su subjetividad, su individualidad y su personalidad; restituirle el mundo reconciliándolo con él. Por este medio es posible que llegue a ser otro, cambie y se transforme sin violentar su humanidad. Este puede ser un camino para desprenderse de lo existente (lo que nos ha hecho) y empezar a abrirse para pensarse distinto y pensar de modo diferente (emanciparse), lo que no se asimila a divergente. (Arias, 2010, p. 718). 


\subsubsection{Restaurar la confianza}

La tesis EC/043/006/D aborda este tópico y representa el 0.3 $\%$ de los trabajos estudiados en la zona. La confianza es abordada como posibilidad hacia una

... nueva forma de pensar la promoción del desarrollo y trabajar decididamente por su generalización entre los actores de la educación, en los sectores de la administración pública y en la comunidad. Es algo así como una propagación a manera de pandemia: rápido y a todos los escenarios de actuación, la cual llega a los rincones más apartados de la ciudad y se coloca en las entrañas de cada niño o niña, de cada ser humano, para habitarle por siempre (Hincapié-Rojas, 2011, p. 700)

Por el contrario, desconfiar es el panorama que tenemos hoy en la sociedad; esta es la semilla que se está instaurando en cada ser, que extiende sus raíces y esparce sus ramas a lo ancho y largo; este es el sabor que degustan los niños, las niñas y los adolescentes; este es el legado de la sociedad; este es el contenido educativo el cual se encuentra entre las líneas de los noticieros del día a día. Transformar este contexto para que se convierta en espacio para creer en el otro, para construir con el otro, para soñar mejores espacios para todos y todas es el llamado. La invitación es hacer que la confianza vuelva a convertir en el escenario común y común denominador de las relaciones entre personas e instituciones.

Restaurar la confianza, zurcir nuevamente los tejidos rotos no es una tarea sencilla; no es una labor de uno, por el contrario, es un trabajo colosal que requiere del concurso de todas las instancias de decisión y de actuación de la vida social y de cada uno de los ciudadanos y ciudadanas. [...]

No es una responsabilidad única de los políticos, de los legisladores, de los maestros y maestras, de los medios de comunicación; es una tarea de todos y todas, una tarea la cual no puede postergarse porque los hilos se ajan en el día a día y se hace más grande el tejido por zurcir. [...] 
Desde esta perspectiva, tanto la escuela en su carácter institucional, como la sociedad, en general, están llamadas a repensarse, a reestructurarse y a exigirse con base en un acuerdo social, cultural y colectivo; desde el cual sea posible leer, pensar, administrar y producir nuevas y más pedagógicas formas de promover el desarrollo humano en su complejidad (Hincapié-Rojas, 2011, p. 700-701).

\subsubsection{Miradas comunes en relación con la educación ética y moral}

Llama la atención que en tiempos en los que en un contexto como el colombiano se hace más necesario que nunca la educación ética y moral, este sea un tópico global con tantas opacidades en la Universidad de Manizales. El que ningún trabajo de grado lo esté abordando debería ser un llamado institucional. Así mismo, aun cuando en el nivel de doctorado se cuenta con dos tesis las cuales han trabajado este tópico global, sigue siendo una temática poco desarrollada. Por lo que se sugiere intencionar la investigación en estas temáticas y generar continuidades temáticas en este tópico en alguna de las líneas de investigación.

A pesar de las opacidades, señaladas, las dos tesis que se han ocupado de este tópico global plantean interesantes desafíos los cuales podrían ser profundizados en futuras investigaciones.

El proyecto que se pregunta sobre el sujeto trascendental kantiano y el sujeto emancipado hace un llamado a la educación a pasar del sujeto individual al sujeto colectivo (EC/043/006/D); así mismo cuestiona el papel de la formación en cuanto a la reproducción de modos hegemónicos de ser sujeto al mostrar cómo la educación, en momentos, se ha centrado en la normalización de los sujetos y de sus cuerpos. Se enfatiza en la importancia del docente y de los participantes como sujetos emancipados, capaces de revertir el orden lineal y normalizador de la educación y de promover a través de prácticas emancipadoras la creatividad y la gestación. Para ello la tesis invita a través de los planteamientos 
de Foucault, a la ruptura entre el discurso y la verdad única ya que comprende el discurso como acontecimiento humano y, de este modo, logra emanciparse de la educación como verdad única de adoctrinamiento y normalización. Mirada al acontecimiento y el lenguaje, semejante a la propuesta por Badiou (1998); y aproximación a la ética similar a la propuesta por Mc Namee (2015) al considerarla como un potencial discursivo.

Por su parte, la investigación EC/043/006/D la cual explora el tópico local consistente en restaurar la confianza, también hace un llamado, tanto a los escenarios educativos como comunitarios, a abandonar el ámbito individualizante, pero en este caso en función de revertir la desconfianza producto de la ruptura de los tejidos sociales en nuestro país, para aportar a la reconstrucción de lazos relacionales de confianza. Lo interesante de dicha investigación en relación con este tópico local es que muestra la importancia del trabajo mancomunado entre los decisores de política pública, las instituciones educativas y las comunidades al mostrar que el restablecimiento de la confianza no se trata exclusivamente de una responsabilidad estatal.

El llamado para la UM-C estaría en función de preguntarse por su aporte a la restauración de la confianza como práctica presente en los procesos educativos; así como a la importancia de proponer nuevos estudios los cuales amplíen las comprensiones en este sentido y favorezcan en sí mismas prácticas de confianza en los ambientes educativos, lo cual podría posibilitarse a través de la promoción de la responsabilidad frente a la vida del otro, como lo ha propuesto Lévinas (2006); de la participación en prácticas colaborativas, como las descritas por Anderson (2012); de la promoción de políticas de la amistad, como lo ha propuesto Derrida (1998); o de la complicidad y la hospitalidad, propuestas por Mèlich (1997; 2000). 


\subsubsection{Tópico global: cultura juvenil/cultura estudiantil}

Unadelastesis delaUM-C, la cual equivaleal $0.3 \%$ corresponde al tópico global más bajo entre los hallazgos investigativos del Eje Cafetero, plantea que los jóvenes hoy tienen múltiples identidades en términos de identidades móviles, identidades líquidas las cuales proceden de las culturas y subculturas a las cuales están vinculados y que ellos mismos crean (Feixa Pàmpols, 2008; Muñoz González, 2007; 2011; Reguillo, 2000; 2012; Valenzuela, 2015). Estas identidades, de una u otra manera, buscan rompen con los esquemas sociales e institucionales los cuales propugnan por una única mirada de los jóvenes como estudiantes. Teniendo dificultades para asimilar las diferentes expresiones culturales de los jóvenes (EC/051-02/029/M).

\subsubsection{Tópico global: pensamiento social}

Este tópico resulta emergente para la Universidad Católica de Pereira en una de sus tesis $(0.3 \%)$ de las incluidas en el estudio para el Eje Cafetero.

Una de las primeras conclusiones que se evidencia es la necesidad de reconocer que no es suficiente el conocimiento como saber disciplinar y las certezas las cuales el docente tiene sobre estos para influir en la comunidad y poder aportar a la resolución de sus necesidades, tal como se evidencia en la tesis de RDA/018/001/M: «... la formación previa...da cuenta de saberes y certezas, las cuales no son suficientes para acompañar los procesos pedagógicos de la comunidad» (p. 7).

Esta condición permite interrogar el rol del docente frente a su que-hacer desde las prácticas educacionales, teniendo como marco de referencia la recuperación y análisis de los relatos (narrativas), tanto de los estudiantes como del docente investigador, lo que posibilita la transformación, no solo, de la práctica pedagógica, si 
no también, de la propia existencia «...los relatos de mi experiencia pedagógica, me permitieron descubrir que en mi decisión de cambio, orientada por mis constantes búsquedas y tensiones, se encuentra los principales agentes de transformación de mi ser y hacer como maestra» (RDA/018/001/M, p. 9).

\subsubsection{Tópico global: educación para el emprendimiento}

Un tópico global emergente con un solo estudio en la Universidad Tecnológica de Pereira, es el de Educación para el emprendimiento, el cual representa el $0.3 \%$ de la totalidad de las tesis del Eje Cafetero.

En el trabajo RDA/133/062/M se concluye que, para los estudiantes y la docente, emprender no es simplemente tener la capacidad de crear empresa, es una actitud frente a la vida, la cual permite a cada quien alcanzar sus más profundos anhelos, haciendo realidad sus sueños y aspiraciones, por lo tanto, no se limita simplemente a interesarse en cursar la carrera de administración de empresas. Sin embargo, en el estudio es relevante que los hallazgos se alejan de manera drástica de la pregunta de investigación y los objetivos formulados, puesto que el foco, los sentidos fenomenológicos del emprendimiento en las narrativas de los estudiantes, poco o nada son abordados, lo que sí impera es una teorización del emprendimiento y su promoción en la institución.

\subsection{Región pedagogía}

El análisis del RIEP, capítulo cinco (hallazgos), devela la predominancia de la región pedagogía y, en ella, sus tópicos y subtópicos permiten aportar a la construcción de la cartografía de la zona. El punto de partida son los datos cuantitativos respecto a la prevalencia de cada tópico para, desde allí, realizar el análisis cualitativo el cual permite comprender los hallazgos de los proyectos de grado de maestría y tesis de doctorado. La TABLA NRO. 27 muestra la prevalencia de los tópicos globales. 
TABLA NRO. 27. Tópicos globales de la Región pedagogía de las tesis en las universidades en la zona del Eje Cafetero.

\begin{tabular}{|c|c|c|c|c|c|c|c|}
\hline \multirow[t]{2}{*}{ Tópicos globales } & \multicolumn{2}{|c|}{$\begin{array}{l}\text { Universidad } \\
\text { Tecnológica de } \\
\text { Pereira }\end{array}$} & \multicolumn{2}{|c|}{$\begin{array}{l}\text { Universidad de } \\
\text { Manizales y el } \\
\text { CINDE }\end{array}$} & \multicolumn{2}{|c|}{$\begin{array}{l}\text { Universidad } \\
\text { Católica de } \\
\text { Pereira } \\
\end{array}$} & \multirow{2}{*}{$\begin{array}{l}\text { Total Eje } \\
\text { Cafetero } \\
\%\end{array}$} \\
\hline & $\overline{\mathbf{F}}$ & $\%$ & $\mathbf{F}$ & $\%$ & $\mathbf{F}$ & $\%$ & \\
\hline Didáctica/enseñanza & 64 & 11.5 & 31 & 5.7 & 11 & 2.1 & 19.3 \\
\hline Prácticas pedagógicas & 41 & 7.5 & 35 & 6.4 & 3 & 0.7 & 14.5 \\
\hline Concepciones & 14 & 2.7 & 13 & 2.5 & & & 5.1 \\
\hline $\begin{array}{l}\text { Uso } \\
\text { educativo/pedagógico de } \\
\text { las TIC }\end{array}$ & 22 & 4.1 & 1 & 0.3 & & & 4.4 \\
\hline Cognición & & & 20 & 3.7 & 1 & 0.3 & 4.0 \\
\hline Aprendizaje & 3 & 0.7 & 10 & 1.9 & 4 & 0.9 & 3.5 \\
\hline Profesores & 5 & 1.1 & 5 & 1.1 & 1 & 0.3 & 2.4 \\
\hline Competencias & 5 & 1.1 & 1 & 0.3 & & & 1.4 \\
\hline Estudiantes & & & & & 3 & 0.7 & 0.7 \\
\hline Comunicación educativa & 1 & 0.3 & & & & & 0.3 \\
\hline Totales & 155 & 29.0 & 116 & 22 & 23 & 5.0 & 56.0 \\
\hline
\end{tabular}

Elaboración propia.

El énfasis está puesto en los procesos de enseñanza (19.3 \%) y las prácticas de los docentes involucrados en ellas (14.5 $\%)$, los cuales se erigen como picos de esta región. Le suceden, como tópicos que apenas emergen o decrecen (dependiendo de la presencia o ubicación temporal de los proyectos), el uso educativo de las TIC, cognición, aprendizaje y profesores. Como opacidades, por su baja presencia general o porque están solo en una de las universidades, aparecen las competencias, los estudiantes y la comunicación educativa. Ahora bien, los tópicos hallados se caracterizan por estar ligados básicamente a las instituciones educativas formales con pocos desarrollos en otros contextos educativos. Una mirada general a los datos plasmados en dicha tabla da cuenta de los diversos intereses.

El análisis cualitativo de los tópicos y subtópicos permite profundizar en la manera de entender la región para dar una visión holística y comprensiva de lo que sucede en su interior. Para ello, se procede al análisis en el orden de prevalencia que presentaron. 


\subsubsection{Tópico global: didáctica}

La didáctica es el tópico global de mayor prevalencia dentro de la región pedagogía con presencia en las tres universidades que hicieron parte de la zona del Eje Cafetero, lo cual no es extraño en una larga tradición que establece relaciones entre educación, pedagogía y didáctica e incluso entre todas ellas, en las denominadas ciencias de la educación, especialmente plasmadas en el ámbito alemán y francés. En la tradición alemana, la relación entre pedagogía y didáctica fue abordada por Willman en el siglo XIX, en su trabajo: Didaktik als Bildunglehre (La didáctica como doctrina de la formación) en el cual propuso diferenciar entre didáctica como «doctrina de la formación» y pedagogía como «teoría de la educación» (Runge-Peña, 2013), posteriormente Klafki (como se citó en Runge-Peña, 2013) planteó una concepción de la didáctica desde el énfasis sobre el papel de lo ejemplar en el aprendizaje como un modo diferente de concebir el trabajo con los contenidos de enseñanza. En la tradición francesa la distinción entre pedagogía y didáctica es menos clara y podría decirse que la didáctica tomó mayor fuerza en detrimento de la pedagogía (De Tezanos, 2006). Ahora bien, esta discusión sobre la relación, estatus, prevalencia o inclusión de una en la otra, es llevada del campo de la didáctica general a las disciplinares o específicas, especialmente en la tradición francesa (Mialaret, 1966). Así, los trabajos de Brousseau y Chevallard en la didáctica de las matemáticas marcaron su consolidación, tal como lo plantea Runge-Peña (2013):

Desde sus primeros momentos, la didáctica se ha definido como la disciplina que estudia aquello que, en las actividades de enseñanza y aprendizaje, es especifico de los contenidos. Desde sus primeros inicios, se establece entonces una suerte de división de trabajo: la de los investigadores en ciencias de la educación y los pedagogos referida al estudio general de las prácticas y de las relaciones pedagógicas, y la de los didactas referida al estudio específico de la enseñanza y el aprendizaje de una disciplina $\mathrm{X}$ o $\mathrm{Z}$ y desde el punto de vista del contenido A o B. De allí que no quepa espacio 
para "la" didáctica, pues siempre se trata de las didácticas "de" las disciplinas. En el contexto francófono la didáctica se diferencia de la pedagogía por el papel central que juegan los contenidos escolares y por su dimensión epistemológica (por la naturaleza de los conocimientos para ser enseñados) (p. 229).

Es quizás, la influencia francesa, alemana y española, traída de la formación de los directores de líneas y macroproyectos y de los directores de proyectos de grado (como lo muestra el análisis bibliométrico), la que puede explicar la prevalencia de la región pedagogía, y dentro de ella del tópico global didáctica, que como se muestra a continuación debería pluralizarse como didácticas, pues están ubicadas en relación directa con la enseñanza de los saberes escolares o universitarios.

A nivel descriptivo, la mayor prevalencia de este tópico está en la Universidad Tecnológica de Pereira, con un $11.5 \%$ de los trabajos de grado de maestría, le siguen en su orden la Universidad de Manizales en su alianza con la Fundación Centro Internacional de Educación y Desarrollo Humano (CINDE), con 5.7 \% y la Universidad Católica de Pereira con un $2.1 \%$. Estos datos, al desglosarse en los subtópicos, evidencian que la mayoría de los trabajos de grado desarrollan propuestas didácticas, no solo para «mejorar» el aprendizaje de los estudiantes en las diversas áreas del currículo escolar y universitario, sino también como una oportunidad para transformar las prácticas de enseñanza, ya sea de los autores del trabajo o de los profesores participantes en él.

En los subtópicos, se identifican las diversas didácticas y al interior de ellas las visiones epistemológicas, enfoques y énfasis, los cuales muestran la complejidad de las posiciones y de los intereses de las universidades y los estudiantes de posgrado. Intereses que están asociados a líneas y macroproyectos de investigación, y a los contextos laborales de los estudiantes. 
En este marco, el subtópico de mayor prevalencia es la didáctica del lenguaje, el cual encierra un panorama amplio sobre lo qué es el lenguaje y su enseñanza. Así, puede verse desde la lectura y escritura canónica, hasta la lectura o escritura emocional, también tipos de lenguaje como el escrito o el lenguaje de señas, o énfasis en lengua materna o segunda lengua, en todo caso, la mayoría se ubican con relación al currículo y contenidos escolares, incluso la escritura emocional, que como se verá se asume como punto de partida para la escritura alfabética.

No obstante, los hallazgos no dan cuenta de las conceptualizaciones, cambios o precisiones teóricas, derivadas de los trabajos de investigación, en la manera de entender el lenguaje, más bien se centran en discusiones sobre las dificultades en el aprendizaje de los estudiantes y los cambios obtenidos a partir de las propuestas de enseñanza. Dichas propuestas van desde secuencias didácticas, proyectos de aula, hasta el uso de la lúdica. Además, hay un marcado acento en los llamados "proyectos de lengua»(Camps, 1996), desarrollados a través de las secuencias didácticas (Camps, 1996; 2003; Dolz, 1996; 2003; Zayas, 2006; 2011), los cuales se implementan en diversos niveles educativos, para mejorar o potenciar la comprensión lectora y la producción textual, articulada siempre a diversas tipologías textuales: narrativas, argumentativas o descriptivas, como puede verse en los siguientes ejemplos de trabajos de grado: RDA/133/023/M; RDA/133/025/M; RDA/133/031/M; RDA/133/036/M; RDA/133/041/M; RDA/133/042/M; y RDA/133/045/M. Este tipo de propuestas, adquieren su impronta no solo por el tipo de texto, sino también por el enfoque desde el cual se abordan, como: los enfoques comunicativos (Hymes, 1972; Casalmiglia y Tuson, 1999; Lomas, 2015), constructivistas (Jolibert, 2002; 2009) discursivo-interactivo (Martinez, 2005; 2006; 2013), y los socioculturales (Cassany, 2006). 
De otra parte, se identifican proyectos focalizados no solo en el tipo de texto y el enfoque, sino también, en el tipo de comprensión que quieren desarrollar, por ejemplo, la lectura crítica, la literacidad (Cassany, 2006) entendida como una forma de posicionarse ante los textos y ante la realidad social para desarrollar un pensamiento crítico (EC/043/04/D; EC/043/13/D; EC/051-02/045/M; EC/051-02/059/M). Además, se abordan los factores que influencian en aquella literacidad, haciendo énfasis en: la edad, el estrato socioeconómico, el sexo, el nivel educativo de los padres, los procesos de socialización iniciales, la cultura escrita de la familia, la opción de vida y profesional de la familia, los modos de aprendizaje y, el desempeño del docente, los estudiantes y el grupo (EC/043/13/D).

También se presentan los resultados puntuales de proyectos en lengua materna, segunda lengua y lenguaje de señas (EC/O5101/050/M), demostrando en todos los casos, la potencia de las propuestas didácticas para mejorar la comprensión y producción ya sea oral o escrita de los estudiantes.

Según los hallazgos, la potencialidad de las propuestas tiene su explicación en varios factores. El primero de ellos, es la selección del enfoque, el cual parte de la revisión sistemática de las tendencias en didáctica del lenguaje; el segundo, es la elaboración de la propuesta en el marco del enfoque elegido, una elaboración que se justifica como situada y contextualizada, pues parte del análisis de la realidad social de la institución educativa y del grupo de estudiantes; finalmente, responde a las necesidades de aprendizaje de los alumnos, sus intereses y motivaciones. Así, las intenciones de transformación en el aprendizaje de los estudiantes parecen pasar por la discusión de qué enseñar, cómo hacerlo y qué textos usar, ya planteada por diversos autores en el ámbito de la didáctica del lenguaje (Camps 2003; Zayas, 2011; Bronckart, 2007; Pérez y Rincón, 2009; Lerner, 2001; Braslavsky, 2005; Cassany 2006; EC/051-02/074/M). 
Así, la discusión sobre el qué, el cómo y el qué, supera el ámbito disciplinar, que, sin dejarse de lado, incorpora elementos de la didáctica general, la pedagogía, el aprendizaje y propósitos curriculares de las instituciones educativas. A la par, emerge la necesidad de profundizar lo que se denomina Conocimiento Didáctico del Contenido (CDC) el cual implica preguntarse por las condiciones del conocimiento para ser adaptado a las necesidades educativas de cada nivel escolar y de los estudiantes.

Del análisis de los hallazgos en este tópico, se derivan básicamente tres perspectivas, un énfasis en las didácticas específicas, que abordan la enseñanza como praxis, la cual se lleva a cabo de manera sistematizada, con intencionalidades ligadas al contexto escolar, a los saberes escolares y a las competencias. Esta perspectiva, demuestra su eficiencia en cuanto a los aprendizajes, dado que los estudiantes logran «mejorar» o «avanzar» como consecuencia de la intervención realizada y los procedimientos puestos en juego - secuencia, unidades, proyectos de aula, Aprendizaje Basado en Proyectos (ABP), entre otros-. Así, la enseñanza cumple, de alguna manera, con las características descritas por Runge (2013), esto es, la intencionalidad de la intervención educativa (incidir o transformar el aprendizaje), la planeación de la interacción propuesta en términos sistemáticos y metodológicos (propuestas didácticas), la institucionalización de dicha interacción (ligadas a las instituciones educativas, grupos etarios y grados específicos), y la profesionalización del enseñante.

Las transformaciones reportadas en los hallazgos, no solo refieren cambios en los estudiantes, pues durante la planeación sistemática y el desarrollo de la misma, los maestros logran «reflexionar» sobre sus prácticas, revisarlas, profundizar en los contenidos de enseñanza, o en el CDC, así como tener otra perspectiva metodológica de su quehacer, de tal manera que dejan de ser maestros tradicionales, para convertirse en maestros reflexivos o socioconstructivistas, o simplemente transformados, sin especificar en qué sentido. 
La segunda perspectiva, devela el énfasis en la didáctica general, que como lo describe Camilloni (2007), es más próxima a las teorías del aprendizaje, del pensamiento, la cognición, las habilidades del pensamiento, las inteligencias múltiples, entre otras, las cuales abordan la enseñanza desde una visión más panorámica, a través del desarrollo de una serie de procedimientos válidos para cualquier conocimiento o disciplina, con el cual logran, igual que la anterior perspectiva, cambios en el aprendizaje, en los procesos de pensamiento o en la metacognición, o en reconocer cómo se dan estos procesos durante la enseñanza.

Emerge una tercera perspectiva, ligada tanto a las didácticas específicas como a la didáctica general, es el énfasis en el desarrollo humano, las emociones, la inclusión, la interculturalidad, el conflicto, las competencias ciudadanas, entre otras, que adjetivan la didáctica como: didáctica intercultural, inter-didáctica, didáctica problematizadora, o no parametral, las cuales se desligan de la enseñanza de contenidos para atender problemáticas sociales y culturales, con la pretensión de lograr aulas o escenarios escolares democráticos e inclusivos o de superar los límites de la escuela, como propuestas de enseñanza más ligadas a la formación del ser humano.

Estas perspectivas podrían ubicarse como lo plantea Flechsig (como se citó en Runge, 2013), en los dos primeros niveles de la didáctica: descripciones de la praxis de enseñanza (práctica) y modelos de enseñanza (modelos de trabajo). En el primero porque se describe de manera detallada los eventos particulares de la enseñanza, y el segundo, porque se hace una reconstrucción de segundo orden de la praxis, desde modelos en los cuales se precisan las características comunes de un conjunto de prácticas de enseñanza ya descritas en la primera perspectiva, con criterios de semejanzas y diferencias (secuencias, unidades, ABP). 
En ninguno de los casos analizados se llega el nivel tres, esto es, elaborar modelos categoriales de la didáctica, en los cuales se construya un marco teórico para la fundamentación de las propuestas de enseñanza.

\subsubsection{Tópico global: prácticas pedagógicas}

En la región pedagogía, un tópico global de importancia es el de práctica pedagógica, el cual hace referencia al quehacer del docente, entendiendo la práctica como un hacer reflexivo, donde el sujeto-maestro aprende de su experiencia y construye conocimiento acerca de su actividad como enseñante. De acuerdo con Arbeláez et al. (2012):

La práctica sería una actividad intencional, que el docente desarrolla en forma consciente, desde la caracterización de su propio quehacer, enmarcada en las actuaciones de sus colegas, éstas a su vez enmarcadas en un conjunto de creencias relativas a lo que hacen, la situación en el que actúan y lo que tratan de conseguir, lo que le imprime su característica de práctica social (p. 89).

En este sentido, la práctica pedagógica se asume en tensión, y algunas veces, en oposición a la teoría educativa, dado que lo que hacen cotidianamente los docentes con los alumnos, en las aulas, pueden o no estar basado en un cuerpo teórico concreto (Álvarez-Álvarez, 2015), tal vez por esta razón, diversos trabajos de investigación se realizan en torno a la comprensión, reflexión y análisis de dicha práctica, durante el proceso formativo posgradual. Quizás por ello, en las tres universidades aparece como tópico global prácticas pedagógicas, en relación el estudio de los imaginarios, la formación, los valores y las comprensiones que tienen los docentes acerca de este concepto. La Universidad Tecnológica de Pereira tiene cuarenta y una frecuencias (7.5 $\%)$, en la Universidad de Manizales y el CINDE treinta y cinco frecuencias (6.4\%), y en la Universidad Católica de Pereira, tiene tres frecuencias $(0.7 \%)$. 
Ahora bien, los hallazgos en este tópico hacen referencia a diversos aspectos del quehacer del maestro, los cuales se pueden organizar en tres grandes categorías: la práctica reflexiva o reflexión en la práctica, las prácticas pedagógicas de aula, y las tradiciones o concepciones de práctica asumidas por los docentes.

En cuanto a la práctica reflexiva, en palabras de Perrenoud (2007) implica «formar un practicante reflexivo es ante todo formar a un profesional capaz de dominar su propia evolución, construyendo competencias y nuevos saberes, o más precisos, a partir de lo que ha adquirido y de la experiencia» (p. 23). En las tres universidades se entiende la práctica en consonancia con el autor, como un espacio de producción de saber pedagógico, mediado por la reflexión, a la cual se le atribuye la posibilidad de cambio en los desempeños áulicos. Estos cambios, se producen gracias al análisis hecho por los actores acerca de sus prácticas desde diferentes ángulos: desde los conocimientos que tienen sobre la disciplina a enseñar, desde sus habilidades para diseñar escenarios de aprendizaje, desde la posibilidad de realizar prácticas inclusivas, desde las formas de gestionar el control, desde la participación y desde las relaciones entre los estudiantes.

Como puede observarse, esta reflexión se asume como el camino para la transformación dela misma práctica, como se señala en varios trabajos de grado: RDA/133/017/M, RDA/133/023/M, $\mathrm{RDA} / 133 / 024 / \mathrm{M}, \mathrm{RDA} / 133 / 29 / \mathrm{M}$ y RDA/133/033/M; en los cuales, se pudo evidenciar que, gracias a la reflexión, el docente comprende que sus prácticas estaban ancladas en actuaciones tradicionales-transmisivas o eficientistas, ya sea en la forma de enseñar o en la forma de concebir la disciplina, el aprendizaje de los estudiantes, los conflictos y el género. El ejercicio reflexivo, según los hallazgos, permitió a los maestros no solo identificar aspectos no conscientes de su práctica, sino acoger de manera consciente nuevas formas de realizar su quehacer, casi todas cercanas a los procesos formativos objeto de estudio en el posgrado. 
Si bien, en la mayoría de trabajos, el sujeto reflexivo es el docente, en unas pocas investigaciones se señala también la importancia de la reflexión de los estudiantes para autorregular sus aprendizajes (EC/051-1/038/M), asunto que puede relacionarse con explicaciones sobre los procesos metacognitivos o con los planteamientos de Pujol (2007), cuando menciona que el aprendizaje es efectivo si el estudiante es consciente de sus limitaciones, de los objetivos a alcanzar y de las vías a seguir, en razón de las metas que se pretenden alcanzar.

Respecto a las prácticas pedagógicas en el aula, los hallazgos encuentran una interacción entre la experiencia adquirida por el maestro y las teorías con las cuales está siendo formado en el posgrado. En este marco, se advierte que la formación recibida, les permite incrementar y mejorar sus «saberes» para el actuar, para transformar su manera de enseñar los saberes escolares (lenguaje, ciencias sociales o naturales, matemáticas, artes, entre otros) y comparar sus desempeños anteriores con los desarrollados a partir de la implementación de la investigación. El análisis está relacionado con algún tipo de intervención didáctica (secuencia didáctica, unidad didáctica, proyecto de aula), como puede encontrarse en trabajos de grado tales como el de RDA/133/002/M, RDA/133/017/M, RDA/133/061/M, RDA/133/058/M, RDA/133/093/M, entre muchos otros, cuya pretensión es contribuir al aprendizaje de los estudiantes, y al mejoramiento o cambio en el quehacer docente, mediante la puesta en escena de nuevas propuestas teóricas y/o metodológicas aplicadas a la enseñanza de los saberes escolares.

En cuanto a las tradiciones o concepciones de práctica asumidas por los docentes, tópico que aparece específicamente en la Universidad Tecnológica de Pereira, se señala la importancia de relacionar la reflexión con el «hacer conciencia» acerca de las concepciones o teorías implícitas que orientan el quehacer, las cuales son entendidas como «tradiciones» desde la clasificación hecha por Davini (1997), como configuraciones del pensamiento y la acción, las cuales se han institucionalizado en el tiempo 
y perduran en el quehacer de los maestros: academicista; personalista o humanista; técnico-eficientista, normalizadora disciplinadora; técnico academicista.

Los hallazgos evidencian que, al hacer conciencia sobre sus propias concepciones, o comprender las de otros, se abre la posibilidad de identificar incoherencias entre el actuar y la forma de pensar. En este sentido, algunos trabajos de grado, tales como el de RDA/133/061/M, RDA/133/066/M y RDA/133/095/M develan que, tanto maestros en ejercicio como estudiantes de últimos semestres de licenciaturas, desarrollan su quehacer desde una perspectiva «tradicional», la cual representa la carga histórica que se revela en sus relatos, explicaciones y actuaciones, llevando a privilegiar contenidos establecidos, relaciones de autoridad vertical, transmisión verbal o mediada por textoguía y la evaluaciones centrada en la calificación. Otro hallazgo importante en estos estudios es que los participantes no se encuentran enmarcados en una concepción específica o libre de otras tradiciones, por el contrario, los docentes conjugan en sus discursos y sus prácticas diferentes tradiciones, lo que en palabras de Rodrigo et al. (1993) se constituye en una hibridación no programada.

En su gran mayoría, los trabajos donde aparece el tópico global prácticas pedagógicas, se reflexiona sobre los cambios, las emociones, las actitudes y conocimientos que desarrollan y aplican los maestros-investigadores, asunto que coincide con Tardif (2004) quien señala la posibilidad de racionalizar la práctica, criticarla, revisarla y objetivarla, para fundamentar las razones del actuar.

Sin embargo, se encuentra un vacío en la construcción teórica a partir del análisis de las conclusiones o hallazgos acerca de las prácticas, lo cual puede parecer contradictorio, pero puede afirmarse, debido a que las reflexiones o elaboraciones de los investigadores se limitan a corroborar los cambios, avances, implicaciones en relación con los referentes teóricos de las prácticas o la didáctica que ponen en juego. En general, no hay una 
construcción o teorización profunda acerca del saber disciplinar que se enseña, acerca de la función social, política o ética en el quehacer práctico, o teorizaciones didácticas que vayan más allá de los supuestos iniciales y que pueda atribuirse al resultado del estudio realizado o de la metodología empleada.

\subsubsection{Tópico global: Concepciones}

Otro tópico relevante en esta región es el de concepciones. Este tópico se concreta en el concepto derivado de los estudios hechos por Viennot (como se citó en Tamayo, 2013), acerca de las "concepciones alternativas», las cuales se definen como «las nociones que los alumnos traen consigo antes del aprendizaje formal de una determinada materia» (p. 91). Ahora bien, hacia los años 80, estos estudios se ampliaron a otras poblaciones, entre ellas a los docentes, y demarcaron las concepciones como las creencias basadas en experiencias y emociones, las cuales se evidencian en conocimientos conceptuales, estrategias de enseñanza, maneras de evaluar, y las dinámicas que se establecen en la clase, entre otras. Desde entonces, las concepciones se han estudiado, dada su capacidad predictiva o determinante en la actuación de los docentes (y estudiantes) en el aula, para identificar de qué manera se constituyen en un obstáculo para la transformación de la enseñanza o el aprendizaje (Bonil y Marquéz, 2011).

El tópico de concepciones aparece en dos de las tres universidades del Eje Cafetero, en la Universidad de Manizales y el CINDE con un $2.5 \%$, y en la Universidad Tecnológica de Pereira con un 2.7 \%. En los trabajos de maestría, este tópico se relaciona con diversas temáticas: cinco de ellas se refieren a la diversidad en las concepciones de los maestros; cuatro se refieren a práctica pedagógica; cuatro más concepciones de enseñanza, evaluación y aprendizaje; dos a políticas institucionales; y un trabajo por cada una de las siguientes temáticas: emociones positivas y aprendizaje, deficiencia en la concepción de pedagogía que tiene los docente, 
las tradiciones de práctica, los estudiantes, la enseñanza de las ciencias, la cultura física, las concepciones de maestro, el conflicto, la evaluación, el género y la educación de adultos.

Pese a la diversidad de temáticas en las cuales se estudian las concepciones, se puede identificar un marcado interés por conocer el pensamiento de los maestros (Bonil y Márquez, 2011), por comprender sus puntos de vista en profundidad, ylas implicaciones que éstos tienen en sus actuaciones. Es así, como aparece en la $\mathrm{UM}-\mathrm{C}$, un interés por conocer las concepciones del maestro frente a la inclusión, encontrando en los hallazgos, los obstáculos para su comprensión e implementación, entre ellos, la estigmatización de la diferencia, la desatención a las particularidades de los estudiantes en razón de su diversidad étnica, cognición, cultura, y la dificultad del maestro para adaptarse al cambio propuesto en la políticas nacionales y los requerimientos de la sociedad para enfrentar la educación de un sujeto diverso.

De manera similar, en la UTP se analizan las concepciones de los docentes sobre las prácticas pedagógicas, la evaluación, el conflicto, el género, el adulto-aprendiz, y la enseñanza de las ciencias, temáticas ligadas directamente con el desempeño del docente. En algunos de estos trabajos de maestría, relacionados con las concepciones, como RDA/133/020/M, RDA/133/048/M, RDA/133/063/M y RDA/133/073/M, se encontró que los maestros de las instituciones educativas tienen visiones tradicionales sobre evaluación, en sus formas y procedimientos; visiones tradicionales acerca del género, en relación con actividades, tareas y función social presente y futura de los estudiantes; en relación a la manera como aprenden los adultos. En general, la tradición aflora en los diferentes estudios que indagan el pensar y hacer del docente; sin embargo, también se evidencia la hibridación entre la tradición, las perspectivas eficientistas, academicistas, y reflexivas, ya presentadas en el apartado de práctica pedagógica. En algunos maestros se encuentra también la incorporación de 
lenguaje constructivo, socioconstructivo, cognitivista, más a nivel de explicaciones orales o escritas, y solo en algunas ocasiones, en sus desempeños áulicos.

Así mismo, se encuentra que los docentes han desarrollado concepciones híbridas, en relación con las diversas tradiciones en pedagogía y didáctica; sin embargo, es constante la prevalencia de modelos tradicionales en la comprensión de su profesión, sus metodologías, formas de evaluar, de controlar la disciplina y los comportamientos esperados en los estudiantes. Adicionalmente, los hallazgos develan incongruencias entre los discursos de los docentes y sus actuaciones en el aula, las cuales se articulan más con las estrategias del "gremio», la tradición; que a apuestas personales. Esta constante puede explicarse desde la posición de Tardif (2004), desde la cual, no hay concepciones individuales, sino formas sociales de entender las prácticas, que impactan de manera profunda los desempeños individuales.

En términos generales, todos los trabajo de grado sobre concepciones en el entorno educativo, ratifican lo encontrado en diversas investigaciones (Wittrock, 1997; Ballesteros, 2000; Rodrigo, et al., 1993; Tardif, 2004; Scheuer et al., 2006; Kember, 1997), en las cuales se señala que los maestros, pese a sus procesos formativos y su experiencia en el sector, continúan anclados en teorías tradicionales, en relación no solo a su desempeño, sino a su visión respecto a diferentes aspectos sociales y culturales que han evolucionado. Ahora bien, gracias a los procesos formativos, la normatividad del gobierno y las exigencias de las instituciones, aparecen ideas relacionadas con el constructivismo, la pedagogía humanista o la crítica, sin que se logre un verdadero impacto en la transformación de su desempeño en el aula.

En suma, estas tesis de doctorado y trabajos de grado de maestría, develan una intención comprensiva por parte de los maestros investigadores; para develar como son, cómo se han conformado, y cómo se podrían transformar diversos conceptos 
relacionados con el quehacer de los docentes, con resultados que pueden constituirse en un insumo importante para que las instituciones educativas de diferentes niveles, realicen proyectos de investigación acerca de la formación inicial y continua de estos educadores.

\subsubsection{Tópico global: Uso educativo y pedagógico de las TIC}

Este tópico aparece con prelación en la Universidad Tecnológica de Pereira con un $4.1 \%$, mientras que en la Universidad de Manizales y el CINDE apenas emerge con un proyecto de grado que representa el $0.3 \%$ y está ausente en la Universidad Católica de Pereira. Ahora bien, los hallazgos develan las discusiones frente a las mediaciones tecnológicas, así como su influencia y potencialidad sobre los procesos de enseñanza y aprendizaje; debido a ello se habla de uso educativo y pedagógico de las TIC.

De manera específica, en la Universidad Tecnológica de Pereira, este tópico se ha desarrollado a través de cuatro tendencias: el análisis de la interactividad cuando se usan las TIC en la enseñanza de algún saber universitario o escolar; el uso para la enseñanza, como mediador ya sea en clases presenciales, virtuales o Blended learning; los usos de las redes sociales con fines educativos; y los resultados del análisis de tendencias en TIC para la educación.

Respecto a la primera tendencia, análisis de la interactividad, se describe cómo se da la actividad conjunta entre profesores y estudiantes, y entre los mismos estudiantes; cómo se da la participación de estos a nivel individual y grupal; y cómo se da el traspaso del control durantelos procesos deenseñanza y aprendizaje de algún saber escolar o universitario durante el desarrollo de unidades didácticas (RDA/133/011/M, RDA/133/010/M y RDA/133/009/M). En este marco, las actividades planeadas y desarrolladas en la unidad didáctica son analizadas a profundidad 
desde la perspectiva del triángulo interactivo, propuesto por Coll (2008) y Colomina et al. (2008), en Barberá, Mauri y Onrubia), para dar cuenta de las transformaciones o dificultades en la interactividad. Los resultados evidencian transformaciones que acercan a los estudiantes a mejores comprensiones de los saberes enseñados.

La segunda tendencia, el uso de las TIC para la enseñanza, describe la potencialidad de unidades didácticas elaboradas a través de diseños tecno-pedagógicos (Colomina et al., 2008), para la enseñanza de algún contenido (RDA/133/015/M), en ellas se presentan las distancias o cercanías entre los usos planeados, desarrollados y esperados. En ambas tendencias se evidencia la influencia de la perspectiva constructivista de orientación social, derivadas de las investigaciones del Grupo de Investigación en Interacción e Influencia Educativa (GRINTIE), liderado por Coll (2008).

La tercera tendencia, usos de redes sociales, da cuenta de los tipos de usos educativos que pueden tener las redes sociales como Google Plus, Twitter y Facebook, y también dentro de ellas las distancias entre los tipos de uso (planeados, esperados y desarrollados), la presencia del profesor (presencia distribuida o no) y de los estudiantes, la cesión del control y el desarrollo de la autonomía dentro del proceso de formación (RDA/133/014/M, $\mathrm{RDA} / 133 / 016 / \mathrm{M})$.

La cuarta tendencia, explica cómo a través del análisis del contenido publicado en la red Twitter, surge información significativa que contribuye a entender las tendencias educativas. En este sentido, se destaca la importancia del seguimiento a las publicaciones de los curadores de contenido educativo, como aspecto clave para la comprensión de tendencias que se perfilan en el sector educativo y en el aula. De hecho, la información publicada a través de las redes sociales genera conocimiento 
educativo valioso para los usuarios de la red (RDA/133/019/M), en términos de innovaciones educativas, usos de recursos educativos y reflexiones teóricas y éticas sobre dicho uso.

En general, los hallazgos relacionados con las TIC, evidencian que estas no son objeto de investigación por sí mismas, sino desde su potencialidad como mediadoras en los procesos de enseñanza y aprendizaje; de hecho, tanto el número de tesis como los momentos de aparición y declive, indican que es un tópico más ligado al interés particular de los estudiantes y directores de trabajos de grado, el cual no ha logrado instaurarse como eje en sí mismo, o en relación con las didácticas o en la explicación global del impacto de las TIC en los procesos educativos. Más bien, su mediación en los procesos de enseñanza y aprendizaje ha contribuido a la instrumentalización de la enseñanza, desde una visión eficientista, que reporta progresos en la enseñanza y el cambio a una metodología enmarcada en el socioconstructivismo.

\subsubsection{Tópico global: Cognición}

Este tópico es abordado especialmente por la UM-C, con un porcentaje de $3.7 \%$ y un proyecto de la UCP, el cual representa el $0.6 \%$. En ambos casos, se han desarrollado explicaciones o propuestas sobre la cognición en relación con la pedagogía.

Los subtópicos de la UM-C, giran en torno a varios ejes. El primero de ellos compuesto por el desarrollo lingüístico y competencias comunicativas, los trabajos de grado en esta coordenada, develan cómo las personas no oyentes están en capacidad de realizar elaboraciones cognitivas avanzadas, pero para lograrlo es necesario generar alternativas educativas de calidad, primordialmente a través de la lengua de señas, complementada con el acceso comprensivo a los textos escritos que, al igual que en el caso de las personas oyentes, permiten desarrollar su suficiencia lingüística y en consecuencia, mejores niveles de desarrollo académico los cuales incidan además, en el enriquecimiento de sus esquemas conceptuales (EC/043/02/D). 
El segundo eje, tiene que ver con los estilos cognitivos (dependencia/independencia), los estilos de pensamiento, e Inteligencias múltiples (EC/051-02/003/M, EC/051-02/010/M), en todos los casos lo central, según los hallazgos, no sería encasillar a los estudiantes en un estilo concreto o en un tipo de inteligencia, sino comprender cómo son influenciados por el capital sociocultural y las prácticas pedagógicas en los contextos y territorios, y por tanto la necesidad del maestro de identificar las características del estudiante y tenerlas en cuenta en los procesos de enseñanza para actuar en coherencia, detectar los talentos de los estudiantes y direccionar sus habilidades para potenciar sus aprendizaje.

El tercer eje, hace referencia a la regulación metacognitiva y la autorregulación (EC/051-02/051/M, EC/051-02/071/M). En los resultados obtenidos de este, se identifica y caracterizan diecinueve estrategias de regulación metacognitiva que manifiestan los estudiantes al enfrentarse a un entorno virtual de aprendizaje, lo cual implica que dichos entornos pueden servir de mediadores para que el estudiante pueda mejorar su rendimiento académico, al indagar sobre nuevas formas de aprender que le faciliten la apropiación del conocimiento y el desarrollo de la autonomía. En tal sentido, el fortalecimiento y orientación de procesos y estrategias de regulación metacognitiva en los niños y niñas, supone herramientas indispensables que no solo podrán ser implementadas en el aula, sino que podrán trascender en todos los campos en los cuales se encuentran inmersos. En cuanto a la autorregulación, se logró refutar la creencia de que hay una relación directa y unidireccional entre motivación y rendimiento académico, ya que lo observado muestra que tiene más peso para el aprendizaje las estrategias de autorregulación, pues son las que generan el desarrollo de estrategias motivacionales.

Respecto a los hallazgos reportados por la UCP, este tópico es subsidiario de otros como la resolución de conflictos, la inteligencia emocional, y la comunicación e interacción, de manera que el desarrollo cognitivo aporta elementos para la convivencia escolar y el desarrollo de las emociones (RDA/018/015/M). 
En general, los hallazgos evidencian cómo el tópico cognición se pone al servicio tanto de la didáctica específica, especialmente de las ciencias naturales, como de la didáctica general. En la primera, al dar cuenta de los modelos mentales respecto a un contenido particular, su descripción y avance; y en la segunda, respecto a la descripción de los procesos cognitivos involucrados en el aprendizaje, ya sea porque se analizaron a la luz de una propuesta didáctica o porque se describen en los actores del proceso educativo escolar.

\subsubsection{Tópico global: Aprendizaje}

Otro tópico que aparece en la región pedagogía es el de aprendizaje, término que de acuerdo con Schunk (2012) puede entenderse como «un cambio perdurable en la conducta o en la capacidad de comportarse de cierta manera, el cual es resultado de la práctica o de otras formas de experiencia» (p. 3). El aprendizaje es visto entonces, como un cambio duradero que permite al ser humano, adquirir o modificar sus comportamientos y desempeños.

Este tópico, se presenta en un $3.5 \%$ del total de la región pedagogía. Su mayor presencia está en la UM-C con un $1.9 \%$ de los trabajos de grado, le siguen en su orden la UCP con un $0.9 \%$ y la UTP con un $0.7 \%$. La tendencia general de los trabajos se enmarca en la relación entre los estilos y estrategias de aprendizaje, para los cuales las tres universidades realizan aportes en uno $\mathrm{u}$ otro sentido. De igual manera, se evidencian algunas reflexiones en torno a tópicos como las relaciones entre aprendizaje y modelos mentales, y el desarrollo de habilidades metacognitivas y el aprendizaje como desempeño académico.

Se entiende por estilos de aprendizaje «los rasgos cognitivos, afectivos y fisiológicos, que sirven de indicadores relativamente estables de la forma de percibir, interactuar y responder a sus ambientes de aprendizaje» (Castro y Guzmán, 2005, p. 6), siendo entonces, la manera en que el estudiante «percibe y procesa la 
información para construir su propio aprendizaje» (p. 6). En el aula, se encontrarían estudiantes con diversidad de estos estilos, siendo tarea del maestro identificarlos; de manera que, sus propuestas respondan a rasgos personales, tal como se evidencia en trabajo de maestría de EC/051-02/076/M, el cual apunta que, el ejercicio del maestro está en reconocer los estilos, identificar fortalezas en los estudiantes y a partir de allí, orientar los procesos de enseñanza para reducir el fracaso escolar, principalmente en aquellas personas que han desertado de la escuela y requieren de oportunidades innovadoras para enfrentar su proceso de aprendizaje.

Por otra parte, según Monereo (2002), las estrategias de aprendizaje se entienden como "capacidades $\mathrm{y}$ habilidades cognitivas, hábitos de trabajo intelectual, técnicas y métodos de estudio y resolución de problemas o procedimientos de aprendizaje» (p. 24), en este sentido, las estrategias son susceptibles de ser enseñadas durante el proceso educativo, ya que implicarían a los estudiantes en el reconocimiento del objetivo y la selección deliberada de los caminos o procedimientos mejor ajustados al logro o alcance de este. De acuerdo con el trabajo EC/051-02/046/M, el desarrollo de estrategias personales en los estudiantes para controlar y regular el aprendizaje, demarcan rutas más efectivas para el cumplimiento de metas.

Con relación al segundo tópico local, aprendizaje y modelos mentales, el énfasis está en el aprendizaje del maestro. En este sentido, se reconoce en los trabajos EC/043/031/D y EC/05102/068/M, cómo los modelos mentales que se encuentran en el profesor, van evolucionando producto de las experiencias vividas dentro del aula. Sin embargo, los hallazgos indican que, en algunos sujetos la formación que se les brinde puede ser de gran utilidad para efectuar cambios en sus modelos, mientras que en otros no lo es. Así las cosas, entre más experto y mayores conocimientos previos posea un maestro, mayor influencia tendrá la información recibida en la configuración del modelo mental. Vistos en su 
conjunto, los modelos iniciales de los casos estudiados presentan una importante cercanía con las tradiciones imperantes sobre el aprendizaje, algunas de las cuales, si bien son ampliamente criticadas como las teorías conductuales y cognitivas, también son empleadas más de lo que se espera, tanto por maestros en ejercicio, como por aquellos que se encuentran en proceso de formación.

Frente al tercer tópico local, el desarrollo de habilidades metacognitivas, en algunos trabajos de grado de la UM-C, se encuentra que éstas pueden ser estimuladas y desarrolladas a partir de las intervenciones y reflexiones las cuales fomenta el docente. Dentro de las habilidades metacognitivas estudiadas (EC/0511/038/M; EC/051-1/059/M y EC/051-02/060/M) se encuentran las de planificación, supervisión, evaluación y motivación, tanto de las ideas como en las acciones de los estudiantes. Los hallazgos de estos trabajos evidenciaron «avances» vinculados a las acciones de los docentes que generaron ambientes de aprendizaje apropiados para la edad y la diversidad, a partir de situaciones problema, trabajos de grupo, exposiciones, control de tareas, temas contextualizados y relevantes.

En un sentido similar, en la UTP, el trabajo de grado RDA/133/058/M, encuentra que el Aprendizaje Basado en Problemas desarrolla habilidades como la toma de decisiones, la búsqueda de información, la selección de fuentes informativas y la reflexión sobre los textos escritos, es decir, se logran desarrollar habilidades cognitivas mediante estrategias de enseñanza adecuadas.

En algunas tesis de esta misma institución, se asimila el aprendizaje al desempeño académico; esto al encontrar que existe una relación entre la percepción que tiene el maestro del estudiante y el desempeño académico de éste, o que los aprendizajes mejoran cuando se hacen propuestas intencionadas, claras, desde unidades o secuencias didácticas que busquen mejorar los desempeños de los estudiantes en las áreas disciplinares de interés (RDA/133/002/M, RDA/133/040/M y RDA/133/058/M). 
Puede evidenciarse en este tópico, la existencia de una preocupación en los estudiantes de posgrado de las tres universidades por mejorar los procesos de aprendizaje en los estudiantes, al reconocer su diversidad de estilos y la necesidad de fomentar o integrar estrategias adecuadas las cuales permitan, estimulen y propendan por el desarrollo de habilidades cognitivas y metacognitivas, a partir de la creación de escenarios apropiados para potenciar la autonomía y el autocontrol, que en últimas, pretenden lograr el tan esperado aprender a aprender de manera continua.

\subsubsection{Tópico global: profesores}

El tópico global de profesores aparece en las tres universidades del Eje Cafetero, aunque con poca frecuencia en la UM-C, UTP, cada una con el $1.1 \%$; y en la UCP con un $0.3 \%$.

Específicamente, en la UM-C, los hallazgos evidencian un interés por reconocer al maestro desde su función histórica y social, en primer lugar, valorando la importancia de la formación del profesor como profesional, y en segundo lugar, desde la necesidad de construir formas adecuadas de enseñar a los niños de preescolar. Así puede encontrarse en el trabajo EC/043/001/D, el cual se centra en realizar un análisis histórico de la función del profesor en la historia de la educación, y enfatiza en cómo llegó a ser el maestro un agente normalizador de la sociedad. Los hallazgos resaltan las políticas de formación de maestros que, a pesar de sostener un discurso humanista, en sus prácticas se exige la transmisión instrumental del saber y una suerte de adoctrinamiento social de las nuevas generaciones.

En esta visión, hay concordancia con algunos hallazgos de la UTP, en la cual se encuentra que la visión tradicional acerca del quehacer es la más frecuente, con maestros instalados en zonas de comodidad, que hacen poco por modificar sus actuaciones, tal como se aludió en el apartado acerca de las tradiciones de la práctica pedagógica. 
Otros hallazgos acerca de los profesores, en la Universidad Tecnológica de Pereira, se centran en la preocupación por incorporar las TIC a sus prácticas de enseñanza. En estos estudios, se encuentra un colectivo de profesores que, si bien están interesados en actualizar sus conocimientos para mejorar su enseñanza, en buscar recursos, en compartir experiencias y en dialogar con otros maestros sobre diversos aspectos de su profesión (RDA/133/018/M, RDA/133/019/M), tienden a no asumir un liderazgo en las actividades de construcción colectiva en las redes en que participan.

En la UCP, los hallazgos encontrados se relacionan con la responsabilidad del profesor en la creación de ambientes de bienestar y libertad en el aula, los cuales dependen de su capacidad para generar ambientes comunicativos, expresivos y lúdicos, los cuales se privilegien sobre el desarrollo de los contenidos (RDA/018/009/M,).

Este tópico parece constituirse en una opacidad en las tres universidades, en la medida que, aparecen pocas investigaciones acerca de los profesores (o docentes); sin embargo, es abordado con mayor profundidad, de manera tácita, en otros tópicos globales, como las prácticas pedagógicas y las concepciones, donde adquiere relevancia al ser objeto de estudio desde su pensamiento, acción, e historia de vida. Así mismo, en muchos hallazgos se resalta la importancia de sus reflexiones a partir de las intervenciones que desarrolla.

\subsubsection{Tópico global: Competencias}

Este tópico global aparece en la UTP, con un $1.1 \%$ y en la UM-C con $0.3 \%$, lo cual implica que su discusión ha sido más bien periférica y ligada al desarrollo de habilidades o al uso de las TIC. Entre las primeras, se encuentra la relación entre competencias y desarrollo de habilidades cognitivo-lingüísticas, habilidades sociales y emocionales, implicadas en el desarrollo de 
las competencias ciudadanas. Desde esta perspectiva, se señala que estas competencias se desarrollan siempre y cuando haya una intencionalidad clara y expresa del maestro por incidir en ellas, desde su planeación y desarrollo de clase, como puede evidenciarse en los trabajos de la Universidad Tecnológica de Pereira (RDA/133/017/M, RDA/133/076/M, RDA/133/091/M y RDA/133/092/M). En estos trabajos se encuentra que, es imperante descentrar la enseñanza del desarrollo cognitivo y girar hacia procesos centrados en el desarrollo emocional, para ayudar a los estudiantes a reconocer y gestionar las emociones en sí mismo y en relación con los otros, con lo cual se estimula el desarrollo de las competencias de regulación y gestión emocional, gracias a las cuales se crean ambientes motivantes, aptos no solo para el aprendizaje, sino para el desarrollo competencias ciudadanas. Esta tarea involucra al educador, quien de manera consciente genera espacios de participación, de expresión y de gestión emocional los cuales generen valores en las actividades cotidianas.

Otros estudios como el (RDA/133/012/M) señalan la importancia de un trabajo ordenado, conjunto, intencionado y consciente, el cual involucre el uso de TIC en el análisis y resolución de problemas referidos a temas específicos de las ciencias naturales o sociales, y que permita el desarrollo de habilidades cognitivo-lingüísticas tales como la descripción, la explicación y la argumentación. Todas ellas fundamentales en los aprendizajes de estas áreas.

Pese a que, en el discurso nacional, el desarrollo de competencias se ha convertido en centro de discusiones de política educativa y un propósito en la formación de los estudiantes en todos los niveles educativos, no parece tener el mismo interés en los investigadores de las universidades de la zona del Eje Cafetero, o no se hace de manera explícita. 


\subsubsection{Tópico global: Estudiantes}

Este tópico se presenta únicamente en la Universidad Católica de Pereira con un 0.7 \% del total de la región pedagogía. En las demás universidades no se encuentra de manera explícita.

Los hallazgos en los tres trabajos giran al rededor del estudiante entendido como sujeto de desarrollo y como sujeto pedagógico, ambos en el marco de la escolaridad. Como sujeto pedagógico, se hace énfasis en el rol asumido por el estudiante desde la descripción e interpretación de sus gustos e intereses, así como de sus capacidades para explicar la dinámica de los grupos de trabajo escolar y el uso de los recursos personales dentro de dichos grupos. Como sujeto de desarrollo, se vincula al estudiante con los procesos de progreso evolutivo, esto es, la edad cronológica y mental, las cuales deben ser tenidas en cuenta para planear y desarrollar las propuestas de intervención pedagógica y didáctica (RDA/18/005/M).

\subsubsection{Tópico global: Comunicación educativa}

Este tópico se presenta únicamente en la Universidad Tecnológica de Pereira con un trabajo de grado el cual representa el $0.3 \%$ del total de la región pedagogía.

La comunicación educativa es entendida en el contexto áulico, en el cual se desarrolla a partir de los pactos entre los actores del proceso educativo (profesores y estudiantes, y entre los mismos alumnos). En estos pactos, es necesaria la flexibilidad, la comprensión sobre la norma y la mediación que se da a través del lenguaje. En este marco, es la comunicación educativa la que permite la construcción de pactos de aula, desde la inmersión de los estudiantes en escenarios de realidades democráticas, justas y seguras, en la medida que rompen con posturas autoritarias, prohibitorias o descalificantes, para dar paso a relaciones dialógicas, empáticas, respetuosas y reflexivas. Así, pactar normas 
implica el encuentro de actores políticos en el aula; tanto el docente como el estudiante tienen un lugar en las interacciones que se presentan en escenarios dialógicos y reflexivos los cuales les permiten tomar decisiones que lleven al bien común, lo cual les ayuda para formarse en el ejercicio de la ciudadanía y de las competencias ciudadanas.

\subsection{Territorios recorridos en otras regiones ${ }^{25}$}

De los programas de formación posgradual analizados en la zona del Eje Cafetero, solo los ofrecidos por la UM-C, y por la UTP presentan aportes para la región llamada otras regiones (región que cuenta con el 5.5 \% de las investigaciones de la zona).

En la maestría de la UTP se ubicó una tesis correspondiente al $0.3 \%$ de total de trabajos analizadas en el estudio para la zona del Eje Cafetero. Esta abordó como tópico global el género, mientras que la UM ha transitado por esta región por ser abordada en las tesis de dos maestrías, una de ellas ofrecida en alianza con la Fundación Centro Internacional de Educación y Desarrollo Humano (CINDE), y en las tesis de un doctorado, desarrollado por el Centro de Estudios Avanzados en Niñez y Juventud (CINDE-Universidad de Manizales), para el período de estudio comprendido entre el 2010 y el 2017; allí se encuentran diecisiete trabajos analizados, catorce tesis de maestría y tres tesis de doctorado, $5.2 \%$ del total de trescientos quince proyectos tenidos en cuenta en el estudio para el Eje Cafetero, los cuales se han preocupado por diversos tópicos globales de esta región, siendo el más relevante el de desarrollo humano (3.1\%), seguido por familia (1.2\%), junto con otros tópicos los cuales se distribuyen en opacidades al ser temas poco abordados, tales como: salud ( 0.3 $\%)$, resistencia cotidiana (0.3\%) y alteridad (0.3\%). Distribución temática que se sintetiza a continuación en la TABLA NRO. 28.

25 En Otras Regiones se recogen algunos tópicos globales que emergieron en el estudio y que no responden directamente a la región educación o a la región pedagogía, sino que abren otros territorios en las investigaciones analizadas. 
TABLA NRO. 28. Frecuencias y porcentajes de la región y otras regiones.

\begin{tabular}{|c|c|c|c|c|c|c|c|c|}
\hline \multirow[t]{2}{*}{ Tópicos globales } & \multicolumn{2}{|c|}{$\begin{array}{l}\text { Universidad de } \\
\text { Manizales y el } \\
\text { CINDE }\end{array}$} & \multicolumn{2}{|c|}{$\begin{array}{l}\text { Universidad } \\
\text { Tecnológica de } \\
\text { Pereira }\end{array}$} & \multicolumn{2}{|c|}{$\begin{array}{l}\text { Universidad } \\
\text { Católica de } \\
\text { Pereira }\end{array}$} & \multicolumn{2}{|c|}{$\begin{array}{l}\text { Total Eje } \\
\text { Cafetero }\end{array}$} \\
\hline & $\mathbf{F}$ & $\%$ & $\mathbf{F}$ & $\%$ & $\mathbf{F}$ & $\%$ & $\mathbf{F}$ & $\%$ \\
\hline Desarrollo humano & 10 & 3.1 & 0 & 0 & 0 & 0 & 10 & 3.1 \\
\hline Familia & 4 & 1.2 & 0 & 0 & 0 & 0 & 4 & 1.2 \\
\hline Salud & 1 & 0.3 & 0 & 0 & 0 & 0 & 1 & 0.3 \\
\hline $\begin{array}{l}\text { Resistencia } \\
\text { cotidiana }\end{array}$ & 1 & 0.3 & 0 & 0 & 0 & 0 & 1 & 0.3 \\
\hline Alteridad & 1 & 0.3 & 0 & 0 & 0 & 0 & 1 & 0.3 \\
\hline Género & 0 & 0 & 1 & 0.3 & 0 & 0 & 1 & 0.3 \\
\hline Total & & & & & & & & 5.5 \\
\hline
\end{tabular}

Elaboración propia.

Lo anterior permite evidenciar que la amplitud de tópicos en la región llamada otras regiones es un reflejo de la diversidad de intereses que traen consigo los estudiantes-investigadores y las estudiantes-investigadoras, los cuales a su vez dan cuenta de prioridades relacionadas con sus territorios e instituciones de procedencia. Al hacer un zoom en esta región, se identifica una temática fuerte, otra temática que está en proceso de auge y otras que requieren atención y motivación para propiciar su desarrollo.

\subsubsection{Caminos recorridos en otras regiones que mostraron los hallazgos}

A continuación, se presentan los resultados de las investigaciones analizadas en la región nombrada otras regiones en función de los tópicos globales en los cuales se agrupan desarrollo humano, familia, salud, resistencia cotidiana, alteridad, y género- y en algunos casos en relación con los tópicos locales en los cuales aportan.

\subsubsection{Tópico desarrollo humano}

Este tópico fue abordado por diez tesis de la UM-C, lo que corresponde al $3.1 \%$ de los estudios analizados en la zona. 
El desarrollo humano es concebido desde una de las tesis como una finalidad de la educación que trasciende la formación en ciencias básicas y que en cambio se proyecta hacia la integralidad (EC/051-1/007/M).

En un sentido similar, y al acoger la escuela como un aliado del proceso formativo y del desarrollo humano de los estudiantes, otro estudio aborda este tópico desde el juego como una manera de expresar sentidos y significados acerca de la diversidad, para posteriormente hacer de estos un medio que permita fomentar conductas positivas y mejorar el clima escolar. Es así como el término diversidad en la escuela, significa para los niños y las niñas tener en cuenta las particularidades e individualidades de cada compañero o compañera, es aceptar a la otra persona tal como es, es verse como un individuo diferente al otro y desde allí ir descubriendo en la interrelación las posibles soluciones a las dificultades o situaciones problémicas que deben afrontar en su cotidianidad. En este sentido, se asume la diversidad como una posibilidad de brindar espacios para que los niños y las niñas construyan sus sueños, pregunten y resuelvan sus inquietudes, crezcan en humanidad, sean libres, autónomos, democráticos y justos en la toma de decisiones para que finalmente se sientan realizados y felices consigo mismos y con los demás. El juego por ser con otros y otras, se torna comunitario, es lugar de encuentro con la otra persona, con quien no es como él, y permite crear lazos de amistad, de solidaridad, de unión, de cooperación, y de compañerismo. Es por medio del juego como se conocen y reconocen a los otros seres humanos, porque en él hay libertad y alegría, hay espontaneidad y lucidez (EC/051-1/064/M).

Otro estudio, contempla el desarrollo humano a partir de la lectura y el análisis de los mensajes escritos en los muros de una institución educativa, en donde las nociones utilizadas por los integrantes de la comunidad educativa para denominar las inscripciones murales están fuertemente influenciadas por los roles desempeñados en la estructura social de la institución; van 
desde la calificación de grafitis, hasta palabras pertenecientes al ámbito estudiantil como: copias, rayas, marcas, huellas, firmas, nombres, manchones, entre otros. El grafiti en la escuela es una práctica de la cual emergen multiplicidad de lenguajes los cuales rompen la linealidad y la monotonía del escenario escolar. En voz de los y las estudiantes son códigos de comunicación, en la percepción del grupo de docentes, son formas de confrontar la norma y retar la autoridad. Según los hallazgos de esta tesis, la lectura de los mensajes contenidos en los muros es un intento de construir significados; en el acto de descifrar los códigos utilizados por el escritor, el lector aporta sus propios significados; ahí, escritor y lector se confunden. Por tanto, los significados de las inscripciones resultan de la amalgama entre los actos escriturales y lectorales (Martínez, 2014).

En esta misma línea, el estudio de Blandón et al. (2016), abordó las diversas expresiones iconográficas las cuales pueden encontrarse en los espacios escolares (baños, aulas de clase, algunas paredes), en las cuales se destacan expresiones de arte, momentos de amor, resistencia escolar, identidad de género, retaliaciones, evocación del pasado, entre otros elementos, por lo que se señala que, de cierta manera, han ocasionado situaciones de agravio y deterioro de la convivencia escolar. La amplia información a través de las redes de comunicación le ha permitido al colectivo de estudiantes encontrar páginas con todo tipo de contenidos informativos de índole positivo o negativo, emergiendo en ellos y ellas nuevas formas de pensamiento con relación a sus «libertades» $\mathrm{y}$ formas de comportamiento y relaciones entre compañeros y compañeras de la institución.

Desde otra perspectiva, una investigación retoma los campos que tiene en cuenta el SENA regional Caldas (sede Manizales), para la implementación de sus procesos (educación y desarrollo humano, juventud y prosperidad) con el fin de visibilizar resultados del programa de Jóvenes en Acción, entre los cuales se destaca que ha permitido que surjan procesos de estabilidad laboral en jóvenes, 
en el ámbito social y cultural, los cuales impactan fuertemente a la población educativa, siendo de gran atractivo para las juventudes más desprotegidas del ámbito nacional, dado que de una u otra forma, dan respuestas satisfactorias frente a las necesidades en el ámbito educacional (Giraldo, 2015).

En otro estudio (EC/051-02/047/M) se presentan los avances logrados por una red académica, Red de Educación y Desarrollo Humano (REDH), para la cual, la apuesta por el desarrollo humano ha implicado la consolidación, la diseminación, la potenciación y la articulación nodal de la red académica, desde el pensamiento, la acción y el esfuerzo compartido, parahacerse cargo delos horizontes los cuales animan los deseos de transformación social. En este esfuerzo hermenéutico, fenomenológico, existencial, pedagógico y político, se requiere del liderazgo de quienes componen la red, de la exposición de sus afecciones, de la autenticidad y la honestidad de sus motivaciones, de la responsabilidad y eticidad de sus acciones; dimensiones internas y externas las cuales hacen posible dinamizar un quehacer colectivo $y$, las cuales orientan y dotan de sentido las prácticas y las reflexiones que de ellas se hacen. En este sentido, las dimensiones de la REDH se vieron potenciadas por los lineamientos estratégicos, los principios misionales y los procesos adelantados desde el CINDE y la UM, lo cual generó un contexto de realidad situada, en el que la reflexión de las prácticas pedagógicas, la investigación y la innovación en educación, inspiran la acción colectiva entre maestros, estudiantes y agentes educativos. En su devenir histórico la REDH ha tenido momentos de estructuración y resignificación los cuales le han permitido renovar su discurso, sus prácticas y sus horizontes, convirtiéndose en una experiencia significativa para diversas comunidades académicas, además de ser el referente de acción colectiva y agenciamiento social de la región. Finalmente, los hallazgos, las reflexiones, las conclusiones de esta sistematización, evidencian dicha red como una plataforma para el agenciamiento de propuestas innovadoras de carácter educativo y social, logrando 
así grandes impactos y transformaciones en los territorios en los cuales esta ha tenido incidencia, y en los espacios en los que hoy, despliega sus acumulados históricos.

Desde apuestas estéticas relacionadas con la improvisación y con el rap social, se aborda en otra la tesis de Mosquera (2016), el desarrollo humano a partir de un proceso en el cual los y las jóvenes participantes comienzan a tener reconocimiento de la comunidad educativa; lo cual lleva a transformar poco a poco sus prácticas de relacionamiento y emplear como vía el lenguaje verbal en las letras de sus improvisaciones. El grupo de jóvenes evidencia sus procesos de apropiación de la experiencia; esto al reconocer que, aunque esta ha logrado posicionarse al interior de la institución, la apuesta va más allá de la institucionalidad, teniendo en cuenta que el rap social para ellos y ellas se convirtió en una oportunidad para la canalizar talento y para crear opciones de ocupación del tiempo libre, y en una práctica en la que despliegan sus capacidades y generan lazos relacionales con sus pares, integrando el este como estrategia creativa para la transformación de sus realidades, lo cual ha sido, en esta medida, un proyecto resignificante para el colegio y su colectivo docente y directivo.

Otra investigación, aquella de Cardozo (2017) aborda el desarrollo humano a partir de la implementación de un programa de hábitos y rutinas en el Colegio Alemán de Cali y la percepción que de este tuvieron sus actores principales (padres, madres, docentes y estudiantes), perspectiva que permitió visualizar cómo lo simboliza la comunidad y cómo lo significa dependiendo de la influencia que tiene en sus vivencias cotidianas. Desde la percepción de padres, madres y docentes se evidencia la relación que encuentran entre la independencia que los niños y las niñas van alcanzando para la realización de las actividades básicas de la vida diaria y la autonomía para el desempeño escolar y familiar. Entre los aspectos que justificaron el origen del programa se encuentran: la falta de independencia en el desempeño del rol escolar como una de las causantes de bajo rendimiento en los y las 
estudiantes, el predominio del tetero o el pañal hasta el preescolar, la carencia de hábitos alimenticios o de sueño saludables y la dependencia en la higiene y en el vestido como factores de riesgo los cuales a futuro se relacionan con la falta de independencia escolar; y la necesidad de apoyo a los padres y las madres para el desarrollo de los hitos relacionados con adquisiciones en las actividades de la vida diaria. El Programa pone el énfasis de sus intervenciones en el contexto familiar, basado en la premisa de que el desarrollo de la independencia de las actividades básicas cotidianas debe consolidarse en el contexto familiar, para que pueda mostrar mayor eficiencia como andamiaje posterior. La encuesta de hábitos o de independencia en actividades de la vida diaria se define como una medida del nivel de independencia alcanzado la cual se va consolidando en rutinas, no de la capacidad para el desarrollo de la tarea, teniendo en cuenta que los objetivos del programa no están relacionados con la habilidad, sino con los hábitos los cuales se van adquiriendo. Además, la escala de independencia considera las relaciones contextuales que se convierten en barreras o facilitadores para el ejercicio de dicha independencia.

Finalmente, dentro de este tópico global se encuentra un estudio más, este perteneciente a EC/043/015/D, el cual, aunque no presenta hallazgos, relaciona el desarrollo humano con el lugar del maestro o la maestra y del temperamento de los niños y las niñas como aspectos que influyen en el comportamiento prosocial de ellos y ellas. La tesis también establece que el aprendizaje por observación y por experimentación permite a los niños y las niñas regular sus emociones, internalizar normas (asumirlas de manera más racional) y avanzar en la toma de perspectiva, procesos psicológicos necesarios para el desarrollo del comportamiento prosocial (EC/043/015/D).

Pareciera que las tesis las cuales han trabajado el desarrollo humano en la UM, en su alianza con la CINDE, han logrado en su mayoría desprenderse de las lecturas lineales de desarrollo humano marcadas por estadios consecutivos y únicamente 
dependientes de la edad y la maduración biológica, para acercarse a lo que Alvarado et al. (2012) han nombrado como el desarrollo humano alternativo. Aun cuando algunas pocas investigaciones permanecen en lecturas dominantes centradas en la estabilidad educativa y laboral.

El tópico de desarrollo humano tiene como tema local el desarrollo moral el cual fue abordado por una tesis (EC/043/017/D) de la UM-C lo cual corresponde al $0.3 \%$ de los estudios de la zona.

La tesis EC/043/017/D presenta narraciones de estudiantes sobre emociones morales como vergüenza, entendida como emoción autoevaluadora (Wollheim, 2006) la cual surge de las expectativaspersonalestenidasfrentea uno omuchosobservadores. Esta condición convoca a la persona observada a buscar ocultarse y en muchos casos, a la desconfianza de reconocerse, de ser aceptado, lo que puede conducirlo por el camino del aislamiento. En los talleres realizados con estudiantes de $90^{\circ}$ grado se halló que, las principales narraciones de emociones morales estaban relacionadas con la vergüenza del cuerpo; repugnancia, que según Nussbaum (2003) «...es una proximidad que no se desea» (p. 107), por tanto, está muy ligada a la dimensión táctil la cual surge de la aproximación física que se tiene con el otro (EC/043/o17/D). Las narraciones de desagrado se clasificaron, de acuerdo al objeto al que van dirigidas - siendo el cuerpo considerado como sucio-, como feo, e incluyendo la discapacidad y el asco moral.; humillación relacionada con la vergüenza, pero en sentido activo (Nussbaum, 2008), es decir, es un proceso de avergonzar, en el cual se le despoja al otro del reconocimiento que tiene frente a una comunidad.

En este sentido,

... se encuentran diferentes manifestaciones de maltrato narradas por distintos estudiantes, especialmente relacionadas con acciones de humillación a compañeros que tienen una condición física 
distinta: baja estatura o sobrepeso, por usar una prótesis móvil como los lentes para poder ver adecuadamente, lo mismo que por el color de piel. El menosprecio también se encuentra en acciones dirigidas hacia alumnos nuevos (EC/043/017/D, p. 132).

Según Spinoza «la envidia es el odio en tanto afecta al hombre de tal suerte que se contrista por la felicidad de los demás, y por el contrario, se alegra del mal de los otros» (2007: 139). [...]. Las narraciones de emociones morales de envidia están dirigidas a compañeros y amigos los cuales se destacan en su desempeño académico, en el deporte, en cuanto a lo físico, o en su condición económica. Es decir, que el ser modelo se convierte en el objeto el cual desencadena la envida (EC/043/017/D, p. 143).

Compasión para Nussbaum (2008) siguiendo a Aristóteles, es un sentimiento de pesar por la mala suerte la cual ha caído en otra persona, y tiene tres características cognitivas: es un asunto grave, se tiene la creencia de que es inmerecido, y el juicio que se hace es que el sujeto que la siente podría estar en la misma circunstancia (EC/o43/o17/D, p. 11).

En las narraciones de emociones morales se encontró que los objetos ante los cuales se manifiesta la compasión son: la muerte, la pobreza y la agresión; Gratitud, reconocimiento de que se ha recibido algún beneficio. En las narraciones de emociones morales se encontraron los siguientes objetos los cuales originan la emoción de gratitud: amistad y ser gratificado; Otras emociones como la culpa, la indignación, la venganza y el miedo son las que se encuentran a lo largo de todas las narraciones, toda vez que están directamente relacionadas, casi fusionadas con las otras emociones ya interpretadas, especialmente con la humillación y la compasión (EC/043/017/D).

\subsubsection{Tópico familia}

Este tópico local fue abordado por cuatro tesis de la UM-C, lo cual corresponde al $1.2 \%$ de los estudios. 
A partir de los hallazgos de dos de los trabajos inscritos en este tópico, se identificó como interés el abordaje de las prácticas de crianza. En uno de estos, específicamente en EC/051-02/044/M, se logró la identificación de los elementos que componen los modelos mentales de prácticas de crianza en las participantes del estudio, lo cual, a su vez, permitió evidenciar la individualidad de estos y al mismo tiempo, reconocer los aspectos que comparten, probablemente debido a que parte de los conocimientos son adquiridos a través de la formación educativa, la interacción social o tomados de la cultura. Así mismo, se logró identificar la fuerza que toma la experiencia propia y el razonamiento en la construcción del modelo mental.

Se identificó que estos modelos mentales estaban conformados tanto por representaciones correspondientes a aspectos del mundo externo - como la comunicación intrafamiliar, las actividades desempeñadas por cada miembro de la familia, los correctivos empleados, entre otros-, como por representaciones del mundo interno - entre las cuales se resaltan las emociones, los sentimientos, las valoraciones y las expectativas de futuro(EC/051-02/044/M). De igual forma, se encontró que a pesar de las diferentes acciones que adelantan las instituciones relacionadas con el bienestar de los niños y las niñas para promover las prácticas de crianza ligadas al buen trato y para prevenir el maltrato infantil y sus múltiples consecuencias, aún se considera el castigo físico como una estrategia de control frente al comportamiento de los hijos y las hijas (EC/051-02/044/M).

El otro estudio, EC/043/015/D, también se interesa por las prácticas de crianza, pero en relación al comportamiento prosocial de los niños y las niñas, encontró que la asociación que realizan ellos y ellas sobre el tema se da en forma diferente cuando se analiza el comportamiento prosocial de los niños y el de las niñas. Los niños con características prosociales se caracterizan por prácticas de crianza de apoyo y comunicación, mientras que las niñas tienen padres y madres positivos. En este sentido, la crianza 
positiva se asocia con la prosocialidad. También se establece que las prácticas de crianza y el temperamento se relacionan con el comportamiento prosocial. Lo anterior tiene como sustento que el padre de familia que apoya a sus hijos es sensible a sus necesidades. Además, tal como lo afirman Coplan et al. (2002) y Hastings et al. (2007), muchos estudios muestran que los padres que manifiestan calidez, aproximación positiva frente a sus hijos y razonamiento, tienen hijos e hijas más prosociales.

Así mismo, el maestro es fundamental en el desarrollo psicosocial de los niños. Como lo señalan Bergevin et al. (2003), en la socialización de los niños entre los ocho y doce años (infancia tardía), el aprendizaje de valores y las formas de actuar se ven facilitadas por el vínculo que se da entre los adultos y los niños. En esta relación, el aprendizaje por observación y por experimentación permite a los niños regular sus emociones, internalizar normas (asumirlas de manera más racional) y tomar perspectiva, procesos psicológicos necesarios para el desarrollo del comportamiento prosocial (EC/043/015/D).

Dos de los estudios los cuales hacen parte de este tópico no presentan hallazgos frente al mismo, sin embargo, uno de estos concibe a la familia como elemento importante en el cual el proceso etnoeducativo puede favorecer su relación con la escuela para conseguir un impacto más potente (Capera y Torres, 2014); mientras que el otro establece una relación entre la familia y el rendimiento académico (Bedoya et al., 2017).

Lo interesante de todos estos estudios es que no consideran que la educación es un proceso que solo le compete a la escuela, sino que se han interesado por comprender la importancia de la articulación entre la familia y la escuela, la participación de la escuela en la formación humana y la participación de la familia en los procesos educativos. 


\subsubsection{Tópico salud}

Este tópico fue abordado por la tesis EC/051-02/017/M de UM-C, lo que corresponde al $0.3 \%$ de los estudios del Eje Cafetero.

Desde la perspectiva de derechos, este estudio buscó sensibilizar respecto a los modos de afectación en salud mental en la juventud, y generar iniciativas que articulen las luchas contra la medicalización e institucionalización psiquiátrica, ya que ambas constituyen trayectos de la misma lucha contra la mercantilización de la vida (EC/051-02/017/M). Como uno de los principales hallazgos se presenta que, a pesar del abordaje que se ha hecho desde la biología, la pedagogía, la psicología, las ciencias sociales, los estudios culturales y la política social, continúa existiendo una precaria caracterización del sujeto joven al no tomar aún distancia suficiente de las simplificaciones etarias y de las miradas generadas desde la perspectiva adulta, básicamente normativas, atravesadas por juicios descalificadores o por temores ante la pérdida de certezas para su manejo. En este sentido, a partir de los relatos de los y las jóvenes se evidenció la necesidad de una resemantización de la condición juvenil, esto al tener en cuenta las formas de agencia y expresión de la misma, y así mismo, de asumir la salud mental desde una perspectiva cotidiana que vindica a la realidad como una construcción social intersubjetiva y a los sujetos como protagonistas de la historia. Esto conduce a comprender la salud mental como posibilidad de creación y no solo como un acto racional de control y orden. La salud mental implica una acción política de encuentro de los diversos, auto reconocimiento y legitimación de lo plural (EC/051-02/017/M).

Esta acción la cual se relaciona con lo político es encarnada por los y las jóvenes como cuerpos que aparecen y desaparecen, los cuales padecen y vindican relatos de una temporalidad diferente a la instituida que colonizan las mentes, los cuerpos y las emociones; ellos y ellas se ubican de otras maneras en el espacio físico y simbólico el cual habitan con otros y otras, y apuestan 
por la deconstrucción y la reconstrucción de las memorias, los lugares y los roles los cuales les han sido propuestas como única posibilidad (EC/051-02/017/M).

Es así, como se plantea el desafío de evitar el sometimiento a discursos hegemónicos los cuales naturalizan la institucionalización como único recurso para los y las jóvenes con sufrimiento psicosocial, y que cierran las posibilidades de acciones creativas, de prácticas que promuevan itinerarios por espacios comunitarios que invitan a la inclusión y a la socialización, y que garantizan el derecho a la salud como uno de los derechos esenciales en la construcción de una ciudadanía plena, lo cual implica la reflexión crítica y la producción de articulaciones teóricas y prácticas rigurosas las cuales permitan la construcción colectiva de dispositivos subjetivantes, evitando la precarización del pensamiento que se ajuste solo a la oferta existente (EC/05102/017/M).

Finalmente, son fundamentales las prácticas colectivas e intersubjetivas, para lo que se requiere un modelo de salud mental comunitaria contextualizada (Dueñas, 2013), que posibilite un horizonte futuro (EC/051-02/017/M).

\subsubsection{Tópico resistencia cotidiana}

Este tópico fue abordado por una tesis de Díaz (2014) de la UM-C, lo que corresponde al $0.3 \%$ de los estudios.

Este estudio (Díaz, 2014) establece que en los relatos de experiencias compasivas expresados por los participantes se encontraron situaciones sorprendentemente parecidas a las planteadas por Aristóteles, las cuales incluso coinciden con estudios hechos en otras sociedades como la norteamericana sobre la gravedad o sobre los eventos infortunados o trágicos los cuales le ocurren a otras personas y que la sociedad valora como muy desafortunados para el alcance del florecimiento humano, 
como los desarrollados desde la sociología por Clark (como se citó en Nussbaum, 2008). De lo anterior se deduce que existe una constante en las consideraciones hechas por las sociedades sobre los principales hechos graves o desastres de la vida humana, y que han perdurado a lo largo del tiempo; incluso en una sociedad como la colombiana, el secuestro, la desaparición forzada y otros tantos hechos violentos podrían considerarse en esta desafortunada lista de hechos considerados graves para alcanzar una vida digna, justa y buena. Específicamente, en los relatos presentados en los resultados de la tesis en mención aparecen juicios valorativos sobre un profundo sufrimiento humano alrededor de los siguientes objetos: la pobreza, la separación de la familia o el no tener familia, la agresión o las lesiones físicas o corporales, la pérdida del hogar o la vivienda por la mala fortuna y la muerte de un ser querido cercano (Díaz, 2014).

\subsubsection{Tópico alteridad}

Este tópico fue abordado por una tesis del autor Arenas (2017) de la UM-C, lo que corresponde al $0.3 \%$ de los estudios.

El estudio que se ubica en este tópico no presenta hallazgos frente al mismo; sin embargo, establece una relación entre la alteridad y la formación ciudadana (Arenas, 2017).

Podríamos decir que esta temática muestra una de las opacidades de las investigaciones de la zona del Eje Cafetero, en cuanto a que la alteridad sería un concepto de necesario estudio en un país como Colombia centrado cada vez más en el individuo y en la competencia, por lo que favorecer mayor profundización en esta categoría, desde estudios orientados a la transformación sería de gran pertinencia.

\subsubsection{Tópico género}

Este tópico fue abordado por RDA/133/047/M, de la UTP y que corresponde al $0.3 \%$ de los estudios del Eje Cafetero. 
En la tesis se propone el tópico local sexismo, y en los subtópicos emergentes se ubican las representaciones sexistas, la discriminación de género y la educación sexista. Se advierte dentro de este tópico, que las representaciones de género se configuran desde los libros de texto, se consolidan estereotipos y modelos sociales frente a la mujer y sus formas de relacionamiento. Se insiste en su invisibilización, por lo que se impone la hegemonía masculina y sexista, en las cuales la heterosexualidad se implanta como única alternativa (RDA/133/047/M).

Según Weisz (2017), las experiencias vividas, la transmisión intergeneracional y los modos de comunicación van configurando representaciones fragmentadas en función de los desiguales espacios los cuales se habitan hoy en las sociedades hipermodernas.

La construcción de sentido, de subjetividad y las identidades móviles fluctúan en el marco de las actuales sociedades de riesgo, generando incertidumbre, fragilización de los vínculos y lazos sociales, obstaculizando la consolidación de sujetos colectivos. En este sentido los diversos fragmentos y estratos socioeconómicos y culturales, así como las diferencias generacionales van conformando diferentes, yuxtapuestas y hasta contrapuestas representaciones sociales. Visibilizar y desnaturalizar las representaciones que están presentes y subyacen en los diversos ámbitos y sectores poblacionales, genera necesariamente reflexividad sobre el mundo de la vida y la cotidianeidad. Y toda reflexividad abre las condiciones de posibilidad de transformación y de cambio. (Weisz, 2017, p. 100).

\subsection{A manera de discusión e invitación a transitar nuevos territorios}

A continuación, se desarrolla un ejercicio de síntesis y discusión de los hallazgos encontrados en las investigaciones analizadas, en función de cada una de las regiones analizadas: educación, pedagogía y otras regiones. En la zona del Eje Cafetero las tesis finalizadas en la región Educación, a nivel de doctorado y 
maestría, abordan como principal tópico global la educación para la paz y la democracia en un $10.1 \%$; habiendo sido estas realizadas en un $9.8 \%$ por la UM-C, lo cual se explica por dos razones. Una razón es que el Doctorado en Ciencias Sociales, Niñez y Juventud y la Maestría en Educación y Desarrollo Humano poseen tres líneas de investigación comunes, una en educación y pedagogía, otra en socialización política y construcción de subjetividades y una tercera en infancias, juventudes y ejercicio ciudadanía; la segunda razón para que este tópico global de educación para la paz y la democracia sea desarrollado tiene relación con la coyuntura colombiana vivida en la segunda década del siglo XxI de las negociaciones de paz entre el gobierno colombiano y la insurgencia levantada en armas. La UCP tiene el $0.3 \%$ de las tesis finalizadas con relación a este tópico global y la UTP no tiene ninguna investigación al respecto. Sería recomendable fortalecer las investigaciones en este tópico, para continuar respondiendo en la investigación educativa a este trascendental momento histórico el cual permea la vida del país; sin embargo, cabe señalar que cada universidad tiene intereses investigativos diferentes los cuales responden a sus líneas de investigación, docentes y autores canónicos.

Estas tesis que se preguntan y problematizan los asuntos referentes a la educación para la paz desde distintos tópicos locales (participación/participación ciudadana, convivencia, ciudadaníal ciudadanía y conciencia crítica, subjetividad política, memoria, construcción de identidad, reintegración, conflicto/resolución de conflictos/pluralidad y conflicto, sujeto autónomo y reflexivo) contribuyen a formar sujetos democráticos comprometidos con una democracia participativa que en Colombia a lo largo de su historia republicana, y hasta hoy, ha sido captada por los intereses y poderes dominantes los cuales han gobernado al país hasta en la actualidad y los cuales impactan la vida cotidiana de los colombianos y las colombianas y que por más de cincuenta años alimentó una guerra fratricida. En las tesis analizadas se concluye que la democracia y la paz tienen relación y afectan todos los aspectos de la vida. 
Consideran algunas tesis que los estudiantes encuentran en la institución educativa posibilidad para llevar a cabo acciones, movilizaciones políticas democráticas, participación libre y autónoma.

Los juicios hechos por los estudiantes acerca de la convivencia escolar y la confianza contribuyen a alcanzar la paz y con ello una sana convivencia para lo cual se requiere de la participación de los estudiantes y la orientación de los profesores.

Plantean algunas tesis la importancia de la formación ciudadana, la responsabilidad de vivir con los otros, y las tareas que al respecto tiene la escuela. Los derechos como orientadores de los procesos de ciudadanía con conciencia crítica.

Desde la subjetividad política plantean algunas tesis la importancia de que los sujetos de la educación o sujetos democráticos y participativos, sean actores capaces de transformar condiciones de poder dominantes, injustas e inhumanas, con conciencia de responsabilidad social.

Sobre la memoria se ha trabajado muy poco en las tesis realizadas en el Eje Cafetero. En la coyuntura de la investigación educativa nacional comprometida con la paz, es importante que se planteen investigaciones al respecto. Se requiere recuperar la memoria de la escuela; escuelas que fueron utilizadas como trincheras de combate por los ejércitos en contienda; escuelas que fueron destruidas; escuelas en las cuales solo quedó un rastro de los tableros, de los niños y niñas que estudiaron, de los profesores que enseñaron; escuelas en las que las minas acabaron con los cuerpos de los niños y las niñas, de los profesores, de los papás y las mamás; escuelas invadidas convertidas en lugares de vivienda de los ejércitos; escuelas de donde fueron perseguidos los profesores; escuelas donde las familias no pudieron volver; Escuelas donde los niños jugaron con armas a matar al vecino, hasta que el juego se convirtió en realidad. Es importante que 
la escuela recupere la historia de violencias y de muerte, que lo exprese en todas sus formas, para que estas barbaries nunca más se repitan. Las investigaciones tienen una deuda con la memoria, con lo que aconteció y por qué aconteció.

Es necesario trabajar desde las investigaciones las identidades políticas, nuevas identidades, los lenguajes y sus formas de transformación.

Un país en el cual se ha vivido por tantos años la guerra no es posible que las investigaciones educativas no trabajen sobre la reintegración de quienes han sido afectados de alguna manera por el conflicto armado. Es necesario continuar investigando sobre la reintegración de los niños, las niñas, los jóvenes y los adultos a procesos democráticos, de participación y justicia política y social.

Abordar el conflicto, la solución de conflictos, el posconflicto, en relación con los procesos educativos, con la escuela, las relaciones entre los educandos y de estos con el educador y las comunidades, y la formación de sujetos autónomos y reflexivos es tarea urgente de los años siguientes en la investigación de maestrías y doctorados. Se trata de poner en cuestión las opacidades que en estas investigaciones se perciben para abrir campos de nuevas posibilidades promisorias para la investigación.

En segundo lugar de relevancia en la región educación con un $7.3 \%$ se aborda el tópico global educación inclusiva, siendo la UM-C con un $4.8 \%$ la que tiene el mayor número de tesis finalizadas en este tópico en el período de estudio, le sigue la UTP con un $2.2 \%$ de las tesis y la UCP solamente con el $0.3 \%$ de los trabajos finalizadas. El número mayor de tesis que aborda la inclusión lo aporta la UM, la cual posee la Maestría en Educación para la Diversidad y también los programas de postgrado del Centro de Estudios Avanzados en Niñez y Juventud; es importante destacar la tradición que al respecto tiene la maestría de la UTP. Las investigaciones referentes a la educación inclusiva en la zona 
del Eje Cafetero, lo hacen desde el análisis de lo que sucede en la educación con relación a las diversidades, las cuales son múltiples como las diversidades especiales y los talentos excepcionales; las diversidades étnico-culturales y de género. Aspectos los cuales se requieren para formar a los educadores y continuar potenciando a través de los procesos de formación escenarios educativos los cuales propendan por el reconocimiento y la participación de todos.

Las investigaciones sobre el tópico global escuela ocupan el tercer lugar en relevancia en la región educación con un $5.9 \%$ de las tesis, de las cuales la que hace el mayor aporte es la UM-C con un $5.4 \%$ de los trabajos, la UCP con el $0.5 \%$ y la UTP con ninguna tesis que aborde este tópico. Es importante esta información pues esto además de mostrar que está sucediendo con relación a los estudios sobre escuela, reta a las instituciones a comprometerse en los estudios de maestría y doctorado con el desarrollo de investigaciones en un tópico como este de tanta importancia. Sin embargo, también es significativo expresar que, en otros tópicos globales, se analiza la escuela, por ejemplo, desde la educación para la democracia y la paz, la educación inclusiva, la gestión educativa, entre otros aspectos.

Estas tesis abordan la escuela desde las relaciones que esta establece con la comunidad, la lectura que hace del contexto, las relaciones que establece con la familia, las relaciones que establece con los estudiantes, las relaciones de los profesores con los estudiantes; haciendo un análisis crítico de estas relaciones para propiciar sujetos con posibilidades humanas las cuales contribuyan a un mejor vivir. Los estudios de la escuela se plantean desde la complejidad de las relaciones en el mundo de hoy cargado de grandes expectativas. Se espera que estos estudios se profundicen y fomenten para que la escuela responda mejor a las necesidades del país, a sus distintos grupos humanos y comunidades, a los educandos en sus diversidades y a un mundo cada vez con mayores incertidumbres. 
Con menor tradición investigativa de la zona del Eje Cafetero están los tópicos globales: sentido de la educación, educación propia, gestión educativa y educación ética y moral, en los cuales solo se tiene en cada uno de estos el $0.6 \%$ de las tesis. La mayor opacidad se encuentra en los tópicos globales cultura juvenil/ cultura estudiantil, pensamiento social, y educación para el emprendimiento, con apenas el $0.3 \%$ de las tesis. Por lo cual se requiere fortalecer la investigación en estos tópicos, realizando aprendizajes de otras zonas del país que tengan mayor desarrollo al respecto.

Las tesis de maestría y doctorado desarrolladas en los tópicos globales de la región educación en la zona eje cafetero permiten pensar en generar a nivel de maestrías y doctorados al interior de una misma institución o en trabajo interinstitucional, programas de investigación los cuales se desarrollen por varios años articulando líneas de investigación, proyectos de profesores $\mathrm{y}$ tesis de estudiantes. Aprovechando las fortalezas y potenciando las opacidades, de tal manera que la investigación educativa se fortalezca aún más en la zona y los aportes propios contribuyan a mejorar la educación en cada uno de los rincones del país; para lo cual, se requiere incidir en políticas públicas las cuales contribuyan a transformar el panorama.

La región pedagogía representa el pico más alto de los hallazgos derivados del instrumento RIEP cinco. Ello denota el interés de las universidades participantes por procesos de formación ligados ámbitos formales o institucionalizados. No obstante, esta no es una posición asumida explícitamente en los proyectos de maestría y tesis de doctorado, sino derivada de los tópicos que fueron emergiendo del análisis realizado: didáctica, prácticas pedagógicas, uso educativo de las TIC, concepciones, entre otras; las cuales parecen responder a los intereses particulares de los grupos de investigación y estudiantes, mas no, a una posición teórica previa respecto a la pedagogía. 
Ahora bien, en la región los tópicos que la componen y que tienen mayor relevancia, por el número de proyectos, son la didáctica y las prácticas pedagógicas, las cuales van delimitando mucho más el interés de dicha región por los procesos de enseñanza, y en ella por sus propios cambios (cambios en la formas de ver la enseñanza, "nuevas didácticas»), por las consecuencias de estos cambios en el aprendizaje de los estudiantes y en las prácticas pedagógicas, las cuales pasan a ser «prácticas reflexivas» o innovadoras. De allí, podría inferirse una visión de pedagogía, planteada por Vasco (1990) como saber teórico-práctico construido por pedagogos, esto es, por maestros, a través de la reflexión personal y dialogal sobre su propia práctica pedagógica. No obstante, los hallazgos no dan cuenta de una discusión al respecto.

Se esperaría entonces, dado el marcado énfasis en las didácticas y las prácticas, que la discusión girara entorno a las posiciones epistemológicas o enfoques dela o las didácticas y las prácticas; pero estas también están ausentes, pues el interés está en dos ejes, de un lado elaborar y desarrollar propuestas enmarcadas en la didáctica general o en los avances de las didácticas disciplinares, para dar cuenta de su potencialidad en el mejoramiento de los procesos de aprendizaje de los estudiantes. De otra parte, y aportando a esta visión, el interés por identificar y describir los procesos cognitivos y metacognitivos de los estudiantes con el propósito de elaborar propuestas didácticas para mejorar o cuestionar las existentes.

Prima, por tanto, una visión instrumental de la didáctica, preocupada por mejorar la enseñanza para lograr el aprendizaje (abordado generalmente como desempeño) especialmente de los saberes escolares, pues parece imperar como lo plantea RungePeña (2013), una visión de instrucción eficiente. Desde esta visión, los resultados resaltan la incidencia de las secuencias o unidades didácticas o genéricamente, propuestas de enseñanza, en los aprendizajes de los estudiantes y en la transformación de las prácticas, las cuales pasan de ser "prácticas tradicionales» a adjetivarse como socioconstructivistas, reflexivas, situadas, 
críticas, no parametrizadas, entre otras. Siendo este el énfasis de la región, se esperaría la producción de teorías o categorías conceptuales sobre la didáctica, pero parece en palabras del mismo Flechsig (como se citó en Runge-Peña, 2013) que las investigaciones renunciaran a reflexiones de fundamentación y crítica y se dedicara a establecer parámetros de implementación de modelos educativos.

Así, los hallazgos en este tópico evidencian una visión instrumental sobre la didáctica, preocupada por mejorar la enseñanza para lograr el aprendizaje, especialmente de los saberes escolares, pues parece imperar como lo plantea RungePeña (2013), una visión de instrucción eficiente. Desde esta perspectiva, los resultados resaltan la eficiencia de las secuencias o unidades didácticas o genéricamente, propuestas de enseñanza, en los aprendizajes de los estudiantes y en la transformación de las prácticas, pero sin que llegue a producirse teoría sobre la enseñanza (nivel tres propuesto por Flechsig). Como si este tipo de investigación renunciara a reflexiones de fundamentación y crítica, y se dedicara a establecer parámetros de implementación de modelos educativos. "Con ello se renuncia a reflexiones amplias sobre la enseñanza y el aprendizaje, y todo queda centrado en métodos y tecnologías aplicables al "acto educativo"» (RungePeña, 2013, p. 236).

En cuanto a los hallazgos referidos al tópico de la práctica pedagógica se mantiene la tensión ya prevista entre la teoría y la práctica educativa. En este sentido, autores como Perrenoud (2007), Zabala (2008), y Runge-Peña y Muñoz-Gaviria (2012) sustentan la importancia y potencia de la reflexión acerca de la práctica como ejercicio fundamental, desarrollado por los maestros, para crear marcos de referencia acerca del quehacer educativo, sus formas, sus procedimientos, sus intencionalidades, su saber en general. Esta reflexión atiende a las necesidades históricas y responde a las contingencias inmediatas del maestro, formando profesionales conscientes de sus responsabilidades en el ejercicio educativo. 
Sin embargo, en los hallazgos encontrados, la reflexión se limita a confirmar la potencia de las propuestas elaboradas desde referentes teóricos previstos, de alguna manera ya validados por teóricos experimentados. No se encuentran reflexiones propias, críticas argumentadas que demarquen nuevos caminos a partir de la validación de las experiencias, permeadas por el contexto, sus problemáticas y oportunidades. Queda por fuera de la reflexión la constitución de un sujeto-maestro consiente de sus responsabilidades y posibilidades como constructor de saber pedagógico y didáctico.

En este mismo sentido, se pone en juego, únicamente, la visión del profesor como aquel que enseña, restringido al desempeño de aula, a procurar la «buena enseñanza», pero no como sujeto político, como parte de un colectivo, de un grupo social el cual comparte intenciones, metas, constitución política y ética de su labor. Tampoco se da cabida a la reflexión del sujeto-maestro como ser humano con emociones, temores, expectativas en su proyecto de vida en relación-tensión con su desempeño profesional.

Otro tópico de importancia es el de aprendizaje, el cual aparece de manera más tácita que explícita en muchas tesis. Acerca de este concepto, se encuentran dos visiones predominantes, una ligada a los desempeños de los estudiantes, según el cual, se valora el mejoramiento o avance en las evaluaciones que realiza el maestro $y$, con la expectativa de impactar también en las evaluaciones censales. De manera reiterativa, las propuestas de intervención se valoran como muy positivas para este tipo de aprendizaje.

La otra visión está ligada a los procesos cognitivos, donde resulta necesario identificar estilos, estrategias de aprendizaje, para incidir o estimular el desarrollo de habilidades cognitivas, metacognitivas, cognitivo-lingüísticas, las inteligencias múltiples, como punto de partida y con el propósito, no solo de mejorar el desempeño académico, sino de formar estudiantes que puedan autorregularse, conscientes de la importancia y necesidad del 
conocimiento. En términos generales, esta visión propende por formar un ciudadano, autónomo y autorregulado, el cual aporte a la convivencia social y a la solución de problemas en su comunidad.

Una opacidad dentro de los hallazgos de la región pedagogía está en escasa relación didáctica practica pedagógica-currículo, la cual no aparece de manera clara o explicita en las investigaciones. Como se señaló anteriormente, las propuestas didácticas diversas, resultan ser exitosas en la mayoría de los trabajos, se hacen procesos y procedimientos racionalizados e intencionados, se tienen en cuenta los contextos, pero no se ven reflejadas en propuestas curriculares estructuradas que apoyen, modifiquen o trasciendan a los proyectos curriculares de área, o a los currículos generales de las instituciones educativas en los cuales fueron hechas las propuestas.

Emerge como opacidad la relación didáctica y desarrollo humano, abordada como visiones humanizantes de lo que sucede en el aula y de los actores involucrados en ellas. Así, las propuestas de enseñanza propenden por la generación de espacios dialógicos, flexibles, democráticos, en los que cuales los estudiantes puedan expresarse sin temor. Además, se describe cómo las propuestas generan espacios para la inclusión, asuntos reclamados como necesarios desde la escuela para la formación de pensamiento crítico y la ciudadanía.

En suma, los resultados evidencian una región que ha construido durante los últimos años un saber procedimental sobre la enseñanza, ligada esencialmente a los saberes escolares y cambios en las prácticas de enseñanza, cambios reclamados por la sociedad, las instituciones, el Ministerio de Educación Nacional y los mismos estudiantes de posgrados, debido a las grandes dificultades que ellos perciben en sus contextos y en sus estudiantes. No obstante, se constituye en un reto el desarrollo teórico sobre los tópicos de interés, la generación de «escuelas» de pensamiento las cuales se atrevan a superar el contexto del aula y de la institución. 
A partir de los análisis realizados en la región llamada otras regiones, se identifica como tópico global más relevante el de desarrollo humano. Principalmente, este tópico se asocia a la educación, a los procesos formativos como medios en los que es posible la convivencia con la diversidad, y la expresión de sentidos y significados sobre la vida cotidiana a partir del juego y la lúdica; de otros lenguajes alternativos como el grafitti y el rap, y del cuidado de sí desde los hábitos y las rutinas. Se evidencian resultados los cuales se enmarcan en propuestas de desarrollo humano dominantes, centradas en procesos de estabilidad educativa y laboral, mientras que otros acogen el desarrollo humano como posibilidad de transformación social a partir de reflexiones y apuestas colectivas alrededor de las prácticas pedagógicas, la investigación y la innovación en educación. El tópico local de desarrollo moral planteó un interesante análisis del tema a partir de las emociones morales las cuales se manifiestan en el ser humano como aspectos necesarios, inevitables y que hacen parte de las dinámicas relacionales, específicamente para este caso en el entorno escolar.

Desde los aportes realizados en el Centro de Estudios Avanzados en Niñez y Juventud de la alianza CINDE-Universidad de Manizales, como se ejemplifica en las tesis analizadas, el desarrollo humano ha sido contemplado a través de una perspectiva alternativa, lo cual implica hacer resistencia a los modelos de desarrollo instaurados por la modernidad como únicas posibilidades de crecimiento. Retomando a Sen (2000) y a Nussbaum (2012), el desarrollo humano implica el reconocimiento de derechos, el fortalecimiento de capacidades y la creación de condiciones para que esto pueda desplegarse. Así, la calidad de vida se comprende como fruto de la posibilidad de despliegue de las capacidades humanas y de la justicia social, siendo estos los mínimos necesarios para acceder a una vida digna. En este sentido, el desarrollo humano es correlato de la construcción relacional, social, histórica y cultural de los sujetos; es bidireccional e incluye tanto a los niños, niñas y jóvenes, como a sus agentes relacionales y 
la sociedad en su conjunto, en un sentido similar al propuesto por Sosenski (2015) en su referencia a Giddens (1998) y por OspinaAlvarado (2018) en su referencia a Gergen (2007); aun cuando el desarrollo humano, visto desde una perspectiva tradicional, ligada a la individualidad y a la personalidad, ha distorsionado la experiencia humana y se ha presentado como un discurso normativo dominante que pretende definir caminos y proyectos de vida en términos de patrones de normalidad y anormalidad sustentados principalmente en la adquisición de bienes y riquezas (Ospina-Alvarado et al., 2018).

Otro tópico global con cierta relevancia es el de familia. En este, la crianza juega un papel central, influenciada por aspectos externos como las representaciones sociales y la comunicación la cual se establece en los núcleos familiares y en la escuela, y por aspectos individuales como las emociones, los sentimientos y las expectativas personales. Esas prácticas de crianza se vislumbran como un elemento que impacta de distintas formas el desarrollo de los niños y las niñas, específicamente en su componente social; aunque la responsabilidad recae especialmente en las familias, se identificó también el papel del maestro y la maestra en la promoción de habilidades sociales y para la vida de los niños y las niñas. Lo anterior muestra la importancia recalcada en otros trabajos (Ospina-Alvarado, 2014) del Centro de Estudios Avanzados en Niñez y Juventud, alianza CINDE-Universidad de Manizales, alrededor de la articulación entre la familia y la escuela.

Como una característica que sobresale en los análisis de esta región está la existencia de opacidades en la mayoría de tópicos globales. Se pueden encontrar cuatro de estos, abordados solo por una tesis. Por una parte, en el tópico salud se realiza un acercamiento a la salud mental desde la perspectiva de derechos, como un aporte a la no estigmatización y a la promoción de condiciones que favorezcan la construcción de otros futuros posibles. Esto se constituye en un abordaje interesante aparte de la mirada tradicional de la salud mental como lo ha propuesto 
Gergen (2007). Por su parte, la resistencia cotidiana fue otro tópico global el cual, a pesar de su opacidad, deja una invitación para continuar explorando a partir de las narraciones y los relatos aquellas acciones las cuales permiten que las sociedades desde mecanismos tanto individuales como comunitarios logren hacer frente a situaciones límite y de emergencia, como por ejemplo las asociadas al conflicto armado; esto, para alcanzar, de la mano de la voluntad política, una vida buena, digna y justa. Se encontró el tópico alteridad, el cual deja la puerta abierta para incentivar la realización de investigaciones acerca del tema en relación con la formación ciudadana, tópico local que se constituye en una gran opacidad de cara al contexto de nuestro país y el cual sería fundamental seguir ampliando en estudios posteriores. Finalmente, como otra opacidad se ubica el tópico género como posibilidad de continuar propiciando reflexiones y transformaciones en aquellas representaciones sociales las cuales históricamente han limitado las formas de relacionamiento a las directrices impuestas por el patriarcado y la heterosexualidad como formas predominantes de ser y actuar en el mundo.

\section{Referencias bibliográficas}

Adorno, T. (1998). Educación para la emancipación. Ediciones Morata.

. (2005). Dialéctica negativa. La jerga de la autenticidad. Ediciones Akal, S. A.

Alvarado Salgado, S. V. y Carreño Bustamante, M. T. (2007). La formación ciudadana: una estrategia para la construcción de justicia. Revista Latinoamericana de Ciencias Sociales, Niñez y Juventud, 5(1), 1-15. www.redalyc.org/ pdf/773/77350102.pdf. 
Alvarado, S. V.; Ospina-Alvarado, M. C. y García, C. (2012). La subjetividad política y la socialización política, desde las márgenes de la psicología política. Revista Latinoamericana de Ciencias Sociales, Niñez y Juventud, 10(1), 235-256. https://www.redalyc.org/pdf/773/77323982014.pdf

Alvarado, S. V.; Ospina, H. F.; Quintero, M.; Luna, M. T.; Ospina, M. C. y Patiño, J. A. (2012). Las escuelas como territorios de paz. Construcción social del niño y la niña como sujetos políticos en contextos de conflicto armado. Clacso.

Álvarez-Álvarez, C. (2015). Teoría frente a práctica educativa: algunos problemas y propuestas de solución. Perfiles Educativos, 37(148), 172-190. http://www.scielo.org.mx/ pdf/peredu/v37n148/v37n148a11.pdf.

Anderson, H. (2012). Collaborative Relationships and Dialogic Conversations: Ideas For a Relationally Responsive Practice. Family Process, 51(1), 8-24.

Apple, M. (2017). ¿Puede la educación cambiar la sociedad? LOM.

Arbeláez, M.; Lanza, C. y Tobón, M. (2012) Las prácticas Educativas: desde lo presencial a la mediación por TIC. En R. Canales. (Ed.). Aprender con tecnologías en la sociedad del conocimiento. Proyecto PEPE: Plataforma de Entornos Pedagógicos Especializados (pp. 82-99). Editorial Universidad de los Lagos.

Arias, F. A. (2011) Emergencia del hombre en la formación de maestros y maestras en Colombia. Revista Latinoamericana de Ciencias Sociales, Niñez y Juventud, 2(9), 703-720. http:// www.scielo.org.co/pdf/rlcs/v9n2/v9n2a15.pdf. 
Arias-Cardona, A. M. y Alvarado, S. V. (2015). Jóvenes y política: de la participación formal a la movilización informal. Revista Latinoamericana de Ciencias Sociales, Niñez y Juventud, 13(2), 581-594. http://www.scielo.org.co/ pdf/rlcs/v13n2/v13n2a03.pdf.

Arroyo,A. (2016). Pedagogías decoloniales y la interculturalidad: perspectivas situadas. En M. V. Di CAudo; D. Llanos y M. C. Ospina (Coords.) Interculturalidad y educación desde el Sur Contextos, experiencias y voces. Abya-Yala.

BADIOU, A. (1998). Introducción al ser y el acontecimiento. Acontecimiento (16). www.grupoacontecimiento.com.ar.

Ballesteros, C. (2000). Percepciones, creencias y actituaciones de los profesores de lenguas propias durante los dos primeros años de funcionamiento de la enseñanza secundaria obligatoria (ESO). Un estudio de caso [Tesis de doctorado, Universidad de Barcelona]. https://www. tesisenred.net/bitstream/handle/10803/1299/01.CBG_1de6. pdf? sequence $=1$ \&isAllowed $=\mathrm{y}$.

Bauman, Z. (2004). La modernidad liquida. Fondo de Cultura Económica.

Black, P. J. \& Wiliam, D. (2009). Developing the Theory of Formative Assessment. Educational Assessment, Evaluation and Accountability, 21(1), 5-31.

Bolívar, A. (2005). Equidad educativa y teoría de la justicia. Revista Electrónica Iberoamericana sobre Calidad, Eficacia y Cambio en Educación, 3(2), 42-69.

BonIL, J. y MÁrQUEZ, C. (2011). ¿Qué experiencias manifiestan los futuros maestros sobre las clases de ciencias? Implicaciones para su formación. Revista de educación, (354), 447-472. 
Bourdieu, P. (2000). Poder, derecho y clases sociales. Desclee.

Braslavsky, B. (2005). Enseñar a entender lo que se lee. Fondo de Cultura Económica.

Bronckart, J. P. (2007). Desarrollo del lenguaje y didáctica de las lenguas. Miño y Dávila.

Brousseau, G. (2007): Iniciación al estudio de la teoría de las situaciones didácticas. Libros del Zorzal.

Cabaluz Ducasse, F. (2017). Entramando pedagogías criticas latinoamericanas. Quimantu.

Cabrera Arismendy, C. E. y García Pérez, D. (2013). Concepciones de conflicto de los estudiantes de la Institución Educativa Luis Carlos Gonzales Mejía de la ciudad de Pereira [Tesis de Maestría en Educación, Universidad Tecnológica de Pereira]. http://repositorio.utp.edu.co/ dspace/bitstream/handle/11059/3388/3036986132C117. pdf? sequence $=1$ \&isAllowed $=y$.

Camilloni, A. (2007). El saber didáctico. Paidós. . (2010). La evaluación significativa. Paidós.

Camps, A. (1996). Proyectos de lengua entre la teoría y la práctica. Cultura y Educación, 8(2), 43-57. DOI: $10.1174 / 113564096763277715$.

. (2003). Miradas diversas a la enseñanza y el aprendizaje de la composición escrita. Lectura y Vida, 24(4).

Carlino, F. R. (1999). La evaluación educacional. Historia, problemas y propuestas. Aique. 
CARr, W. (1996). Una teoría para la educación: hacia una investigación educativa crítica. Ediciones Morata.

Casalmiglia Blancafort, H. y Tusón Valls, A. (1999) Las cosas del decir. Manual de análisis del discurso. Ariel.

Cassany, D. (2006) Tras las líneas. Sobre la lectura contemporánea. Anagrama.

Castillo Sánchez, M. y Gamboa Araya, R. (2012). La Educación para la Paz: Una Respuesta a las Demandas Sociales. Revista Electrónica Diálogos Educativos, 12 (23), 117-133. http://146.83.132.45/articulos/2012/dialogos-e-23castillo.pdf

Castro-Gómez, S. (2012a). Los avatares de la crítica decolonial. Tabula Rasa, (16), 213-230. http://www.scielo.org.co/pdf/ tara/n16/n16a12.pdf.

. (2012b). Crítica de la razón latinoamericana. Editorial Pontificia Universidad Javeriana.

- (2014). Cuerpos racializados. Para una genealogía de la colonialidad del poder en Colombia. En H. CardonaRodas, y Z. Pedraza-Gómez (Comps.), Al otro lado del cuerpo. Estudios biopolíticos en América Latina (pp. 79-95). Alfaomega Ediciones, Uniandes.

Castro y Guzmán de Castro (2005). Los estilos de aprendizaje en la enseñanza y el aprendizaje: Una propuesta para su implementación. Revista de Investigación, (58), 83-102.

Comisisión Económica para América latina y el CARIbe [CEPAL] y Oficina Regional de Educación para América Latina y el Caribe [UNESCO]. (1992). Educación y conocimiento: eje de la transformación productiva 
con equidad. Naciones Unidas. https://repositorio.cepal.org/ bitstream/handle/11362/2130/1/S9250755_es.pdf.

Chevallard, Y. (1997). La transposición didáctica. Del saber sabio al saber enseñado. Arique.

. (1999). La recherche en didactique et la formation des professeurs:problématiques, concepts, problèmes [conferencia]. IUFM d'Aix- Marseille.

Coll, C. y Monereo, C. (Eds.). (2008). Psicología de la educación virtual. Aprender y enseñar con las tecnologías de la información y la comunicación. Ediciones Morata.

Coll, C., Mauri Majós, M.T. y Onrubia GoñI, J. (2008). Análisis de los usos reales de las TIC en contextos educativos formales: una aproximación sociocultural. Revista electrónica de investigación educativa, 10(1), 1-18.

Colomina, R., Naranjo, M., Rochera, M. (2008). La perspectiva de los usuarios sobre la calidad de los materiales educativos multimedia y los procesos formativos en línea: usos, utilidad y valoración. En E. Barberá, T. Mauri, J. Onrubia (Coord.), Cómo valorar la calidad de la enseñanza basada en las TIC: Pautas e instrumentos de análisis (pp. 147-190). Editorial Graó.

Contreras Domingo, J. (Comp.). (2017). Enseñar tejiendo relaciones. Morata.

DARLING-Hammond, L. (2012). Educar con calidad y equidad. Los dilemas del siglo XXI. Fundación Chile.

Davini, M. C. (1995). La formación de los docentes. Un programa de investigaciones. Mino y Dávila Editores. 
. (1997). La formación docente en cuestión: política y pedagogía. Paidós.

Derrida, J. (1998). La amistad como alianza en el silencio. Políticas de la amistad (P. Peñalver, Trad.). Trotta.

Dewey, J. (1975). Democracia y educación. Ediciones Morata.

De Tezanos, A. (2006). Didáctica-pedagogía-ciencia de la educación: la relación que confirma la excepción francesa. Revista Educación y Pedagogía, 18(46), 33-57.

Dolz, J. (2003). ¿Cómo enseñar a escribir el relato histórico? Elaboración de dos secuencias didáctica y evaluación de su impacto pedagógico en la escuela primaria. En A. Camps. (Comp.), Secuencias didácticas para aprender escribir. Grao.

Dolz, J. y PAsquier, A. (1996) Argumentar para convencer. Una secuencia didáctica de iniciación al texto argimentativo para el primer ciclo de la educación secundaria obligatoria. Gobierno de Navarra. Departamento de Educación y Cultura. http:// dpto.educacion.navarra.es/publicaciones/pdf/argum.pdf.

Dubet, F. (1997). La escuela. Sociología de la experiencia escolar. Losada.

Dueñas, V. H. (2001). El aprendizaje basado en problemas como enfoque pedagógico en la educación en salud. Colombia Médica, 32(4), 189-196. https://www.redalyc.org/ pdf/283/28332407.pdf.

Dussel, E. (1980). La pedagógica latinoamericana. Clacso.

ERIKsson, S. (2017). Comunicar la retroalimentación: estudio sobre la evaluación del profesor de la retroalimentación para la evaluación formativa en la advertencia escrita. [Tesis de doctorado, Universidad Karlstad]. 
Escobar, A. (2011). ¿«Pachamámicos» versus «Modérnicos»? Tabula Rasa, (15), 265-274.

(2012). Más allá del desarrollo: postdesarrollo y transiciones hacia el pluriverso. Revista de Antropología Social, 21, 23-62. https://core.ac.uk/download/pdf/38821953. pdf.

. (2016). Sentipensar con la tierra: las luchas territoriales y la dimensión ontológica de las epistemologías del sur. AIBR. Revista de Antropología Iberoamericana, 11(1), 11-32.

EspinosA, T. (2015). La escuela habitada. Experiencias escolares, pensamiento crítico y transformación social en una región intercultural Iván de Jesús. Tesis doctoral. [ Universidad de Málaga, España].

Ezcurra, A.M.(2008, del 1 al3 deoctubre).Educación universitaria: una inclusión excluyente. [conferencia inaugural], Tercer encuentro nacional sobre ingreso universitario, Argentina.

- (2011). Igualdad en educación superior. Un desafío Mundial. UNGS, IEC-Conadu.

FARrell, D. (2018). Las percepciones de los docentes sobre cómo el uso de la evaluación por pares podría mejorar su práctica docente. [Tesis de doctorado, Universidad de Maryland].

Feixa, C. (2008). De Jóvenes, bandas y tribus. Antropología de la juventud. Editorial Ariel, S. A.

Pam, N.; Feixa Pàmpols, C.; Leccardi, C. y Romaní Alfonso, O. (Coord.). (2014). De la generación @ a la \#generación. La juventud en la era digital. Nuevos Emprendimientos Editoriales S. L. 
Ferrer, G. (2006). Sistemas de evaluación de aprendizajes en América Latina, balances y desafíos. Preal.

Ferrer, P. (1999). Aspectos del curriculum prescrito en América Latina: revisión de tendencias contemporáneas en curriculum, indicadores de logro, estándares y otros instrumentos. University at Albany - State.

Flórez Petour, M. T. (2011). La importancia de una perspectiva histórica para el análisis de las políticas educativas (o de cómo llevamos haciendo lo mismo durante mucho tiempo). Historia 2.0. Conocimiento histórico en clave digital, (2), 7191.

Foucault, M. (1966). El nacimiento de la clínica. Una arqueología de la mirada médica. Siglo xxi Editores.

. (1979). Microfísica del poder. Las Ediciones de la Piqueta.

. (2000a). Las palabras y las cosas: una arqueología de las ciencias humanas. Siglo xxI Editores.

. (2000b). Los anormales. Fondo de Cultura Económica.

(2002a). Vigilar y castigar: nacimiento de la prisión. Siglo XXI Editores.

. (2002b). La arqueología del saber. Siglo xxi Editores.

. (2002c). Vigilar y castigar: nacimiento de la prisión. Siglo XXI Editores.

. (2007a). El poder psiquiátrico. Fondo de Cultura Económica. 
- (2007b). El nacimiento de la biopolítica. Fondo de Cultura Económica.

- (2016). La sociedad punitiva: curso en el Collége de France (1972-1973). Fondo de Cultura Económica.

Freire, P. (2005). Pedagogía de la Esperanza. Un reencuentro con la pedagogía del oprimido. Siglo xxI Editores.

Garretón, M. A. (2003). El espacio cultural latinoamericano. Bases para una política cultural de integración. Andrés Bello, Fondo de Cultura Económica.

Gergen, K. (2007). Construccionismo social, aportes para el debate y la práctica. Universidad de los Andes, Facultad de Ciencias Sociales, Departamento de Psicología, Centro de Estudios Socioculturales e Internacionales.

Giddens, A. (1998). La transformación de la intimidad: sexualidad, amor y erotismo en las sociedades modernas. Cátedra Teorema.

Grinberg, S. (2008). Educación y poder en el siglo XXI. Clacso.

Grinberg, S. (2015). De la disciplina al gerenciamiento, del examen al monitoreo. Un estudio sobre el gobierno y la evaluación en las sociedades contemporáneas. Revista de la Asociación de Sociología de la Educación, 8(2), 156-173. https://ojs.uv.es/index.php/RASE/article/view/8373/7966.

GubA, E. G. \& Lincoln, Y. S. (1989). Fourth Ge-neration Evaluation. Sage Publications.

GubA, G. E. \& Lincoln, Y. S. (1982). Effective evaluation. Jossey Bass Publishers. 
Gysling, J. (2017). La evaluación: ¿dispositivo para promover el aprendizaje de todos o para seleccionar? La formación de profesores en evaluación en Chile. [Tesis de doctorado, Universidad de Leiden].

Habermas, J. (1981). Conocimiento e interés. Taurus.

RTLEY, C. (2016). Autoeficacia del docente y retroalimentación de la evaluación formativa [Tesis de doctorado, Ball State University].

Hernández Sampieri. R.; Fernández Collado, C. y Baptista Lucio, M. P. (2010). Metodología de la investigación (5. a ed.). McGraw-Hill Interamericana.

Hidalgo, N. (2018). Concepciones sobre una evaluación justa de los estudiantes [Tesis de doctorado, Universidad Autónoma de Madrid].

Hincapié-Rojas, C. M. (2011). Escuelas: espacios vitales. De sectores a Actores. Revista Latinoamericana de Ciencias Sociales, Niñez y Juventud, 2(9), 683-702. http://www.scielo. org.co/pdf/rlcs/v9n2/v9n2a14.pdf.

Hymes, D. (1972). Models of the Interaction of Language and Social Life. En J. J. Gumperz y D. Hymes (Eds.). Directions in sociolinguistics: the ethnography of communication. Rinehart \& Winston.

Jacinto, C. y Terigi, F. (2007). ¿Qué hacer ante las desigualdades en la educación secundaria? Aportes de la experiencia latinoamericana. Santillana, Iipe, Unesco.

JACKson, P. (1980). La vida en las aulas. Morata. 
Jares, X. (2001). La educación para la paz en el umbral del nuevo siglo: retos y necesidades. En Centro Pignatelli (Ed.). La Paz es una cultura: seminario de investigación para la paz (pp. 507-536). Octavio y Félez, S. A.

JARES, X. R. (1997). El lugar del conflicto en la organización escolar. Revista Iberoamericana de Educación, 15(15), 5373. https://rieoei.org/historico/oeivirt/rie15a02.pdf.

Jolibert, J. (2002). Formar niños productores de texto. Dolmen.

Jolibert, J. (2009). Niños que construyen su poder de leer y escribir. Manantial.

Jorba, J. y SANMARTí, N. (1996). Enseñar, aprender y evaluar: un proceso de regulación continua. Propuesta didáctica para las áreas de Ciencias de la Naturaleza y Matemáticas. Ministerio de Educación Cultura.

KemBer, D. (1997). A Reconceptualization of the Research Into University Academics' Conceptions of Teaching. Learning and Instruction, 7(3), 255-275.

LERNER, D. (2001). Leer y escribir en la escuela: lo posible, lo real y lo necesario. Fondo de Cultura Económica.

LÉvinas, E. (2006). Humanismo del otro hombre. Siglo XXI Editores.

LEY 115 DE 1994. (1994, 8 de febrero). Congreso de la República de Colombia. Diario oficial No. 41.214. http://www. secretariasenado.gov.co/senado/basedoc/ley_0115_1994. html. 
Ley 1098 de 2006. Congreso de la República de Colombia. (2006, 8 de noviembre). Congreso de la República. Diario oficial No. 46.446. http://www.secretariasenado.gov.co/ senado/basedoc/ley_1098_2006.html.

Litwin, E. (2000). Las configuraciones didácticas. Una nueva agenda para la enseñanza superior. Paidós.

Litwin, E. (2008). El oficio de enseñar. Condiciones y contextos. Paidós.

Lomas, C. (Ed.). (2015). La educación lingüística, entre el deseo y la realidad. Octaedro Editorial.

LÓPEZ JIMÉNEZ, N. (1995). La reestructuración curricular de la educación superior: hacia la integración del saber. Icfes, Presencia.

López, N. (2007). Las nuevas leyes de educación en América Latina: Una lectura a raíz del panorama social de la región. Iipe, Clade.

Lundgren, L. (1997). Teoría del currículum y escolarización. Morata.

Maffesoli, M. (2004). El nomadismo. Vagabundeos iniciáticos. Fondo de Cultura Económica.

Magendzo, A. (2004). Formación ciudadana. Cooperativa Editorial Magisterio.

MAGNus, J. (2018). Evaluación formativa: actitudes y preferencias de los estudiantes en la escuela secundaria superior sueca [Tesis de doctorado, Universidad de Örebro]. 
Marquina, M. y Chiroleu, A. (2015). ¿Hacia un nuevo mapa universitario? La ampliación de la oferta y la inclusión como temas de agenda de gobierno en Argentina. Propuesta Educativa, (43), 7-16. https://www.redalyc.org/ pdf/4030/403041714003.pdf.

Martín-Barbero, J. (2001). Al sur de la modernidad. Comunicación, globalización y multiculturalidad. Instituto Internacional de Literatura Iberoamericana, University of Pittsburgh.

Martín-Barbero, J. (2010a). Comunicación y cultura mundo: nuevas dinámicas globales de lo cultural. Signo y Pensamiento, 29(57), 20-34.

. (2010b). Mutaciones culturales y estéticas de la política. Revista de Estudios Sociales, (35), 15-25. http://www.scielo. org.co/pdf/res/n35/n35a02.pdf.

Martínez Solís, M. C. (2006). Los géneros discursivos: situación de comunicación y situación de enunciación. DINTEV Cátedra UNESCO Lectura y Escritura. Universidad del Valle.

(2013). Los géneros desde una perspectiva socioenunciativa. La noción de contexto integrado. Revista Latinoamericana de Estudios del Discurso, 13(2), 21-40. https://raled.comunidadaled.org/index.php/raled/article/ view/51/53.

- (2015). La argumentación en la enunciación, la construcción del proceso argumentativo en el discurso. Universidad del Valle.

Mc Namee, S. (2015). Ethics as Discursive Potential. Australian and New Zealand Journal of Family Therapy, 36, 419-433. Doi: 10.1002/anzf.1125. 
Mayer, L. (2012). La escuela y la conflictividad cotidiana. Un análisis de las estrategias para su prevención y/o minimización [Tesis de doctorado, Universidad de Buenos Aires].

Mayer, L. y Cerezo, L. (2016). Tutorías y estipendio mensual: contribuciones a la trayectoria universitaria de jóvenes en situación de vulnerabilidad. Revista Latinoamericana de Ciencias Sociales, Niñez y Juventud, 14(2), 1421-1433. http:// www.scielo.org.co/pdf/rlcs/v14n2/v14n2a37.pdf.

Mejía, M. R. (2011). Educación y pedagogías críticas del sur. Ceaal.

MèLICH, J. C. (1997). Del extraño al cómplice: La educación en la vida cotidiana. Editorial Anthropos.

MèLich, J. C. (2000). Narración y hospitalidad. La Ausencia del testimonio. Editorial Anthropos.

Mialaret, G. (1966). Introducción a la pedagogía. Vicens-Vives.

Ministerio de Educación Nacional. (1998). Lineamientos curriculares de matemáticas. Ministerio de Educación Nacional.

Monereo, C. (2002). Estrategias de aprendizaje. Universitat Oberta de Catalunya.

Moreno, E. A. (2004). Concepciones de práctica pedagógica de la UPN. Revista de la Facultad de Artes Y Humanidades, (16), 105-129. https://revistas.pedagogica.edu.co/index.php/RF/ article/view/5919/4902.

Motsenbocker, P. (2018). Análisis comparativo de la evaluación basada en la competencia frente a la tradicional con respecto al rendimiento académico y los procesos de retroalimentación [Tesis de doctorado, Universidad de Chicago]. 
Mulder, M.; Weigel, T. y Collings. K. (2008). El concepto de competencia en el desarrollo de la educación y formación profesional en algunos Estados miembros de la UE: un análisis crítico. Profesorado. Revista de Currículum y Formación de Profesorado, 12(3), 1-25. https://www.redalyc.org/articulo. oa? id $=56712875007$.

Muñoz GonzÁlez, G. (2007). La comunicación en los mundos de vida juveniles. Revista Latinoamericana de Ciencias Sociales, Niñez y Juventud, 5(1), 283-308. http://www.scielo.org.co/ pdf/rlcs/v5n1/v5n1a09.pdf.

Muñoz GonzÁlez, G. (2011). De las culturas juveniles a las ciberculturas del siglo xxI. Revista Educación y Ciudad, (18), 19-32. http://vitela.javerianacali.edu.co/bitstream/ handle/11522/3004/Culturas_juveniles_ciberculturas. pdf;jsessionid=996E9B8C1DEC7D1531EA942C84DE5 39F? sequence $=1$.

Nirenberg, O. (2010). Enfoques para la evaluación de políticas públicas. En P. Amaya (Comp.), El Estado y las políticas públicas en América Latina. Editorial UNLP.

Nussbaum, M. (2012). Crear capacidades. Propuesta para el desarrollo humano. Paidós.

Ortiz Ocaña, A.; Arias López, M. I. y Pedroso Conedo, Z. E. (2018). Decolonialidad de la educación. Emergencial urgencia de una pedagogía decolonial. Editorial Universidad del Magdalena.

Ospina-Alvarado, M. C. (2014). Las familias: sistemas interaccionales y construcciones relacionales, dialógicas, sociales, culturales e históricas. En S. V. Alvarado y H. F. Ospina. Serie Latinoamericana de Niñez y Juventud (pp. 225263). Siglo del Hombre Editores, Universidad de Manizales, Cinde. 
Ospina-Alvarado, M. C. (Ed.). (2018). Construcción social de niños y niñas: familias, docentes y otros agentes relacionales. Universidad Pedagógica Nacional, Fundación Centro.

Ospina-Alvarado, M. C.; Alvarado, S. V; Cardona, L. M.; Alvarado, L. y Molina, E. (2018). Aproximación al estado del arte en primera infancia: memorias del conflicto armado y narrativas de paz. En S. V. Alvarado, M. C. OspinaAlvarado, J. A. Patiño López y M. A. Fajardo Mayo (Eds.). Aproximación a un estado de la cuestión sentidos y prácticas políticas de niños, niñas y jóvenes en territorios marcados por la violencia: paz, democracia, reconciliación y memoria (pp. 51-98). Fundación Centro Internacional de Educación y Desarrollo Humano (Cinde), Universidad de Manizales, Colciencias.

Ospina-Alvarado, M.C.;Alvarado,S.V.yFajardo,M.A.(2018). La niñez en contextos de conflicto armado comprendida desde el construccionismo social, la socialización política y las perspectivas alternativas del desarrollo humano: apuesta epistemológica desde el sur. En M. C. Ospina-Alvarado, S. V. Alvarado, J. A. Carmona Parra, A. Arroyo Ortega (Eds.). Construcción social de niñas y niños en contextos de conflicto armado: narrativas generativas para la construcción de paz (pp. 29-60). Universidad Pedagógica Nacional, Fundación Centro Internacional de Educación y Desarrollo Humano (Cinde), Universidad de Manizales, Colciencias.

PACE, I. (2018). Evaluación para el Aprendizaje (AFL) en un Maltese State College [Tesis de doctorado, Universidad de Sheffield].

PAGÉs, J. (2009b). Enseñar y aprender ciencias sociales en el siglo XxI: reflexiones casi al final de una década. Investigación en Educación, Pedagogía y Formación Docente, II Congreso Internacional. Universidad Pedagógica Nacional, Universidad de Antioquia, Corporación Interuniversitaria de Servicios. 
Peñaloza, M. L. y Quiceno, H. (2017). El campo de la evaluación educativa en Colombia. Bonaventuriana.

Pérez, M. y Rincón, G. (2009). Actividad, secuencia didáctica y pedagogía por proyectos: tres alternativas para la organización en el trabajo didáctico en el campo del lenguaje. CERLALC.

Perrenoud, P. (2007). Desarrollar la práctica reflexiva en el oficio de enseñar. Editorial Graó.

Piussi, A. M. (2013). Volver a empezar. Entre vida, política y educación: prácticas de libertad y conflictos fecundos. DUODA: estudis de la diferència sexual, (45), 2235. https://www.raco.cat/index.php/DUODA/article/ view/271403/359032.

Porlan, R. (2000). Hacia un modelo de enseñanza-aprendizaje de las ciencias por investigación. En M. Kaufman y L. Fumagali. (Eds.), Enseñar ciencias naturales. Reflexiones y propuestas didácticas (pp. 23-64). Paidós educador.

Posner, G. (2005). Análisis del currículo. MacGraw-Hill.

Scheuer, N.; Pozo Municio, J. I.; Pérez Echeverría, M.; Mateos Sanz, M.; Martín Ortega, E. y de la Cruz, M. (2006). Nuevas formas de pensar la enseñanza y el aprendizaje: las concepciones de profesores y alumnos. Grao.

Preal. (2008). Sistemas de evaluación de aprendizajes en América Latina. Balances y desafios. Preal. http://www.Preal.org/ BibliotecaDes.asp? $\mathrm{id}=1064 \&$ Camino $=315$.

Pujol, R. M. (2007). Didáctica de las ciencias en la educación primaria. Síntesis Educación. 
Quijano, A. (1980). Los usos de la democracia burguesa. Sociedad y Política, (10), 545-568. http://biblioteca.clacso.edu.ar/ gsdl/collect/clacso/index/assoc/D9647.dir/eje2-5.pdf.

. (1981). Poder y democracia en el socialismo. Sociedad $y$ Política, 3(12), 33-50. http://biblioteca.clacso.edu.ar/ clacso/se/20140506052228/eje2-6.pdf.

. (1987). La tensión del pensamiento latinoamericano. Hueso Húmero, (22), 106-113. http://biblioteca.clacso.edu. ar/clacso/se/20140507093456/eje3-3.pdf.

. (1988). Modernidad, identidad y utopía en América Latina. Sociedad y Política Ediciones.

. (1993). América Latina en la economía mundial. Problemas de desarrollo, 24(95), 43-59. http://www.revistas. unam.mx/index.php/pde/article/view/32381/29776.

- (2000). Colonialidad del poder, eurocentrismo y América Latina. En E. Lander (Comp.). La colonialidad del saber: eurocentrismo y ciencias sociales (pp. 201-246). Clacso. http://bibliotecavirtual.clacso.org.ar/ar/libros/lander/ quijano.rtf.

Ramos, E. (2003). El desarrollo de la educación por la paz: un camino de obstáculos y oportunidades. Educación, 21(6), 129-146. http://revistas.uned.es/index.php/educacionXX1/ article/view/355/308.

Reguillo, R. (1999a). La construcción simbólica de la ciudad. Sociedad, desastre, comunicación. Iteso.

. (1999b). Ciudadano N. crónicas de la diversidad. Iteso. . (2000). Emergencia de culturas juveniles. Estrategias del desencanto. Norma. 
- (2005). Horizontes fragmentados. Comunicación, cultura, pospolítica. El (des)orden global y sus figuras. Iteso.

- (2012). Culturas juveniles: formas políticas del desencanto. Siglo XXI Editores.

Martínez Rizo, M. (2012). La evaluación formativa del aprendizaje en el aula en la bibliografía en inglés y francés. Revisión de literatura. Revista Mexicana de Investigación Educativa, 17(54), 849-875. https://www.redalyc.org/articulo. oa?id=14023127008.

Rockwell, E. (2005). La escuela cotidiana. Fondo de Cultura Económica.

Rodrigo, M. J. (1997). La construcción del conocimiento escolar. Paidós.

Rodrigo, M.; Rodríguez, A. y Marrero, J. (1993). Las teorías implícitas. Una aproximación al conocimiento cotidiano. Aprendizaje Visor.

Runge-Peña, A. K. (1996). Formación y comprensión en la obra de Rafael Flórez. Revista Educación y Pedagogía, 7(14-15), 220-235. http://bibliotecadigital.udea.edu. co/bitstream/10495/3182/1/RungeAndre_1995_ formacioncomprensionobrarafaelflorez.pdf.

. (2002). Formación post-humana en los tiempos de los nuevos medios y de las nuevas tecnologías. Algunas reflexiones antropológico-pedagógicas. Revista Educación y Pedagogía, 14(33), 1-20. https://revistas.udea.edu.co/index. $\mathrm{php} /$ revistaeyp/article/view/24806/20229. 
. (2005). Reflexiones pedagógicas sobre la investigación y la docencia universitarias a la luz de la formación: el modelo humboldtiano como ejemplo. Uni-Pluriversidad, 5(2), 1-20. https://revistas.udea.edu.co/index.php/unip/article/ view/12151/11032.

(2011). Jean-Jacques Rousseau: cuerpo, educación y formación. Perspectivas filosóficas, antropológicas y pedagógicas. Intempo.

(2012). La tematización de sí en la formación docente: una mirada antropocrítica. Edipucrs.

(2013). Didáctica: una introducción panorámica y comparada. Itinerario Educativo, 27(62), 201-240.

. (2014). Los espacios pre-escolares vivenciados y narrados por niños y niñas: estudios sobre la formación de la infancia desde un enfoque fenomenográfico-narrativo. São Editora CRV.

Runge-Peña, A. K. y Garcés-Gómez, J. F. (2010). Alcances y limitaciones de la formación de maestros desde la perspectiva de las competencias en la resolución 5443 del 30 de junio de 2010: ¿aún es la pedagogía el saber fundante de la formación de maestros. Revista Educación y Pedagogía, 22(57), 187199. https://revistas.udea.edu.co/index.php/revistaeyp/ article/view/7404/6840

- (2011). Educabilidad, formación y antropología pedagógica: Repensar la educabilidad a la luz de la tradición pedagógica Alemana. Guillermo De Ockham, 9(2), 13-25. 
Runge-Peña, A. K. y Muñoz-Gaviria, D. A. (2006). Individualización y formación universitaria en la sociedad de riesgo. Reflexiones a propósito del trabajo de Ulrich Beck. Uni-Pluriversidad, 6(3), 33-44. https://revistas.udea.edu.co/ index.php/unip/article/view/11938/10818.

. (2012). Pedagogía y praxis (práctica) educativa o educación. De nuevo: una diferencia necesaria. Revista Latinoamericana de Estudios Educativos, 8(2), 75-96. https://www.redalyc.org/pdf/1341/134129257005.pdf.

Runge-Peña, A. K.; Pineres-Sus, J. D. e Hincapié García, A. (2007). Una mirada pedagógica a la imagen, la imaginación y la formación humana, tomando como ejemplo el Orbis sensualium pictus de Juan Amós Comenio. Revista Educación y Pedagogía, 19(47), 71-97.

Salguero, J. (2004). Educar para la paz. El caso de un país dominado por la violencia: Colombia [Tesis de doctorado, Universidad Complutense de Madrid].

Sánchez, M. C., Alvarado, S. V. y Ospina-Alvarado, M. C. (2018). Narrativas de Memoria: aprendizajes éticos y políticos con niños y niñas en contextos de conflicto. En Alvarado, S. V., Ospina-Alvarado, M. C., Patiño, J. y Fajardo, M. A. (eds.). Aproximación a un Estado de la Cuestión Sentidos y Prácticas Políticas de Niños, Niñas y Jóvenes en Territorios marcados por la Violencia: Paz, Democracia, Reconciliación y Memoria. Editorial CINDE-Universidad de Manizales. Bogotá: Universidad Pedagógica Nacional-CINDE.

Santisteban, A. (2009). El conocimiento de lo Social. [Programa de doctorado en Didáctica de las Ciencia Sociales]. Universidad Autónoma de Barcelona.

Savater, F. (2000). El valor de educar. Editorial Ariel. 
Schwartzman, S. y Cox, C. (Eds.). (2009). Politicas educativas y cohesión social en América Latina. Uqbar.

SEN, A. (2000). Desarrollo y libertad. Planeta.

Serna, J. (2004). Paradigmas filosóficos y sus implicaciones curriculares. Rudecolombia.

Serres, M. (1995). Atlas. Éditions Julliard.

Schunk, D. (2012). Teorías del aprendizaje. Pearson.

SOSENSKi, S. (2015). ENSEÑAR HISTORIA DE LA INFANCIA A LOS NIÑos y NIÑAS: ¿PARA QUÉ? REVISTA TEMPO E ARGUMENTO, $7(14), 132154$.

Stenhouse, L. (1998). Investigación y desarrollo del Currículum. Morata.

Stufflebeam, D. L. (1987). Evaluación sistemática. Guía teórica y práctica. Paidós.

Tamayo Alzate, O. E (2012). La argumentación como constituyente del pensamiento crítico en niños. Hallazgos, 9(17), 211-233.

Tamayo Alzate, O. E. (2013). Modelos y modelización en la enseñanza y el aprendizaje de las ciencias. $\mathrm{x}$ Congreso Internacional sobre Investigación en Didáctica de las Ciencias.

TARdif, M. (2004). Los saberes del docente y su desarrollo profesional. Narcea.

Tinto, V. (2006). Research and Practice of Student Retention: What is Next? Journal of Collegestudent Retention, 8(1), 1-19. 
Torres, C. (2008). Después de la tormenta neoliberal: la política educativa latinoamericana entre la crítica y la utopía. Revista Iberoamericana de Educación, (48), 207-229. https://rieoei. org/historico/documentos/rie48a10.pdf.

Urresti, M. (1999). Cambio de escenarios sociales, experiencia juvenil urbana y escuela. En E. Tenti-Fanfani (Comp.) Una escuela para los adolescentes. Iipe, Unesco, Ministerio de Educación de la Provincia de Santa Fe, Unicef, Oficina de Argentina.

Uzuriaga, V.; Castro, F. y Sánchez, G. (2020). Indagación del docente durante su propia práctica. En J. Adler. Teachers of Mathematics Working and Learning in Collaborative Groups. University of Lisbon.

Valenzuela, J. M. (2015). Cuerpos en red y movimientos juveniles. En A. Hernández y A. Campos (Coords.), Actores, redes y desafíos. Juventudes e infancias en América Latina. El Colegio de la Frontera Norte.

VAsco, E. (2001). El saber tiene sentido. Una propuesta de integración curricular. Anthropos.

VAsco Uribe, C. E. (1990). Algunas reflexiones sobre la pedagogía y la didáctica. En M. Díaz y J. Muñoz. Pedagogía, discurso y poder (pp. 107-119). Editorial El Griot.

Vidales, I. y Maggi, R. (Eds.). (2007). La democracia en la escuela. Un sueño posible. Colegio de Estudios Científicos y Tecnológicos.

De Vincenzi, A. (2009). Concepciones de enseñanza y su relación con las prácticas docentes: un estudio con profesores universitarios. Educación y Educadores, 12(2), 87-101. https://www.redalyc.org/pdf/834/83412219006.pdf. 
Walsh, C. (2014). Lo pedagógico y lo decolonial. Entretejiendo Caminos.

WEIsz, C.B. (2017). La representación social como categoría teórica y estrategia metodológica. Revista CES Psicología, 10(1), 99108. http://www.scielo.org.co/pdf/cesp/v10n1/2011-3080cesp-10-01-00099.pdf.

Wittrock, M. (1997). La investigación de la enseñanza, III Profesores y alumnos. Paidós.

Zabala, A. (2008). La práctica Educativa. Cómo enseñar. Editorial Graó.

ZAYAs, F (2006). Hacia una gramática pedagógica. En A. Camps y F. Zayas (Coords.). Secuencias didácticas para aprender gramática (pp. 17-30). EditorialGraó.

- (2011). La educación literaria. Cuatro secuencias didácticas. Octaedro.

Trabajos de grado de maestría y tesis de doctorado citados

EC/043/001/D Arias Murillo, F. A. (2010). La emergencia del hombre en la formación de maestros en Colombia. Segunda mitad del siglo XX. [Tesis de Doctorado en Ciencias Sociales, Niñez y Juventud, Universidad de Manizales].

EC/043/002/D PatiÑo Giraldo, L. E. (2010) La lengua de señas colombiana como mediadora en el proceso de conceptualización de nociones espaciales relacionadas con las ciencias sociales en niños y niñas no oyentes de una ciudad intermedia de los Andes colombianos. [Tesis de Doctorado en Ciencias Sociales, Niñez y Juventud, Universidad de Manizales]. 
EC/043/04/D Osorio Vargas, A. E. (2010). Desarrollo de competencias para la lectura comprensiva de textos científicos en el ámbito universitario. [Tesis de Doctorado en Ciencias Sociales, Niñez y Juventud, Universidad de Manizales].

EC/043/005/D Alvarado, S. y López, L. (2011). Emergencia de las relaciones intergeneracionales: un análisis genealógico de las prácticas discursivas en una escuela pública urbana. [Tesis de Doctorado en Ciencias Sociales, Niñez y Juventud, Universidad de Manizales].

EC/o43/oo6/D Palacios Mena, N. (2010). Derechos, socialización y subjetividad política en la escuela. [Tesis de Doctorado en Ciencias Sociales, Niñez y Juventud, Universidad de Manizales].

EC/043/oo7/D Mejía Franco, D. N. (2012). Elementos estructurales de los videojuegos potencialmente educativos, para el desarrollo de temáticas escolares relacionadas con el pensamiento espacial en niños y niñas entre 8 y 10 años. [Tesis de Doctorado en Ciencias Sociales, Niñez y Juventud, Universidad de Manizales].

EC/043/o11/D. Alvarado, S. y Carreño, M. (2012). Concepciones de participación de los estudiantes de derecho en Colombia. [Tesis de Doctorado en Ciencias Sociales, Niñez y Juventud, Universidad de Manizales].

EC/043/013/D Londoño VÁsquez, D. A. (2013). Análisis sociolingüístico de los niveles de literacidad en jóvenes de la institución universitaria de Envigado. [Tesis de Doctorado en Ciencias Sociales, Niñez y Juventud, Universidad de Manizales]. 
EC/043/015/D Aguirre Dávila,E. (2013).Relaciónentreprácticas de crianza, temperamento y comportamiento prosocial de niños de $5^{\circ}$ y $6^{\circ}$ grado. [Tesis de Doctorado en Ciencias Sociales, Niñez y Juventud, Universidad de Manizales].

EC/o43/o17/D Martínez Morales, E. M. (2014). Base emocional de la ciudadanía. Narrativa de emociones morales de estudiantes de noveno grado de dos instituciones escolares de la cuidad de Bogotá. [Tesis de Doctorado en Ciencias Sociales, Niñez y Juventud, Universidad de Manizales].

EC/043/o19/D VÉlez, C. Y Jurado, C. (2014). Enfoques de extensión rural en programas profesionales agropecuarios. Comprensión de imaginarios desde la voz de sus actores. [Tesis de Doctorado en Ciencias Sociales, Niñez y Juventud, Universidad de Manizales].

EC/043/022/D Herrera, J. y Palacios, N. (2015). La pasión de aprender. El punto de vista de los estudiantes universitarios. [Tesis de Doctorado en Ciencias Sociales, Niñez y Juventud, Universidad de Manizales].

EC/o43/o24/D González Melo, H. S. (2016). Caracterización del saber pedagógico de los profesores del Proyecto Académico de Investigación y Extensión de Pedagogía -PAIEP- en la Universidad Distrital Francisco José de Caldas. [Tesis de Doctorado en Ciencias Sociales, Niñez y Juventud, Universidad de Manizales].

EC/o43/o28/D Alvarado, S.; Artiles, L. y Ceballos, R. (2016). Para cambiar la cara de la escuela. Sistematización de la propuesta socioeducativa del centro Oveda de la república dominicana. Doctorado en ciencias sociales, niñez y juventud. [Tesis de Doctorado en Ciencias Sociales, Niñez y Juventud, Universidad de Manizales]. 
EC/043/029/D Alvarado, S. y Arias, A. (2016). Relaciones sociales en la universidad: poder, conflicto y pluralidad entre jóvenes. [Tesis de Doctorado en Ciencias Sociales, Niñez y Juventud, Universidad de Manizales].

EC/043/031/D OCAmpo, E. (2017). Modelos mentales sobre aprendizaje en estudiantes de Pedagogía Infantil. [Tesis de Doctorado en Ciencias Sociales, Niñez y Juventud, Universidad de Manizales].

EC/051-01/o07/M Garzón Díaz, A.; Muñoz Narváez, C. X. Y QuiÑones DíAZ, W. H. (2012). El tiempo curricular en la reconstrucción de las identidades de niños, niñas y jóvenes en situaciones de vulnerabilidad: una mirada de las concepciones y prácticas de los maestros. [Tesis de Maestría en Educación desde la Diversidad, Universidad de Manizales].

EC/051-1/008/M. IsazA, G. Alvarez, A y JURADO, c. (2012). Implicaciones interdisciplinarias para para una Educación desde el contexto. [Tesis de Maestría en Educación desde la Diversidad, Universidad de Manizales].

EC/051-1/009/M. Menjura, M.; GuZMÁn, E. y MuÑoz, J. (2012). La convivencia escolar: Una mirada desde la diversidad cultural. [Tesis de Maestría en Educación desde la Diversidad, Universidad de Manizales]. Implicaciones interdisciplinarias LA CONVIVENCIA ESCOLAR: UNA MIRADA DESDE LA DIVERSIDAD CULTURAL. MaEstría EN EDUCACIÓN DESDE LA DIVERSIDAD.

EC/051-01/015/M Castro, J.; Bravo, F. y Grisales, M. (2013). Diferentes miradas acerca de las causas del desempeño bajo en los estudiantes de la institución educativa Vasco Núñez de Balboa, Cauca -Colombia. [Tesis de Maestría en Educación desde la Diversidad, Universidad de Manizales]. 
EC-051-1-017-M. Isaza, G.; MuÑoz, W.; Ortega, B. y Ríos, A. (2013). El desarrollo emocional de los niños y niñas en situación de vulnerabilidad social. [Tesis de Maestría en Educación desde la Diversidad, Universidad de Manizales].

EC/051-01/020/M. Agredo, J. y Burbano, T. (2013). El pensamiento crítico, un compromiso con la educación. [Tesis de Maestría en Educación desde la Diversidad, Universidad de Manizales].

EC/051-01/025/M EnríQueZ, R.; GuIllermo, J. y Ríos, A. (2013). La evaluación de contenidos como herramienta para generar pensamiento crítico: una mirada desde las prácticas de los maestros de tres instituciones educativas del departamento del Cauca. [Tesis de Maestría en Educación desde la Diversidad, Universidad de Manizales].

EC/051-01/032-M Quintero FigueroA, Y. M. Y Quintero Figueroa, N. M. (2014). Aportes para el trabajo lúdico pedagógico en contexto rural, desde las percepciones diversas de los niños de $4^{\circ}$ de primaria, de la Institución Educativa El Tigre. Manizales. [Tesis de Maestría en Educación desde la Diversidad, Universidad de Manizales].

EC/051-01/035/M Medina Galvis, S. N.; Rosero Getial, O. Y.; Bolaños Bravo, L. E.; Goyes Chamorro, J. A. y Cabrera CAsabón, A. (2014). Desarrollo de habilidades metacognitivas para el aprendizaje de las matemáticas a través de una didáctica basada en problemas y mediada por los juegos autóctonos y tradicionales, en estudiantes de grado $5^{\circ}$ de básica primaria de la escuela Normal Superior de Pasto, en el marco de una escuela inclusiva. [Tesis de Maestría en Educación desde la Diversidad, Universidad de Manizales]. 
EC/051-01/036/M Ortega Ordoñez, Y. E., Galeano Bolaños, S. M. (2014). Desarrollo de las habilidades relativas al pensamiento creativo. Estudio reflexivo y crítico. [Tesis de Maestría en Educación desde la Diversidad, Universidad de Manizales].

EC/051-01/038/M Pantoja Vallejo, M.; Chauza Domínguez, L. D.; Cabrera Arcos, J. A. y Bastidas Bastidas, D. C. (2014). Didáctica no parametral mediada por la minga de saberes y las TIC en el aprendizaje de la educación ambiental, para el desarrollo de habilidades metacognitivas en estudiantes de grado noveno de la Institución Educativa Cunchila. [Tesis de Maestría en Educación desde la Diversidad, Universidad de Manizales].

EC/051-01/039-M. Ruiz Calvache, M.; Coral Delgado, F. R. y Almeida Mejía, M. F. (2014). Didáctica problematizadora para la configuración del pensamiento crítico, en el marco de la atención a la diversidad. [Tesis de Maestría en Educación desde la Diversidad, Universidad de Manizales].

EC/051-01/040/M QuiÑonez DaZa, M.; Martínez Ruiz, I.; ZÚÑiga QUisoboni, D. H. (2014). Diferencias y semejanzas en las estrategias de aprendizaje de las operaciones básicas matemáticas en contextos: de escolarización y no escolarización. [Tesis de Maestría en Educación desde la Diversidad, Universidad de Manizales].

EC/051-01/041/M, Molina, A, Ríos, A Y Guarín, G (2014). Maestros intelectuales en la Educación Colombiana. [Tesis de Maestría en Educación desde la Diversidad].

EC/051-01/042/M. Andrade, P.; Ibarra, A.; Ortega, M. Y Pineda, J. (2014). El valor político de la educación. [Tesis de Maestría en Educación desde la Diversidad, Universidad de Manizales]. 
EC/051-01/043/M PeÑa, P.; SÁnCheZ, J.; RAmíreZ, J. y Menjura, M. (2015). Concepciones y modelos de gestión sobre convivencia escolar de directivos y docentes de instituciones educativas del sector público y privado. [Tesis de Maestría en Educación desde la Diversidad, Universidad de Manizales].

EC/051-01/044/M. Burbano, A.; Muñoz, D. y Gil, G. (2015). Configuración de sujetos para la paz en escenarios educativos incluyentes a partir de los aportes de la pedagogía de la esperanza de paulo freire. [Tesis de Maestría en Educación desde la Diversidad, Universidad de Manizales].

EC/051-01/045/M Samboni, A.; Nieto, N.; Argote, L.; Argote, O.; RuIZ, A. Y MejíA, M. (2015). Construcción de pensamiento crítico: alternativa de desarrollo social a través de la educación no formal en algunos habitantes de la vereda "Buenavista" del municipio de Cajibío, departamento del Cauca (Colombia). [Tesis de Maestría en Educación desde la Diversidad, Universidad de Manizales].

EC/051-01/049/M Cortez Solar, A. R. y Mera Prieto, I. Y. (2015). El reconocimiento de los "otros" a través del juego en la didáctica de las matemáticas permite dinamizar las aulas inclusivas. [Tesis de Maestría en Educación desde la Diversidad, Universidad de Manizales].

EC/O51-01/050/M Restrepo Quiñones, L. D., Moncada Lopera I. C., Chaux Tabarez, D. P. (2015). Estrategia didáctica en el español como lengua extranjera para la escritura en personas sordas. [Tesis de Maestría en Educación desde la Diversidad, Universidad de Manizales].

EC/051-01/053/M Palacio, Y.; Quejada, N. Y RodrígueZ, W. (2015). Impacto de las políticas educativas para el reconocimiento de la diversidad cultural afrocolombiana en el municipio de turbo, Antioquia. [Tesis de Maestría en Educación desde la Diversidad, Universidad de Manizales]. 
EC/051-01/056/M; Velazco Vidal, N. C. y Rodríguez Argote, A. M. (2015). La educación artística: una práctica pedagógica en la formación de sujetos diversos. [Tesis de Maestría en Educación desde la Diversidad, Universidad de Manizales].

EC/051-01/057/M Martínez, J.; Mesa, M.; Piarpuzan, L. Y Mejía, M. (2015). La educación musical: alternativa pedagógica de transformación social. [Tesis de Maestría en Educación desde la Diversidad, Universidad de Manizales].

EC/051-01/058/M Yonda, M.; Obregón, J. Y Quijano, O. (2015). La escuela como dispositivo de sujeción o espacio para la subjetivación. Una lectura en contextos locales. [Tesis de Maestría en Educación desde la Diversidad, Universidad de Manizales].

EC/051-01/059/M Guapucal Cuasanchir, M. E. y Jaguandoy Chamorro, M. Y. (2015). La formación docente como estrategias pedagógicas para fortalecer la atención a estudiantes con necesidades educativas diversas en la Institución Educativa Luis Irizar Salazar del municipio de Barbacoas (NAR). [Tesis de Maestría en Educación desde la Diversidad, Universidad de Manizales].

EC/51-01/o64/M Timaná Sánchez, C.; Timaná Sánchez, D. O.; Rodríguez González, J. A. (2015). Los Significados y Sentidos sobre Diversidad en los Niños (as) de Tercero y Cuarto de Educación Básica Primaria del Sector Rural de la Institución Educativa San Alejandro del Municipio de Guaitarilla. [Tesis de Maestría en Educación desde la Diversidad, Universidad de Manizales].

EC/051-01/069/M. Toro-Marín, S. P. y Quintar, E. B. (2016). El aula como espacio de reconocimiento: una mirada desde la sobreexigencia [Tesis de Maestría en Educación desde la Diversidad, Universidad de Manizales]. 
EC/051-01/072/M. Arango Tutalchac, S. C. (2016). La didáctica desde la educación artística: Una práctica del quehacer pedagógico para la formación en la diversidad. [Tesis de Maestría en Educación desde la Diversidad, Universidad de Manizales].

EC/O51-01/075/M Rodríguez Chávez, J. O. y Armero Chávez, P. A. (2016). La lúdica en el desarrollo del pensamiento lógico matemático en los estudiantes del grado primero de la institución educativa municipal ITSIM sede San Vicente II de la ciudad de San Juan de Pasto. [Tesis de Maestría en Educación desde la Diversidad, Universidad de Manizales].

EC/051-01/079/M QuiÑones, M. Y GuARÍN, G. (2017). Recuperación de la memoria desde la ciudadanía por el colectivo cartografías, en el centro de memoria, paz y reconciliación de Bogotá, D.C. [Tesis de Maestría en Educación desde la Diversidad, Universidad de Manizales].

EC/051-01/o80/M Angulo, S.; Arias, D.; Fajardo, J.; Salazar, W.; Timaran, C.; Serna, A. Y Cadavid, A. (2017). Transformaciones desde el lenguaje en el reconocimiento del maestro. [Tesis de Maestría en Educación desde la Diversidad, Universidad de Manizales].

EC/051-02/003/M Orozco Rubio, M. (2010). Confiabilidad y validez predictiva de prueba de evaluación de inteligencias múltiples de las estudiantes de grado $7^{\circ}$ y $9^{\circ}$ del Colegio Eugenia Ravasco de Manizales. [Tesis de Maestría en Educación desde la Diversidad, Universidad de Manizales].

EC/051-02/006/M Ordoñez, G. Y Gómez E. (2011). Representaciones sociales sobre la escuela que presentan un grupo de niñas internas de una institución educativa de la zona centro del Departamento del Huila. [Tesis de Maestría en Educación desde la Diversidad, Universidad de Manizales]. 
EC/051-02/oo8/M Farfán, M, Álzate, C, y Arias, G. (2011). Factores motivacionales de la población en proceso de reintegración social y económica para su ingreso $y$ permanencia en el sistema educativo, área metropolitana de Risaralda durante el año 2010: estudio cualitativo realizado con participantes del proceso de reintegración en el área metropolitana de Risaralda. [Tesis de Maestría en Educación desde la Diversidad, Universidad de Manizales].

EC/051-02/o09/M. Álvarez, A, Y García, C. (2012). Las prácticas de crianza en primera infancia como tecnologías de poder en el contexto familiar y en el contexto educativo. [Tesis de Maestría en Educación desde la Diversidad, Universidad de Manizales].

EC/051-02/010/M Palma Cuervo, R. (2012). Pensamiento integral y creatividad en estudiantes del Colegio San José de Pereira, Risaralda. [Tesis de Maestría en Educación desde la Diversidad, Universidad de Manizales].

EC/051-02/014/M Bejarano, L, Galván, F, y López, B. (2013). Pensamiento crítico y motivación hacia el pensamiento crítico en estudiantes de psicología. [Tesis de Maestría en Educación desde la Diversidad, Universidad de Manizales].

EC/051-02/016/M Guzmán, A. y Amador, P. (2014). Prácticas discursivas sobre agencia política de jóvenes en contextos de vulnerabilidad y violencia en la Institución Educativa Liceo Mixto Sinaí de la Comuna \# 5 "Ciudadela del arte" de la ciudad de Manizales-Caldas-Colombia. [Tesis de Maestría en Educación desde la Diversidad, Universidad de Manizales].

EC/051-02/017/M Bermudez Pacheco, A. (2014). Prácticas discursivas de la salud mental de los jóvenes de la Institución Educativa Belisario Peña Piñeiro IEBPP del municipio de Roldanillo Valle del Cauca. [Maestría en Educación y Desarrollo Humano, Universidad de Manizales]. 
EC/051-02/018/M Castañeda, A, y Salazar, M.(2014).Prácticas discursivas de la agonía institucional de niños en contexto de vulnerabilidad en la corporación superarse y el centro juvenil amigoniano. [Maestría en Educación y Desarrollo Humano, Universidad de Manizales].

EC/051-02/019/M HenaO, C. y Salazar, M. (2014). Prácticas discursivas de jóvenes sobre la sanción escolar en la escuela pública, (institución educativa Nuestra Señora del Carmen, municipio de La Dorada Caldas). [Maestría en Educación y Desarrollo Humano, Universidad de Manizales].

EC/051-02/020/M JimÉneZ, D.; Franco, J. y SAlazAR, M. (2014). Formas y expresiones de la capacidad de agencia de un grupo de jóvenes del servicio social estudiantil. [Maestría en Educación y Desarrollo Humano, Universidad de Manizales].

EC/051-02/022/M Capera Cardoso, I. C. y Torres López, A. Y. (2014). Sentidos y Prácticas Frente a la Relación FamiliaEscuela en Comunidades Indígenas Etnias: "Nasa" de Cajibio Cauca y "Pijao" de Coyaima - Tolima. [Maestría en Educación y Desarrollo Humano, Universidad de Manizales].

EC/051-02/025/M López Chaparro L. Y. (2014) Caracterización de las habilidades cognitivas y las disposiciones para el pensamiento crítico en universitarios de una institución privada de la ciudad de Bucaramanga. [Maestría en Educación y Desarrollo Humano, Universidad de Manizales].

EC/051-02/027/M Martínez Patiño, M. J. (2014). Las Inscripciones Murales como Prácticas de Resistencia. [Maestría en Educación y Desarrollo Humano, Universidad de Manizales]. 
EC/051-02/028/M DíAz SepúlvedA, R. (2014). La Paz Imperfecta en la Escuela. Narraciones y Prácticas de Compasión en Clave de Capacidades Emocionales de Martha Nussbaum. [Maestría en Educación y Desarrollo Humano, Universidad de Manizales].

EC/051-02/029/M Ruiz, R, Riascos, Y, y Amador, L. (2014). Imaginarios y representaciones sociales sobre emigración como alternativas de éxitos en los educandos afrocolombianos de los grados $10^{\circ}$ y $11^{\circ}$ de la institución educativa José Ramón Bejarano, distrito de Buenaventura. [Maestría en Educación y Desarrollo Humano, Universidad de Manizales].

EC/051-02/030/M Henao, R, López, D, Mosquera, E, Pardo, N, y LoAiza, J. (2014). Narrativas de jóvenes sobre los sentidos de convivencia pacífica en la escuela. [Maestría en Educación y Desarrollo Humano, Universidad de Manizales].

EC/051-02/032/M Restrepo, S.; Serna, F.; Serna, P. y Salazar, M. (2014). Prácticas políticas y agencia juvenil en los jóvenes del colegio fe y alegría la paz del barrio el Caribe de la comuna ciudadela del norte. [Maestría en Educación y Desarrollo Humano, Universidad de Manizales].

EC/051-02/033/M Salazar L., Plata, I. C. y Cristina Drada, S. (2014). Mujeres y arte en la construcción de una cultura de paz. [Maestría en Educación y Desarrollo Humano, Universidad de Manizales].

EC/051-02/034/M Herrera, X, Gómez, Y, y Ramírez, C. (2014). Sentidos de Pensamiento Crítico que se constituyen desde la participación de jóvenes de una experiencia de Educación Popular. [Maestría en Educación y Desarrollo Humano, Universidad de Manizales]. 
EC/051-02/036/M Contreras, A, Jaramillo, K, Tovar, S, y Castellanos, J. (2015). Prácticas pedagógicas de los agentes educativos que promueven la participación de niñas y niños entre los dos y cinco años en doce centros de atención tradicional e integral del ICBF. Maestría en educación y desarrollo humano. Manizales democracia desde la perspectiva de narrativas generativas de niños y niñas. La paz: una construcción social desde la escuela. [Maestría en Educación y Desarrollo Humano, Universidad de Manizales].

EC/051-02/037/M Espinosa, C. (2015). Procesos de construcción social de la niñez en contextos de conflicto armado en el eje cafetero, Antioquia y Área metropolitana de Bogotá: La paz, la reconciliación y la democracia desde la perspectiva de narrativas generativas de niños y niñas. La paz: una construcción social desde la escuela. CINDE

EC/051-02/041/M Fernández, O.; Gómez, A. Y SÁnchez, C. (2015). Los aportes de la educación experiencial a la constitución de jóvenes como sujetos políticos. [Maestría en Educación y Desarrollo Humano, Universidad de Manizales].

EC/051-02/043/M Giraldo Velásquez, R. (2015). Perspectivas del Desarrollo Humano desde el Sujeto Politico del Programa "Jóvenes En Acción. [Maestría en Educación y Desarrollo Humano, Universidad de Manizales].

EC/051-02/044/M Nieto Silva, S. X. (2015). Modelos Mentales de Prácticas de Crianza en Madres de Estudiantes que Presentan Signos de Castigo Físico. [Maestría en Educación y Desarrollo Humano, Universidad de Manizales].

EC/051-02/045/M. Palomino Angarita, D. M. (2016). Procesos de regulación metacognitiva que desarrollan los estudiantes de tercer grado de básica primaria en la producción escrita de textos narrativos. [Maestría en Educación y Desarrollo Humano, Universidad de Manizales]. 
EC/051-02/046/M Alarcón, D. I. (2016). Relación entre autoeficacia y autorregulación en el aprendizaje en estudiantes de primer grado del nivel de educación básica. [Maestría en Educación y Desarrollo Humano, Universidad de Manizales].

EC/051-02/048/M Osorio L. D.; Muñoz Torres, M. E. Y Carmona Ocampo, K. J. (2016). Desarrollo de pensamiento crítico en ciencias naturales a través de un semillero de investigación. [Maestría en Educación y Desarrollo Humano, Universidad de Manizales].

EC/051-02/049/M Ramos, K. y Orrego, J. (2016). Vivencias de los espacios del aula en grado transición: un aporte a la comprensión de las prácticas pedagógicas de Maestras de los municipios de salado blanco y Elías- Huila. [Maestría en Educación y Desarrollo Humano, Universidad de Manizales].

EC/051-02/051/M Rendón Monsalve, S. M., Calderón Lindarte, L. K. y Osorio López, X. (2016). Estrategias de regulación metacognitiva en entornos virtuales de aprendizaje. [Maestría en Educación y Desarrollo Humano, Universidad de Manizales].

EC/051-02/052/M García VAREla, L. F. (2016). El cine como herramienta para la sensibilización ambiental: piloto para estudiantes de contaduría pública nocturna. Fundación Universitaria de Popayán. [Maestría en Educación y Desarrollo Humano, Universidad de Manizales].

EC/051-02/054/M Mosquera, M. V. (2016). Sentidos de la formación ciudadana en jóvenesparticipantes en el proyecto integrador Rap Social en laInstituciónEducativa Oficial- IEOINEM de Santiago de Cali - Valle del Cauca. [Maestría en Educación y Desarrollo Humano, Universidad de Manizales]. 
EC/051-02/056/M Zapata Herrera, O. M. y Blandón Henao, G. (2016). El Grafiti. Formas De Comunicación Emergentes En La Escuela. [Maestría en Educación y Desarrollo Humano, Universidad de Manizales].

EC/051-02/059/M Botero Carvajal, A. (2017). Modelos mentales de pensamiento crítico en actividades de escritura en estudiantes y docentes universitarios. [Maestría en Educación y Desarrollo Humano, Universidad de Manizales].

EC/051-02/06o/M Noreña Amaya, M. A. y Betancourth Llano, G. A. (2017). Las huellas vitales como generadoras de procesos de transformación de las prácticas pedagógicas. [Maestría en Educación y Desarrollo Humano, Universidad de Manizales].

EC/051-02/061/M Hincapié, A. y Hernán, M. (2017). Prácticas universitarias estudiantiles en la Universidad de Manizales como aporte a la construcción de Cultura de Paz. [Maestría en Educación y Desarrollo Humano, Universidad de Manizales].

EC/051-02/062/M Bedoya Quintero, B. Y.; Grisales Zamora, C. Y Jiménez Osorio, L. D. (2017). Relación entre Rendimiento Académico y el Contexto Social y Familiar en los Estudiantes de Grado $5^{\circ}$ de la Institución Educativa San Gerardo María Mayela del Municipio de Norcasia, Caldas (Colombia). [Maestría en Educación y Desarrollo Humano, Universidad de Manizales].

EC/051-02/063/M. Arenas, C. y Loaiza, J. (2017). Mediaciones de la alteridad en las prácticas pedagógicas. Una apuesta para la construcción de paz imperfecta desde la primera infancia. [Maestría en Educación y Desarrollo Humano, Universidad de Manizales]. 
EC/051-02/067/M. Carmona, M.; Hernández, L. y Ocampo, E. (2017). La escritura, una experiencia de paz. Transformación en las comprensiones sobre la paz, a través de la producción escrita, en niños y niñas de quinto grado. [Maestría en Educación y Desarrollo Humano, Universidad de Manizales].

EC/051-02/068/M Parra Castrillón, L. (2017). Modelos mentales sobre la enseñanza de docentes de la Institución Educativa Fe y Alegría la Paz del municipio de Manizales. [Maestría en Educación y Desarrollo Humano, Universidad de Manizales].

EC/051-02/069/M Albarracín Arango, M. L. (2017). Aprendizaje del concepto de combinatoria en estudiantes de grados $6^{\circ}$ y $7^{\circ}$ del programa Ondas. [Maestría en Educación y Desarrollo Humano, Universidad de Manizales].

EC/051-02/071/M Salazar Morales, D.; Flórez Rincón, E. Y Bernal Echeverry, M. (2017) Motivación, autorregulación para el aprendizaje y rendimiento académico en estudiantes de $7^{\circ}$ de una institución educativa del municipio de Aránzazu (Caldas) adscrita al programa Ondas de Colciencias. [Maestría en Educación y Desarrollo Humano, Universidad de Manizales].

EC/051-02/072/M Cardozo TAFur, M. L. (2017). Sistematización de la Experiencia del Programa de Hábitos y Rutinas del Colegio Alemán de Cali. [Maestría en Educación y Desarrollo Humano, Universidad de Manizales].

EC/051-02/074/M Largo Betancourt, S. M. (2017). Conocimiento didáctico del contenido (CDC) en docentes de primaria con formación de dominio específico. [Maestría en Educación y Desarrollo Humano, Universidad de Manizales]. 
EC/051-02/075/M Valencia Castrillón, A. y Ortiza Bueno, S. X. (2017). Conocimiento metacognitivo en estudiantes de básica primaria. [Maestría en Educación y Desarrollo Humano, Universidad de Manizales].

EC/051-02/o76/M Orozco Atehortúa, V. y CAstro Ceballos, V. (2017). Estilos y estrategias de aprendizaje en estudiantes de un programa de educación para adultos en la ciudad de Manizales. [Maestría en Educación y Desarrollo Humano, Universidad de Manizales].

RDA/018/003/M Puerta Gonzales, D. P. (2016). Factores psicosociales escolares y desarrollo Cognitivo en la escuela. [Maestría en Pedagogía y Desarrollo Humano, Universidad Católica de Pereira].

RDA/018/005/M Tabares Tobón, M. y Valencia García, L. F. (2017). Configuraciones afectivo-corporales en el tránsito de la escuela al colegio en 2017 de niños de edades intermedia de las instituciones Patio Bonito de la Celia y Ciudad Boquía de Pereira. [Tesis de la Maestría en Educación, Universidad Tecnológica de Pereira].

RDA/o18/014/M Gutiérrez VAlencia, K. (2013). Usos reales de la red social Google Plus en una experiencia de enseñanza y aprendizaje universitaria. [Tesis de la Maestría en Educación, Universidad Tecnológica de Pereira].

RDA/o18/015/M Gutiérrez Marín, G. (2015). Desarrollo de habilidades a partir de la inteligencia emocional con estudiantes de grado tercero del Centro Educativo San Antonio de Padua de Pereira. [Tesis de la Maestría en Pedagogía y Desarrollo Humano, Universidad Católica de Pereira]. 
RDA/018/017/M Quiroga Zapata, S. P., Corales Orozco, L. A., Bernal García, K. y Trujillo Trujillo, J. M. (2015). Proyecto pedagógico de aula basado en el arte, para el desarrollo de aprendizaje significativo. [Tesis de la Maestría en Pedagogía y Desarrollo Humano, Universidad Católica de Pereira].

RDA/133/oo2/M Gonzales López, M. Y. y Bejarano Forero, B. (2015). Concepciones, percepciones y práctica docente sobre la relación maestro alumno en la enseñanza y el aprendizaje en los grados transición y primero de la Institución Educativa Suroriental de Pereira. [Tesis de la Maestría en Educación, Universidad Tecnológica de Pereira].

RDA/133/003/M Herrera, M. y Melo, M. (2016). Características de las prácticas educativas que aportan a la construcción de la educación inclusiva en el grupo $6^{\circ} b$ de una institución educativa de Calarcá Quindío. [Tesis de la Maestría en Educación, Universidad Tecnológica de Pereira].

RDA/133/oo7/M TABima García, D. (2010). Didácticas en la enseñanza de la promoción de la salud, en la asignatura Programas de Salud del programa de Medicina de la Universidad Tecnológica de Pereira. [Tesis de la Maestría en Educación, Universidad Tecnológica de Pereira].

RDA/133/oog/M Pulido Duque, L. A. y Salazar Correa, D. T. (2011). La interactividad en la enseñanza y el aprendizaje de procesos argumentativos con apoyo de TIC. [Tesis de la Maestría en Educación, Universidad Tecnológica de Pereira].

RDA/133/o10/M MARÍN JARAMILlo, J.H. (2011). Lainteractividad en la enseñanza y el aprendizaje de búsqueda de información electrónica, en un ambiente bimodal. [Tesis de la Maestría en Educación, Universidad Tecnológica de Pereira]. 
RDA/133/011/M Gonzales Aguirre, G. y Céspedes de los Ríos, G. A. (2012) La interactividad en la enseñanza y el aprendizaje de la unidad didáctica suma de números fraccionarios en grado $7^{\circ}$, con apoyo de TIC. [Tesis de la Maestría en Educación, Universidad Tecnológica de Pereira].

RDA/133/012/M Monal Salazar, J. G. (2012). La gestión ambiental apoyada por realidad aumentada, para el desarrollo del pensamiento social en estudiantes de grado noveno. [Tesis de la Maestría en Educación, Universidad Tecnológica de Pereira].

RDA/133/014/M GutiérRez VAlencia, K. (2013). Usos reales de la red social Google Plus en una experiencia de enseñanza y aprendizaje universitaria. [Tesis de la Maestría en Educación, Universidad Tecnológica de Pereira].

RDA/133/015/M Montoya Osorio, A. Y. (2014) Usos de las TIC, una experiencia de enseñanza y aprendizaje universitario. [Tesis de la Maestría en Educación, Universidad Tecnológica de Pereira].

RDA/133/o16/M Rendón Londoño, A. y Escobar M. L. (2015). Usos de Facebook por parte de los estudiantes de grado 11 de la institución Lestonnac de Pereira, como espacio para el aprendizaje dentro y fuera del aula. [Tesis de la Maestría en Educación, Universidad Tecnológica de Pereira].

RDA/133/017/M Rivera Aguirre, M. (2015). Habilidades cognitivo-lingüísticas en la enseñanza y el aprendizaje de la lengua inglesa, con uso de TIC. [Tesis de la Maestría en Educación, Universidad Tecnológica de Pereira].

RDA/133/o18/M Arenas SÁnchez, E. (2016). Usos del Grupo MOODLE de la red social internet en el aula como espacio para la formación profesional docente. [Tesis de la Maestría en Educación, Universidad Tecnológica de Pereira]. 
RDA/133/019/M Aguirre Arias, C. y Mejía Solanilla, A. M. (2016). Tendencias de las TIC para uso en educación a partir del monitoreo de las cuentas de Twitter en 24 curadores del contenido educativo. [Tesis de la Maestría en Educación, Universidad Tecnológica de Pereira].

RDA/133/o20/M González Londoño, A.L. (2013). Concepciones de evaluación de los maestros y maestras de la Institución Educativa Santo Domingo Savio en el municipio de Balboa. [Tesis de la Maestría en Educación, Universidad Tecnológica de Pereira].

RDA/133/023/M Tabarez Henao, A. M y Castañeda Garcés, R. A. (2015) Secuencia didáctica de enfoque interactivo para comprender textos narrativos en $3^{\circ}$ primaria. [Tesis de la Maestría en Educación, Universidad Tecnológica de Pereira].

RDA/133/024/M Londoño Henao, L. F. y Diaz Mosquera, J. (2016). Secuencia didáctica de enfoque interactivo para comprender textos narrativos en quinto primaria. [Tesis de la Maestría en Educación, Universidad Tecnológica de Pereira].

RDA/133/025/M TorRes Londoño, L. F. y Rengifo FernándeZ, E. L. (2017). GEA, nos explica para comprender nuestro mundo. Una secuencia Didáctica para la comprensión de textos expositivos-descriptivos en estudiantes de grado $4^{\circ}$ de la Institución Educativa Jaime Salazar Robledo de la Ciudad de Pereira. [Tesis de la Maestría en Educación, Universidad Tecnológica de Pereira].

RDA/133/29/M Zamora Velásquez, M. E. Y SÁnchez RAmírez, E. J. (2017). Cultural, para la comprensión de textos argumentativos. [Tesis de la Maestría en Educación, Universidad Tecnológica de Pereira]. 
RDA/133/031/M Suaza Giraldo, Y. A. (2017). El artículo de opinión para formar lectores críticos en grado $8^{\circ}$. Incidencia de una Secuencia didáctica de enfoque sociocultural, en la comprensión de textos argumentativos en estudiantes de grado $8^{\circ}$ de la Institución Educativa San Nicolas. [Tesis de la Maestría en Educación, Universidad Tecnológica de Pereira].

RDA/133/033/M VelázQuez MejÍA, O. P. (2017). Implementación de una secuencia didáctica de enfoque discursivo interactivo, para el mejoramiento de la producción de textosargumentativos, en estudiantes de grado séptimo de la Institución educativa INEM José Celestino Mutis de Armenia. [Tesis de la Maestría en Educación, Universidad Tecnológica de Pereira].

RDA/133/035/M Puerta Giraldo, C. E. y Guzmán Montiel, J. R. (2011). La conversación en la clase de filosofía. [Tesis de la Maestría en Educación, Universidad Tecnológica de Pereira].

RDA/133/036/M Garzón Osorio, M. L. (2012). Incidencia de una secuencia didáctica de trabajo colaborativo, con apoyo de TIC para el desarrollo de la argumentación en estudiantes del programa Ciencias del Deporte y la Recreación de la Universidad Tecnológica de Pereira. [Tesis de la Maestría en Educación, Universidad Tecnológica de Pereira].

RDA/133/040/M Gómez Pineda, M. I. y Bedoya Serna, C. S. (2014). Incidencia de una secuencia didáctica basada en el análisis de las estructuras organizacionales del cuento, en la comprensión lectora de los estudiantes del grado transición. [Tesis de la Maestría en Educación, Universidad Tecnológica de Pereira].

RDA/133/041/M Bernal García, H. O. y Bernal Betancur, C. A. (2016) Implementación de una secuencia didáctica, de enfoque comunicativo, en la producción escrita de resumenes en inglés, con estudiantes de una universidad oficial de Pereira. [Tesis de la Maestría en Educación, Universidad Tecnológica de Pereira]. 
RDA/133/042/M Salazar Marín, T. y Quintero Arango, E. (2016) De héroes y villanos: una propuesta didáctica mediada por TIC para la producción de textos narrativos. [Tesis de la Maestría en Educación, Universidad Tecnológica de Pereira].

RDA/133/045/M. Morales Morales, M. y Arenas Franco, E. A. (2017) relatos, sueños y arte de mi pueblo: produciendo crónicas con estudiantes de la institución educativa nuestra señora de la presentación. [Tesis de la Maestría en Educación, Universidad Tecnológica de Pereira].

RDA/133/047/M Forero Granados, L. I. y Gómez AvendaÑo, L. S. (2011). Representaciones de Género en las Imágenes Icónicas de los Textos Escolares de Ciencias Naturales de los Grados Sexto a Noveno de Básica Secundaria Publicados En El Período 1995 - 2009. [Tesis de la Maestría en Educación, Universidad Tecnológica de Pereira].

RDA/133/048/M Villalba Baza, C. A. (2012). Concepciones y modelos acerca de la enseñanza de las ciencias naturales en estudiantes de la Licenciatura en Pedagogía Infantil de la Universidad Tecnológica de Pereira. [Tesis de la Maestría en Educación, Universidad Tecnológica de Pereira].

RDA/133/052/M García Castro, G. (2016). Aprendizaje Basado en Problemas y Argumentación. Herramientas para promover cambios en los modelos explicativos sobre el infarto agudo del miocardio. [Tesis de la Maestría en Educación, Universidad Tecnológica de Pereira].

RDA/133/053/M Regalado Tabares, A. C. y Rubio Guarín, D. M. (2017). Caracterización de las actividades de argumentación, explicación y modelización en los libros de texto más utilizados para la enseñanza de las ciencias naturales de grado $5^{\circ}$ de primaria en colegios privados de Armenia (Quindío). [Tesis de la Maestría en Educación, Universidad Tecnológica de Pereira]. 
RDA/133/054/M Trejos Ceballos, A. M. y Franco Ariza, Y. F. (2017). Aprendizaje en profundidad de biología celular (ciclo celular) basado en un proceso de evaluación formativa. [Tesis de la Maestría en Educación, Universidad Tecnológica de Pereira].

RDA/133/057/M García Quiroz, C. y García Gallego, A. C. (2011) La educación artística: un estado del arte para nuevos horizontes curriculares en la Institución Educativa Mundo Nuevo de la ciudad de Pereira. [Tesis de la Maestría en Educación, Universidad Tecnológica de Pereira].

RDA/133/058/M Díaz Suarez, M. J. (2011) Aprendizaje de la asignatura Derecho Comercial II a partir del aprendizaje basado en problemas, en estudiantes de Derecho de la Universidad Libre Seccional Pereira. [Tesis de la Maestría en Educación, Universidad Tecnológica de Pereira].

RDA/133/061/M Marín Hernández, O. A. (2013). Estilos de enseñanza y prácticas pedagógicas en educación física: tensiones constitutivas en el Instituto Estrada de Marsella (Risaralda). [Tesis de la Maestría en Educación, Universidad Tecnológica de Pereira].

RDA/133/062/M Gallego, E. (2014). El emprendimiento en estudiantes de la institución educativa Manuel Quintero Penilla" del municipio de Cartago-Valle. Relatos de sueños y vivencias. [Tesis de la Maestría en Educación, Universidad Tecnológica de Pereira].

RDA/133/063/M Zapata Gómez, O. J. (2015). Concepciones de educación de adultos de los docentes del Instituto Comfamiliar. [Tesis de la Maestría en Educación, Universidad Tecnológica de Pereira]. 
RDA/133/o66/M Carmona, R. (2015). Concepciones de práctica pedagógica en docentes en ejercicio de la ciudad de Pereira. [Tesis de la Maestría en Educación, Universidad Tecnológica de Pereira].

RDA/133/069/M Escalante Villegas, Y. (2011) Implementación de una propuesta didáctica centrada en las competencias emocionales y comunicativas para la solución de conflictos en el aula de clase. [Tesis de la Maestría en Educación, Universidad Tecnológica de Pereira].

RDA/133/071/M Mejía Giraldo, Olga Liliana, Dallos Santos Clara Patricia. (2012). Resolución de conflictos desde las competencias ciudadanas con estudiantes de grado $9^{\circ}$. Del colegio Nuestra Señora de la Anunciación de Cali. [Tesis de la Maestría en Educación, Universidad Tecnológica de Pereira].

RDA/133/073/M VArgas SAldarriaga, D. L. (2012). Concepciones de género en docentes de secundaria de la Institución Educativa "Cristo Rey" de Dosquebradas. [Tesis de la Maestría en Educación, Universidad Tecnológica de Pereira].

RDA/133/075/M García Pérez, D. y Cabrera Arizmendi, C. E. (2013). Concepciones de conflicto de conflicto de estudiantes de la Institución educativa Luis Carlos Gonzales Mejía de la ciudad de Pereira. [Tesis de la Maestría en Educación, Universidad Tecnológica de Pereira].

RDA/133/o76/M Rodríguez Osorio, G. I. (2014). Pactos de aula para el desarrollo de competencias ciudadanas. [Tesis de la Maestría en Educación, Universidad Tecnológica de Pereira]. 
RDA/133/077/M Murillo Sandoval, J. A. Y MartíneZ Valencia, C. A. (2015) Habilidades del pensamiento social en una práctica de enseñanza y aprendizaje del concepto de libertad con estudiantes de grado $10^{\circ}$ de la Institución Educativa La Graciela de Tuluá. [Tesis de la Maestría en Educación, Universidad Tecnológica de Pereira].

RDA/133/o78/M Ríos Monsalve, Y. y LoAiza, L. M. (2014) Una práctica no directiva en el conocimiento y manejo del conflicto escolar. [Tesis de la Maestría en Educación, Universidad Tecnológica de Pereira].

RDA/133/081/M Sarria Dávila, H. y Hurtado Valencia, L. A. (2016) Habilidades cognitivo-lingüísticas de pensamiento social a través de la enseñanza una Unidad Didáctica, en el derecho al voto, en estudiantes del grado 10-3 de la Institución Educativa San José, del Municipio de Obando. [Tesis de la Maestría en Educación, Universidad Tecnológica de Pereira].

RDA/133/083/M PeÑA Londoño, P. A. (2016) Habilidades cognitivo-lingüísticas de pensamiento social en estudiante de primero y segundo de primaria analizadas a través de una unidad didáctica enfocada en la dignidad y el buen trato. [Tesis de la Maestría en Educación, Universidad Tecnológica de Pereira].

RDA/133/084/M Osorio Ruiz, M. E. y Osorio Ruiz, R. M. (2017). El desarrollo de la Memomoría histórica en la enseñanza primaria. [Tesis de la Maestría en Educación, Universidad Tecnológica de Pereira].

RDA/133/085/M Escobar Silva, N. J. (2017) Representaciones sociales sobre la memoria histórica que construye el profesorado de ciencias sociales y filosofía de la educación básica y media obligatoria. [Tesis de la Maestría en Educación, Universidad Tecnológica de Pereira]. 
RDA/133/o86/M Cardona Bustos, D. M. y Reyes, A. M. (2017). El reconocimiento de la diversidad etnica en el aula rural multigrado. [Tesis de la Maestría en Educación, Universidad Tecnológica de Pereira].

RDA/133/o88/M Villegas FernándeZ, J. H. (2017). Estrategias utilizadas en la resolución del conflicto en estudiantes de grado 11 de la institución educativa el Caimo, de la ciudad de Armenia. [Tesis de la Maestría en Educación, Universidad Tecnológica de Pereira].

RDA/133/o91/M Gil Gómez, M. J. y Giraldo López, A. M. (2017). Manifestaciones de las competencias ciudadanas emocionales y la convivencia en dos grupos de básica primaria de la Institución Educativa Ciudadela Cuyabra de Armenia. [Tesis de la Maestría en Educación, Universidad Tecnológica de Pereira].

RDA/133/092/M Montoya Rivera, S. L. y Martínez Naranjo, M. C. (2017). Las competencias ciudadanas emocionales $y$ la convivencia en estudiantes de preescolar de la Institución Educativa Nuestra Señora de Guadalupe de Dosquebradas, y los Quindos de Armenia. [Tesis de la Maestría en Educación, Universidad Tecnológica de Pereira].

RDA/133/093/M Hurtado Cifuentes, M. A. (2017). Reconocimiento de la diversidad cultural en una propuesta didáctica basada en problemas socialmente relevantes en un grupo de estudiantes de educación media. [Tesis de la Maestría en Educación, Universidad Tecnológica de Pereira].

RDA/133/095/M Mejía Baena, R. H. (2012). Concepciones de la práctica pedagógica de los estudiantes practicantes de $x$ semestre de la Licenciatura en Matemáticas y Física de la Universidad Tecnológica de Pereira. [Tesis de la Maestría en Educación, Universidad Tecnológica de Pereira]. 
RDA/133/o97/M Serna Calderón, A. P. y Cuartas Palacio, L. (2017). Práctica docente mediada por una unidad didáctica fundamentada en la metodología de la indagación, para la enseñanza de la construcción del número en grado $1^{\circ}$. [Tesis de la Maestría en Educación, Universidad Tecnológica de Pereira].

RDA/133/o98/M. Ardila Ortiz, L. M. (2017). Práctica docente mediada por una unidad didáctica fundamentada en la indagación, para la enseñanza de las figuras geométricas grado $2^{\circ}$. [Tesis de la Maestría en Educación, Universidad Tecnológica de Pereira].

RDA/133/o99/M. López ZuluagA, S. M. (2017). Práctica docente mediada por una unidad didáctica fundamentada en la metodología de la indagación, para la enseñanza del sistema de numeración decimal-grado $2^{\circ}$. [Tesis de la Maestría en Educación, Universidad Tecnológica de Pereira].

RDA/018/001/M. TrujILlo-GonzÁlez, A. L. (2015). Maestra en Obra. [Tesis de Maestría en Pedagogía y Desarrollo Humano, Universidad Católica de Pereira]. 


\section{Conclusiones}

En este libro se presentan las conclusiones derivadas del análisis de la información, producto de los diferentes instrumentos (RIEP uno, dos, cuatro y cinco). Para ello se procede, en primer lugar, a presentar las conclusiones de cada instrumento para luego ofrecer una visión general que caracteriza la zona del Eje Cafetero en cuanto a lo que ha sido la producción, las posibles líneas de investigación y preguntas que emergen y que pueden direccionar otros proyectos con esta misma información o a partir de la discusión que pueda generar en el contexto académico que la recibe.

La caracterización de los autores, las citaciones y palabras clave han sido de manera independiente o articulada, ejes de investigación de diversos estudios bibliométricos. Sus resultados muestran la potencia de estos análisis para demarcar tendencias en la línea de construcción de un campo disciplinar, la caracterización 
de quien produce conocimiento en una disciplina, las influencias temporales de las referencias en los autores, la construcción de tradiciones, de igual manera, la construcción de colegios invisibles, y del análisis de las concepciones en un campo del saber, entre muchas otras. Precisamente, desde esta perspectiva, el análisis del RIEP uno pretendió identificar y caracterizar a los autores, asesores, referencias y palabras clave para delinear la cartografía de la producción del Eje Cafetero.

Dicho análisis deja en evidencia varios asuntos, el primero de ellos tiene que ver con el género de los autores en su mayoría mujeres (mujeres $72 \%$ y hombres $28 \%$ ), lo cual, de alguna manera, devela la democratización del acceso a la formación posgradual. Ello se evidencia en su mayor prevalencia no solo para formarse y contar con mayor cualificación en un área profesional, sino también para dirigir proyectos y líneas de investigación, lo cual implica su presencia activa en la generación de conocimiento en el campo de la educación y la pedagogía. Este mayor acceso de las mujeres a la educación se traduce, a su vez, en un mayor acceso a las comunidades académicas, a la ciencia y —de manera consecuente-, a la profesionalización de la docencia, pues la mayoría son maestras en los diversos niveles educativos. El segundo asunto tiene que ver con las tendencias. Si bien la producción se encuentra alineada con los datos arrojados por el Ministerio de Educación en el 2017, en las maestrías se pasa del $44 \%$ en 2008 al $53 \%$ en el 2016; y en los doctorados se pasa del $28 \%$ en el 2008 al $41 \%$ en el 2016 (MEN, 2017). Aún es necesario dar un paso más allá, el cual permita una mayor equidad en posicionamiento académico de las mujeres pues, según los datos arrojados respecto a los investigadores reconocidos en la Convocatoria del Ministerio de Ciencia Tecnología e Innovación (Minciencias) del 2017, el 37 $\%$ (4858) de los investigadores reconocidos eran mujeres, cifra que, en el 2019 tan solo aumentó un punto porcentual (38 \%, es decir, 6411). 
Respecto a las referencias, el análisis puso de manifiesto una tradición endógena con énfasis en los documentos emanados por el MEN, lo cual puede entenderse en el marco de quienes ingresan a los posgrados, maestros o personas interesadas en vincularse a la educación, los cuales tienen o deben tener como marco de referencia los lineamientos ministeriales para, desde allí, elaborar propuestas educativas, evaluar dichas propuestas o incluso cuestionarlas. Esta tradición se complementa, en menor medida, con una exógena, la cual bebe sus fuentes especialmente en las perspectivas españolas de la educación, la didáctica o la psicología (Coll, Pozo, Camps, entre otros), en perspectivas críticas (con Freire a la cabeza) y en perspectiva sociocultural (con Vigotsky como principal fuente).

Ahora bien, este panorama puede estar mostrándole a la región sus debilidades en la construcción de una verdadera tradición autóctona que, sin desconocer los aportes del Ministerio, se distancie de los documentos oficiales para producir y consumir su propia producción académica, idea que no riñe con el diálogo con fuentes internacionales, las cuales siempre nutrirán la discusión. Esta debilidad, es evidente en la presencia esporádica de citaciones a la producción académica de los profesores y directores de los seminarios y líneas de investigación de los posgrados, lo cual podría explicarse en la satanización de lo que se ha denominado "colegios invisibles», de citaciones mutuas, que suceden especialmente entre los profesores; no obstante, se esperaría que los estudiantes, en sus proyectos, articulen su producción a la de las líneas que han ido construyendo los programas, generando de esta manera escuelas de pensamiento sobre la educación, la pedagogía, la didáctica, la cognición, el desarrollo humano, la inclusión, y en ellas, todas las relaciones que tejen las líneas de investigación. Además, esta situación puede ser un llamado a la producción académica de los profesores y la comprensión de su relevancia para la construcción, la evaluación y la revisión permanente de los mismos posgrados. 
Quizás esta timidez en socializar la producción o en generarla da como resultado el poco énfasis hecho en la selección de las palabras clave. Ellas son fundamentales para darle visibilidad a un proyecto, para no desvirtuar su esencia en las búsquedas y para marcar la impronta de los programas. El análisis perfiló los programas a través de sus palabras clave, así:

- Maestría en Educación de la Universidad Tecnológica de Pereira: la didáctica, una didáctica ligada a unos saberes escolares.

- La Maestría en Pedagogía y Desarrollo Humano de la Universidad Católica de Pereira: el aprendizaje significativo y docente.

- La Maestría en Educación desde la Diversidad de la Universidad de Manizales: la diversidad y las prácticas pedagógicas.

- La Maestría en Educación y Desarrollo Humano de la Universidad de Manizales y el CINDE: los estudiantes y las prácticas pedagógicas.

- El Doctorado de Ciencias Sociales, Niñez y Juventud de la Universidad de Manizales y el CINDE: aprendizaje, la educación y la escuela.

Precisamente, este perfil abre la discusión frente a la pertinencia de la identidad la cual refleja cada programa, si ella está dando cuenta de su propósito y de los propósitos de los grupos de investigación los cuales direccionan las líneas investigativas; si esta identidad demarca o no los objetivos, la tradición y prospección en la formación posgradual la cual se oferta a la sociedad.

Lo expuesto no solo abre, para los posgrados de la zona, líneas de discusión sobre su propia producción académica, sino que también plantea el desarrollo de otras líneas de investigación sobre la propia producción y, más allá de ello, sobre la necesidad de cuidar los aspectos formales canónicos de la escritura académica que terminan opacando y quizás desvirtuando las identidades de las fuentes y de los programas. 
Por su parte el RIEP dos, desde el cual se analizaron los marcos metodológicos, evidenció la pluralidad de enfoques, metodologías, técnicas e instrumentos de investigación de la zona. Esta diversidad da cuenta de los posicionamientos epistemológicos, teóricos y metodológicos de las líneas de investigación y particularmente de los asesores de los trabajos de grado de maestría y tesis de doctorado. Ahora bien, los términos con los que se definen dichas posiciones no siempre son aclarados o justificados en el marco de la investigación, de tal manera que los autores asumen que pueden tener interpretaciones univocas o claras para la comunidad académica en la cual se insertan. Así, paradigmas y enfoques aparecen como sinónimos $\mathrm{y}$, dentro de ellos, se van perfilando de un lado - como predominantes-, el cualitativo, el hermenéutico, la teoría fundada y la etnografía; y de otro lado - con menor preponderancia-, los paradigmas o enfoques empírico analítico o cuantitativos. Ambos como maneras particulares de entender la realidad y acceder a ella.

Respecto al primer énfasis, el interés está en comprender a profundidad lo que sucede en el ámbito escolar desde dos perspectivas, darle sentido y a la vez empoderar tanto al investigador como a los participantes desde posiciones tanto interpretativas como críticas respecto a los fenómenos estudiados. En esta misma lógica, los abordajes metodológicos son inductivos, por ello se explora, identifica y describen los participantes, sus actuaciones, y sus interacciones (según los objetivos), esto para poderlas comprender y teorizar, en proceso de ida y vuelta entre los actores, los contextos de los cuales hacen parte, y la teoría. Respecto al segundo énfasis, el interés está puesto en cuantificar o medir ciertos procesos o fenómenos sociales para probar o refutar hipótesis, establecer correlaciones y hacer generalizaciones. Las lógicas son deductivas y pretenden identificar, caracterizar, establecer relaciones de causalidad y comparar resultados entre diferentes pruebas aplicadas en diversos momentos (según los 
objetivos); entre ellos se encuentran diseños experimentales, cuasi-experimentales, correlaciones y evaluativos.

Emergen en la zona los paradigmas mixtos - como opacidades-, los cuales generalmente se presentan en fases donde se correlacionan datos para luego describir y generar las explicaciones pertinentes sobre lo estudiado. En ellos se analiza a profundidad uno o varios aspectos, con el fin de explicar y comprender el fenómeno estudiado.

Estos abordajes metodológicos hacen uso de diversas técnicas e instrumentos los cuales también aparecen como sinónimos, y son usados indistintamente en los enfoques expuestos, ya sea de manera exclusiva o complementaria, a modo de triangulación de la información. En su orden están la entrevista, la observación y los cuestionarios, el análisis de documentos, los grupos focales, las narraciones, los registros autobiográficos, las experiencias significativas y los diarios de campo.

Ahora bien, un análisis de los autores más citados en los marcos metodológicos denota la preocupación más por los aspectos metodológicos que epistemológicos, en razón de ello, el autor más citado es Hernández et al., el cual posiblemente por tener como obra un manual de investigación, es de fácil acceso para investigadores nóveles; aquellos que, en muchos casos, es la primera vez que se enfrentan a la elaboración de un proyecto de investigación $y$, por ello, las fundamentaciones epistémicas y teóricas les pueden resultar complejas.

La diversidad metodológica tanto en su fundamentación epistémica como en los procedimientos e instrumentos denota la vocación de la región por la formación en investigación desde diversas perspectivas, las cuales no demarcan posiciones definidas en los posgrados. En ello puede estar una fortaleza, en el sentido de no restringirse a un solo tipo de abordaje investigativo (en todos los programas hay presencia de diversos enfoques); y una 
debilidad, en el marco de no fortalecer un paradigma que los identifique, o incluso, la osadía de elaborar propuestas propias que evidencien nuevas lógicas para abordar los actores y procesos educativos, esto es, consolidar o construir una tradición.

Si bien, la caracterización de autores, asesores, fuentes bibliográficas y la metodología tributan a la comprensión de las dos regiones, educación y pedagogía, son los instrumentos que abordan la fundamentación teórica (RIEP cuatro), como los hallazgos (RIEP cinco), los cuales delimitan la geografía de dichas regiones, con sus tópicos y subtópicos. Posiblemente, un análisis inverso (esto es, partir de las regiones y en ellas caracterizar las metodologías, autores y fuentes) permitiría, en el futuro, afinar los análisis. Ahora bien, en los dos últimos instrumentos, se encuentran, como era de esperarse, continuidades y tensiones pues, en los hallazgos, a veces se retoma la fundamentación teórica para explicar y comprender los tópicos y subtópicos mientras que, en ocasiones, emergen nuevos tópicos dando lugar a una nueva región, denominada «otras regiones».

Específicamente el RIEP cuatro dejó en evidencia, lo que luego confirmaría el RIEP cinco, la prevalencia de la región pedagogía sobre la región educación, lo cual resulta explicable y paradójico. Explicable, porque teóricamente las relaciones entre educación y pedagogía han sido interpretadas en diversas tradiciones académicas, ya sea porque se entiende la primera como una práctica social, cuyo objeto es la formación en cualquier contexto; y la segunda, porque se liga a la educación institucionalizada, o porque se piense la segunda como una teoría descriptiva y prescriptiva de la primera. Paradójico porque ninguno de los posgrados tiene como nombre o apellido la pedagogía.

Ahora bien, al interior de cada una de las regiones no aparece la discusión explícita sobre cómo los proyectos o los posgrados entienden la educación, la pedagogía o las relaciones entre ellas, y en consecuencia cual es la posición que asumen. Parece entonces 
que este no es un foco de interés en la zona o se presume que los estudiantes, grupos de investigación y posgrados, ya han asumido una y debe inferirse al interior de los proyectos lo cual no sucede. En uno u otro caso, el análisis devela la necesidad de discusiones explícitas, no necesariamente para asumir una posición, sino para construir conceptualmente los ejes que componen la formación posgradual.

Respecto a la región pedagogía, la tendencia apunta a definir y explicar cómo se entiende la didáctica y dentro de ella dos líneas; una, la didáctica general como un modelo que explica los procesos de enseñanza, más cercanas a las teorías del aprendizaje (significativo, profundo, comprensivo) con propuestas genéricas (propuestas pedagógicas) para lograr estos aprendizajes; la otra línea, las didácticas específicas, ligadas a los contenidos, niveles educativos, con procedimientos o propuestas muy concretas como las unidades y secuencias didácticas. En el marco de estas dos líneas se realizan aproximaciones conceptuales a la práctica pedagógica, el aprendizaje, el uso pedagógico de las TIC, el maestro, su autobiografía y sus concepciones, cognición, entre otras.

Acerca de la región educación, las investigaciones orientan su fundamentación teórica a la formación de sujetos sociales, respetuosos de la diferencia que comprendan y participen de manera empática en la transformación de la realidad histórica, geográfica y social en la cual transcurren sus vidas en presente y futuro; para lo cual es necesario que asuman posturas críticas y reflexivas, enmarcadas en escenarios de diálogo, argumentación y concertación con el fin de tomar decisiones en la resolución de problemas de carácter ético, político, sociales, y así construir una sociedad más equitativa, incluyente, democrática y justa.

En las tres regiones, los trabajos de grado de maestría y las tesis de doctorado hacen énfasis en el papel que debe asumir el docente como formador de los seres humanos o aquellas personas 
que la sociedad demanda. En este sentido, se enfatiza en un maestro con conciencia de su responsabilidad ética, política y social, un docente crítico y emancipado que, como integrante de una sociedad diversa, cuente con una disposición permanente a favor de la justicia; para ello, es necesario que promueva la apertura en el aula de espacios democráticos, participativos y libres, donde se interrogue, se escuche, se discrepe, se argumente y se negocie sobre el saber escolar, y también sobre la tarea compartida con los estudiantes; lograr la transformación social. Además, en ambas regiones prima como contexto educativo la escuela y en ella el aula.

Esta mirada se complementa con el RIEP cinco o hallazgos, en él aparecen las dos regiones anteriores y emerge la denominada «otras regiones», en la cual se incluyeron aquellos tópicos globales que, desde la perspectiva de los investigadores, si bien se relacionaban con una u otra, tenían particularidades las cuales las hacía diferentes, quizás como tópicos emergentes que van marcando nuevas tendencias e intereses investigativos de la zona.

Convergen los hallazgos de este instrumento con los del RIEP cuatro, pues prima la región pedagogía y en ella el tópico global didáctica. La especificidad está en el énfasis y en la enseñanza de saberes escolares, esto es en las didácticas específicas, las cuales cuando fueron puestas en escena como propuestas, unidades o secuencias didácticas, demostraron su impacto positivo en el aprendizaje y en las prácticas de enseñanza. Así, las diferentes propuestas que, para los autores de los proyectos resultan «innovadoras», logran romper con las prácticas de enseñanza «tradicionales», para generar aprendizajes significativos, aprendizajes profundos, argumentación, comprensión, transformación de las concepciones, desarrollo del pensamiento crítico, desarrollo de los procesos cognitivos y metacognitivos, emocionales y sociales de estudiantes y profesores, y mucho más allá, generar espacios democráticos e incluyentes en el aula. 
Se evidencia en estos hallazgos una visión instrumental y eficientista de la didáctica, en la cual, los maestros parecen resolver los problemas que les plantea la sociedad y las propias urgencias del aula, con miras a lograr mejores resultados en pruebas de evaluación. Una visión que deja el sinsabor de la no constitución de cuerpos teóricos o categoriales en torno a la enseñanza en general y de los saberes específicos en particular, los saberes mismos, las prácticas pedagógicas, los currículos. Un cuerpo teórico que aporte no solo a resolver las urgencias de las prácticas, las cuales son transitorias y contextuales, sino que también aporte a la construcción de saber disciplinar en el campo de la pedagogía; exigencia hecha por la sociedad y la academia a los maestros y a los posgrados.

En cuanto a la región educación, también en línea con el RIEP cuatro, aparece la discusión sobre el sujeto social en el marco de la ciudadanía (subjetividad política y ciudadanía, y ciudadanía y conciencia crítica), lo cual traduce la necesidad sentida por los investigadores de generar propuestas formativas que incidan en la formación política, en la participación y en la creación de espacios para el ejercicio de la ciudadanía; en un país en el que tradicionalmente la participación política y la conciencia ciudadana es escasa.

Ahora bien, emergen las «otras regiones», aquellas que desde la perspectiva de Serres, se podría considerar como opacidad y no por su falta de luz, sino porque es el lugar de nacimiento de nuevas discusiones, donde la preocupación por el desarrollo humano cobra relevancia. Este desarrollo, pensado desde los actores y sus relaciones, visto como la oportunidad de encontrar en las aulas otras alternativas, diferente a las actuales, que tengan en cuenta los derechos humanos, la emocionalidad, el desarrollo moral, la justicia social, la diversidad y la inclusión, como mínimos básicos para establecer las relaciones en las sociedades futuras. 
Podría pensarse entonces, desde los hallazgos, en visiones complementarias de enseñanza y formación, desde nuevas reflexiones y apuestas. Sin embargo, los trabajos de grado y las tesis, siguen constreñidas a los escenarios escolares formales, lo cual en sí mismo no es problemático, pero restringe la mirada de la educación y la pedagogía, la limita, y esto, aunque es natural por el escenario educativo en el cual se desenvuelven los investigadores, no deja de ser problemático en un país donde según datos de UNICEF, 1.5 millones de niños, niñas y adolescentes en Colombia, entre los cinco y los dieciséis años, no van al colegio por distintas razones. Se encuentra entonces que hay una amplia franja de población en edad escolar, la cual no es atendida por el sistema educativo formal, $\mathrm{y}$ tampoco es objeto de los estudios académicos en esta zona.

Una visión genérica dela producción en educación y pedagogía de los posgrados deja en evidencia su interés por la formación en investigación de sus estudiantes, esto desde proyectos los cuales parten de sus realidades y resuelven las problemáticas que dentro de ellas los convocan. No obstante, también queda el reclamo de una producción académica explícita, la cual supere visiones procedimentales y eficientistas para consolidar un cuerpo teórico, a modo de una tradición propia que direccione las políticas educativas de la zona, y que propenda por mejorar la calidad de la educación que se ofrece. 
Este libro terminó de imprimirse en Febrero del 2021, en los talleres gráficos de Gráficas Olimpica, bajo el cuidado de sus autores.

Pereira, Risaralda, Colombia. 
Este libro, construido a partir de la metáfora de relieve, da cuenta del estado de la investigación en Educación y Pedagogía presente en los trabajos de grado de las maestrías y tesis de doctorado de universidades de la zona Eje Cafetero, elaborados entre los años 2010 - 2017. Es una cartografía que invita a explorar y comprender las dinámicas propias que caracterizan la investigación, y le dan su impronta a cada uno de los posgrados objeto de estudio. El análisis se derivó de cinco instrumentos que permitieron la revisión del corpus documental, acerca de los tópicos: fuentes citadas en las tesis, las palabras clave y su recurrencia; la aproximación conceptual respecto a la educación y la pedagogía; la orientación metodológica con el alcance, las técnicas y los instrumentos empleados; y los hallazgos de las investigaciones. Una visión general de la producción en educación y pedagogía de los posgrados deja en evidencia su interés por la formación en investigación de sus estudiantes, con proyectos que parten del análisis de las realidades y la proposición de alternativas para resolver las problemáticas que dentro de ellas los convocan, la gran mayoría enmarcadas en contextos escolares formales. No obstante, también queda el reclamo de una producción académica, la cual supere visiones procedimentales y eficientistas de la educación y la pedagogía, para consolidar un cuerpo teórico, a modo de una tradición propia que direccione las políticas educativas de la zona, y que propenda por mejorar la calidad de la educación que se ofrece.
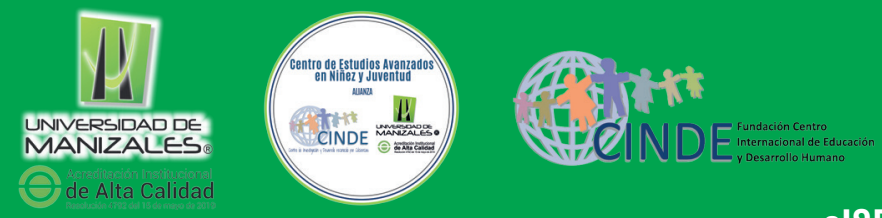

elSBN: 978-958-722-515-0
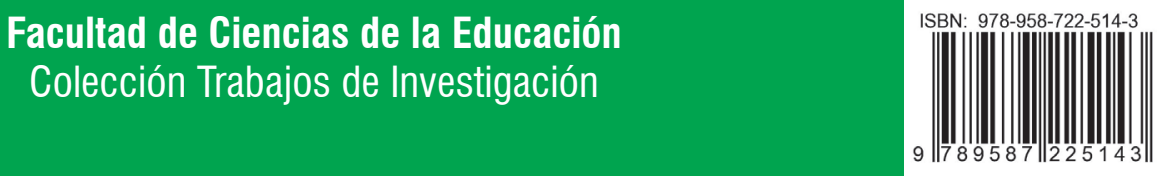